\title{
ESTUDIO DE LAS COMUNIDADES DE HONGOS FORMADORES DE MICORRIZAS ARBUSCULARES EN SOJA: RELACIÓN CON LA NUTRICIÓN FOSFORADA EN AGROECOSISTEMAS
}

Tesis presentada para optar al grado de Doctor en Ciencias Naturales

Facultad de Ciencias Naturales y Museo

Universidad Nacional de La Plata

\section{Tesista}

Ing. Agr. M.Sc. Valeria S Faggioli

Directoras

Dra. Marta N Cabello

Dra. Fernanda Covacevich

Noviembre 2016 
A mis padres Pilar y José A mis hermanas Natalia y Sofía A mi compañero de vida Dino A mi querido amigo Enrique Luis Ángel Solans 


\section{AGRADECIMIENTOS}

Esta tesis no hubiera sido posible sin la colaboración de muchas personas que de una u otra manera facilitaron el camino para alcanzar la meta.

En primer lugar, a mis directoras Dras Marta Cabello y Fernanda Covacevich quienes estuvieron siempre cerca a pesar de la distancia, respondiendo inmediatamente a todas mis consultas y haciendo que todo sea más simple. Estaré siempre agradecida por su generosidad y predisposición. También agradezco a los Dres Mariana Melchiorre y Ramiro Lascano por todo su asesoramiento en lo relacionado a fisiología vegetal. A la Ing. Agr. Mónica Sagadin, quien dejó sus actividades, viajó y se instaló conmigo para extraer miles de esporas que se identificaron en esta tesis. Por siempre agradecida!

Mi agradecimiento especial al coordinador de proyecto INTA Ing. Agr. Jorge Ullé por su calidez humana, sus constantes palabras de aliento y motivación y por sus contribuciones para llevar adelante este trabajo. A Dra Silvina Vargas Gil, Dr Adrián Andriulo y a Ing. Agrs. Alejandro Perticari, Fernando Flores y Pedro Vallone por contribuir económicamente en esta investigación.

A mi jefe Ing. Agr. Carlos Galarza por darme el tiempo para realizar este posgrado, al Ing. Geogr. Hugo Marelli, Tco. Juan Arce e Ing. Agr. Vicente Gudelj por poner a mi disposición las parcelas de los ensayos de larga duración que llevan adelante con mucho esfuerzo.

A mis compañeros de trabajo, principalmente Ing. Agr. Dannae Serri por su inmensa ayuda y compromiso en la tinción de raíces, a Ings. Agrs. Mariana Bonetto y Cristian Cazorla por realizar las determinaciones de textura de suelo, sé que fue un gran trabajo la puesta a punta de la metodología! Al Bioq. Claudio Lorenzón, por llevar adelante las mediciones de química de suelos y darme su valioso aporte en los cálculos estequiométricos. A la Ing. Agr. Jimena Ortiz, quien se hizo cargo de las determinaciones de nitratos y supo brindarme el tiempo para llevar adelante esta tesis. Al Ing. Agr. Sebastián Muñoz por su asesoramiento en sistemas de información geográfica. Al Sr Domingo Villarruel por la molienda de todo el material vegetal. A los Ing. Agr. Lisando Lenzi y Trichi Formica por facilitarme espacio en sus invernáculos para que los invadiera con todas mis macetas. Especialmente agradezco al Ing. Agr. Tomás Baigorria por hacerme el aguante todos los días en que la jornada laboral se extendía, por su compañía, sus palabras de aliento y sus mates.

A mis queridas amigas Silvina, Jessica, Analía, Sole, Paula, Silvia, Paula por estar siempre y entender mis ausencias en el trayecto final de mi tesis. 


\section{RECONOCIMIENTOS}

Las actividades de esta tesis fueron realizadas en el Laboratorio de Biología de Suelos del Instituto Nacional de Tecnología Agropecuaria (INTA), EEA Marcos Juárez - provincia de Córdoba-

Algunas tareas puntuales se llevaron a cabo por $V$ Faggioli en otras instituciones bajo la dirección de diferentes especialistas:

- Identificación de esporas de Glomeromycota: en Instituto de Botánica Carlos Spegazzini, Facultad de Ciencias Naturales y Museo, Universidad Nacional de La Plata, Buenos Aires. Con la dirección de Dra Marta N Cabello

- Extracción de ADN y análisis preliminares de fingerprinting de muestras de suelo: en Laboratorio de Microbiología, Unidad Integrada EEA Balcarce, Buenos Aires. Con la dirección de Dra Fernanda Covacevich

- Amplificación de porción 18S rRNA de Glomeromycota y test preliminares de T-RFLP a partir de las muestras de raíces de soja: en Laboratorio de ecología, The James Hutton Institute, Invergowrie, Escocia. Con la dirección de PhD Timothy Daniell

- Análisis bioinformático y estadístico de datos de pirosecuenciación: en Laboratorio de Biología, Universidad de Tartu, Estonia. Bajo la dirección de PhD Maarja Öpik

En el transcurso del doctorado V Faggioli obtuvo las siguientes becas:

- The COIMBRA group scholarship programme for young professors and researchers from Latin American Universities. Capacitación en Universidad de Tartu, Estonia. Octubre y Noviembre 2014

- Beca otorgada por el Centro Argentino Brasilero de Biotecnología (CABBIO) para asistir al curso "Métodos avanzados para el estudio de hongos formadores de micorrizas", en la Universidad Federal de Viçosa, MG, Brasil. Julio 2011

Esta tesis fue financiada por:

Gerencia de Formación y Capacitación de INTA; Fundación Argeninta; proyectos: PNS 1134043, PNCYO 1127033, CORDO 1262101, REDAE 1136021, REDGEN 1137041; y el aporte de las compañías Rizobacter Argentina SA y Mycophos Argentina SRL. 


\section{INDICE GENERAL}

DEDICATORIA ......................................................................................... it

AGRADECIMIENTOS

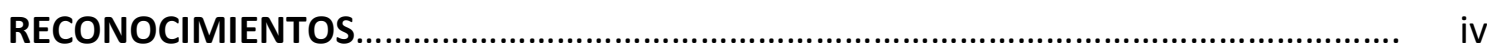

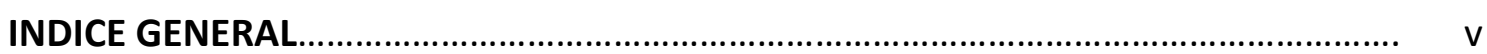

INDICE DE TABLAS .......................................................................................... vii

INDICE DE FIGURAS

RESUMEN

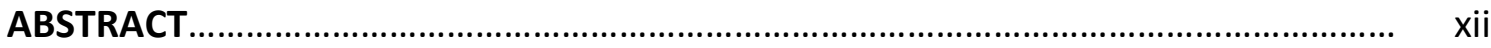

Capítulo 1: INTRODUCCIÓN GENERAL........................................................................... 1

Expansión del cultivo de soja en Argentina y su impacto en la biodiversidad............. 2

Hongos formadores de micorrizas arbusculares............................................................. 4

El fósforo del suelo y la simbiosis micorrícica de soja..................................................... 6

Importancia de los hongos formadores de micorrizas en el 7 agroecosistema................

Efecto del cultivo de soja sobre los hongos formadores de 8 micorrizas.

Objetivo e hipótesis generales...................................................................................... 10

Aproximación metodológica y estructura de la tesis................................................... 11

Capítulo 2: INFECTIVIDAD MICORRÍCICA DEL SUELO Y SU RELACIÓN CON LA FORMACIÓN DE MICORRIZAS EN SOJA.................................................................. 12

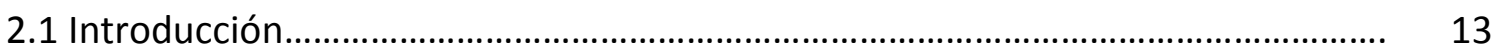

2.2 Materiales y Métodos.................................................................................... 15

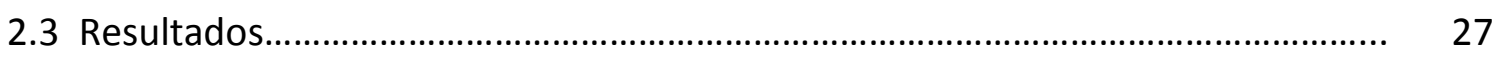

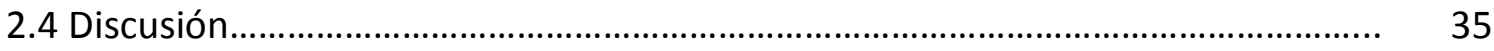

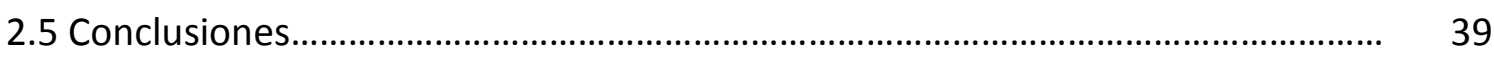

Capítulo 3: COMPOSICIÓN DE COMUNIDADES DE HONGOS FORMADORES DE MICORRIZAS ARBUSCULARES EN LOTES DE SOJA DEL SUR DE LA PROVINCIA DE CORDOBA.

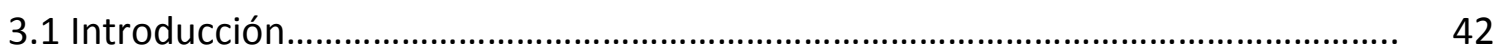

3.2 Materiales y Métodos.................................................................................. $\quad 45$

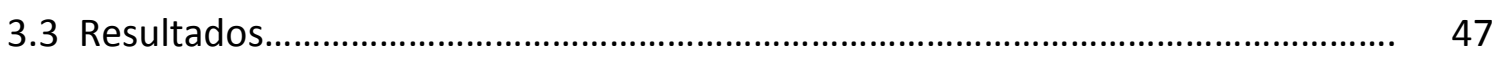

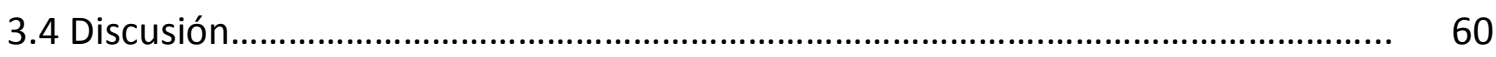

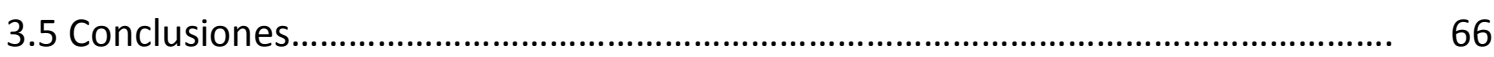


Capítulo 4: COMUNIDADES DE GLOMEROMYCOTA ASOCIADAS AL SUELO RIZOSFÉRICO Y A LA RAÍZ DE SOJA IDENTIFICADAS MEDIANTE TÉCNICAS MOLECULARES.

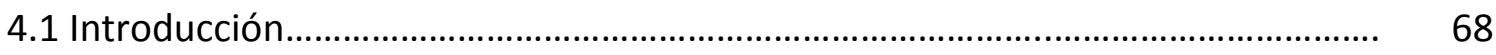

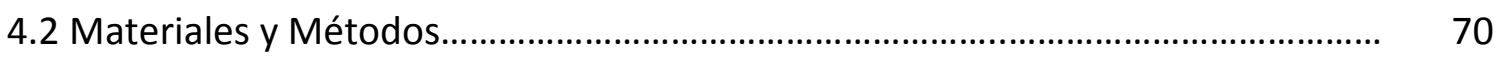

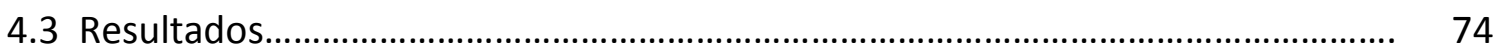

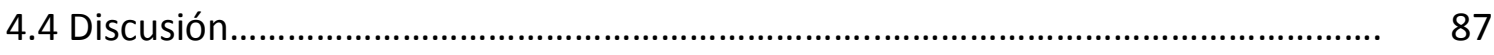

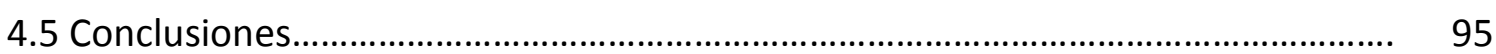

Capítulo 5: EFECTO DE MICORRIZAS NATIVAS SOBRE LA NUTRICIÓN FOSFORADA Y PARTICION DE FOTOASIMILADOS DE SOJA................................................................ 97

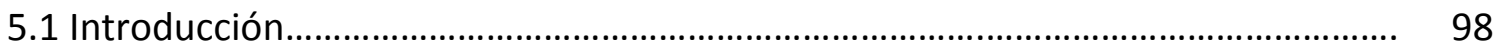

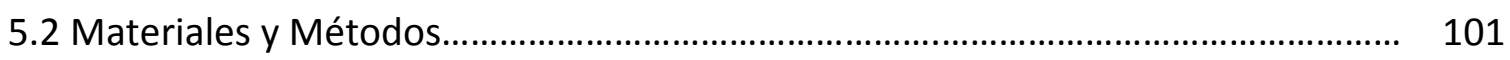

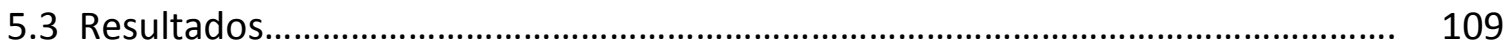

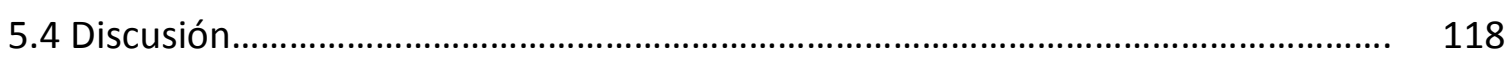

$\begin{array}{ll}5.5 & 125\end{array}$

Conclusiones.

Capítulo

6:

DISCUSIÓN 126

GENERAL

BIBLIOGRAFIA. 


\section{INDICE DE TABLAS}

Tabla 2.1: Características del suelo y del cultivo de soja de las zonas muestreadas.

Tabla 2.2: Coeficientes de regresión y estimación del índice $I M S_{50}$ a partir de bioensayo con suelo rizosférico de lotes de soja de diferentes zonas homogéneas del $\mathrm{S}$ de la Provincia de 29

Córdoba

Tabla 2.3: Valores promedio ( \pm Error Estándar) de hifas, arbúsculos y vesículas (\%) en raíces de soja de diferentes zonas homogéneas del $\mathrm{S}$ de la Provincia de Córdoba.....

Tabla 2.4: Análisis de correlación de Spearman entre $\mathrm{IMS}_{50}$ y estructuras micorrícicas y variables de suelo, del cultivo de soja y de 34 HFMA

Tabla 3.1: Abundancia relativa de esporas (\%) de Glomeromycota halladas en muestras de campo $\mathrm{y}$ plantas trampa......

Tabla3. 2: Índices biológicos de HFMA en muestras de campo y plantas trampa.

Tabla 3.3: Especies de Glomeromycota indicadoras de las zonas homogéneas....

Tabla 3.4: Análisis de correlación de Spearman entre índices biológicos de HFMA y variables de suelo y del cultivo de 55 soja

Tabla 3.5: Parámetros del test de comparación de composición de comunidades de Glomeromycota (PERMANOVA)

Tabla 4.1: Características del suelo y del cultivo de las zonas homogéneas..........

Tabla 4.2: Abundancia relativa (\%) de VT en muestras de raíces y suelo asociados a plantas de soja de diferentes zonas 76 homogéneas.

Tabla 4.3: Coeficientes y p-valor de correlaciones significativas (Spearman, $p<0,05)$ entre riqueza de taxa y variables de suelo y del cultivo en muestras de raíz y suelo rizosférico de soja de diferentes áreas 80 homogéneas.

Tabla 4.4: Análisis de comparación de composición de comunidades (PERMANOVA) entre las muestras de suelo y raíces de las diferentes áreas homogéneas. Análisis basado en la matriz de abundancia relativa

Tabla 4.5: Taxa indicadores de cada zona homogénea (valor indicador $>0,25$ ) de muestras de suelo raíz. 
Tabla 5.1: Propiedades químicas del suelo antes (+HFMA) y después (-HFMA)

del tratamiento con formaldehido $( \pm$ Error 102

Estándar)

Tabla 5.2: Altura, peso y nodulación de plantas de soja luego de 60 días de crecimiento en presencia (+HFMA) o ausencia (-HFMA) de propágulos micorrícicos autóctonos y condiciones de nutrición fosforada contrastantes $(+P$ y $\quad-P)$. Valores medios $(n=4)$ y resultados de ANOVA.

Tabla 5.3: Concentración de azúcares solubles y almidón ( $\mu \mathrm{gg}^{-1} \mathrm{PF}$ ) de plantas de soja luego de 60 días de crecimiento en presencia o ausencia de propágulos micorrícicos autóctonos y condiciones de nutrición P 115 contrastantes.

\section{INDICE DE FIGURAS}

Figura 1.1: Evolución de la superficie implantada con los principales cultivos estivales en Argentina durante el período 1969 - 2014.

Figura 1.2: Esquema que representa las diferentes estructuras intra y extraradicales que forman los hongos micorrícicos en la raíz de la planta hospedera......

Figura 2.1: Ubicación de los 126 sitios de muestreo (lotes de soja) distribuidos en las zonas ecológicas homogéneas del Sur de la Provincia de Córdoba...

Figura 2.2: Resultados del bioensayo de infectividad micorrícica potencial de suelos extraídos de lotes de soja de zonas homogéneas del S de la Provincia de Córdoba.

Figura 2.3: Infectividad Micorrícica del Suelo $\mathrm{IMS}_{50}$ (unidades $100 \mathrm{~g}$ suelo ${ }^{-1}$ ) estimada a partir de bioensayo con suelo rizosférico de lotes de soja del $\mathrm{S}$ de la Provincia de Córdoba.

Figura 2.4: Estructuras micorrícicas (\%) cuantificadas en raíces de soja de lotes del S de la Provincia de Córdoba

Figura 3.1: Curvas de acumulación de especies de las zonas Agrícola, Mixta y Sierras construidas con las especies de Glomeromycota identificadas a partir de las muestras de campo y plantas 50 trampa.

Figura 3.2: Densidad de esporas de HFMA (n 100g suelo-1 ${ }^{-1}$ hallada en lotes de soja de diferentes zonas homogéneas de la Provincia de Córdoba: Agrícola.

Figura 3.3: Especies más abundantes de Glomeromycota en lotes de soja de diferentes zonas homogéneas de la Provincia de Córdoba.

Figura 3.4: Distribución relativa de géneros de Glomeromycota hallada en lotes de 
soja de diferentes zonas homogéneas de la Provincia de Córdoba

Figura 3.5: Riqueza de géneros de Glomeromycota hallada lotes de soja de diferentes zonas homogéneas de la Provincia de Córdoba.

Figura 3.6: Composición de comunidades de Glomeromycota de lotes de soja en zonas homogéneas del $S$ de la Provincia de Córdoba (NMDS, stress $=59$ $0,11)$

Figura 4.1: Análisis de rarefacción de secuencias obtenidas de muestras de suelo (a) y raíces (b) de soja de diferentes zonas homogéneas. Las líneas de puntos perpendiculares al eje de número de secuencias corresponden a la mediana

Figura 4.2: Curvas de acumulación de especies con los taxa de muestras de suelo (a) y raíces (b) de soja de diferentes zonas homogéneas.

Figura 4.3: Riqueza de taxa de HFMA en muestras de suelo y raíz de soja de diferentes zonas homogéneas

Figura 4.4: Correlaciones entre el contenido de arena del suelo (\%) y el número de taxa por muestra (riqueza) de muestras de suelo (a) y raíces (b)

Figura 4.5: Composición de la comunidad de HFMA (NMDS) de lotes de producción de soja de diferentes áreas homogéneas del $\mathrm{S}$ de la Pcia de 83 Cba.

Figura 4.6: Composición de comunidades de HFMA de diferentes zonas homogéneas del S de la Pcia de Córdoba: (a) Agrícola (stress=0,09); (b) Mixta (stress $=0,10), y(c)$ Sierras (stress=0,10)

Figura 4.7: Abundancia relativa por muestra de taxa abundantes $(>0,20$ abundancia relativa en al menos 10 muestras) de muestras de suelo y raíz de soja de diferentes áreas homogéneas del Sur de la Provincia de 86 Córdoba.

Figura 5.1: Porcentaje de colonización (a) y viabilidad (b) de hifas, arbúsculos y vesículas en raíces de soja a los 60 días de recibir dos niveles de oferta fosforada...

Figura 5.2: Longitud de hifas de Glomeromycota $\left(\mathrm{mm} \mathrm{g}^{-1}\right)$ en suelo con plantas de soja a los 60 días de crecimiento bajo dos niveles de oferta 111 fosforada..

Figura 5.3: Concentración de $P$ de tejidos aéreos ( $a$ y $b$ ) y radicales (c y d) de plantas de soja a los 60 días de crecimiento bajo dos niveles de oferta fosforada: +P (izq.) y -P (der.); en presencia (+HFMA) o en ausencia (-HFMA) de inóculo micorrícico 
autóctono

Figura 5.4: Acumulación de $P$ de tejidos aéreos ( $a$ y $b$ ) y radicales ( $c$ y d) de plantas de soja a los 60 días de crecimiento bajo dos niveles de oferta fosforada: +P (izq.) y -P (der.); en presencia (+HFMA) o en ausencia (-HFMA) de inóculo micorrícico autóctono.

Figura 5.5: Dependencia micorrícica (\%) de plantas de soja a los 60 días de crecimiento bajo dos niveles de oferta fosforada: $+P$ y $-P$. Variables de crecimiento $y$ acumulación de $P$

Figura 5.6: Dependencia micorrícica (\%) de plantas de soja a los 60 días de crecimiento bajo dos niveles de oferta fosforada: $+\mathrm{P}$ y $-\mathrm{P}$; de azúcares solubles e insolubles en hojas $y$ raíces de soja $\left(\mu \mathrm{g} \quad \mathrm{mg}^{-1} 118\right.$

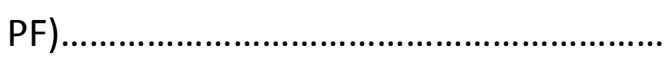




\section{Estudio de comunidades de hongos formadores de micorrizas arbusculares en soja: relación con la nutrición fosforada en agroecosistemas}

\section{RESUMEN}

Los hongos formadores de micorrizas arbusculares (HFMA) son simbiontes obligados que proporcionan importantes servicios ecosistémicos, entre ellos la mejora en la nutrición fosforada de las plantas. En las últimas décadas, ventajas económicas sumadas al uso de la siembra directa y de variedades genéticamente modificadas favorecieron una masiva expansión del cultivo de soja, incluso en lotes dedicados a la ganadería o áreas silvestres. El objetivo general de esta tesis fue estudiar comunidades nativas de HFMA asociadas al cultivo de soja en agroecosistemas del Sur de la Provincia de Córdoba, con énfasis en la nutrición fosforada del cultivo. Se realizó un muestreo en 126 lotes de soja ubicados en zonas de historial agrícola, mixto, y de reciente deforestación de las sierras cordobesas. En primer lugar, se cuantificó el nivel de micorrización de las raíces de soja y la infectividad micorrícica de los lotes y se correlacionaron con variables medidas en el suelo y en el cultivo. Se observó que la totalidad de las plantas estaban colonizadas por HFMA, pero en menor cantidad en suelos arenosos y bien provistos de fósforo (P). La misma tendencia se observó con el grado de infectividad micorrícica. Esta variable se correlacionó positivamente con el carbono (C), arcilla y agua del suelo, y con la acumulación de materia seca y $\mathrm{P}$ de las plantas de soja. Posteriormente se analizó la estructura de las comunidades nativas de HFMA mediante identificación taxonómica de esporas (suelo) y por secuenciación del gen 18S SSU rRNA (suelo y raíces). Las esporas mostraron una mayor riqueza y diversidad de especies en los sitios recientemente deforestados. El $\mathrm{P}$ del suelo afectó en forma negativa a estos parámetros e impactó significativamente sobre la composición de las comunidades. Mediante secuenciación del gen 18S SSU rRNA se observó que las comunidades de HFMA del suelo no difirieron entre las tres zonas de estudio y que el gradiente textural fue la variable más influyente. En las raíces, en cambio, la zona agrícola tuvo una comunidad de HFMA diferente a la hallada en las zonas mixta y de las sierras. También se halló un efecto significativo de la textura, los suelos arcillosos fueron más ricos en especies dentro de las raíces que los arenosos. Finalmente, se realizó un experimento en macetas con plantas de 
soja en presencia y ausencia de micorrizas nativas, con alta y baja disponibilidad de P. Se utilizó como inóculo suelo de un ensayo de 40 años de monocultivo de soja sin fertilización. Se midieron variables relacionadas a la simbiosis micorrícica, al crecimiento, acumulación de $\mathrm{P}$ y partición de fotoasimilados. Se observó que la oferta de $\mathrm{P}$ afectó negativamente el nivel de micorrización, la longitud de hifas extra-radicales y la actividad de estructuras micorrícicas dentro de la raíz. Sin embargo, independientemente de la oferta de $\mathrm{P}$, las micorrizas promovieron mejoras en el crecimiento de las plantas de soja. La mayor demanda de fotoasimilados de las raíces para mantener a la simbiosis micorrícica no afectó negativamente el crecimiento de las plantas. En general, se concluye que las comunidades nativas de HFMA, tanto del suelo como de las raíces, fueron diferentes según el historial de las zonas de producción de soja, y que la textura y $\mathrm{P}$ del suelo fueron factores determinantes de su composición. No se halló evidencias para descartar beneficios atribuidos a la simbiosis aún en niveles de altos de P. La información generada en esta tesis aporta conocimiento sobre la importancia y prevalencia de estos organismos en los agroecosistemas actuales.

Palabras clave: Glomeromycota, Glycine max (L) Merr, Córdoba, SSU rRNA, biodiversidad, servicios ecosistémicos 


\section{Study of arbuscular mycorrhizal fungal communities in soybean crops: their relation with phosphorus nutrition in agroecosystems.}

\section{ABSTRACT}

Arbuscular mycorrhizal fungi (AMF) are obligate symbionts which proportionate important ecosystem services, such as improvement of plant phosphorus (P) nutrition. During the last decades, economic advantages in addition to the use of no tillage practices and genetically modified cultivars favoured a massive expansion of soybean crop, even in fields intended to cattle production and wild areas. The aim of this theses was to study native communities of AMF associated to soybean plants in agroecosystem located in Southern Cordoba Province, with emphasis on crop P nutrition. A sampling in 126 soybean fields was conducted in zones with contrasting historical land use: agricultural, livestock and forest. First, the level of mycorrhizal colonization of soybean roots and mycorrhizal infectivity were determined and correlated with soil and crop related variables. Results showed that every sampled roots presented HFMA structures, but lower values in sandy, $\mathrm{P}$ rich soils. The same trend was observed with the level of mycorrhizal infectivity. The latest was positively correlated with soil carbon, clay and water; and plant dry matter and $\mathrm{P}$ accumulation. Secondly, the structure of native communities of AMF was analysed through spore identification (soil) and sequencing of gen 18S SSU rRNA (soil and root). Spores showed higher richness and diversity in recently deforested sites. Soil $\mathrm{P}$ negatively affected them, and significantly affected the composition of AMF communities. In soil, DNA sequencing revealed that AMF communities did not differed among study zones while textural gradient was highly determinant. However, in roots, agricultural zones had a different community composition compared to the observed in livestock and forest. Soil texture was also important, clayed soils were richer in species numbers inside roots than sandy soils. Finally, a pot experiment was carried out in presence and absence of native AMF, with high and low soil P. The mycorrhizal inoculum consisted of a soil with 40 years under soybean cultivation without fertilization. Mycorrhizal symbiosis variables, plant growth, $\mathrm{P}$ accumulation and carbohydrates partition were determined. It was observed that soil $\mathrm{P}$ negatively affected mycorrhizal colonization, extraradical hyphal length and mycorrhizal viability inside roots. However, in spite of the $P$ soil 
level, mycorrhizal symbiosis stimulated soybean plant growth. The higher root demand for carbohydrates, to support the fungal structures, did not affect plant growth. In conclusion, native communities of AMF, in soil and root samples, differed among study zones, and soil texture and $\mathrm{P}$ were determinant factors of community composition. There were no evidences to discard mycorrhizal benefits even under high levels of soil P. The information generated in this thesis expand our knowledge about the importance and prevalence of AMF in current agroecosystems.

Key words: Glomeromycota, Glycine max (L) Merr, Córdoba, SSU rRNA, biodiversity, ecosystem services 
CAPÍTULO 1

INTRODUCCIÓN GENERAL 


\section{Expansión del cultivo de soja en Argentina y su impacto en la biodiversidad}

La soja (Glycine max (L) Merril) es una leguminosa originaria del Sudeste Asiático que se ha adaptado exitosamente a la producción en el continente americano, donde se produce el $84,5 \%$ de la producción mundial (FAO, 2015). Es actualmente el cultivo más importante, tanto en la Región Pampeana como en la Argentina y ha tenido una expansión exponencial desde principios de los 70. En la campaña 1990/1991 el área nacional (producción) de soja alcanzó 5,1 millones de hectáreas (11 millones de toneladas), en 2004/05 llegó a 14,4 millones de hectáreas (38 millones de toneladas) y en 2014/2015, 19,8 millones de hectáreas (61 millones de toneladas) (SAGPyA, 2016). La producción de esta leguminosa se extiende a lo largo y ancho de todo el país, abarcando regiones con características agroecológicas contrastantes. Las provincias de mayor superficie destinada a este cultivo son Córdoba, Buenos Aires y Santa Fe, con 3,8; 3,7 y 0,9 millones de hectáreas, respectivamente (datos de la campaña 2014) (SAGPyA, 2016).

La expansión del cultivo de soja respondió a múltiples factores de carácter climático, económico y de manejo. El aumento de las lluvias desde 1950 (Berbery et al., 2006) mejoró la productividad de áreas tradicionalmente agrícolas y permitió la expansión hacia áreas climáticamente marginales (Magrin et al., 2005). Además, los cambios en el contexto económico global y nacional mejoraron la rentabilidad de la agricultura (Schnepf, et al., 2001). Sumado a ello, la incorporación de dos innovaciones tecnológicas a mediados de los 90 -siembra directa y variedades de soja tolerantes al herbicida glifosato- fue también un factor crítico en la expansión de la soja (Bert et al., 2011). Estas tecnologías mejoraron la productividad, redujeron los costos y simplificaron el manejo (Qaim y Traxler, 2005; Trigo et al., 2009).

En las últimas décadas el cultivo de soja comenzó a avanzar drásticamente en áreas agrícolas, ganaderas y sobre espacios silvestres. En zonas históricamente agrícolas se impuso sobre otros cultivos estivales, tales como el maíz y el girasol (Figura 1.1). Por ejemplo, mientras la superficie destinada a maíz se mantuvo relativamente estable entre 1994 a 2014, el área ocupada por soja se incrementó 2,3 veces. En ese mismo período el área destinada a la agricultura se duplicó, pasando de 12 a 27 millones hectáreas (SAGPyA, 2016). Esta expansión representa un total de 15 millones de hectáreas, las cuales provinieron del 
desplazamiento de la actividad ganadera y ocupación de nuevas tierras mediante la deforestación.

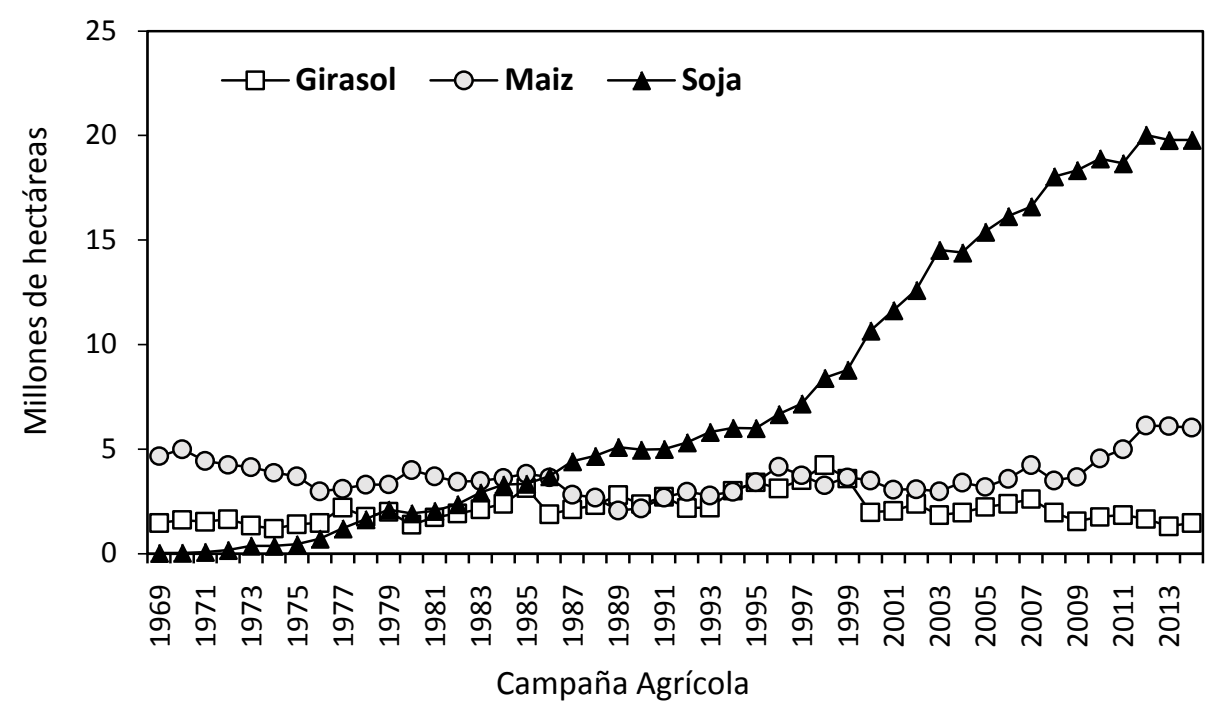

Figura 1.1: Evolución de la superficie implantada con los principales cultivos estivales en Argentina durante el período 1969 - 2014 (Fuente: SAGPyA, 2016).

Las provincias de la Región Pampeana fueron las más afectadas por el avance de la agricultura, lo cual queda demostrado por la disminución del stock de ganado (RIAN, 2016). Según los informes publicados por SENASA, el stock ganadero de 2015 llegó a los 51 millones de cabezas, un valor que se mantiene desde 2011 pero que ha quedado muy lejos de los 63 millones que se alcanzaron en 2007 (SENASA, 2016). Desde entidades productoras de carne afirman que sólo en 2006 y 2007 al menos 6,6 millones de hectáreas dejaron de destinarse a la ganadería y dieron lugar a la agricultura (Canosa, 2009). Sumado a ello, el ganado lechero mantuvo en la última década una tendencia de reducción del 1\% anual del stock (SENASA, 2016) y un $2,6 \%$ anual de cierre de establecimientos (Taverna, 2013). Finalmente, la deforestación es el otro factor sobre el cual se basa el avance de la frontera agrícola. En el último informe de la FAO de agosto 2015, Argentina figura novena entre los países que más superficie boscosa perdieron en el último quinquenio. Según sus estimaciones, la tasa anual de deforestación es de 1\%, lo cual representa un promedio de 0,29 millones de hectáreas desmontadas por año (FAO, 2015). Este índice supera el que se había calculado en 2001 cuando el promedio era del 0,8\% (FAO, 2002). Cabido y Zak (2010) afirman que en la Provincia de Córdoba este valor se supera ampliamente afectando a las ecorregiones de El 
Chaco Seco y la de El Espinal que abarcan la región Norte y central del territorio de la provincia, respectivamente. En la primera, la expansión de la agricultura entre 1970-2000 ocasionó la pérdida de más de 1 millón de hectáreas de bosques xerófilos por conversión a cultivos anuales, principalmente soja. Por su parte, el Espinal posee suelos muy aptos para el desarrollo de actividades agrícolas por lo cual sus bosques comenzaron una franca declinación, especialmente en los últimos 20 años (Cabido y Zak, 2010). La expansión de la frontera agrícola desde la ecorregión Pampeana es responsable de la reducción de las masas boscosas en la Provincia de Córdoba, quedando escasos manchones, como un relicto inmerso en una extensa matriz de cultivos anuales (Brown et al., 2005).

El avance del cultivo de soja como el principal exponente de la agricultura nacional ha ocasionado una gran homogeneización del paisaje. La flora y fauna autóctona quedó relegada a reservas o pequeños fragmentos de monte que aún persisten. Las especies vegetales sólo están representadas por uno o dos cultivos según las rotaciones agrícolas. Frente a este panorama, el único vestigio de biodiversidad del agroecosistema lo constituye la biota del suelo. La diversidad de especies tiene consecuencias funcionales ya que determinan importantes procesos del ecosistema (Chapin et al., 2000). Muchos de los actuales problemas que presentan los sistemas agrícolas, por ejemplo: pérdida de nutrientes, plagas, malezas y erosión, son aquellos que un ecosistema equilibrado podría contrarrestar. El rol funcional de la diversidad microbiana del suelo ha recibido mayor atención en los últimos años. Entre los procesos edáficos mediados por los microorganismos del suelo se destacan la eficiencia en el uso de los nutrientes, incremento en la estabilidad de los agregados del suelo, formación de materia orgánica y regulación hídrica (Mäder et al., 2002; Toljander et al., 2008; Shenan 2008). Sin embargo, aún queda mucho por conocer acerca de la diversidad de estas comunidades en sistemas agrícolas y qué relación tiene su composición y riqueza con la performance agronómica de un cultivo. En esta tesis se intentó responder a dicho interrogante estudiando un grupo crítico de microorganismos, abundantes tanto en ambientes naturales como en agroecosistemas: los hongos formadores de micorrizas arbusculares (HFMA).

\section{Hongos formadores de micorrizas arbusculares}


Los HFMA son microorganismos simbióticos que pertenecen al phylum Glomeromycota (Schüßler et al., 2001). Representan uno de los grupos más abundantes de organismos y se encuentran en una gran variedad de ambientes (Read, 1991). En la actualidad, son los principales determinantes de las interacciones en los ecosistemas y tienen diversos roles tanto en ambientes naturales como agrícolas. En un sistema radical micorrícico arbuscular hay tres componentes principales: la raíz, el micelio intra-radical (MIR: dentro del apoplasto de la raíz) y el micelio extra-radical (MER: en el suelo circundante). El MIR de los HFMA está involucrado en la transferencia de nutrientes entre los simbiontes y se diferencia en: arbúsculos intracelulares, vesículas intra o intercelulares y circunvoluciones (Figura 1.2), cada una de estas estructuras posee una función particular (Bonfante-Fasolo, 1988; Morton et al., 1997). La formación de arbúsculos constituye la característica diagnóstica de las micorrizas arbusculares. Son estructuras formadas por hifas muy ramificadas que se encuentran dentro de las células corticales del hospedante e incrementan la superficie de contacto entre el hongo y la planta. En la zona de interfase o apoplasto se produce el intercambio, los nutrientes inorgánicos tales como el fósforo (P) y el zinc ( $\mathrm{Zn}$ ) fluyen hacia la planta y los fotosintatos hacia el hongo (Smith y Read, 2010). Las vesículas son estructuras globosas llenas de lípidos que se forman en la raíz del hospedante en espacios inter o intracelulares y su función principal es de reserva (Bonfante-Fasolo, 1988) o como propágulos (Biermann y Linderman, 1983). Se ha observado que algunas especies de HFMA incrementan la formación de vesículas cuando la simbiosis ocurre en situaciones de alta oferta nutricional (Nijjer et al., 2010). En situaciones de estrés y cuando disminuye el suministro de metabolitos desde la planta hospedante, el hongo utiliza las reservas lipídicas de las vesículas, que posteriormente degeneran (Sieverding, 1991). EI MER es altamente afectado por la heterogeneidad del suelo y está involucrado en la búsqueda de nuevas plantas y en la exploración del suelo para la adquisición de nutrientes minerales que utilizarán tanto el hongo como la planta. Las hifas del MER pueden tener un crecimiento extenso (hasta $8 \mathrm{~cm}$ desde la raíz) (Sieverding, 1991), son capaces de conectar diferentes plantas hospedantes y establecer simbiosis micorrícica con las diversas especies de plantas con las cuales se contactan (Giovannetti et al., 2004). Durante el crecimiento del MER se pueden diferenciar esporas y células auxiliares. Las esporas de los HFMA son estructuras que contienen lípidos, citoplasma y hasta 2000-3000 núcleos y se forman asexualmente por diferenciación de hifas del MER en el suelo o las raíces. Las esporas pueden estar agregadas en grupos 
denominados esporocarpos que funcionan como estructuras de reserva y propágulos (Smith y Read, 2010). Los propágulos de los HFMA son las esporas, los fragmentos de raíces colonizados y los fragmentos de hifas o micelio del MER, tienen la capacidad de iniciar la colonización micorrícica en una planta. Las principales fuentes de propágulos en ecosistemas naturales son los fragmentos de raíces y el MER (Martins y Read, 1997). Mientras que las esporas son consideradas propágulos a largo plazo (Kabir, 2005), ya que tardan más tiempo en germinar y hacer contacto con las raíces que las hifas de un MER bien desarrollado (Klironomos y Hart, 2002).

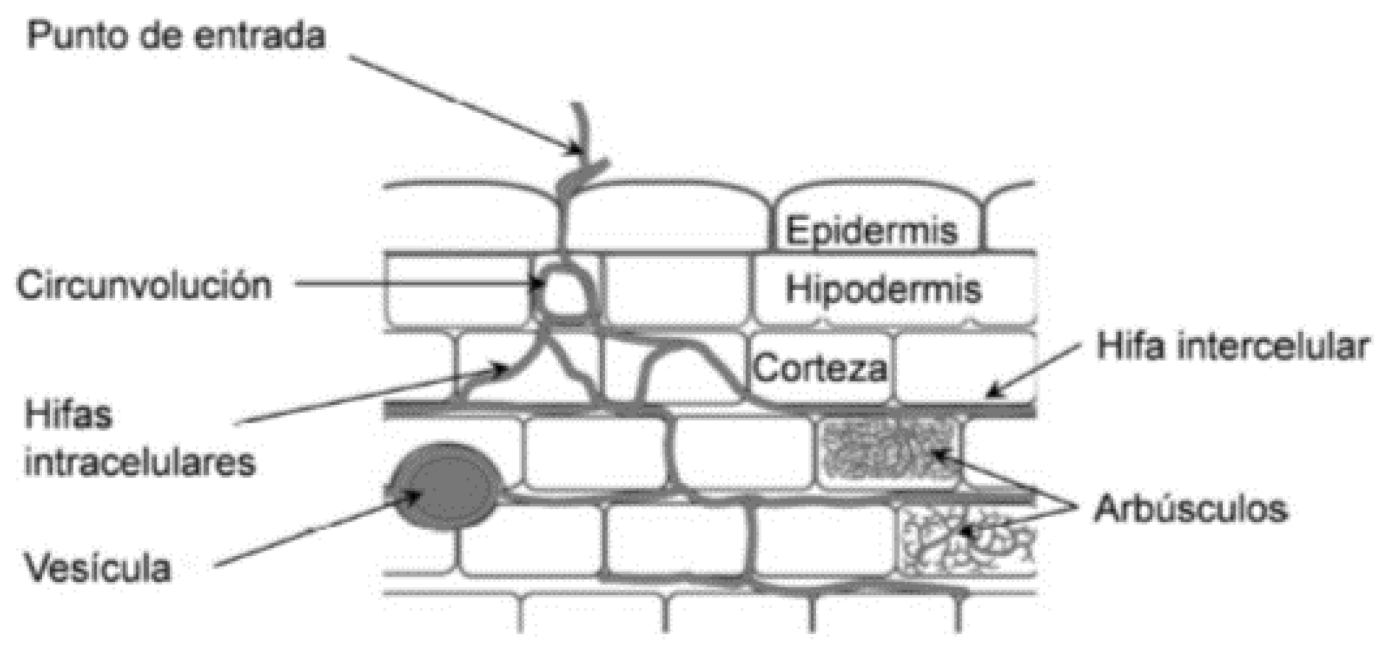

Figura 1.2: Esquema que representa las diferentes estructuras intra y extra-radicales que forman los hongos micorrícicos en la raíz de la planta hospedera (Brundrett, 2008; versión 2 on line http://mycorrhizas.info/resource.htm)

\section{El fósforo del suelo y la simbiosis micorrícica de soja}

Entre los beneficios atribuidos a la simbiosis micorrícica, la mejora en la eficiencia de adquisición de $\mathrm{P}$ ha sido ampliamente estudiada. El $\mathrm{P}$ es un nutriente que aunque es muy abundante en los suelos se encuentra fuertemente retenido y no disponible para las plantas (Marschner, 1995). Puesto que la única forma en que puede ser absorbido por las raíces es como ion ortofosfato $\left(\mathrm{H}_{2} \mathrm{PO}_{4}{ }^{-}\right)$, las plantas deben adoptar diversas estrategias para lograr la liberación de $\mathrm{P}$ desde las estructuras coloidales y complejos orgánicos que lo retienen. Comparada con otros cultivos estivales, la soja es altamente demandante de $P$, sus requerimientos ( $6 \mathrm{kgP} \mathrm{tn}^{-1}$ grano) son considerablemente superiores a los de maíz y girasol (3,1 y $3,9 \mathrm{kgP} \mathrm{tn}^{-1}$ grano, respectivamente). Sin embargo, su respuesta a la fertilización es 
muy errática incluso en suelos de baja disponibilidad de P (Gutierrez-Boem y Salvagiotti, 2015). La baja dependencia a la fertilización fosfatada a pesar de la gran demanda del nutriente permite inferir que la soja posee estrategias exitosas para abastecerse de $P$ del suelo (Marschner, 1995). Ciertos mecanismos, tales como el aprovechamiento de P orgánico por hidrólisis mediada por fosfatasas o el acceso diferencial a ciertas formas químicas del suelo han sido descartados (Rubio et al., 2011; Tadano y Sakai, 1991; Tadano et al., 1993). Es por ello que la simbiosis con los HFMA parece ser una posible explicación para la eficiente adquisición de $\mathrm{P}$ de la soja (Fernández et al., 2009). Incluso se ha hallado que es posible mantener el rendimiento de soja con reducción en la aplicación de fertilizante fosfatado si el cultivo antecesor es con plantas micorrícicas (Oka et al., 2010).

Algunos experimentos han demostrado que los HFMA contribuyen hasta con el $90 \%$ del total del P que absorbe una planta (Jakobsen et al., 1992; Leake et al., 2004; Smith y Smith, 2011). El influjo de $P$ en raíces con micorrizas puede ser 3 a 5 veces mayor que en plantas no micorrizadas (Smith y Read, 2010). Esta eficiencia se debe a que las hifas extra radicales pueden acceder a $\mathrm{P}$ de la solución de suelo fuera de la zona de agotamiento de la rizósfera y transferirlo a la raíz (Munkvold, et al., 2004); tienen un menor $\mathrm{K}_{\mathrm{m}}$ que las raíces, por lo que pueden tomar $\mathrm{P}$ a menores concentraciones en la solución de suelo (Schachtman et al., 1998), y a que poseen la habilidad de aprovechar formas de $P$ del suelo que no son accesibles para la raíz (Smith y Read, 2010). A cambio de los nutrientes obtenidos por las micorrizas la planta transfiere fotosintatos a las estructuras fúngicas de la raíz. Los HFMA son completamente dependientes de su huésped para cubrir los requerimientos de $\mathrm{C}$ y no pueden completar su ciclo vital sin una planta. Se ha medido que la simbiosis micorrícica puede demandar hasta un $20 \%$ de los hidratos de C de la planta (Jakobsen y Rosendhal, 1990). El balance entre el costo y el beneficio de la simbiosis determina respuestas positivas o negativas en la planta. Dicho equilibrio está determinado por varios factores, tales como el estadio de crecimiento del huésped y la provisión de recursos vitales tales como agua, nutrientes y luz (Smith y Read, 2010).

\section{Importancia de los hongos formadores de micorrizas en el agroecosistema}

Además de los efectos directos sobre las plantas, la simbiosis provee una serie de servicios ecosistémicos que están comenzando a ser más estudiados en los últimos años. Por ejemplo: 
la supresión de patógenos (Lendzemo, et al., 2005), supresión de malezas en sistemas agrícolas (Rinaudo et al., 2010), protección de la herbivoría (Bennett et al., 2009), tolerancia a condiciones sub-óptimas de potenciales hídricos tales como sequía, anegamiento, salinidad (Augé, 2001, Fougnies et al., 2007), y a altas temperaturas edáficas (Bunn et al., 2009). Otro de los beneficios atribuidos a la micorrizas es la producción de un agente estructurante de los suelos. Dentro de las paredes de las hifas, los HFMA producen una glicoproteína denominada glomalina (Driver et al., 2005; Wright y Upadhyaya, 1999). Cuando estas hifas mueren, la glomalina se deposita en el suelo donde comienza a acumularse llegando a alcanzar el 5\% del C edáfico (Rillig et al., 2003, 2001). Es un compuesto muy abundante en los suelos que secuestra considerables cantidades de $\mathrm{C}$ y $\mathrm{N} \mathrm{a}$ escala global (Lovelock et al., 2004). Treseder y Turner (2007) hallaron que los stocks de glomalina son mayores en presencia de plantas de alta dependencia micorrícica ya que destinan más $\mathrm{C}$ al hongo. De este modo las micorrizas intervienen en el ciclo del $\mathrm{C}$ de la naturaleza y sus beneficios se traducen en mejoras en la acumulación de materia orgánica del suelo y en la estabilidad de agregados (van der Heijden et al., 2006; Wilson et al., 2009). Otros estudios han demostrado que los HFMA contribuyen en la reducción de pérdidas de nutrientes, es decir, la mejora en la eficiencia de absorción de $\mathrm{P}$ y $\mathrm{N}$ reduce el riesgo de pérdidas ya sea por lixiviación o denitrificación. En efecto, se ha registrado que los HFMA disminuyeron significativamente las pérdidas de $\mathrm{N}$ (hasta $70 \mathrm{~g}$ ha año) y de $\mathrm{P}$ (hasta $150 \mathrm{~g}$ ha año) por lixiviación (Asghari y Cavagnaro, 2012; Bender et al., 2015). Incluso en ausencia de respuesta de la planta los HFMA demostraron reducir la lixiviación de nutrientes (van der Heijden et al., 2010). Estudios más recientes también hallaron que estos hongos producen una reducción en la emisión de óxido nitroso $\left(\mathrm{N}_{2} \mathrm{O}\right)$, un gas con un poder de producir el efecto invernadero 300 veces superior al del dióxido de carbono $\left(\mathrm{CO}_{2}\right)$ (Bender et al., 2014). Este beneficio es indirecto ya que los HFMA influyen sobre las comunidades de bacterias que habitan la rizósfera y micorrizosfera (Johansson et al., 2004; Sheublin et al., 2010), y pueden inducir cambios en las comunidades denitrificantes (Veresoglou et al., 2012). Puede afirmarse, entonces, que los servicios ecosistémicos provistos por los HFMA son capaces de trascender el beneficio inmediato para los cultivos y tienen el potencial de contribuir fuertemente en la sustentabilidad de los agroecosistemas. 


\section{Efecto del cultivo de soja sobre los hongos formadores de micorrizas}

La intensificación de la producción de soja en siembra directa puede impactar negativamente sobre los HFMA nativos a través de las prácticas de monocultivo, la fertilización y el uso del herbicida glifosato. El monocultivo podría exacerbar los efectos de procesos de selectividad inducidos por la planta (Helgason et al., 2002; Vandenkoornhuyse et al., 2003) y la competencia entre especies generando fuertes desequilibrios en la abundancia de estos hongos (Roger et al., 2013). La rotación de cultivos también impide que algunas especies se tornen dominantes, permite una mayor diversidad (Oehl et al., 2003; Hijri et al., 2006), y puede generar que las comunidades de HFMA sean más similares a las de situaciones prístinas (Verbruggen et al., 2010). Incluso, Oehl et al. (2009) demostraron que un sistema agrícola con un intensivo esquema de rotación puede alojar una comunidad más diversa que la de su respectivo ambiente natural. Verbruggen y Kiers (2010) sostienen que repetidos ciclos con el mismo cultivo puede generar el predominio de especies de Glomeromycota menos mutualistas que evolucionan siendo más efectivas en contrarrestar las estrategias de la planta para estimular la cooperación. Esto puede resultar en una respuesta negativa por parte de la planta, por ejemplo, una disminución del crecimiento (Kiers y Denison, 2008). Johnson et al. (1992) hallaron consistentes correlaciones negativas entre la abundancia de esporas que proliferaron en monocultivo y la performance del cultivo en el cual se generaron. Sin embargo, las mismas esporas promovieron respuestas positivas en otros cultivos. Estos resultados demuestran que la rotación tendría el potencial de promover comunidades de HFMA más benignas o menos parasíticas para la planta. No obstante, también podría suceder que ante monocultivo sea la planta -y no el hongo- la que seleccione a favor de especies de HFMA más mutualistas. Esta es una hipótesis planteada por Verbruggen y Kiers (2010) que aún no ha sido corroborada.

Diversos estudios demuestran que la fertilización impacta sobre la composición comunidades de HFMA (Bainard et al., 2014; Hijri et al., 2006; Gosling et al., 2013) y que afecta negativamente a las funciones micorrícicas (Johnson, 1993; Kahiluoto et al., 2009). En ambientes ricos en nutrientes, las plantas pueden disminuir drásticamente la asignación de recursos a las estructuras micorrícicas afectando la colonización y por ende, la propagación de las especies de HFMA (Mäder et al., 2000). Al reducirse la asignación de fotoasimilados, se incrementa la competencia por los recursos escasos dentro de la raíz. Se ha observado 
que esto genera un cambio en el balance competitivo de las especies, favoreciendo a aquellas más agresivas en detrimento de aquellas más mutualistas (Kiers et al., 2002; Kiers y Denison, 2008). Por ejemplo, Bainard et al. (2014) observaron que ante aumentos en la oferta de P del suelo, especies de Funneliformis y Septoglomus incrementaban su abundancia dentro de la raíz, mientras que con el resto de las especies de HFMA ocurría lo contrario. Johnson et al. (1997) hallaron que la fertilización generó que el hongo destinara más recursos a la formación de estructuras de reserva (vesículas) que de hifas y arbúsculos. En consecuencia, la fertilización a largo plazo genera un ambiente más propicio para especies eficientes en la colonización y persistencia, pero poco mutualistas desde el punto de vista nutricional.

Finalmente, otro aspecto inherente al cultivo de soja es el uso de variedades genéticamente modificadas (GM) con resistencia al glifosato y/o insectos. Uno de los efectos de los cultivos GM sobre los HFMA radica en la variación en la composición de los exudados radicales los cuales pueden inhibir el proceso de infección radical por el hongo (Liu, 2010). En el caso de cultivos GM con la toxina de Bacillus thuringiensis; ésta se acumula en la zona rizosférica e impacta directamente sobre el crecimiento y desarrollo de hifas extra-radicales y sobre la esporulación del hongo (Turrini et al., 2004). Sumado al efecto del cultivar GM, se debe añadir el impacto de la adición de glifosato, un herbicida sistémico no selectivo, ampliamente empleado en la producción de soja. Se ha demostrado que este producto puede impactar sobre los HFMA de manera directa, afectando a las esporas con las que toma contacto, e indirecta debido a los cambios que induce en la planta. Druille et al. (2013ab, 2015) observaron una reducción en la formación de arbúsculos luego de la aplicación foliar de glifosato, y diminución de la viabilidad de esporas al aplicarlo en el suelo. En definitiva, prácticas usuales en la producción de soja, tales como el monocultivo, la fertilización, el uso de variedades GM y la aplicación de herbicidas actúan negativamente a lo largo de tiempo sobre las comunidades nativas de HFMA debido a los efectos acumulados en los propágulos micorrícicos del suelo.

\section{Objetivo e hipótesis generales}


El objetivo general de esta tesis fue estudiar comunidades nativas de HFMA asociadas al cultivo de soja en agroecosistemas del Sur de la Provincia de Córdoba, con énfasis en la nutrición fosforada del cultivo.

Las hipótesis generales que se pusieron a prueba son:

- La infectividad, riqueza de especies y composición de comunidades autóctonas de HFMA variará de acuerdo al historial de uso de los agroecosistemas y se correlacionarán con las propiedades edáficas de los mismos.

- La simbiosis micorrícica mejorará la nutrición fosforada de soja y la respuesta de la planta dependerá de la oferta de P del medio.

\section{Aproximación metodológica y estructura de la tesis}

En esta tesis se utilizó una aproximación exploratoria para estudiar la riqueza de especies y composición de comunidades autóctonas de HFMA en agroecosistemas del $\mathrm{S}$ de la Provincia de Córdoba dedicados al cultivo de soja, con énfasis en la nutrición fosforada del cultivo. Las zonas de estudio correspondieron a lotes de soja con diferentes historial de uso: agrícola, mixto y de reciente deforestación en la serranía cordobesa. En el Capítulo 2 se cuantificó la infectividad micorrícica del suelo y se estudió su relación con los niveles de micorrización de las raíces de soja, densidad de esporas de HFMA y variables del suelo y del cultivo. En los Capítulos 3 y 4 se abordó el estudio de la composición de las comunidades nativas de HFMA con diferentes metodologías. En el Capítulo 3 se identificaron las especies a través de la morfología de esporas halladas al momento del muestreo y luego de la multiplicación con plantas trampa. En el Capítulo 4 las especies de Glomeromycota presentes tanto en el suelo como dentro de las raíces de soja se identificaron mediante una técnica de secuenciación de última generación (454 Roche) a partir de un fragmento del gen 18S rRNA y su comparación con una base de datos internacional (MaarjAM). En ambos capítulos se estudiaron las correlaciones entre la riqueza de especies y composición de comunidades de HFMA con variables de suelo y del cultivo. En el Capítulo 5 se estudió el efecto de HFMA nativos sobre la nutrición fosforada de soja utilizando como inóculo un suelo con más de 40 años de monocultivo de soja en siembra directa sin fertilización. Se evaluaron parámetros de crecimiento, acumulación de $\mathrm{P}$ y partición de fotoasimilados de plantas de soja que crecieron con niveles contrastantes de $\mathrm{P}$, en presencia y en ausencia de HFMA. La 
originalidad de esta tesis radica en dos aspectos: por un lado no se han hallado hasta el momento estudios de la composición de comunidades nativas de HFMA bajo cultivo de soja en agroecosistemas contrastantes, realizando simultáneamente la identificación de esporas y el uso de técnicas moleculares en suelo y raíces. Por otro lado, el efecto del P en la simbiosis y composición de comunidades de HFMA bajo cultivo de soja se estudió a lo largo de toda la tesis y finalizó con un experimento empleando como inóculo un suelo de un historial conocido de monocultivo de la leguminosa. 
CAPÍTULO 2

INFECTIVIDAD MICORRÍCICA DEL SUELO Y SU RELACIÓN CON LA FORMACIÓN DE MICORRIZAS EN SOJA

Resultados preliminares presentados:

Faggioli VS y MN Cabello. 2013. Micorrizas en soja y su relación con la densidad de esporas e infectividad en suelos de diferentes ambientes agricolas. IX Reunión Nacional de Biología de Suelos. Santiago del Estero 4, 5 y 6 septiembre 2013. Presentación oral. 


\subsection{INTRODUCCIÓN}

En agroecosistemas, el aprovechamiento del amplio espectro de servicios ecosistémicos en los que intervienen los HFMA depende de la conservación de dichos integrantes de la biota del suelo. Las redes de micelio, los fragmentos de raíces infectadas y las esporas constituyen la reserva de inóculo micorrícico del suelo (Smith y Read, 2010). Hart y Reader (2005) compararon la función del micelio externo de HFMA durante la etapa inicial de infección radical y observaron que la colonización era más rápida en presencia de mayor número y tamaño de estructuras infectivas y puntos de contacto con las raíces. Kiers y Denison (2014) sostienen que una producción sustentable es aquella que tiene en cuenta tanto la performance de los cultivos como de las comunidades de microorganismos simbióticos del suelo. Jansa et al. (2009) proponen que la capacidad de un suelo de inducir la formación de micorrizas debería ser considerada como un indicador de la calidad del suelo.

Se denomina infectividad micorrícica a la habilidad natural de un suelo que contiene HFMA de inducir la formación de micorrizas en las plantas (Plenchette et al., 1989). Jansa et al. (2009) sugieren establecer umbrales de infectividad considerados "normales" para ciertos manejos de suelo y condiciones ambientales. Este parámetro es afectado por características intrínsecas del mismo suelo y por las prácticas de manejo. Por ejemplo, se ha reportado una fuerte relación negativa entre la infectividad y la disponibilidad de fósforo $(P)$ del suelo (Duvert et al., 1990; Jansa et al., 2009; McGee, 1989). Los sistemas de labranza, fertilización y la rotación de cultivos influyen fuertemente sobre la infectividad (Schalamuck y Cabello, 2009; Wang et al., 2008). En los sistemas antrópicos, el hombre determina en gran medida la micorrización de un cultivo según el impacto ejercido sobre el banco de propágulos del suelo. Al mismo tiempo, de modo desapercibido, también interfiere sobre los potenciales beneficios de la simbiosis.

El nivel de infectividad micorrícica representa un parámetro de la fertilidad edáfica debido a la multiplicidad de servicios ecosistémicos provistos por las micorrizas arbusculares (Verbruggen et al., 2011). Su diagnóstico y seguimiento es indispensable para exacerbar la productividad de los cultivos y la sustentabilidad de los agroecosistemas. Suelos con mayor infectividad han sido relacionados con incrementos en las tasas de crecimiento y mejoras en la nutrición de las plantas (Jansa et al., 2009). Sin embargo, la información disponible es escasa en nuestro país y en particular en la Provincia de Córdoba (Cofré, 2014). Sumado a 
ello, los resultados son muy dependientes de las condiciones experimentales empleadas para su estimación haciendo poco factible la comparación cuantitativa con otras investigaciones (Jansa et al., 2009). En consecuencia, a los fines de cotejar distintos tipos de suelo o manejo es recomendable que la información sea generada en un mismo ensayo lo cual muchas veces es inviable por la gran demanda operativa de la metodología (Wang et al., 2008; Wilson y Trinick, 1983).

El objetivo general de este capítulo fue cuantificar la infectividad micorrícica de lotes de soja de diferentes zonas homogéneas del S de la Provincia de Córdoba.

Los objetivos específicos fueron:

1) Analizar las relaciones entre la infectividad micorrícica estimada y las estructuras micorrícicas cuantificadas en cultivos de soja.

2) Analizar las relaciones entre infectividad micorrícica y variables del suelo y del cultivo.

Se pusieron a prueba las siguientes hipótesis:

1) El nivel de infectividad micorrícica del suelo estará relacionado positivamente con la formación de micorrizas en el cultivo de soja.

2) La infectividad micorrícica será afectada por las propiedades del suelo, especialmente el contenido de $\mathrm{P}$, y se relacionará significativamente con variables del cultivo de soja. 


\subsection{MATERIALES Y METODOS}

\section{Área de estudio}

La división del área de estudio está basada en un informe socioeconómico de sustentabilidad de los sistemas de producción y recursos naturales llevado a cabo por INTA (Ghida Daza y Sánchez, 2009). La provincia de Córdoba se subdividió en zonas de características homogéneas en cuanto a clima, suelo y sistemas agropecuarios. En el relevamiento de suelos de esta tesis se seleccionaron sitios de muestreo en todas las zonas homogéneas del Sur de la provincia (Figura 2.1). De aquí en adelante, denominaremos como sub-zonas o sitio a cada subdivisión de las zonas homogéneas Agrícola, Mixta y Serrana que se describirán a continuación.

\section{a) Zona de historial de uso agrícola}

Área núcleo agrícola

Corresponde a la zona agrícola del $\mathrm{N}$ de la provincia de Buenos Aires, S de Santa Fe y SE de Córdoba. Está conformada por las áreas ecológicas homogéneas de Marcos Juárez y Canals. Suman 1,4 millones de hectáreas, lo cual representa el 8,7\% del total de la superficie de la provincia. A continuación se presenta una breve descripción de cada sub-zona homogénea del Área Núcleo Agrícola:

- Canals (Ca): zona húmeda subhúmeda del E de producción agrícola. Su superficie alcanza los 0.3 millones de hectáreas (2,4\% del total provincial). Las localidades de referencia son Canals y Alejo Ledesma. El relieve corresponde en su mayor parte a una llanura eólica de materiales franco arenosos en la que aumentan los tenores de las fracciones arenosas hacia el $\mathrm{O}$ donde comienzan a aparecer relictos medanosos estabilizados. El drenaje superficial es casi nulo y se presenta más bien como un conjunto de cuencas cerradas localizadas. Hacia el $\mathrm{N}$ presenta una llanura en transición con la Pampa Ondulada, constituida por amplias lomadas planas surcadas por vías de escurrimiento con distinto grado de expresión. La vegetación natural está constituida especialmente por gramíneas. Los suelos presentan una secuencia de clases taxonómicas de $\mathrm{E}$ a $\mathrm{O}$ que replica el gradiente de disminución de las precipitaciones. Comienza con Argiudoles típicos en las proximidades del límite con la provincia de Santa Fe, le siguen Hapludoles énticos y típicos, y los Haplustoles al O. La 
temperatura media anual es de $17^{\circ} \mathrm{C}$ c con una amplitud térmica de $14^{\circ} \mathrm{C}$. La precipitación media anual se distribuye en un rango de $850 \mathrm{~mm}$ al O y $900 \mathrm{~mm}$ al E, con una distribución estacional de tipo monzónica. La principal actividad de la zona es la agrícola y en menor medida la ganadera. En agricultura predomina el cultivo de soja y en ganadería la actividad bovina de carne y de leche. Es una zona cuyos suelos se adaptaron exitosamente al cultivo de soja en siembra directa, desplazando otras actividades agropecuarias.

- Marcos Juárez (MJ): corresponde a la zona húmeda del E de producción agrícola, con una superficie de 1,1 millones de hectáreas (7,2\% del total provincial). Las localidades de referencia son Marcos Juárez, Bell Ville y Corral de Bustos. Su relieve pertenece a la Pampa Ondulada, una llanura entre moderada y suavemente ondulada, con gradientes de pendientes que oscilan entre el $3 \%$ al $0.5 \%$. Se caracteriza por la naturaleza de los materiales originarios loessicos ricos en limos. Tiene un relieve de lomas altas, planas, con marcadas pendientes hacia los arroyos. La vegetación natural se compone principalmente de gramíneas. Los suelos se desarrollaron sobre sedimentos eólicos, son franco limoso fino. La característica sobresaliente es su importante grado de desarrollo, fertilidad y alta productividad, consecuencia de sus caracteres físico químicos intrínsecos y del régimen de precipitaciones que los convierte en los suelos tradicionalmente de mayor productividad de la provincia. Los suelos dominantes son Molisoles, profundos, con un horizonte superior rico en materia orgánica y bien estructurado que facilita el movimiento superficial del aire y el agua. Son Argiudoles (44\%), Hapludoles (10\%) y Haplustoles (34\%) en las lomas; en los bajos son Natracualfes (3\%) y Natralboles (5\%). La temperatura media anual es de 17 o C y la amplitud térmica de 14 으. La precipitación media anual se distribuye en un rango de 850 $\mathrm{mm}$ al $\mathrm{O}$ y supera los $900 \mathrm{~mm}$ al E, con una distribución estacional de tipo monzónica. La principal actividad económica de la zona ha sido siempre la agricultura, en la actualidad el cultivo de soja abarca la totalidad del área ocupada por tierras aptas para el cultivo (96\%) con baja ocupación de maíz, el segundo cultivo estival de la zona.

\section{b) Zona de historial de uso agrícola - ganadero}

Área Ganadera Agrícola del Sur

Corresponde a la zona mixta del NO de la provincia de Buenos Aires, E de La Pampa, S de Córdoba y E de San Luis. Está integrada por las zonas ecológicas homogéneas de Laboulaye, 
Villa Huidobro y Rio Cuarto. Constituye un área extensa de 3.88 millones de hectáreas, es decir, un $31 \%$ del total del área de la provincia. A continuación se presenta una breve descripción de cada sub-zona homogénea del Área Ganadera - Agrícola del S:

- Laboulaye (La): ocupa la región semiárida subhúmeda del SE de producción mixta con una superficie de 1,7 millones de hectáreas (12,3\% total provincial). Las localidades de referencia son: General Cabrera, Ucacha, La Carlota y Laboulaye. El relieve alcanza ambientes diversos y diferenciados muy arenosos y medanosos al $\mathrm{S}$, anegable en el centro y llanuras loéssicas con bajas pendientes al N. La vegetación natural es la estepa, predominantemente de gramíneas. La región central de esta zona se caracteriza por las frecuentes inundaciones, asociadas a la salinización y sodificación edáfica. Los suelos predominantes son Haplustoles énticos y udorténticos (58\%) y Hapludoles (2\%). En los bajos son frecuentes los Natralboles (14\%) y Natracualfes (7\%), mientras que en las crestas de los médanos los Ustipsamentes y Ustortentes (3\%). La temperatura media anual es de 16 ㅇ con una amplitud térmica de 15 ㅇ․ La pluviometría regional posee una distribución con un rango de $700 \mathrm{~mm}$ al O y más de $900 \mathrm{~mm}$ al E, con una distribución estacional de tipo monzónico. Los principales cultivos de la zona son maíz, trigo, sorgo, soja, maíz y girasol. La existencia de ganado bovino para carne y leche, ovino y porcino alcanza el $20 \%$ del total provincial. Históricamente ha sido una región predominantemente ganadera pura y mixta con más del $40 \%$ de la superficie destinada a pasturas. Sin embargo, en la última década el avance de la soja ha desplazado otros cultivos y constituye el principal cultivo estival de la zona.

- Rio Cuarto (RC): ocupa la región semiárida centro O de producción mixta con una superficie de 0,8 millones de hectáreas (6\% del total provincial). Las localidades de referencia son Río Cuarto, Alcira y Las Acequias. El relieve comprende parte de la Pampa Alta Arenosa al S y de la Pampa Alta Loéssica al N. También abarca el extremo meridional del sistema serrano (Sierra de Comechingones y Las Peñas) y su piedemonte. Conforma una llanura que suaviza su relieve desde el piedemonte hacia el $E$, constituida por sedimentos franco arenosos que se hacen areno francos hacia el S y más limosos en las llanuras al N. La región está surcada por cursos de agua de régimen torrencial que nacen en las sierras o en depresiones tectónicas en la llanura. La vegetación natural corresponde a la de la región Del Espinal, es la de sabana con pastizales y árboles aislados. Está caracterizado por el género Prosopis (algarrobo, ñandubay, caldén). El Espinal rodea a la Región Pampeana por el N, el O 
y el SO. Los materiales originales de los suelos son de origen eólico, de textura franco arenosa fina. Muchos de estos suelos están sujetos a severos procesos de erosión hídrica que condicionan su manejo. Los suelos predominantes son Haplustoles (62\%) y Hapludoles (21\%) en las lomas e interfluvios; y Ustortentes (5\%) en las crestas medanosas. La temperatura media anual es de $17{ }^{\circ} \mathrm{C}$ con una amplitud de 14 으. La precipitación media anual se distribuye en un rango de $650 \mathrm{~mm}$ al $\mathrm{O}$ y supera los $700 \mathrm{~mm}$ al $E$, con una distribución estacional de tipo monzónico. La principal actividad ha sido la producción agrícola - ganadera. Los cultivos principales son: maíz, soja, maní y en menor medida girasol. La producción ganadera es principalmente de carne. Los bosques y montes implantados representan el $23 \%$ del total provincial. En esta zona el avance de la soja no sólo ha ocurrido por sustitución de otras actividades sino también por la ocupación de tierras recientemente desmontadas.

- Villa Huidobro (VH): comprende la región semiárida del S de producción mixta con una superficie de 1,34 millones de hectáreas (11\% del total provincial). Las localidades de referencia son Villa Huidobro, Del Campillo y Jovita. El relieve ocupa la denominada Pampa Medanosa, caracterizada por un relieve ondulado o suavemente ondulado, generado por sobre imposición de formas medanosas de diferente edad. Las antiguas son dunas longitudinales disipadas, cuyos materiales han sido removilizados recientemente, dando lugar a dunas parabólicas de gran magnitud. Las cubetas centrales generalmente están ocupadas por lagunas que al alcanzar la napa freática adquieren carácter permanente. Es un medio de alta fragilidad ecológica, donde los procesos dominantes son eólicos. En forma subordinada se dan procesos de desborde y sedimentación asociados a los arroyos. La vegetación natural corresponde a la Del Espinal (sabana, descripta anteriormente en RC) al S y la Pampeana al $\mathrm{N}$ (gramíneas). Los suelos muestran un bajo grado edafogénico y de evolución, con poca diferenciación de horizontes, desarrollados sobre materiales ricos en arenas geoquímicamente estables bajo el clima prevaleciente. Son suelos poco profundos, excesivamente drenados, sin agregación y pobremente estructurados. Predominan los Haplustoles (49\%) y Haplustentes (33\%); seguidos por Argiustoles (5\%) en zonas de libre drenaje, Natracualfes (5\%) en lo bajos y Ustortentes (8\%) en las crestas de lomadas medanosas. La temperatura media anual es de $16^{\circ} \mathrm{C}$ con una amplitud térmica de $15^{\circ} \mathrm{C}$. Las precipitaciones alcanzan los $650 \mathrm{~mm}$ anuales al $\mathrm{O}$ y superan los $800 \mathrm{~mm}$ al $\mathrm{E}$, con una 
distribución estacional de tipo monzónico. Esta zona ha sido históricamente ganadera, con producción de bovinos de carne. El principal cultivo agrícola ha sido el girasol convirtiendo a esta zona en su principal productora. También se cultiva maíz, maní y trigo. En la actualidad el avance de la soja no sólo ha sustituido la producción de carne sino que también al resto de cultivos agrícolas.

\section{Área Lechera del Centro}

En el relevamiento se tomaron muestras de la porción $\mathrm{S}$ del Área Lechera Centro correspondiente a la denominada zona lechera del centro E de la provincia de Córdoba y centro de Santa Fe. Está integrada por las zonas ecológicas homogéneas de Villa María, Arroyito y San Francisco. A continuación sólo se describirá la sub-zona de Villa María porque es la única que se incluyó en el muestreo.

- Villa María (VM): zona semiárida y sub-húmeda central de producción lechera ubicada en el centro de la provincia de Córdoba. Su superficie es de 0,34 millones de hectáreas (3\% del total provincial). Las localidades de referencia son Villa María, Etruria y La Playosa. El relieve forma parte de la Pampa Loéssica Plana que ocupa la parte central de la Ilanura cordobesa. El relieve es marcadamente plano, con pendientes regionales hacia el E. La vegetación natural en el $\mathrm{S}$ de la zona corresponde a la formación típica Del Espinal, es decir, la sabana descripta anteriormente. Los suelos predominantes son Haplustoles (énticos, típicos y údicos) desarrollados sobre materiales limosos. La temperatura media anual es de 17 으 con una amplitud térmica de 14 으. La pluviometría regional posee una distribución con un rango de $750 \mathrm{~mm}$ al $\mathrm{O}$ y $800 \mathrm{~mm}$ al $\mathrm{E}$, con una distribución estacional tipo monzónica. Históricamente, la producción agropecuaria predominante era la lechería, sin embargo en los últimos años ha crecido considerablemente la superficie agrícola, lo que ha ido desplazando a la ganadería tanto de leche como de carne. La producción agrícola de la zona es en base a soja, trigo, maní, maíz y sorgo.

\section{c) Zona Serrana}

Área agrícola de las Sierras del Sur de Córdoba

- Rio Cuarto Sierras (RCs): la zona fue delimitada en el marco de esta tesis dada la frecuencia de "nuevos" lotes de soja en áreas serranas tras el desmonte. Corresponde a la zona semiárida del centro $\mathrm{O}$ de producción agrícola y forma parte de la zona RC, descripta 
anteriormente. A la fecha no se cuenta con estadísticas sobre su superficie. Presenta las características climáticas detalladas en el área RC y su relieve se enmarca en la Pampa Alta Loéssica, en el sistema serrano de Comechingones y Las Peñas. Las actividades humanas como la tala, la agricultura y la quema han producido un cambio en la vegetación, afectando el gradiente altitudinal en algunos sectores. En tramos del $\mathrm{O}$ y $\mathrm{S}$ de las sierras hay áreas de relieve suavizado, que presentan valles con relleno sedimentario de origen co-luvial y aluvial, pocas pendientes, suelos profundos y bien desarrollados, con alto contenido de materia orgánica y alta disponibilidad hídrica por su ubicación en el relieve. Cabe destacar la existencia de una gran variedad de suelos como resultado de las diferencias de relieve, posición en el paisaje, materiales originarios y clima. Aún no se han publicado estudios sobre la clasificación taxonómica de sus suelos en producción agrícola o ganadera. Esta región no posee registros meteorológicos como caracterizar su gran variedad climática. La topografía, entre otros elementos, determina la existencia de diferentes microclimas. Sin embargo, un patrón regional general es la disminución de la precipitaciones hacia el O. Según registros de la Dirección de Ambiente de la Provincia de Córdoba, las precipitaciones medias alcanzan los $750 \mathrm{~mm}$ (DACYT, 2003). En la última década los suelos más profundos y fértiles de este paisaje han sido paulatinamente ocupados con fines productivos. 


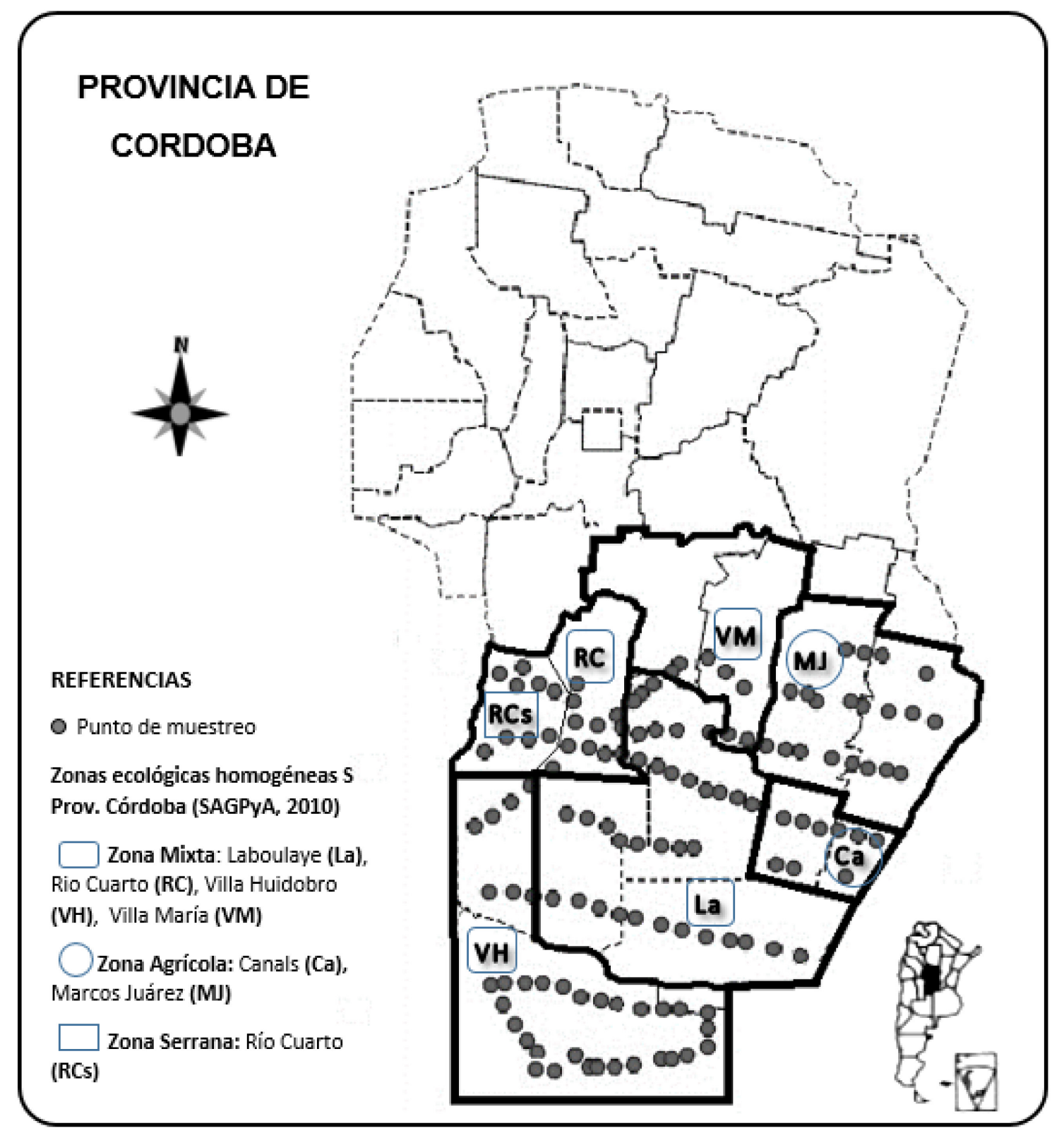

Figura 2.1: Ubicación de los 126 sitios de muestreo (lotes de soja) distribuidos en las zonas ecológicas homogéneas del Sur de la Provincia de Córdoba. 


\section{Muestreo de campo}

Entre fines de diciembre de 2011 y mediados de enero de 2012 se seleccionaron 126 sitios correspondientes a lotes de producción de soja del S de la Provincia de Córdoba. Los puntos de muestreo se distribuyeron de manera uniforme y aleatoria sobre las áreas homogéneas descriptas anteriormente (Figura 2.1). Las transectas se ubicaron sobre rutas nacionales, provinciales y caminos rurales. Los sitios de muestreo consistieron en cultivos de soja en estadíos vegetativos o reproductivos tempranos (R1-R3, Fehr et al., 1971). La distancia entre un lote y otro fue de 5-10 km en la dirección E - O, y de aproximadamente $30 \mathrm{~km}$ en la dirección $\mathrm{N}-\mathrm{S}$, excepto en la zona S de VH y en la serranía de RCs, por la disponibilidad de caminos y las condiciones del relieve, respectivamente.

Dentro de cada lote se seleccionaron 4 puntos de muestreo de $50 \mathrm{~cm}$ lineales de surco y se unificaron en una sola muestra compuesta por lote. Cada punto de muestreo dentro a $20 \mathrm{~m}$ de distancia del otro. Las muestras se extrajeron a partir de $100 \mathrm{~m}$ de distancia del alambrado para evitar efectos de bordura. Con la finalidad de mantener las propiedades biológicas en estudio, la recorrida de muestreo se realizó durante tres viajes comprendidos en tres semanas consecutivas. En cada viaje, la toma de muestras se llevó a cabo en un lapso de $48 \mathrm{~h}$ e inmediatamente se procedió al acondicionamiento de suelo y material vegetal recolectado. Una vez concluido éste se continuó con el siguiente viaje de campo.

El muestreo de suelo se realizó con dos fines: estudios de HFMA y las determinaciones de propiedades físicas y químicas. Para el primero, se recolectó el suelo que quedaba en la línea de siembra luego de retirar las plantas de soja de manera cuidadosa con la ayuda de una pala de jardinería $(0-10 \mathrm{~cm}$ profundidad). La muestra de aproximadamente $4 \mathrm{~kg}$ de suelo se mantuvo en condiciones refrigeradas hasta su procesamiento en el laboratorio. Adicionalmente, se extrajeron muestras de $0-20 \mathrm{~cm}$ de profundidad con barreno $(2,5 \mathrm{~cm}$ de diámetro) para análisis físicos y químicos. Se tomaron un total de 20 piques por sitio (aprox. $500 \mathrm{~g}$ ) distribuidos entre los 4 puntos de extracción de muestras del lote.

El muestreo de plantas completas de soja, tanto de órganos aéreos como raíces, se realizó en los mismos sitios que el de suelo rizosférico. Se registró el número de plantas de $50 \mathrm{~cm}$ lineales de surco removidos durante el muestreo de suelo. Posteriormente, se seleccionaron un total de 20 plantas a partir de cada punto de muestro del lote ( 5 plantas por punto). La 
muestra compuesta se mantuvo en condiciones refrigeradas hasta su procesamiento en laboratorio.

\section{Acondicionamiento de muestras}

Las muestras de suelo rizosférico fueron tamizadas por $2 \mathrm{~mm}$, fraccionadas y procesadas de acuerdo a los objetivos de cada capítulo:

- Capítulo 2: se conservaron 1,5 kg de suelo a 5으 C hasta la realización del experimento de infectividad.

- Capítulo 3: se reservaron $200 \mathrm{~g}$ de suelo a 5으 para la extracción y posterior identificación de esporas. En forma separada, se conservaron $2 \mathrm{~kg}$ de suelo a 5 으 C hasta la instalación de macetas con plantas trampa para la multiplicación de esporas.

- Capítulo 4: se conservaron $150 \mathrm{~g}$ de suelo a -20C para extracción de ADN y posterior secuenciación

Por otra parte, las muestras de suelo extraídas con barreno $(0-20 \mathrm{~cm})$ se secaron a temperatura ambiente y se destinaron a análisis químicos y físicos para caracterización de los sitios. Una alícuota se llevó a estufa a 105ํ para cuantificar el contenido de humedad.

Las muestras de plantas de soja se dividieron entre raíces y biomasa área. Una porción de las raíces se conservó a -20C para extracción de ADN (Capítulo 4) y el resto se destinó a la tinción para determinación del porcentaje de colonización micorrícica. La biomasa aérea se llevó a estufa a 60 ㅇ C para cuantificar peso seco y contenido de $\mathrm{P}$, esta información de utilizó en los Capítulos 2, 3 y 4.

\section{Determinaciones}

\section{- Aislamiento e identificación de esporas}

Las esporas de las muestras de suelo provenientes de lotes de soja y de plantas trampa se extrajeron por el método de tamizado en húmedo (Gerdemann y Nicolson, 1963) utilizando mallas de $110 \mu \mathrm{m}$ y $74 \mu \mathrm{m}$, seguido de centrifugación en gradiente de sacarosa (Walker et al., 1982). Las esporas y esporocarpos de HFMA se montaron en portaobjeto con poli vinil alcohol (Omar et al., 1979) con y sin agregado de reactivo de Melzer (Morton 1988). Posteriormente se examinaron por microscopía óptica y se identificaron morfológicamente 
por el sistema taxonómico propuesto por Schüßler y Walker (2010), por comparaciones con las descripciones de especies publicadas en el sitio web de International Culture Collection of Vesicular Arbuscular Mycorrhizal Fungi (INVAM, http://invam.caf.wvu.edu/) y material del cepario del Instituto Spegazzini.

De cada una de las muestras de suelo se analizaron las diferentes variables de la comunidad de esporas de HFMA: densidad de esporas (número total de esporas en $100 \mathrm{~g}$ de peso seco de suelo); frecuencia de ocurrencia (número de esporas de una morfoespecie particular en una muestra); riqueza de morfoespecies (S) (número total de morfoespecies diferentes en $100 \mathrm{~g}$ de peso seco de suelo), índice de dominancia de Simpson e índice de diversidad ( $\mathrm{H}-$ Shannon) calculado como una medida de la diversidad de morfoespecies de HFMA que combina los dos componentes de diversidad: la riqueza de especies y la equitatividad (Magurran y McGill, 2011).

\section{- Porcentaje de micorrización}

Inmediatamente luego del muestreo se seleccionó $1 \mathrm{~g}$ de raíces finas para proceder a su clarificación y tinción (Phillips y Hayman, 1970). Las muestras se conservaron en glicerol hasta la cuantificación de micorrizas. El porcentaje de raíces con presencia de estructuras correspondientes a HFMA se midió de acuerdo a la metodología propuesta por McGonigle et al. (1990).

\section{- Propiedades físicas y químicas de suelos}

De cada sitio muestreado se determinó contenido de fósforo extractable (Bray y Kurtz, 1945), nitrógeno (Bremmer 1965), carbono (Walkley y Black, 1934), humedad gravimétrica por secado de la muestra en estufa a 105으 C hasta peso constante, conductividad eléctrica a 25 으, $\mathrm{pH}$ en agua con una relación $1: 2,5(\mathrm{p} / \mathrm{v}$ ) y fracciones de arena, arcilla y limo (Gee y Bouder, 1986). Los resultados se presentan en Tabla 2.1.

\section{- Materia seca y contenido de fósforo en plantas de soja}

Los órganos aéreos de las plantas de soja se secaron en estufa a $60^{\circ} \mathrm{C}$ durante $48 \mathrm{hs}$, se pesaron y se molieron a 0,5 mm. Para la determinación de fósforo se pesó 0,07 g del material vegetal molido y se calcinó en mufla a 500ㄷ C durante 16 hs (Fernandez et al., 2009). Las cenizas se re-suspendieron en $8 \mathrm{ml}$ de $0,1 \mathrm{~N} \mathrm{HCl}$ y el contenido de fósforo se determinó 
por colorimetría según la metodología de Murphy y Riley (1962). Los resultados se expresaron como concentración $\left(\mathrm{mgP} \mathrm{g}^{-1}\right)$, por planta $\left(\mathrm{mgP} \mathrm{pl}^{-1}\right)$ y por unidad de superficie ( $\mathrm{mgP} \mathrm{m}^{-2}$ ) ya que se registró el número de plantas existentes en los $50 \mathrm{~cm}$ lineales muestreados y la distancia entre hileras del cultivo. Los resultados se presentan en Tabla 2.1.

\section{Infectividad potencial del suelo}

\section{- Principio del método}

La infectividad micorrícica potencial del suelo se estimó de acuerdo al método propuesto por Plenchette et al. (1989). El principio de esta metodología se basa en una relación dosisrespuesta empleando plántulas crecidas durante un tiempo definido en diferentes concentraciones de suelo natural y sustrato estéril bajo condiciones controladas. Finalizado el período experimental se cuantifica la proporción de plantas micorrizadas y se estima el nivel de infectividad de dicho suelo.

\section{- Bioensayo}

Se utilizó suelo rizosférico extraído de los 126 lotes de soja muestreados, previamente tamizados por malla de $2 \mathrm{~mm}$ y conservados a $5^{\circ} \mathrm{C}$ como se describió anteriormente en la sección "Acondicionamiento de muestras". Para la dilución se utilizó arena fina de rio previamente enjuagada con agua corriente y luego agua destilada. La arena se tindalizó a $121^{\circ} \mathrm{C}$ en autoclave en dos períodos consecutivos de $1 \mathrm{~h}$ cada 48 hs. Se emplearon 4 diluciones para cada suelo $(3,10,30,100 \%)$ de suelo natural en arena fina y se colocaron en macetas de 150 cc cada una, con 4 repeticiones (16 macetas por sitio).

Para este bioensayo se emplearon plantas de puerro (Allium porrum L. var Carentan) por su reconocida capacidad de establecer simbiosis con HFMA (Plenchette et al. 1983; 1989). Las semillas se desinfectaron superficialmente con una solución $10 \% \mathrm{H}_{2} \mathrm{O}_{2}$ durante 5 minutos. Luego se enjuagaron con agua destilada y se llevaron a germinación durante 7 días en arena fina tindalizada. Se seleccionaron plántulas de tamaño uniforme y se trasplantaron 10 de ellas por cada maceta. Las plantas se mantuvieron con un fotoperiodo de día/noche equivalente a $8 / 16 \mathrm{~h}$ y $25 / 20$ ㅇ , respectivamente, intensidad de la iluminación fue de 500

$\mu \mathrm{mol}$ fotones $\mathrm{m}^{-2} \mathrm{~s}^{-1} \mathrm{y}$ humedad relativa de $40-60 \%$, durante 28 días. Debido a la importancia de mantener el stand de 10 plantas por maceta durante todo el período 
experimental, se sacrificó una de las repeticiones para reponer aquellas plántulas que no prosperaron. Al finalizar el experimento, las plantas se extrajeron individualmente de las macetas, se descartó la biomasa aérea mientras que el sistema radical se lavó y se sometió al procedimiento de tinción descripto anteriormente. En todo momento se mantuvo cada raíz por separado y se almacenaron en glicerol hasta su cuantificación. La presencia - ausencia de estructuras micorrícicas se midió de acuerdo al método de Newman (1966) visualizando la totalidad de la raíz. La sistematización y organización de las tareas relacionadas a la instalación, seguimiento y finalización de este experimento constituyó un aspecto clave. Las labores se dividieron en 4 semanas tanto para la preparación (febrero 2012) como para la cosecha y tinción de raíces (abril 2012). En total, se prepararon 1968 macetas con 10 plantas cada una. Al finalizar el experimento se cosecharon 1356 macetas (una repetición se eliminó y 13 sitios tuvieron que ser descartados por bajo stand de plantas), en consecuencia, se tiñeron 13560 raíces de puerro.

\section{- Cálculo de Infectividad Micorrícica del Suelo $\left(\mathrm{IMS}_{50}\right)$}

Se construyeron curvas entre la concentración de suelo expresado en peso de suelo seco (eje $x$ ) y el porcentaje de plantas con presencia de micorrizas (eje y) con el conjunto de suelos de cada sub-zona. Se ajustó su respectiva función logarítmica y se calculó la cantidad de suelo natural necesaria para infectar el $50 \%$ de las plantas bajo las condiciones evaluadas. En base a esta información se estimó el índice de Infectividad Micorrícica del Suelo $\left(\mathrm{IMS}_{50}\right)$ según Plenchette et al. (1989).

\section{Análisis estadístico}

Se realizaron comparaciones mediante test no paramétrico por comparación de pares de rangos del test Kruskal-Wallis. Se analizó la correlación entre $\mathrm{IMS}_{50}$ y estructuras micorrícicas con variables del suelo y del cultivo mediante correlaciones de Spearman. Para los análisis estadísticos se utilizó el software Infostat (Di Rienzo et al., 2014) 


\subsection{RESULTADOS}

\section{Características del suelo y del cultivo}

Se observaron diferencias estadísticamente significativas en las variables edáficas evaluadas (Tabla 2.1). El contenido de P extractable alcanzó los mayores valores en los suelos de la zona Mixta con un rango de $32,4-35,6 \mathrm{mg} \mathrm{kg}^{-1}$, en tanto que en las zonas Agrícolas y de Sierras tendió a ser más bajo y osciló entre $15,7-22,7 \mathrm{mg} \mathrm{kg}^{-1}$. Los valores medios de $\mathrm{N}$ fueron más erráticos entre los sitios (i.e. sub-zonas). Las sub-zonas del S (La, RC y VH) mostraron un bajo contenido de $\mathrm{C}$ y suelos más arenosos. Por otra parte, la situación de VM en cuanto a sus propiedades edáficas fue más similar a los sitios de la zona Agrícola que a sus pares de historial de uso mixto. La humedad gravimétrica del suelo fue un atributo que manifestó gran diferencia entre sub-zonas: mientras que en Ca alcanzó un 20\%, los suelos de VH sólo llegaron a un $3 \%$ al momento del muestreo. Las variables relacionadas al cultivo de soja se mantuvieron sin diferencias significativas entre sub-zonas (Tabla 2.1). Al momento del muestreo las plantas no difirieron en el contenido de materia seca aérea acumulada ni de $\mathrm{P}$ en sus tejidos. La concentración de $\mathrm{P}$ estuvo comprendida en un rango de 1,1-1,4 mgP $\mathrm{g}^{-1}$ con un contenido de $\mathrm{P}$ por planta entre 10,2 a 14,9 $\mathrm{mgP} \mathrm{pl}^{-1}$. En resumen, pudo observarse que las condiciones edáficas de cada zona ofrecieron ambientes contrastantes para el cultivo de soja, principalmente en cuanto a disponibilidad de $P$ y textura. Sin embargo, las plantas de soja no demostraron respuesta a tales variaciones y mantuvieron valores similares de materia y seca y $\mathrm{P}$ a lo largo de toda el área de estudio. 
Tabla 2.1: Características del suelo y del cultivo de soja de las zonas muestreadas.

\begin{tabular}{|c|c|c|c|c|c|c|c|c|c|c|c|c|c|c|c|c|}
\hline \multirow{2}{*}{$\begin{array}{c}\text { Zona } \\
\text { Ecológica }\end{array}$} & \multicolumn{3}{|c|}{ Sitios } & \multicolumn{7}{|c|}{ Suelo } & \multicolumn{6}{|c|}{ Cultivo de soja } \\
\hline & ID & Sub-zona (n) & Altitud & $\mathbf{P}$ & C & $\mathrm{pH}$ & CE & Agua & Arena & $A+L$ & $M$ & & & Fósforo & & Densidad \\
\hline tomogénea & & & $m s n m$ & $m g k^{-1}$ & $\%$ & & $\mu \mathrm{Scm}^{-1}$ & & $\%$ & & $g p \Gamma^{1}$ & $g m^{-2}$ & $m g g^{-1}$ & $m g p I^{-1}$ & $m g m^{-2}$ & $\mathrm{pl} \mathrm{m} \mathrm{m}^{2}$ \\
\hline
\end{tabular}




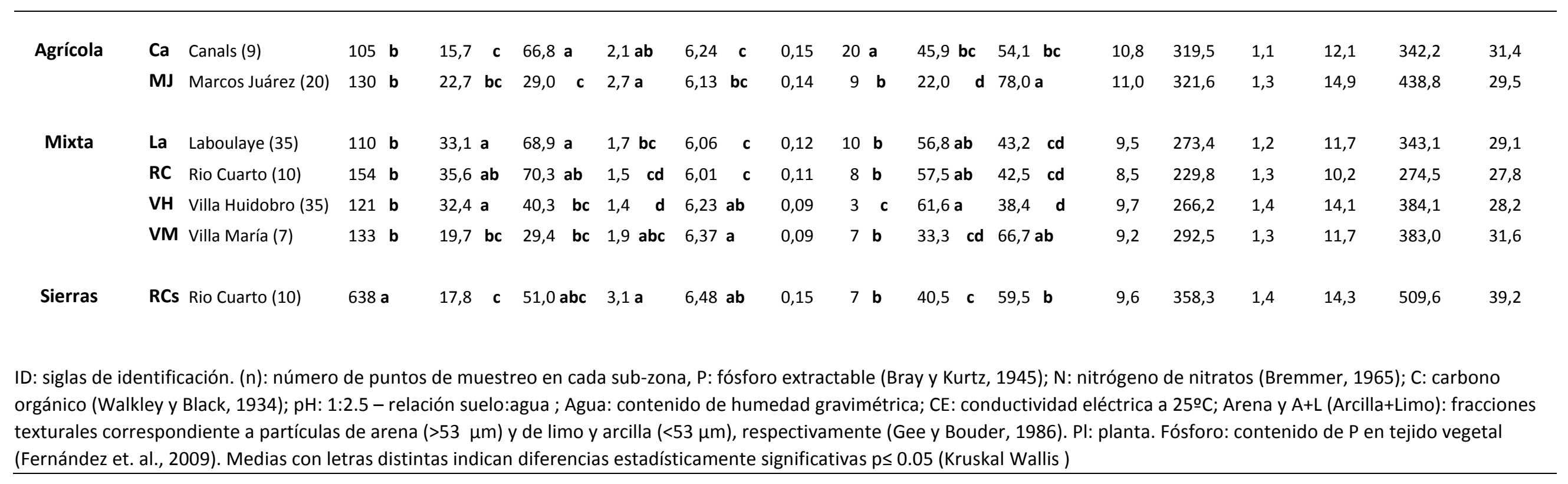




\section{Infectividad del suelo}

A partir del bioensayo realizado con diluciones de suelo rizosférico extraído de lotes de soja se estimó el índice IMS 50 según la metodología propuesta por Plenchette et al. (1989) (Tabla 2.2). En la Figura 2.2 pueden observarse gráficamente las funciones ajustadas con los resultados de la totalidad del bioensayo. Se observaron diferencias estadísticamente significativas entre las pendientes de las funciones logarítmicas ajustadas para cada zona y su $\mathrm{IMS}_{50}$ (Tabla 2.2). En promedio, las zonas Agrícola y de Sierras tuvieron mayor infectividad que la zona Mixta y ello estuvo explicado por la pendiente de la función generada entre la concentración de suelo y el porcentaje de plantas micorrizadas. La infectividad de las respectivas sub-zonas mantuvo la tendencia observada anteriormente. Los sitios de las zonas Agrícola y de Sierras tuvieron un mayor índice $\mathrm{IMS}_{50}$ que los sitios de la zona Mixta (Figura 2.3). En la zona Agrícola, el $\mathrm{IMS}_{50}$ (unidades $100 \mathrm{~g}$ suelo ${ }^{-1}$ ) fue: Ca $9,97( \pm 1,18)$ y $\mathrm{MJ}$ $10,23( \pm 1,19)$; en la zona Mixta: La 6,17 $( \pm 0,59), \operatorname{RC} 3,93( \pm 1,50)$, VH 6,49 $( \pm 0,85)$ y VM $5,87( \pm 1,78)$; en Sierras el promedio fue $11,26( \pm 1,32)$.

Tabla 2.2: Coeficientes de regresión y estimación del índice $\mathrm{IMS}_{50}$ a partir de bioensayo con suelo rizosférico de lotes de soja de diferentes zonas homogéneas del $\mathrm{S}$ de la Provincia de Córdoba.

\begin{tabular}{lccccc}
\hline \multicolumn{1}{c}{ Zona } & $\mathbf{n}$ & $\boldsymbol{r}^{2}$ & $\boldsymbol{b} \ln (\mathbf{x})$ & \multicolumn{1}{c}{$\boldsymbol{a}$} & $\mathbf{I M S}_{50}{ }^{\mathrm{s}}$ \\
\hline Agrícola & 27 & 0,9622 & $13,764 \mathbf{a}$ & $23,56 \mathbf{a b}$ & $10,10 \mathbf{a}$ \\
Mixta & 77 & 0,9619 & $11,248 \mathbf{b}$ & $17,04 \quad \mathbf{b}$ & $6,03 \mathbf{b}$ \\
Sierras & 9 & 0,9433 & $13,644 \mathbf{a}$ & $30,65 \mathbf{a}$ & $11,26 \mathbf{a}$ \\
\hline
\end{tabular}

$\S \mathrm{IMS}_{50}$ : Infectividad Micorrícica del Suelo son las unidades infectivas de HFMA en $100 \mathrm{~g}$ de suelo seco. Una unidad infectiva es la mínima cantidad de suelo necesaria para infectar el $50 \%$ de plantas bajo las condiciones de bioensayo propuesto por Plenchette et al. (1989). El resultado está expresado en unidades $100 \mathrm{~g}_{\text {suelo }}{ }^{-1}$.

Letras distintas indican diferencia estadísticamente significativa $(p<0,05)$ en la columna según test no paramétrico de comparación de rangos Kruskal-Wallis 


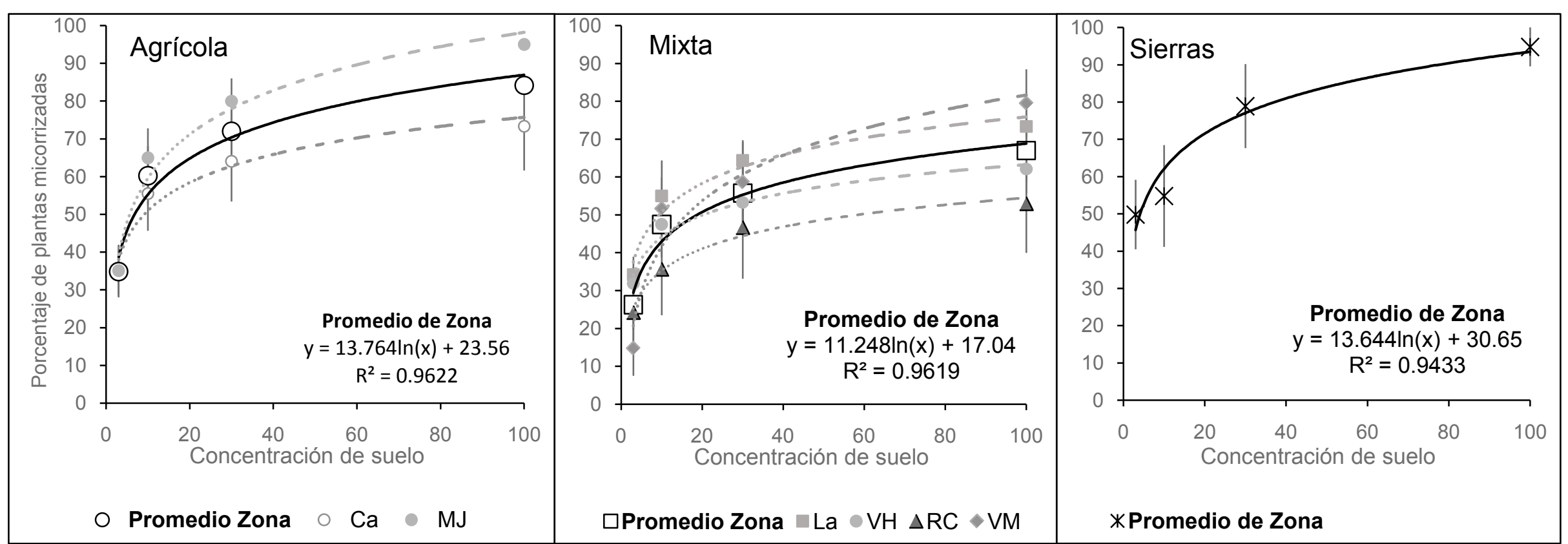

Figura 2.2: Resultados del bioensayo para estimación de infectividad micorrícica potencial de suelos extraídos de lotes de soja de zonas homogéneas del $\mathrm{S}$ de la Provincia de Córdoba. Relación entre la concentración de suelo (\%) y el porcentaje de plantas de puerro micorrizadas luego de 28 días de crecimiento. En zona Agrícola se representan las sub-zonas Canals (Ca) y Marcos Juárez (MJ); en zona Mixta: Laboulaye (La), Villa Huidobro (VH), Rio Cuarto (RC) y Villa Maria (VM). En la zona de Sierras sólo se presenta el promedio. Estas curvas se representan mendiante lineas de puntos mientras que la curva de línea sólida corresponde al promedio calculado a partir de sus respectivas sub-zonas. 


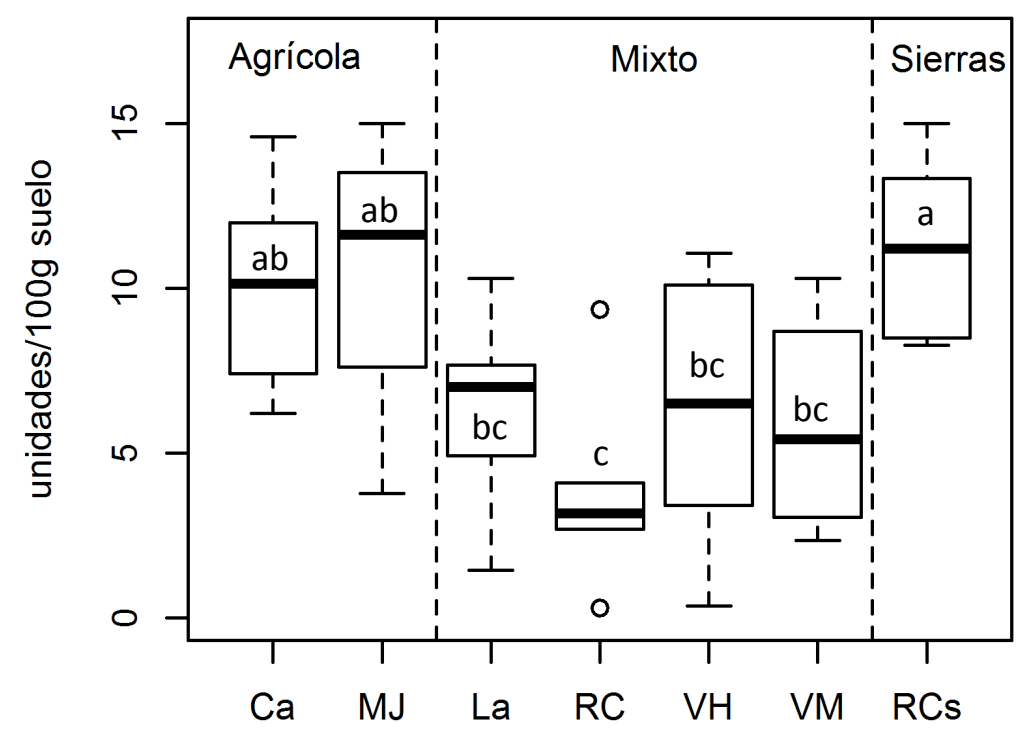

Figura 2.3: Infectividad Micorrícica del Suelo $\mathrm{IMS}_{50}$ (unidades $100 \mathrm{~g}^{\text {suelo }}{ }^{-1}$ ) estimada a partir de bioensayo con suelo rizosférico de lotes de soja del $\mathbf{S}$ de la Provincia de Córdoba. En zona Agrícola se representan las sub-zonas Canals (Ca) y Marcos Juárez (MJ); en zona Mixta: Laboulaye (La), Villa Huidobro (VH), Rio Cuarto (RC) y Villa Maria (VM). En la zona de Sierras sólo se presenta el promedio. Las líneas sólidas representan la mediana. Letras distintas en las cajas indican diferencias significativas entre sub-zonas $(p<0,05)$ según test no paramétrico de comparación de rangos Kruskal-Wallis.

\section{Micorrizas en soja}

Las raíces de soja presentaron diferencias en el porcentaje de hifas y arbúsculos de acuerdo a la zona homogénea (Tabla 2.3). La estructura micorrícica correspondiente a los arbúsculos fue significativamente superior en las plantas de soja de la zona Agrícola. Las vesículas no difirieron significativamente entre zonas y mantuvieron los valores más bajos en comparación con los porcentajes de hifas y arbúsculos. 
No se observaron mayores cambios al analizar estas estructuras por comparación entre las sub-zonas (Figura 2.4). Sólo se hallaron diferencias estadísticamente significativas en el porcentaje de arbúsculos. El mínimo valor de esta estructura fúngica fue observado en los sitios de la zona Mixta RC y VH con un valor de 1\%, mientras que el valor máximo se halló en la zona Agrícola MJ donde alcanzó un 84\%. Al finalizar la cuantificación de micorrizas en raíces de soja se observó que de los 126 sitios muestreados sólo uno de ellos no presentó estructuras de HFMA en su raíz al momento del muestreo.

Tabla 2.3: Valores promedio ( \pm Error Estándar) de hifas, arbúsculos y vesículas (\%) en raíces de soja de diferentes zonas homogéneas del $\mathrm{S}$ de la Provincia de Córdoba.

\begin{tabular}{lccc}
\hline \multirow{2}{*}{ Zona } & \multicolumn{3}{c}{ Raíces de cultivo de soja } \\
\cline { 2 - 4 } & Hifas & $\begin{array}{c}\text { Arbúsculos } \\
\%\end{array}$ & Vesículas \\
\hline Agrícola & $\begin{array}{c}61 \mathbf{a} \\
( \pm 4)\end{array}$ & $\begin{array}{c}55 \mathbf{a} \\
( \pm 4)\end{array}$ & $\begin{array}{c}\text { a } \\
( \pm 3)\end{array}$ \\
Mixta & $49 \quad \mathbf{b}$ & $40 \quad$ b & 10 \\
& $( \pm 2)$ & $( \pm 2)$ & $( \pm 1)$ \\
Sierras & 54 ab & $41 \quad$ b & 14 \\
& $( \pm 5)$ & $( \pm 5)$ & $( \pm 3)$ \\
\hline
\end{tabular}

Letras distintas en la columna indican diferencia estadísticamente significativa $(p<0,05)$ según test no paramétrico de comparación de rangos Kruskal-Wallis 

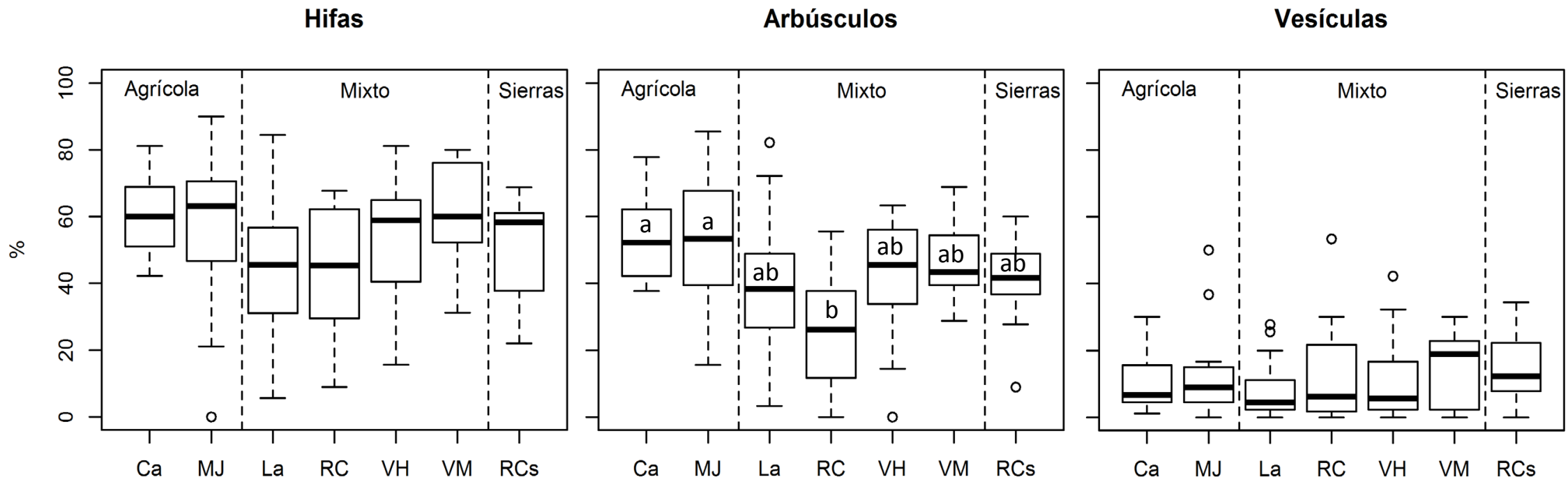

Figura 2.4: Estructuras micorrícicas (\%) cuantificadas en raíces de soja de lotes del $\mathrm{S}$ de la Provincia de Córdoba. En zona Agrícola se representan las subzonas: Canals (Ca) y Marcos Juárez (MJ); en zona Mixta: Laboulaye (La), Villa Huidobro (VH), Rio Cuarto (RC) y Villa Maria (VM); y en la zona de Sierras: Río Cuarto (RCs). Las líneas sóllidas representan la mediana. Letras distintas indican diferencias significativas entre sub-zonas $(p<0,05)$ según test no paramétrico de comparación de rangos Kruskal-Wallis. 


\section{Correlaciones entre HFMA e infectividad con variables de suelo, cultivo y fúngicas}

Las correlaciones entre los porcentajes de hifas, arbúsculos, vesículas e $\mathrm{IMS}_{50}$ con variables del suelo, del cultivo de los HFMA se presentan en la Tabla 2.4 .

Tabla 2.4: Análisis de correlación de Spearman entre $\mathrm{IMS}_{50}$ y estructuras micorrícicas y variables de suelo, del cultivo de soja y de HFMA.

\begin{tabular}{|c|c|c|c|c|c|}
\hline & & \multicolumn{3}{|c|}{ Raíces de cultivo de soja } & \multirow{2}{*}{$\frac{\text { Suelo }}{\mathrm{IMS}_{50}}$} \\
\hline & & Hifas & Arbúsculos & Vesículas & \\
\hline \multicolumn{6}{|c|}{ Variables de suelo $^{\mp}$} \\
\hline$P$ & $\mathrm{mg} \mathrm{kg}^{-1}$ & $-0,29 * *$ & $-0,28 * *$ & $-0,33 * * *$ & $-0,31 * *$ \\
\hline Altitud & msnm & $-0,02$ & $-0,16$ & 0,14 & $-0,19$ \\
\hline $\mathrm{C}$ & $\%$ & $-0,05$ & $-0,04$ & 0,03 & $0,41 * * *$ \\
\hline $\mathrm{N}$ & $\mathrm{mg} \mathrm{kg}{ }^{-1}$ & 0,01 & 0,01 & $-0,01$ & 0,09 \\
\hline $\mathrm{pH}$ & & $-0,05$ & $-0,03$ & 0,18 & 0,03 \\
\hline CE & $\mu S \mathrm{~cm}^{-1}$ & $-0,05$ & $-0,01$ & 0,01 & $-0,04$ \\
\hline Arena & $\%$ & $-0,06$ & $-0,06$ & $-0,10$ & $-0,29 * *$ \\
\hline Arcilla & $\%$ & 0,06 & 0,06 & 0,10 & $0,29 * *$ \\
\hline Agua & $\%$ & 0,02 & 0,14 & $-0,07$ & $0,30 * *$ \\
\hline \multicolumn{6}{|c|}{ Variables del cultivo $^{F}$} \\
\hline \multirow[t]{3}{*}{$P$} & $\mathrm{mg} \mathrm{g}^{-1}$ & $-0,12$ & $-0,14$ & $-0,01$ & 0,08 \\
\hline & $\mathrm{mg} \mathrm{pl}^{-1}$ & 0,04 & $-0,02$ & 0,12 & 0,18 \\
\hline & $\mathrm{mg} \mathrm{m}^{-2}$ & 0,06 & 0,02 & 0,01 & $0,24 *$ \\
\hline \multirow[t]{2}{*}{ Biomasa } & $\mathrm{g} \mathrm{pl}^{-1}$ & 0,17 & 0,08 & $0,22 * *$ & $0,28 * *$ \\
\hline & $\mathrm{g} \mathrm{m}^{-2}$ & $0,21 *$ & 0,16 & 0,16 & $0,35 * * *$ \\
\hline Densidad & $\mathrm{pl} \mathrm{m}^{-2}$ & 0,09 & 0,10 & 0,10 & 0,06 \\
\hline \multicolumn{6}{|c|}{ Variables micorrícicas ${ }^{\S}$} \\
\hline Hifas & $\%$ & --- & --- & --- & $0,22 *$ \\
\hline Arbúsculos & $\%$ & $0,93 * * *$ & --- & --- & $0,27 * *$ \\
\hline Vesículas & $\%$ & $0,62 * *$ & $0,40 * *$ & --- & 0,13 \\
\hline Densidad de & & $0,22 *$ & $0,22 *$ & $0,26 *$ & 0,19 \\
\hline Riqueza de & & 0,11 & 0,13 & 0,18 & 0,02 \\
\hline
\end{tabular}

\footnotetext{
${ }^{\mp}$ Variables de suelo y del cultivo: corresponden a las mediciones realizadas durante el muestreo de lotes de soja.

$\S$ Variables micorrícicas: Hifas, Arbúsculos y Vesículas corresponden a las estructuras fúngicas cuantificadas en las raíces del cultivo de soja. La densidad de esporas (número de esporas $100 \mathrm{~g}^{-1}$ ) y la riqueza de especies (número de especies $100 \mathrm{~g}^{-1}$ ) se midieron en las muestras de suelo rizosférico extraídas de los lotes de soja.

La variable $\mathrm{IMS}_{50}$ (Infectividad Micorrícica del Suelo) se estimó a partir de bioensayo con suelo rizosférico extraído de dichos lotes (Plenchette et al., 1989).

Los $p$-values se indican: *. $p<0,10 ;{ }^{* *} . p<0,05 ;{ }^{* * *} . p<0,001$ y se resaltaron en negrita
} 


\subsection{DISCUSION}

El nivel de infectividad de suelos difirió entre las zonas en estudio, lo cual indica que el método empleado pudo detectar diferencias entre comunidades autóctonas de HFMA. EI desarrollo de una infección micorrícica es afectado por varios factores, el más importante de ellos es el número y tamaño de las estructuras infectivas: hifas, fragmentos de raíces micorrizadas y esporas (Hart y Reader, 2005). Sin embargo, ante una determinada cantidad de inóculo, la estrategia de colonización de las especies es la que define el inicio de la infección radical (Hart y Reader 2002). El método empleado en esta tesis combina la densidad de propágulos con la estrategia de colonización de las especies de HFMA del suelo brindando un resultado que integra ambos componentes de la infectividad micorrícica (Plenchette et al., 1989; Jansa et al., 2009).

La infectividad estuvo relacionada con el historial de uso de los suelos y las características propias de los ambientes. La diferenciación de zonas homogéneas sobre la que se basó esta investigación fue realizada a partir de la división de áreas con historiales de uso similares de acuerdo con el ambiente (Ghida-Daza y Sánchez, 2009). Se observó que los suelos de uso mixto tuvieron una infectividad micorrícica significativamente más baja que la hallada en suelos de las zonas Agrícola y de Sierras (Tabla 2.2). La zona Mixta ha sido históricamente considerada marginal para la producción agropecuaria debido a su condición semiárida de bajo régimen pluviométrico y suelos arenosos. Sin embargo, el uso de la siembra directa ha hecho más eficiente el uso del agua y la soja se adaptó satisfactoriamente (Fabrizzi et al., 2005; Ghida- Daza y Sánchez, 2009). A pesar de sus limitaciones edáficas y climáticas, estos ambientes han demostrado un gran poder de conservación de estructuras infectivas de HFMA, aunque ello no signifique que sean aptos para promover la micorrización (McGee, 1989). Por un lado, se observó que la densidad de esporas en la zona Mixta no difirió de las registradas en las zonas Agrícola y de Sierras. Además, se ha reportado que las hifas y fragmentos de raíces infectadas pueden permanecer infectivas en suelos de muy bajo potencial hídrico incluso por más de 6 meses (Jasper et al., 1989; Tommerup y Abbot, 1981). McGee (1989) sugiere que las especies de HFMA poseen estrategias de supervivencia en suelos semiáridos para escapar y tolerar las condiciones desfavorables. Entonces, la causa de la baja infectividad de la zona Mixta no sería una menor densidad de inóculo infectivo 
puesto que las tres formas más importantes de propágulos pueden mantenerse viables aún bajo las circunstancias descriptas. Los resultados obtenidos sugieren que fueron las condiciones edáficas las que no favorecieron el inicio de la micorrización. Es decir, que la baja infectividad podría deberse a características propias del suelo.

En esta tesis se observaron correlaciones negativas significativas entre la disponibilidad de $\mathrm{P}$ edáfico con la infectividad y con las estructuras micorrícicas cuantificadas en las raíces de soja (Tabla 2.4). Varios antecedentes demuestran el rol negativo del P en la micorrización (ej. Bundrett et al., 1996; Covacevich et al., 2007; Fernández et al., 2011; Jansa et al., 2009; Kelly et al., 2001). Se han reportado que los iones fosfato tienen un rol inhibitorio de la simbiosis a través de señales con el huésped (Harrison et al., 2005; Javot et al., 2007). Experimentos en los cuales una mitad de la raíz se mantuvo con alto nivel de $P$ mientras que la otra con bajo $\mathrm{P}$, revelaron una inhibición de la micorrización en ambas mitades de la raíz. Esto indica que el efecto inhibitorio es sistémico y altamente dependiente del status de P de los tejidos aéreos vegetales (Balzergue et al., 2010; Breuillin et al., 2010). Olsson et al. (2002) demostraron que cuando una planta no tiene deficiencia de $\mathrm{P}$, limita el envío de $\mathrm{C}$ hacia el hongo afectando el desarrollo de la micorrización y priorizando la absorción del nutriente a través de la raíz. Sin embargo, otros autores no están de acuerdo con dicha interpretación del resultado y lo consideren una simplificación de la ecología de la simbiosis (ej. Smith y Read, 2010). Más allá de dichas controversias, se desconoce cuál es el mecanismo por el cual la planta bloquea el inicio de la infección en condiciones de alta oferta de P como para explicar su correlación negativa con la infectividad (Gutjahr y Parniske, 2013). Kiriachek et al. (2009) plantean como hipótesis que dado que la nutrición fosforada afecta la producción de exudados radicales, ello repercutiría sobre componentes importantes para la señalización molecular durante la etapa de pre-infección y colonización. Estos autores se basan en el trabajo de Graham et al. (1981) quienes demostraron que una alta oferta de P disminuye la permeabilidad de las membranas y la exudación radical. Por otra parte, Lambais (2000) demuestra que la nutrición fosforada puede afectar la expresión de genes de defensa de la planta generando alteraciones en el balance de fitohormonas en los tejidos vegetales que impiden el inicio de la infección. En resumen, de acuerdo a los antecedentes citados, la correlación negativa entre el $\mathrm{P}$ del suelo con las variables micorrícicas hallada en esta tesis 
corrobora lo observado por otros investigadores acerca del rol clave de este nutriente tanto en el inicio como en el desarrollo de la micorrización.

La infectividad micorrícica se correlacionó en forma positiva con variables del suelo (C, agua y arcilla); de la planta (biomasa y $\mathrm{P}$ absorbido); y con la presencia de estructuras fúngicas en las raíces de soja (hifas, arbúsculos) (Tabla 2.4). Entre las variables de suelo, la correlación con el C resultó ser la de mayor significancia estadística (Spearman, $r=0,41 ; p<0,001$ ). Cada vez hay más evidencia sobre el rol clave que los HFMA desempeñan en los ciclos biogeoquímicos de los ecosistemas terrestres (van der Heijden et al., 2015). Experimentos de campo y laboratorio demuestran que las plantas destinan a los HFMA entre un $10 \%$ a $20 \%$ de los fotosintatos (Jakobsen y Rosendahl, 1990; Johnson et al., 2002; Nottingham et al., 2010). Entonces, si se tiene en cuenta que en esta tesis los niveles de micorrización oscilaron entre $49 \%$ y $61 \%$ en promedio (Hifas, Tabla 2.3), puede inferirse que los HFMA aportarían gran parte del stock de C edáfico. Las reservas de C micorrícicas están compuestas por el micelio y las esporas del hongo que permanecen en el suelo y se acumulan en los sucesivos ciclos de cultivos. Clemmensen et al. (2013) observaron que los HFMA son reguladores importantes de la dinámica de $\mathrm{C}$ en el suelo debido a la degradación gradual de dichas estructuras fúngicas residuales. Además, otra parte de la reserva de $\mathrm{C}$ de origen micorrícico es la conformada por los exudados de estos hongos los cuales contribuyen a la agregación y la acumulación de materia orgánica del suelo (Wilson et al., 2009). En consecuencia, la relación hallada entre la infectividad micorrícica con el $\mathrm{C}$ del suelo confirma el rol clave de estos integrantes de la biota edáfica en la dinámica del nutriente. Finalmente, las correlaciones entre la infectividad con el contenido de arcilla y de agua están íntimamente relacionadas. Se sabe que los suelos arcillosos poseen mayor poder de retención de agua que los arenosos (Lal y Shukla, 2004). Sin embargo, a diferencia del tenor de arcilla, el contenido hídrico es altamente influenciado por prácticas de manejo del suelo. Por ejemplo, en ciertas áreas destinadas a la siembra de soja en siembra directa, la inclusión adecuada de un cultivo de cobertura invernal permite mejorar el aprovechamiento hídrico gracias al residuo vegetal que atenúa las pérdidas de agua por evapotranspiración (Unger y Vigil, 1998). En definitiva, un manejo sustentable no sólo debe contemplar la performance de un cultivo, sino que también debe ser favorable para la biota simbiótica asociada (Kiers y Denison, 2014) y abarcar un abordaje holístico que priorice la sustentabilidad (Fester y 
Sawers, 2011). En términos generales, el nivel de infectividad micorrícica observado proporcionó información sobre procesos clave para el funcionamiento del suelo relacionados al C, P y agua, lo cual confirma la importancia de los HFMA en el agroecosistema. Sin embargo, son necesarias más investigaciones locales para maximizar el potencial de las micorrizas autóctonas en la contribución de servicios ecosistémicos.

La infectividad micorrícica demostró ser un buen indicador de la performance del cultivo (Tabla 2.4). Es interesante destacar la correlación hallada entre la infectividad y el $\mathrm{P}$ acumulado por el cultivo de soja $\left(\mathrm{mgP} \mathrm{m}^{-2}\right)$. Las estructuras micorrícicas medidas en las raíces, en cambio, no se correlacionaron con el P de la planta (Tabla 2.4). Estos resultados corroboran lo propuesto por Maherali y Krilonomos (2007) sobre la relevancia de la colonización del suelo en la nutrición fosforada de la planta. Kiers y Denison (2014) enfatizan la importancia de la red de micelio compartido (RMC) que comunica diferentes plantas como una alternativa para maximizar los beneficios para los cultivos. Mikkelsen et al. (2008) demostraron que la RMC permite el traspaso de nutrientes entre plantas conectadas a la red. Rosendahl y Stukenbrock (2004) observaron que puede alcanzar 10 m de diámetro, y por ello es crítica para la planta tenga acceso a nutrientes más allá de su propia zona radicular. Un aspecto sobresaliente la RMC es que las plantas aportan C y se benefician de manera colectiva, no de manera individual. Es por ello, que los nutrientes como el $\mathrm{P}$ se distribuyen homogéneamente entre los integrantes de la red. Es posible que dicho fenómeno ocurra en los cultivos de soja y que sea la causa de la correlación hallada entre la infectividad y la acumulación de $\mathrm{P}$ del cultivo por unidad de superficie, y no por planta individual. A su vez, esta red actúa como un conducto de información entre plantas vecinas, pudiendo transmitir compuestos que incrementan la resistencia a enfermedades (Song et al., 2010). La existencia de RMC es corroborada por la correlación positiva entre el porcentaje de hifas cuantificado en raíces de soja y la biomasa acumulada por la comunidad de plantas $\left(\mathrm{g} \mathrm{m}^{-2}\right.$ ) (Johnson, 1993). Las vesículas, en cambio, representan estructuras más benéficas para el hongo que para la planta (Kiers et al., 2011). Posiblemente, predominen en ambientes de menores limitaciones nutricionales, con plantas más desarrolladas individualmente, donde el hongo no necesite invertir $\mathrm{C}$ en hifas para absorber más $\mathrm{P}$ (Hart y Reader, 2005). En síntesis, las RMC de HFMA estarían funcionando en el cultivo de soja dando como resultado un mayor nivel de infectividad micorrícica del suelo y una comunidad 
de plantas más uniformes en cuanto al $\mathrm{P}$ y a la biomasa acumulada, gracias a una distribución equitativa de recursos.

Finalmente, sumado al efecto de la disponibilidad de $\mathrm{P}$ del suelo, el bajo nivel de micorrización de las raíces de soja en ambientes de la zona Mixta podría deberse a la naturaleza arenosa de sus suelos. La macroporosidad de los suelos arenosos dificulta el contacto entre el inóculo y las raíces de soja, lo cual es un requisito indispensable para el inicio de la infección (Wilson y Trinick, 1983); además, la escasez de agua y las altas temperaturas propias de un clima semiárido interfieren en las etapas de germinación de esporas (Tommerup, 1983) y el desarrollo de microorganismos intervinientes en dicho proceso (Tommerup, 1985). Entonces, ante tal escenario, las esporas no habrían sido una fuente de inóculo exitosa y la colonización recaería mayoritariamente sobre las redes de micelio y fragmentos de raíces micorrizadas. Se sabe que dichas estrategias favorecen a algunas especies en detrimento de otras (Hart y Reader, 2005). Dado que la familia Gigasporaceae depende fuertemente de las esporas para iniciar una infección ya que su micelio tiene una infectividad relativamente nula, es más probable que en estos ambientes predominen especies de HFMA con hifas infectivas, tales Glomeraceae y Acaulosporaceae (Biermann y Linderman, 1983; Hart y Reader, 2002; 2005). El conjunto de factores descriptos inherentes a zonas semiáridas serían la causa de los menores niveles micorrización observados en la zona Mixta.

\subsection{CONCLUSIONES}

El nivel de infectividad micorrícica demostró ser un indicador de la capacidad de un suelo para iniciar una infección por HFMA autóctonos. En el presente capítulo se observó un menor nivel de infectividad en los suelos de ambientes Mixtos y se atribuyó a la pobre aptitud del ambiente para promover la micorrización debido a las condiciones semiáridas predominantes en dicha zona de estudio. La formación de estructuras micorrícicas en las raíces de soja siguió los patrones observados del nivel de infectividad. La alta dependencia 
del cultivo de soja de los HFMA quedó demostrado por los altos niveles de micorrización observados principalmente en la zona Agrícola.

La infectividad del suelo estuvo fuertemente correlacionada con variables edáficas y del cultivo. En base a los análisis de correlaciones se corroboró: el rol inhibitorio de la simbiosis que posee el $\mathrm{P}$ disponible, la relación entre la reserva de C y los HFMA, y la importancia de la conservación del agua del suelo para estos integrantes de la biota simbiótica. La acumulación de materia seca y $\mathrm{P}$ del cultivo estuvieron correlacionadas con la infectividad de modo colectivo, lo cual sugiere la existencia de una red de micelio que conecta plantas vecinas y distribuye uniformemente los recursos limitantes priorizando la performance de la comunidad por encima de las plantas individuales. 
CAPITULO 3

\section{COMPOSICIÓN DE COMUNIDADES DE HONGOS FORMADORES DE MICORRIZAS ARBUSCULARES EN LOTES DE SOJA DEL SUR DE LA PROVINCIA \\ DE CORDOBA}

\section{Resultados preliminares presentados:}

Faggioli VS, F. Covacevich, K. Hernández-Guijarro y MN. Cabello. 2014. Does soybean cultivation generate losses of arbuscular mycorrhizal diversity? $33^{\text {rd }}$ New Phytologist Symposium: Networks of Power and Influence: ecology and evolution of symbioses between plants and mycorrhizal fungi. Zurich, Suiza. Symposio 14 a 16 de mayo 2014

Faggioli VS y MN Cabello. 2013. Biodiversidad de hongos formadores de micorrizas en un gradiente ambiental y de uso de suelo de la provincia de Córdoba. Actas III CONEBIOS. Río Cuarto 24 a 26 de abril 2013. Presentación oral.

Faggioli VS y MN Cabello. 2013. Higher intensity land use allows sporulation of few species of AMF improving phoshorus acquisition by soybean. VII International Conference on Mycorrhiza. 6-11 January 2013, New Delhi, India. 


\subsection{INTRODUCCION}

El avance de la agricultura es un hecho que no ha pasado desapercibido en los últimos años. Históricamente, el suelo y la geografía eran los principales determinantes de la actividad agropecuaria predominante en una región. Así, por ejemplo, la ganadería quedaba relegada a zonas marginales y suelos de baja fertilidad, mientras que la agricultura ocupaba las zonas más fértiles y prósperas del país. En la actualidad, en cambio, tal diferenciación prácticamente ha desaparecido y el $84 \%$ de los suelos aptos para uso agropecuario son ocupados por el cultivo de soja (SAGPyA, 2016). Independientemente de las causas de su masiva adopción, su excelente adaptación a una gran variedad de ambientes ha favorecido su expansión. Como consecuencia, la sustitución de pasturas y de vegetación autóctona ha generado una visible e inevitable pérdida de la biodiversidad.

Los hongos formadores de micorrizas arbusculares (HFMA) son uno de los componentes más importantes de la comunidad microbiana de los suelos. Pertenecen al phylum Glomeromycota (Schüßler et al., 2001) y son organismos simbióticos obligados que se asocian con el $80 \%$ de las especies vegetales (Trappe, 1987). A cambio de fotoasimilados, le transfieren a la planta nutrientes tales como P, Zn, N y micronutrientes (Bucher, 2007), le confieren resistencia a patógenos (Qian et al., 2015) y aumentan la tolerancia a sequía (Grümberg et al., 2014). Los HFMA se encuentran ampliamente distribuidos en los ecosistemas terrestres, desde desiertos, a bosques boreales y tropicales, suelos de uso antrópico, e incluso en la Antártida (Davison, et al., 2015; Cabello et al., 1994). A pesar de su ubiquidad, han demostrado ser sensibles a las condiciones del ambiente en el que se encuentran. En este sentido, puede decirse que el suelo y la geografía no sólo han determinado el uso del suelo sino que también la composición de comunidades de microorganismos edáficos, entre ellos la de HFMA. Por ejemplo, se ha observado que una de sus familias (Gigasporaceae) predomina en ambientes húmedos y fértiles (Anderson, 1984; Veresoglou et al., 2014) y es más abundantes en suelos de texturas arenosas (Jansa et al., 2014; Lekberg, et al., 2006; Velázquez, et al., 2013). Glomeraceae, en cambio, tiene a ser más abundante en suelos de textura arcillosa (Lekberg, et al., 2006; Velázquez, et al., 2013). Debido a que el hombre modifica las condiciones del suelo, también es un factor incidente sobre las especies de HFMA a través de la fertilización y laboreo del suelo, los pesticidas y la elección de hospederos (Smith y Read, 2010). Las rotaciones de cultivo representan uno de 
los factores antrópicos más significativos para estos hongos (Johnson et al., 1991). Los HFMA son muy afectados por la comunidad vegetal con la que interactúan. Las plantas hospedadoras ejercen un rol clave sobre ellos. Algunos de los mecanismos implicados son el favorecimiento selectivo de la esporulación de ciertas especies de HFMA (Bever et al., 1996) y la preferencia de la planta (Vanderkoornhuyse, et al., 2003). A ello debe sumarse la competencia entre HFMA por la colonización radical (Lekberg et al., 2006). En consecuencia, la comunidad autóctona de HFMA estará compuesta por todas aquellas especies que logren adaptarse exitosamente a los filtros abióticos y bióticos del medio.

En nuestro país, la gran extensión de superficie destinada al cultivo de soja se caracteriza por la unificación de las prácticas agronómicas en un amplio rango de condiciones edáficas y geográficas. De un modo inadvertido, dichas prácticas también son aplicadas sobre los HFMA. Por ejemplo, la masiva adopción de la siembra directa desde los '90s, ha conservado las redes hifales y propágulos de HFMA (Schalamuk et al., 2009). Al mismo tiempo, el uso generalizado de glifosato podría estar afectando de manera directa e indirecta a las comunidades de HFMA (Druille et al., 2015). Por otra parte, la sustitución de una comunidad vegetal diversa como las pasturas y flora autóctona por una especie de escasa rotación con otros cultivos es un factor potencialmente perjudicial para la diversidad de HFMA. Johnson et al. (1991) han reportado que sucesivos ciclos de un mismo cultivo impactan sobre la estructura de las comunidades micorrícicas. Frente a este contexto de simplificación del manejo agronómico, la principal diferencia entre lotes de soja es su ubicación geográfica. Queda por esclarecer en qué medida la composición de las comunidades autóctonas de HFMA manifiesta dicha homogeneización en las prácticas agronómicas o si aún refleja el historial de uso determinado por su localización.

El método tradicionalmente empleado para el estudio de los HFMA se basa en la identificación de las esporas presentes en el suelo. Las esporas son células individuales multinucleadas formadas principalmente en la parte apical de hifas esporógenas del micelio extra-radical. Debido a que muchos componentes de la estructura subcelular de las esporas (como la de las láminas de la pared) son estables en condiciones ambientales diferentes, son consideradas como las estructuras más importantes para la identificación morfológica de los HFMA. Algunas estructuras diagnósticas de las esporas son: tamaño, color, forma, formación de esporocarpos, características de la pared (número y grosor de capas, reacción con iodo, 
ornamentaciones) y características de la hifa sustentora o del sáculo esporífero, entre otras. Las esporas colectadas a campo dan una idea de la abundancia y de la diversidad de especies HFMA que esporulan en esas condiciones ambientales (Błaszkowski, 2012). Dado que una alta proporción de HFMA produce esporas estacionalmente, la estimación de la diversidad de especies de HFMA debe realizarse complementariamente con la inducción a esporular en cultivos trampa (Brundrett et al., 1999). La identificación taxonómica de Glomeromycota basada en la morfología de esporas es una tarea compleja que requiere de experiencia y es posiblemente una de las causas de la escasa información disponible en Argentina.

El objetivo general de este capítulo fue estudiar la composición de comunidades autóctonas de HFMA a partir de la identificación de esporas extraídas de lotes de soja, cuyas características edáficas y geográficas determinaron historiales de uso contrastantes en una región comprendida en el centro - Sur de la Pcia de Córdoba. Los objetivos específicos fueron: a) estimar los niveles de densidad de esporas, riqueza, diversidad y composición de las comunidades de HFMA; y b) estimar las correlaciones entre dichos parámetros con variables del suelo y del cultivo. Se muestrearon 126 lotes de soja distribuidos en el área semiárida y arenosa de historial ganadero; en la zona agrícola de suelos fértiles y limosos de la Pampa Ondulada, y regiones de reciente desmonte ubicadas en la zona serrana. En base a la bibliografía local consultada, no hemos hallado antecedentes de un relevamiento taxonómico con una intensidad de muestreo comparable. Esperamos que la información generada sirva de referencia para futuros estudios tendientes a analizar la evolución de las comunidades de HFMA en estos agroecosistemas. 


\subsection{MATERIALES Y METODOS}

\section{Área de estudio, muestreo y acondicionamiento de muestras}

El área de estudio correspondió a las zonas homogéneas Agrícola, Mixta y de Sierras, descriptas en el Capítulo 2. Los detalles sobre el muestreo de suelo y acondicionamiento de muestras también se presentaron en el Capítulo 2.

\section{Extracción de esporas}

Los detalles metodológicos se presentan en el Capítulo 2.

\section{Multiplicación de esporas con plantas trampa}

Con la finalidad de promover la formación de esporas de especies nativas de HFMA se realizó un experimento con plantas trampa de 10 meses de duración. El suelo fresco extraído de la línea de siembra de lotes de soja se mezcló con arena fina tindalizada ( 1 h a 120 ㄷ, 2 veces cada $24 \mathrm{hs}$ ) en una relación 2:1 (v/v) y se colocó en macetas de 1,5 I por triplicado (372 macetas). Para este experimento se utilizaron plantas de rye grass perenne (Lolium perenne L. cv Fusta) y de trébol blanco (Trifolium repens L. cv Rubí) debido a que ambas especies representan importantes grupos funcionales de plantas (gramínea y leguminosa) y por su reconocida aptitud como huéspedes en la simbiosis micorrícica. Las semillas se desinfectaron en una solución $10 \% \mathrm{H}_{2} \mathrm{O}_{2}$ durante 5 minutos y se enjuagaron con agua destilada. Se sembraron 50 semillas de cada especie por maceta. Las macetas se mantuvieron a $60 \%$ de capacidad de campo con agua destilada. Las condiciones de la cámara se mantuvieron con un fotoperiodo de día/noche equivalente a $8 / 16$ h y $25 / 20^{\circ} \mathrm{C}$, respectivamente. La intensidad de la iluminación fue de $500 \mu \mathrm{mol}$ fotones $\mathrm{m}^{-2} \mathrm{~s}^{-1}$ y la humedad relativa se mantuvo entre un $40-60 \%$. Para intensificar la producción de esporas se realizaron dos ciclos de secado de plantas y resiembra a los 90 y 180 días de la siembra inicial. El riego se suspendió 2 semanas antes de cada resiembra y de la finalización del experimento. Después de 10 meses, las plantas se descartaron y el suelo de cada maceta se tamizó por $2 \mathrm{~mm}$ de malla y almacenó en bolsas plásticas a 5 으 hasta la extracción e identificación de esporas. Cabe resaltar que las plantas trampas sólo tuvieron la finalidad de promover la formación de esporas de aquellas especies que podrían haberse no detectado en el muestreo de campo. 


\section{Determinaciones}

Se realizó la extracción e identificación de esporas de HFMA y se estimaron los índices descriptos en el Capítulo 2. Se consideraron las variables de suelo, cultivo y micorrización presentadas en el Capítulo 2.

\section{Análisis estadístico de los resultados}

Se estudió la riqueza y composición de las comunidades de HFMA de las diferentes zonas homogéneas del $\mathrm{S}$ de la provincia de Córdoba. Las comparaciones entre las propiedades de suelo, parámetros vegetales, riqueza y densidad de esporas se realizaron mediante test no paramétrico por comparación de pares de rangos del test Kruskal-Wallis (Di Rienzo, 2014). Se utilizaron modelos lineales para analizar la correlación entre las variables en estudio con la riqueza y densidad de esporas mediante correlaciones de Spearman. Se estimó el índice de diversidad de Shannon para cada zona y sub-zona mediante la aplicación del software Infostat (Di Rienzo, 2014). Los análisis de composición de comunidades se realizaron a partir de la proporción relativa de especies dentro de cada muestra utilizando la función decostand () (método de estandarización = "total") del paquete de R VEGAN (Oksanen, 2013). Para identificar qué especies se asociaron con una zona en particular se utilizó el análisis de especie indicadora (Dufrene y Lagendre, 1997) implementando la función indval () del paquete LBDSV del software estadístico R (Robert, 2012) y se consideraron únicamente aquellas especies con un valor indicador superior a 0,25 . Se identificaron como especies abundantes a aquellas que presentaron más de $25 \%$ de abundancia relativa en alguna muestra. El efecto de las condiciones propias de cada zona homogénea sobre las comunidades de HFMA se analizó mediante análisis permutacional multivariado de la varianza (Anderson, 2001) usando la función Adonis () con 9999 permutaciones, del software R. Mediante dicho análisis es posible detectar si la composición de la comunidad de HFMA de una zona difiere estadísticamente de otra. El análisis fue realizado con las matrices de abundancia relativa. La dispersión multivariada de los grupos se estimó mediante la función betadisper () del paquete VEGAN puesto que podrían hallarse efectos significativos debido a diferencias en la dispersión y no a cambios en la composición de la comunidad. Se halló que no era diferente entre las zonas en estudio $(p>0,05)$. La variación en la composición de las 
comunidades de HFMA de las muestras extraídas directamente de los lotes de soja se visualizó mediante un escalamiento multidimensional no-métrico (NMDS tridimensional, con 50 iteraciones) usando la función metaMDS () de VEGAN. Se graficaron elipses correspondientes a cada zona (Agrícola, Mixta, Sierras) con la función ordiellipse (), graficando los desvíos estándar de los promedios ponderados. Las correlaciones lineales entre los datos de NMDS y las variables de suelo y cultivos medidas se estimó con la función envfit () de VEGAN, y se graficaron los vectores significativos (p.max $=0.05$ ) según lo propuesto por Oksanen (2013). Las correlaciones matriciales entre la composición de las comunidades de HFMA y variables de suelo y cultivo se estimaron por correlaciones de Mantel comparando las matrices de distancia de las comunidades (distancia Bray-Curtis) y cada una de las variables explicativas (distancia Euclidea) según lo propuesto por Moora et al. (2014).

\subsection{RESULTADOS}

\section{Especies de HFMA halladas en lotes de soja}

Se identificaron 29 especies de HFMA del total de muestras de suelo extraídas de lotes de soja. En la zona Agrícola se hallaron 24, en la Mixta 15 y en las Sierras 17. Las esporas que pudieron identificarse hasta el nivel de especie, en orden alfabético fueron: Acaulospora koskei Blazskowsky; Acaulospora mellea Spain \& Schenk; Acaulospora excavata Ingleby; Acaulospora scrobiculata Trappe; Ambispora appendicula (Schenck) Walker; Ambispora fecundispora (Schenck \& Smith) Walker; Ambispora gerdemannii (Rose) Walker; Claroideoglomus claroideum (Schenck \& Smith) Schüßler \& Walker; Claroideoglomus etunicatum (Becker \& Gerdemann) Schüßler \& Walker; Diversispora spurca (Pfeiffer) Schüßler \& Walker; Entrophospora baltica Blazskowsky; Entrophospora infrequens (Hall) Ames \& Scheneider; Funneliformis caledonium (Nicolson y Gerdemann) Schüßler \& Walker; Gigaspora decipiens Hall \& Abbott; Gigaspora margarita Becker \& Hall; Glomus fuegianum (Spegazzini) Gerdemann \& Trappe; Glomus tortuosum Schenck \& Smith; Racocetra fulgida (Koske \& Waker) Oehl; Racocetra gregaria (Nicolson \& Schenck) Oehl; Racocetra pellucida (Nicolson \& Schenck) Walker \& Sanders; Racocetra persicae (Koske y Walker) Oehl; Rhizofagus clarus (Nicolson \& Schenck) Schüßler \& Walker; Rhizophagus irregulare 
(Blazskowsky) Schüßler \& Walker; Glomus microaggregatum Koske \& Gemma; Scutellospora biornata Spain; Scutellospora heterogama Oehl; y Septoglomus constrictum (Trappe) Schüßler \& Walker. Adicionalmente, se hallaron esporas del género Funneliformis que no se pudieron identificar a nivel de especie.

En la Tabla 3.1 se presentan las abundancias relativas de cada especie en los sitios de estudio. Se destacaron Claroideoglomus etunicatum y Acaulospora scrobiculata por su alta frecuencia y abundancia en todas las muestras de campo. En la sub-zona agrícola MJ también se observó alta frecuencia y abundancia de Glomus fuegianum, mientras que en la sub-zona serrana RCs se destacó Ambispora gerdemannii.

\section{Especies de HFMA obtenidas de plantas trampa}

En el experimento con plantas trampa se hallaron un total de 28 especies (Tabla 3.1). Las cuales se distribuyeron de la siguiente manera: 21 en la zona Agrícola, 17 en la Mixta y 14 en las Sierras. Luego de los 10 meses de duración de este experimento con suelo extraído directamente de los lotes de soja, se identificaron 7 especies más que a partir de las muestras de campo lo que permitió incrementar el set de especies descriptas. Dos de éstas correspondieron a Ambispora sp y Gigaspora sp que no pudieron ser identificadas al nivel de especie. Las 5 restantes fueron: Acaulospora delicata Walker \& Bloss; Acaulospora laevis Gerdemann \& Trappe; Entrophospora nevadensis Palenzuela; Pacispora chimonobambuceae (Wu \& Lu) Walker; Pacispora scintillans (Rose \& Trappe) Walker; y Rhizophagus intraradices (Schenck \& Smith) Schüßler \& Walker. Como se observa en la Tabla 3.1, las plantas trampa aumentaron la riqueza hallada en las zonas Agrícola y Mixta, pero no en Sierras.

En términos generales, la frecuencia y abundancia fue similar a la observada en las muestras de campo, con algunas excepciones. Primero, Claroideoglomus etunicatum fue considerablemente más abundante en las plantas trampa que en los lotes de soja. En segundo lugar, Rhizophagus intraradices sólo se detectó en este experimento y estuvo ausente en el relevamiento realizado de los lotes de soja. 
Tabla 3.1: Abundancia relativa de esporas (\%) de HFMA halladas en campo y plantas trampa 


\begin{tabular}{|c|c|c|c|c|c|c|c|c|c|c|c|c|}
\hline & \multicolumn{2}{|c|}{ Agrícola } & \multicolumn{3}{|c|}{ Mixto } & \multirow{2}{*}{$\begin{array}{c}\text { Sierra } \\
\text { RCs }\end{array}$} & \multicolumn{2}{|c|}{ Agrícola } & \multicolumn{3}{|c|}{ Mixto } & \multirow{2}{*}{$\begin{array}{c}\text { Sierra } \\
\text { RCs }\end{array}$} \\
\hline & $\mathrm{Ca}$ & MJ & La & $\mathrm{RC}$ & VH VM & & $\mathrm{Ca}$ & MJ & La & $\mathrm{RC}$ & VH VM & \\
\hline & \multicolumn{6}{|c|}{ Campo } & \multicolumn{6}{|c|}{ Plantas trampa } \\
\hline \multicolumn{13}{|l|}{ Especies frecuentes y abundantes } \\
\hline Claroideoglomus etunicatum & $\square$ & $\bullet$ & 0 & $\mathrm{O}$ & 0 & $\square$ & 0 & $\bullet$ & $\mathrm{O}$ & $\square$ & $\mathrm{O} \square$ & 0 \\
\hline Acaulospora scrobiculata & $\square$ & O & 0 & O & $0 \square$ & 0 & $\square$ & $\bullet$ & $\bullet$ & $\square$ & $\square \bullet$ & \\
\hline Funneliformis mosseae & $\bullet$ & $\bullet$ & $\bullet$ & $\square$ & $\square$ 믜 & $\square$ & & 0 & 므 & $\square$. & 미 $\square$ & 0 \\
\hline Diversispora spurca & & $\square$ & & $\bullet$ & $\square$ & $\square$ & $\bullet$ & 미 & $\square$ & $\square$ & - 0 & $\bullet$ \\
\hline Acaulospora mellea & • & & $\bullet$ & $\square$ & $\bullet$ & $\bullet$ & $\bullet$ & $\bullet$ & $\bullet$ & $\bullet$ & $\square$ & $\bullet$ \\
\hline Gigaspora margarita & $\bullet$ & $\square$ & $\bullet$ & $\bullet$ & $\bullet \bullet$ & $\bullet$ & & & $\bullet$ & $\bullet$ & & $\bullet$ \\
\hline Racocetra pellucida & $\bullet$ & $\bullet$ & $\bullet$ & & $\bullet$ & & & $\bullet$ & $\bullet$ & $\bullet$ & $\square \bullet$ & $\bullet$ \\
\hline Glomus fuegianum & $\square$ & 0 & $\bullet$ & • & - $\square$ & $\bullet$ & & & & & - 0 & \\
\hline Claroideoglomus claroideum & & & $\bullet$ & & & & 미 & $\square$ & & 미 & - $\square$ & \\
\hline Septoglomus constrictum & $\square$ & & $\bullet$ & $\bullet$ & $\square$ & $\bullet$ & & $\bullet$ & & & $\bullet$ & \\
\hline Ambispora gerdemannii & & & & & $\square$ & 므 & & $\bullet$ & & $\bullet$ & $\bullet \bullet$ & \\
\hline Gigaspora decipiens & $\square$ & & $\bullet$ & & • $\square$ & $\bullet$ & & & & & & \\
\hline Rhizophagus clarus & & & $\bullet$ & & $\square$ & $\bullet$ & & $\bullet$ & & & $\bullet$ & $\square$ \\
\hline Racocetra persicae & & $\bullet$ & & $\square$ & $\bullet$ & $\bullet$ & & & & & & $\bullet$ \\
\hline Rhizophagus intraradices & & & & & & & 0 & 므 & $\square$ & $\square$ & & 미 \\
\hline \multicolumn{13}{|c|}{ Especies frecuentes, poco abundantes } \\
\hline Rhizophagus irregulare & & & $\square$ & & - & & & $\bullet$ & & $\bullet$ & & \\
\hline Glomus tortuosum & & $\square$ & & & & & & $\bullet$ & $\bullet$ & & $\bullet$ & \\
\hline Scutellospora biornata & & & & $\bullet$ & $\bullet$ & $\bullet$ & & & & & & $\bullet$ \\
\hline Racocetra gregaria & $\bullet$ & & $\bullet$ & & $\bullet$ & • & & & & & & \\
\hline Acaulospora excavata & & $\bullet$ & $\bullet$ & & - & & & & & & & \\
\hline Acaulospora laevis & & & & & & & $\bullet$ & & • & & $\bullet$ & \\
\hline Entrophospora baltica & & & $\bullet$ & & $\bullet$ & & & & & & & $\bullet$ \\
\hline Racocetra fulgida & & & & & & $\square$ & & $\bullet$ & & & & \\
\hline Scutellospora heterogama & & & & & & $\bullet$ & & & & & $\bullet$ & \\
\hline Acaulospora delicata & & & & & & & & $\bullet$ & & & & $\bullet$ \\
\hline Ambispora fecundispora & & & $\bullet$ & & & & & & & & & $\bullet$ \\
\hline Entrophospora infrecuens & & & & & & $\bullet$ & & $\bullet$ & & & & \\
\hline Entrophospora nevadensis & & & & & & & & $\bullet$ & & & & $\bullet$ \\
\hline Rhizophagus microaggregatum & & & $\bullet$ & & & & & $\bullet$ & & & & \\
\hline \multicolumn{13}{|c|}{ Especies poco frecuentes y poco abundantes } \\
\hline Ambispora sp & & & & & & & & $\bullet$ & & & & \\
\hline Gigaspora sp & & & & & & & & $\bullet$ & & & & \\
\hline Funneliformis caledonium & & $\bullet$ & & & & & & & & & & \\
\hline Pacispora chimonobambuceae & & & & & & & & $\bullet$ & & & & \\
\hline Acaulospora koskei & & & $\bullet$ & & $\bullet$ & & & & & & & \\
\hline Pacispora scintillans & & & & & & & & & & & - & \\
\hline Ambispora appendicula & & & & & $\bullet$ & & & & & & & \\
\hline Funneliformis $s p$ & & & & & $\bullet$ & & & & & & & \\
\hline Total de especies por sitio & 10 & 11 & 19 & 11 & 215 & 17 & 7 & 21 & 11 & 11 & $13 \quad 10$ & 14 \\
\hline
\end{tabular}




\section{Curvas de acumulación de especies}

Se observó que las muestras provenientes de las zonas Agrícola y Sierras tuvieron pendientes más pronunciadas y que posiblemente algunas especies aún no hayan sido identificadas ya que las curvas no llegaron a ser completamente asintóticas. En la zona Mixta, en cambio, la intensidad de muestreo demostró ser suficiente como para captar la riqueza de especies de dicho ambiente (Figura 3.1).

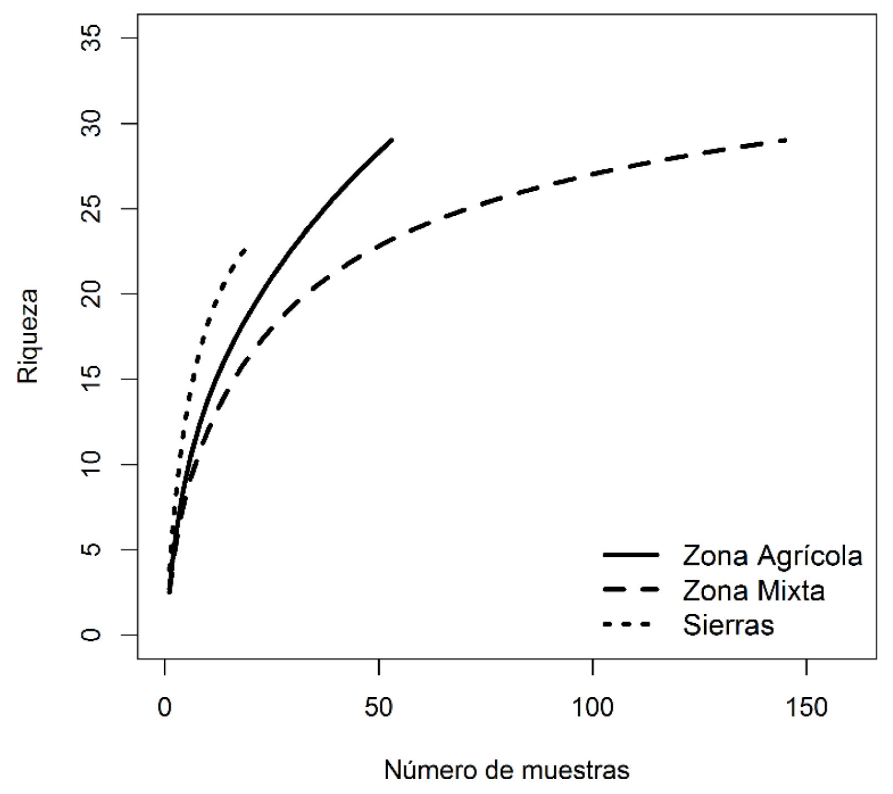

Figura 3.1: Curvas de acumulación de especies de las zonas Agrícola, Mixta y Sierras construidas con las especies de Glomeromycota identificadas a partir de las muestras de campo y plantas trampa.

\section{Índices biológicos}

La riqueza de especies por muestra en cada zona fue: 2,38 Agrícola; 2,72 Mixta; y 4,5 Sierras (Agrícola $=$ Mixto $<$ Sierras, Kruskal-Wallis $p<0,01$ ). La diversidad (Shannon) fue: 1,78; 2,27 y 2,32; mientras que la dominancia (Simpson): 0,27; 0,16 y 0,13 para las zonas Agrícola, Mixta y Sierras, respectivamente. En ambos índices la zona Agrícola difirió de Mixta y Sierras, sin diferencias entre éstas (Kruskal-Wallis $p<0,01$ ). El experimento de plantas trampa permitió incrementar la riqueza sólo en el sitio agrícola MJ y el mixto VM, ambos tuvieron 1,91 y 2 veces más especies en las trampas que en el campo, respectivamente. (Tabla 3.2). 
Tabla3. 2: Índices biológicos de HFMA en muestras de campo y plantas trampa.

\begin{tabular}{|c|c|c|c|c|c|c|c|}
\hline & \multicolumn{2}{|c|}{ Agrícola } & \multicolumn{4}{|c|}{ Mixto } & \multirow{2}{*}{$\begin{array}{c}\text { Sierras } \\
\text { RCs }\end{array}$} \\
\hline & $\mathrm{Ca}$ & MJ & La & RC & VH & VM & \\
\hline \multicolumn{8}{|l|}{ Análisis de muestras de campo } \\
\hline Riqueza por muestra & 2,56 bc & $2,21 \mathrm{c}$ & $3,13 \mathrm{abc}$ & $3,44 a b$ & $2,46 \mathrm{c}$ & $1,86 \mathrm{c}$ & $4,5 \mathrm{a}$ \\
\hline Riqueza por sitio & 10 & 11 & 19 & 11 & 21 & 5 & 17 \\
\hline Índice de Dominancia (Simpson) & $0,31 \mathbf{a}$ & $0,25 a b$ & $0,22 a b$ & $0,21 a b$ & $0,14 \mathrm{c}$ & 0,39 a & $0,13 \mathrm{c}$ \\
\hline Diversidad de especies (Shannon) & 1,6 bc & 1,65 bc & 1,94 bc & $1,84 a b$ & $2,25 \mathrm{a}$ & $1,19 \mathrm{c}$ & $2,32 \mathrm{a}$ \\
\hline Diversidad de géneros (Shannon) & $1,5 \mathrm{~b}$ & $1,39 \mathbf{b}$ & $1,63 \mathbf{b}$ & $1,55 \mathbf{b}$ & $2,06 \mathrm{ab}$ & $1,11 \mathbf{b}$ & $2,11 \mathrm{a}$ \\
\hline \multicolumn{8}{|c|}{ Análisis de muestras de plantas trampa } \\
\hline Riqueza por muestra & $2,4 a b$ & $3,3 \mathrm{a}$ & $1,83 \mathbf{b}$ & $2,67 a b$ & 1,79 b & $3,5 \mathrm{a}$ & $3,1 \mathrm{a}$ \\
\hline Riqueza por sitio & 7 & 21 & 11 & 11 & 13 & 10 & 14 \\
\hline Índice de Dominancia (Simpson) & 0,20 & 0,21 & 0,27 & 0,17 & 0,27 & 0,20 & 0,21 \\
\hline Diversidad de especies (Shannon) & 1,44 & 2,27 & 1,67 & 1,61 & 1,76 & 1,55 & 1,64 \\
\hline Diversidad de géneros (Shannon) & 1,04 & 1,92 & 1,37 & 1,18 & 1,56 & 1,47 & 1,42 \\
\hline \multicolumn{8}{|c|}{ Resumen de análisis de muestras de campo y plantas trampa } \\
\hline Riqueza total por sitio & 15 & 25 & 24 & 16 & 26 & 12 & 23 \\
\hline \multicolumn{8}{|l|}{ Relación entre especies halladas } \\
\hline En plantas trampa/campo & 0,70 & 1,91 & 0,58 & 1,00 & 0,62 & 2,00 & 0,82 \\
\hline
\end{tabular}

Tesis Doctoral - CAPITULO III Ing. Agr. M.Sc. Valeria S Faggioli 


\section{Densidad de esporas}

El número de esporas hallado en los lotes de soja presentó una gran variación entre sitios (Figura 3.2). Estuvo comprendido entre 9,14 a 95 esporas $100 \mathrm{~g}^{-1}$, en los sitios VM y Ca, respectivamente. Los valores medios (n 100g suelo ${ }^{-1}$ ) fueron: $43,5( \pm 14,55)$ en zona Agrícola; 49,9 $( \pm 7,57)$ en zona Mixta y 58,2 $( \pm 10,54)$ en la zona de Sierras. No se registró diferencias estadísticamente significativas entre ellas, pero sí se detectaron entre sub-zonas (Figura 3.2)

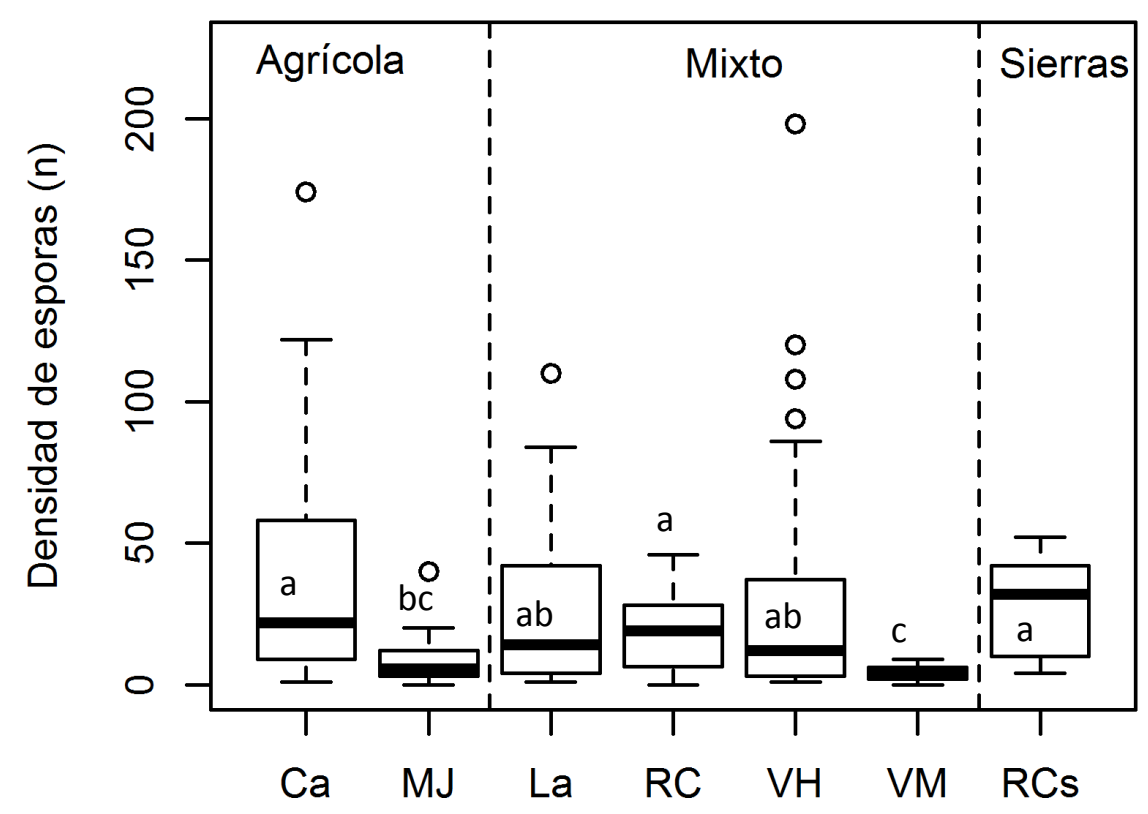

Figura 3.2: Densidad de esporas de HFMA (n 100 suelo $^{-1}$ ) hallada en lotes de soja de diferentes zonas homogéneas de la Provincia de Córdoba: Agrícola: Ca (Canals) y MJ (Marcos Juárez); Mixto: La (Laboulaye), RC (Rio Cuarto), VH (Villa Huidobro) y VM (Villa María); Sierras: RCs (Rio Cuarto). Las líneas sólidas representan la mediana. Letras distintas en las cajas indican diferencias estadísticamente significativas por comparación de rangos Kruskal Wallis $(p<0.05)$ 


\section{Especies abundantes}

Se detectaron 4 especies cuya abundancia relativa fue mayor a 0,25 en al menos una muestra: Acaulospora scrobiculata; Claroideoglomus etunicatum; Funneliformis mosseae y Glomus fuegianum (Figura 3.3).

Ac. scrobiculata

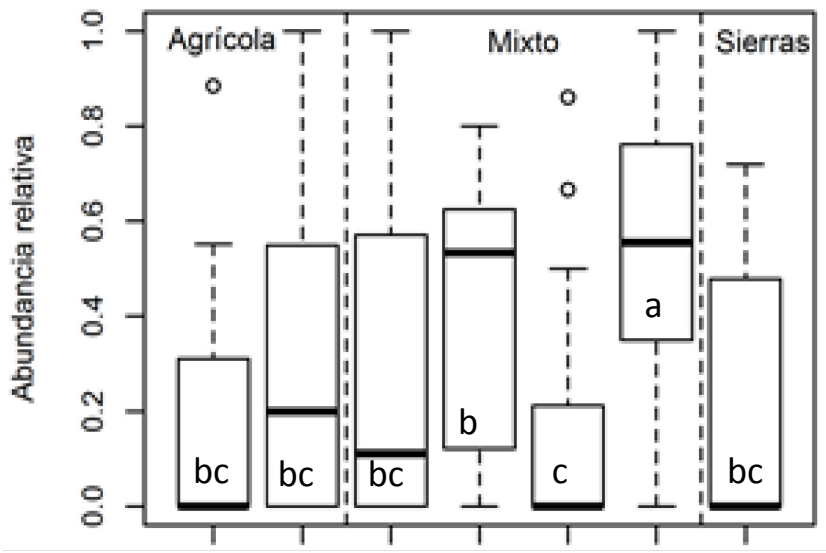

Funn. mosseae

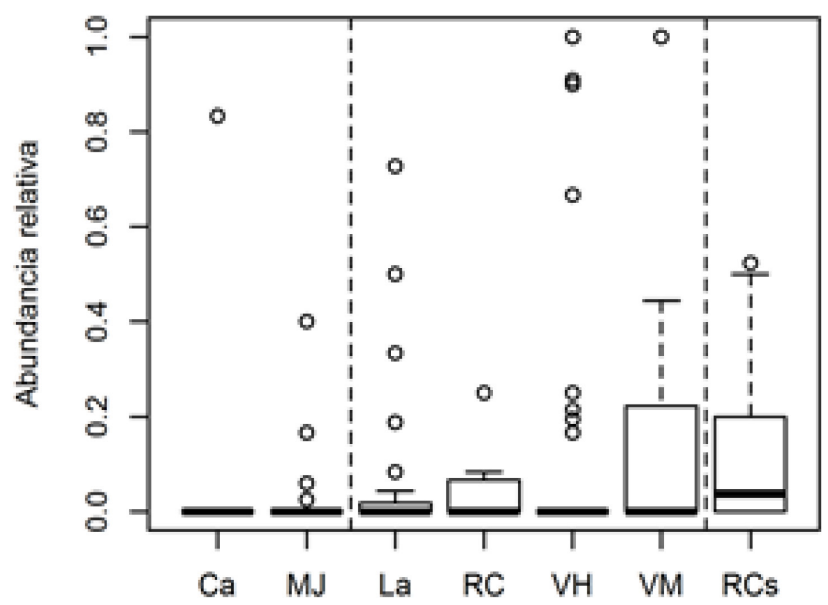

Cl. etunicatum

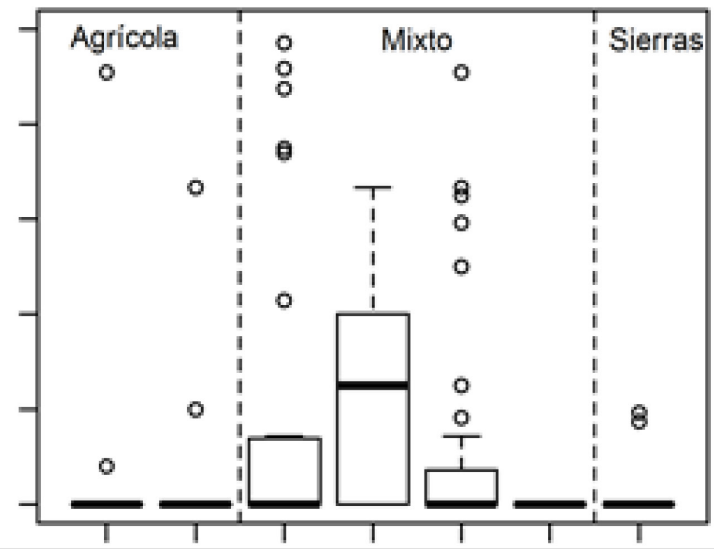

Gl. fuegianum

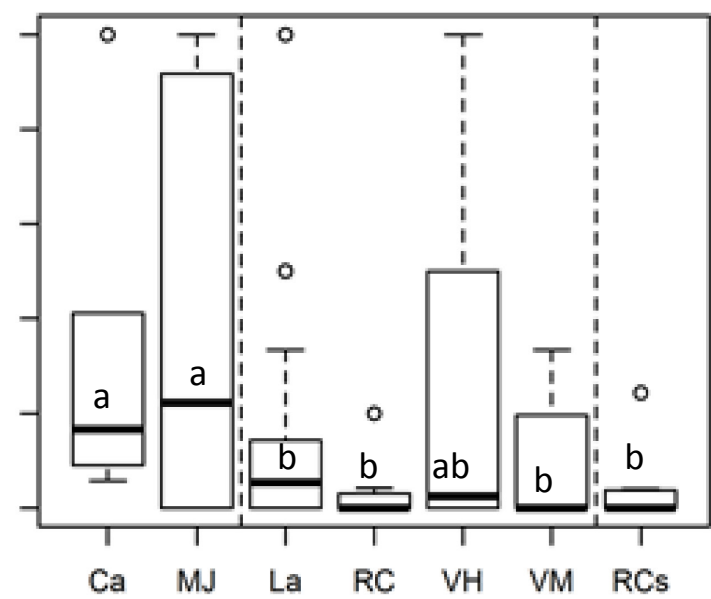

Figura 3.3 Especies más abundantes de Glomeromycota en lotes de soja de diferentes zonas homogéneas de la Provincia de Córdoba: Agrícola: Ca (Canals) y MJ (Marcos Juárez); Mixto: La (Laboulaye), RC (Rio Cuarto), VH (Villa Huidobro) y VM (Villa María); Sierras: RCs (Rio Cuarto). Las líneas sólidas representan la mediana. Letras distintas en las cajas indican diferencias estadísticamente significativas por comparación de rangos Kruskal Wallis $(p<0.05)$ 
Tesis Doctoral - CAPITULO III Ing. Agr. M.Sc. Valeria S Faggioli 


\section{Especies indicadoras}

Se identificaron especies cuya presencia y abundancia pudo asociarse con una determinada zona homogénea. (Tabla 3.3)

Tabla 3.3: Especies de Glomeromycota indicadoras de las zonas homogéneas

\begin{tabular}{clcc}
\hline Zona & Especie & Valor indicador & p_value \\
\hline Agrícola & Glomus fuegianum & 0.475 & 0.015 \\
Sierras & Ambispora gerdemannii & 0.462 & 0.001 \\
& Diversispora spurca & 0.365 & 0.001 \\
& Racocetra fulgida & 0.300 & 0.001 \\
& Racocetra persicae & 0.245 & 0.005 \\
\hline
\end{tabular}

\section{HFMA y variables del suelo y del cultivo.}

Se observó que la altitud y el contenido de $\mathrm{P}$ del suelo fueron las únicas variables edáficas correlacionadas significativamente con los índices biológicos de HFMA (Tabla 3.4). Con respecto a la variable "altitud" cabe aclarar que las muestras provenientes de la zona de Sierras estaban ubicadas en las zonas más altas (msnm) del área de estudio (Tabla 2.1). Es decir, el efecto sobre los índices micorrícicos evaluados no corresponde a la altura por sí misma, sino a las condiciones edafo-climáticas y biológicas del agroecosistema Sierras.

Entre las determinaciones realizadas sobre el cultivo de soja, la concentración de $\mathrm{P}\left(\mathrm{mg} \mathrm{g}^{-1}\right)$ y la acumulación de $\mathrm{P}\left(\mathrm{mg} \mathrm{pl}^{-1}\right)$ se correlacionaron con la riqueza de especies. Sólo la concentración de $\mathrm{P}$ mostró correlación significativa con la diversidad y no se observaron variables del cultivo correlacionadas con la densidad de esporas. Adicionalmente, se estimó la correlación entre la concentración de $\mathrm{P}\left(\mathrm{mg} \mathrm{g}^{-1}\right)$ y el $\mathrm{P}$ del suelo $\left(\mathrm{mg} \mathrm{kg}^{-1}\right)$ y se observó una correlación positiva significativa (Spearman, $p<0,01 ; R=0,23$. El $P$ del suelo no tuvo otras correlaciones significativas con las variables del cultivo analizadas. 
Tabla 3.4: Análisis de correlación de Spearman entre índices biológicos de HFMA y variables de suelo y del cultivo de soja.

\begin{tabular}{|c|c|c|c|c|c|}
\hline & & Riqueza & Diversidad & Densidad & Dominancia \\
\hline \multicolumn{6}{|c|}{ Variables de suelo } \\
\hline$P$ & $\mathrm{mg} \mathrm{kg}^{-1}$ & $-0,22 * *$ & $-0,21 * *$ & $-0,24 * * *$ & $0,18^{*}$ \\
\hline Altitud & $\mathrm{msnm}$ & $0,37 * * *$ & $0,40 * * *$ & $0,29 * * *$ & $-0,39 * * *$ \\
\hline $\mathrm{C}$ & $\%$ & $-0,10$ & $-0,12$ & $-0,05$ & 0,10 \\
\hline $\mathrm{N}$ & $\mathrm{mg} \mathrm{kg}^{-1}$ & 0,03 & 0,08 & 0,07 & 0,04 \\
\hline $\mathrm{pH}$ & & 0,01 & $-0,01$ & 0,02 & 0,03 \\
\hline CE & $\mu \mathrm{S} \mathrm{cm}-1$ & 0,01 & $-0,05$ & 0,05 & 0,09 \\
\hline Arena & $\%$ & 0,11 & 0,10 & 0,11 & $-0,06$ \\
\hline Arcilla & $\%$ & $-0,11$ & $-0,10$ & $-0,11$ & 0,06 \\
\hline Agua & $\%$ & 0,01 & 0,02 & 0,05 & 0,05 \\
\hline \multicolumn{6}{|c|}{ Variables del cultivo } \\
\hline \multirow[t]{3}{*}{$\mathrm{P}$} & $\mathrm{mg} \mathrm{g}^{-1}$ & $-0,29 * * *$ & $-0,21 * *$ & $-0,18$ & 0,17 \\
\hline & $\mathrm{mg} \mathrm{pl}^{-1}$ & $-0,19 *$ & $-0,16$ & $-0,09$ & 0,09 \\
\hline & $\mathrm{mg} \mathrm{m}^{-2}$ & $-0,10$ & $-0,11$ & $-0,01$ & 0,03 \\
\hline \multirow[t]{2}{*}{ Biomasa } & $\mathrm{g} \mathrm{pl}^{-1}$ & $-0,02$ & $-0,01$ & 0,05 & $-0,03$ \\
\hline & $\mathrm{g} \mathrm{m}^{-2}$ & 0,12 & 0,07 & 0,13 & $-0,14$ \\
\hline Densidad & $\mathrm{pl} \mathrm{m}^{-2}$ & 0,14 & 0,07 & 0,07 & $-0,09$ \\
\hline
\end{tabular}

\section{Géneros de Glomeromycota}

\section{Distribución relativa}

Los géneros más abundantes hallados en los lotes de soja fueron Acaulospora, Claroideoglomus y Glomus (Figura 3.4). Mientras que Glomus predominó en ambas subzonas agrícolas (Ca y MJ), Claroideoglomus lo hizo en 3 de las sub-zonas mixtas (La, VH y RC). Además, aunque en menor proporción que los géneros mencionados anteriormente, se registró la presencia de Gigaspora y Funneliformis en todos los sitios muestreados. Por otra parte, Rhizophagus se encontró en las zonas Mixtas y de Sierras, pero estuvo ausente en la Agrícola. 


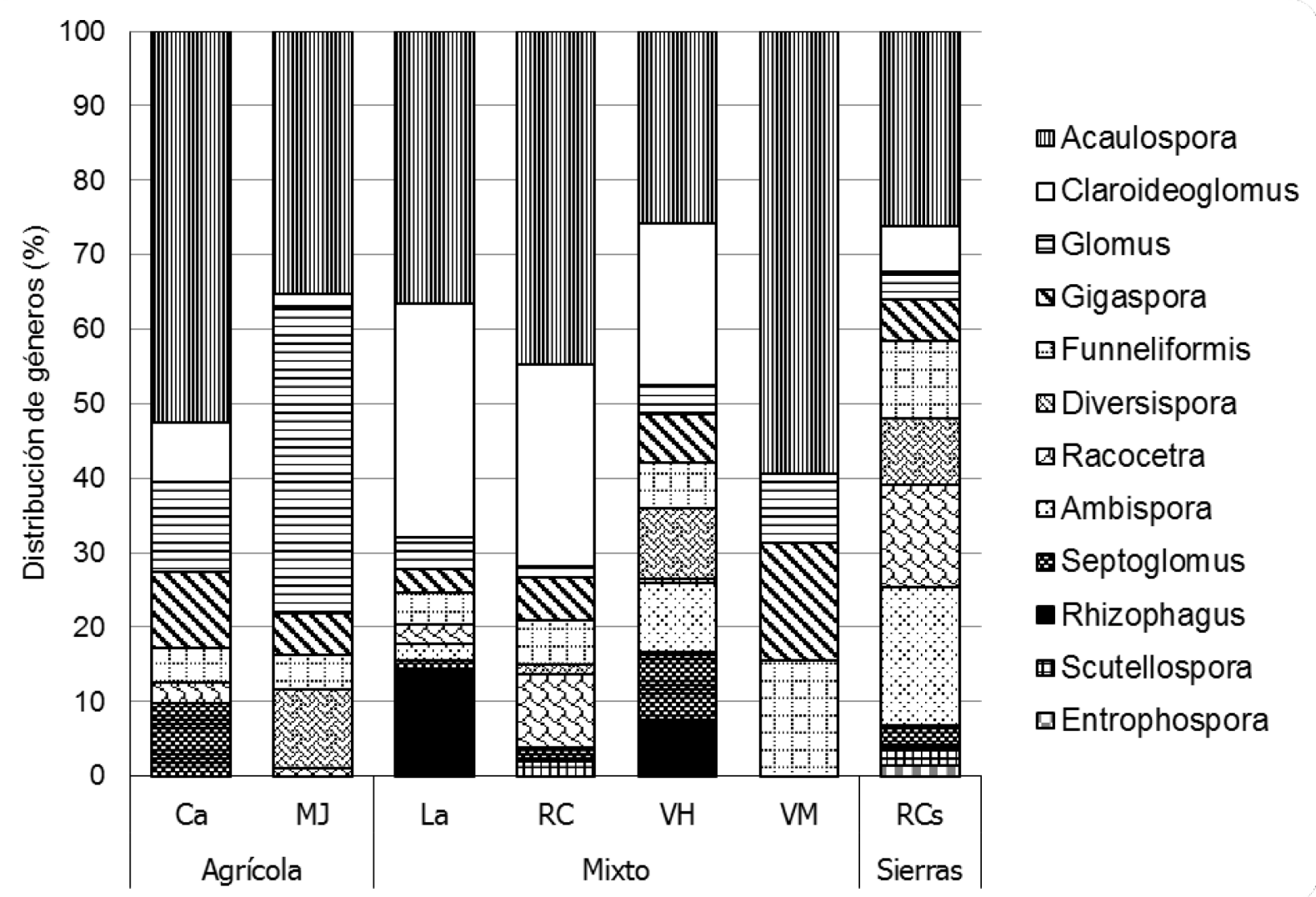

Figura 3.4: Distribución relativa de géneros de Glomeromycota hallada en lotes de soja de diferentes zonas homogéneas de la Provincia de Córdoba: Agrícola: Ca (Canals) y MJ (Marcos Juárez); Mixto: La (Laboulaye), RC (Rio Cuarto), VH (Villa Huidobro) y VM (Villa María); Sierras: RCs (Rio Cuarto). 


\section{Riqueza de géneros}

Se identificaron un total de 8 géneros de Glomeromycota. En términos absolutos, la riqueza de géneros hallada en lotes de soja fue comparable a la riqueza de especies (Tabla 3.2, Figura 3.5). Los sitios con mayor número de géneros fueron los de Sierras con un promedio de 4,10 géneros por sitio $( \pm 0,66)$ y el de la zona Mixta RC 3,22 $( \pm 0,40)$; le siguieron La 2,80 $( \pm 0,25)$, Ca $2,44( \pm 0,44), \operatorname{VH} 2,31( \pm 0,21), \operatorname{MJ} 2,11( \pm 0,25)$ y VM $1,86( \pm 0,26)$. La mayor dispersión se registró en la zona de Sierras donde se observó una muestra con 9 géneros de HFMA, lo que constituyó el mayor valor observado en este estudio.

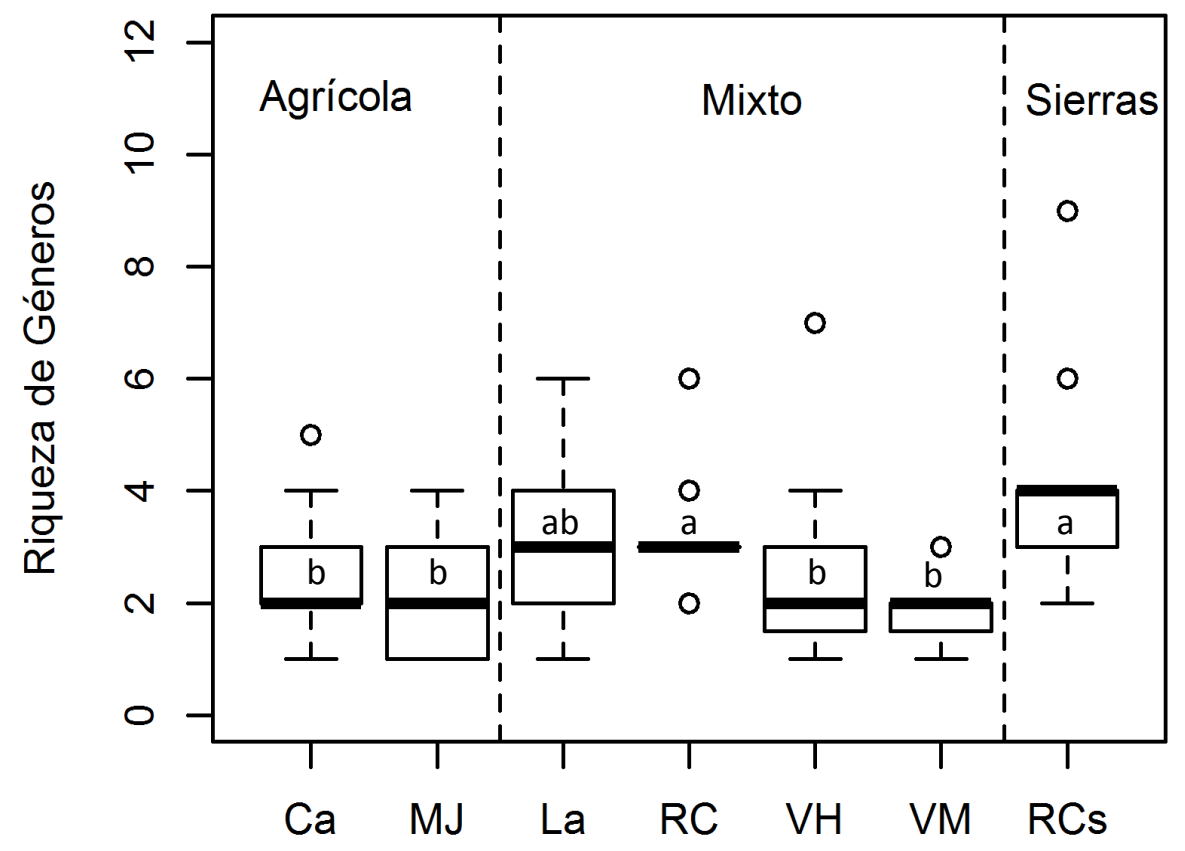

Figura 3.5: Riqueza de géneros de Glomeromycota hallada lotes de soja de diferentes zonas homogéneas de la Provincia de Córdoba: Agrícola: Ca (Canals) y MJ (Marcos Juárez); Mixto: La (Laboulaye), RC (Rio Cuarto), VH (Villa Huidobro) y VM (Villa María); Sierras: RCs (Rio Cuarto). Las líneas sólidas representan la mediana. Letras distintas en las cajas indican diferencias estadísticamente significativas por comparación de rangos Kruskal Wallis $(p<0.05)$ 


\section{Análisis de comparación de composición de comunidades}

Mediante test de análisis de varianza permutacional (PERMANOVA) se comparó la composición de las comunidades de HFMA entre zonas y sub-zonas. En términos generales, se observó que la comunidad de HFMA de la zona Agrícola tuvo una composición de especies estadísticamente diferente a la de Sierras (PERMANOVA, $p<0,004 ; R=0,11$ ) pero no distinta a la observada en la zona Mixta (PERMANOVA, $p<0,058 ; R=0,02$ ). Por su parte, las zonas Mixta y de Sierras también difirieron entre sí (PERMANOVA, $p<0,019 ; R=0,10$ ). Los resultados indican que la comunidad de HFMA de Sierras fue diferente a las otras dos zonas estudiadas. Las comparaciones entre sub-zonas se presentan en la Tabla 3.5. Puede concluirse que a pesar de ciertas diferencias individuales entre sitios, la totalidad de las comunidades de HFMA de las sub-zonas Agrícolas y Mixtas fueron distintas a la de Sierras.

Tabla 3.5: Parámetros del test de comparación de composición de comunidades de Glomeromycota (PERMANOVA)

\begin{tabular}{|c|c|c|c|c|c|c|c|}
\hline \multirow{2}{*}{\multicolumn{2}{|c|}{$\begin{array}{l}\text { PERMANOVA } \\
\text { R\p-value }{ }^{(*)}\end{array}$}} & \multicolumn{2}{|c|}{ Agrícola } & \multicolumn{4}{|c|}{ Mixto } \\
\hline & & \multirow{2}{*}{$\begin{array}{c}\mathrm{Ca} \\
--\end{array}$} & \multirow[t]{2}{*}{ MJ } & \multirow[t]{2}{*}{ La } & \multirow[t]{2}{*}{ RC } & \multirow[t]{2}{*}{ VH } & \multirow[t]{2}{*}{ VM } \\
\hline Agrícola & $\mathrm{Ca}$ & & & & & & \\
\hline & MJ & 0.02 & --- & & & & \\
\hline \multirow[t]{4}{*}{ Mixta } & La & 0.02 & 0.03 & --- & & & \\
\hline & RC & $0.16^{*}$ & $0.11 * *$ & 0.04 & --- & & \\
\hline & VH & 0.01 & 0.02 & 0.01 & 0.06 & & \\
\hline & VM & 0.12 & 0.07 & 0.04 & 0.11 & 0.06 & --- \\
\hline Sierras & RCs & $0.14^{* *}$ & $0.11 * *$ & $0.10 * *$ & $0.12 *$ & $0.05^{*}$ & $0.21 * *$ \\
\hline
\end{tabular}

Los $p$-values se indican: ${ }^{* *} .<0,01 ;{ }^{*},<0,05$ y se resaltaron en negrita. 


\section{Composición de comunidades de HFMA}

La composición de las comunidades de HFMA se representó gráficamente en la Figura 3.6. La altitud (msnm), la riqueza de especies de HFMA hallada en los lotes de soja y el contenido de $\mathrm{P}$ vegetal por unidad de superficie $\left(\mathrm{mgP} \mathrm{m}^{-2}\right)$ estuvieron correlacionados linealmente con la composición de las comunidades en un sentido opuesto al del P extractable del suelo (mgP $\mathrm{kg}^{-1}$ ). El test de Mantel arrojó similares tendencias que los vectores para las mismas variables: $P$ vegetal $(p<0,05, R=0,10)$; riqueza de especies $(p<0,001, R=0,19)$; altitud $(p<0,006, R=0,10)$ y $P$ extractable $(p<0,01 ; R=0,15)$.

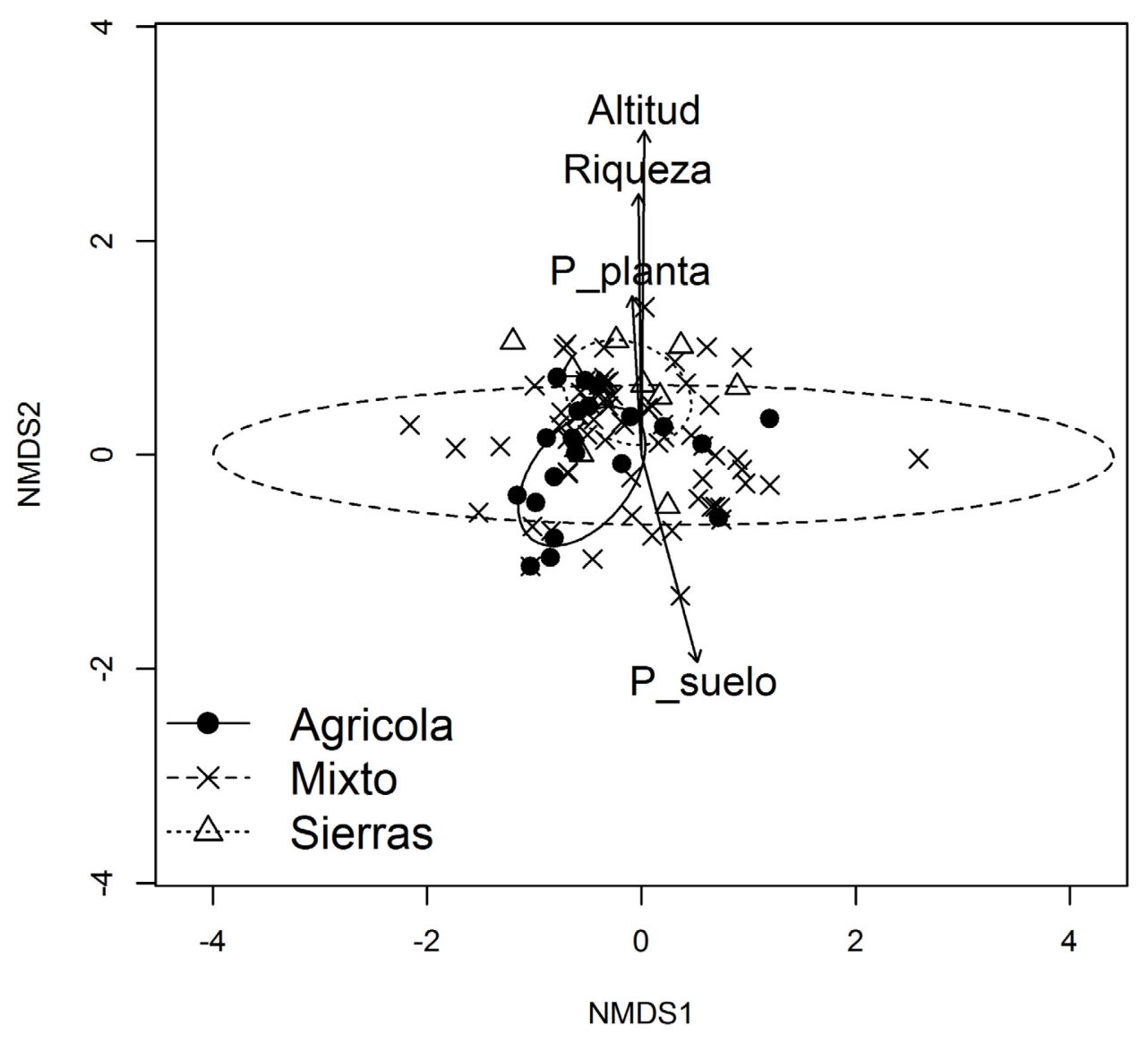

Figura 3.6: Composición de comunidades de Glomeromycota de lotes de soja en zonas homogéneas del S de la Provincia de Córdoba (NMDS, stress = 0,11). Las elipses indican una unidad de desviación estándar alrededor del centroide de cada grupo. Las flechas representan a los vectores de las variables con ajuste estadísticamente significativo $(p<0.05)$. La punta de la flecha indica la dirección del gradiente y su longitud la magnitud de la correlación. Los vectores con significancia estadística fueron: P_suelo (P extractable 
$\mathrm{mg} \mathrm{kg}^{-1}$ ); $\mathrm{P} \_$planta ( $\mathrm{P}$ en plantas de soja $\mathrm{mg} \mathrm{m}^{-2}$ ); Riqueza de especies de esporas de HFMA presente en las muestras; Altitud (msnm).

\subsection{DISCUSION}

En total en este trabajo se identificaron 36 especies de Glomeromycota, 7 de las cuales se hallaron luego de multiplicación en plantas trampa (Tabla 3.1). Considerando que se realizó sólo un muestreo en un momento del ciclo del cultivo, representa uno de los relevamientos de mayor riqueza de especies hallada en un agroecosistema. Este resultado coincide con lo hallado por Cofré (2014), quien definió sitios de buenas prácticas agrícolas, prácticas no sustentables y ambientes naturales, y halló en ellos un total de 43, 37 y 44 especies, respectivamente. En su relevamiento los sitios de prácticas agrícolas no sustentables (37 especies) correspondieron a lotes con un alto grado de monocultivo de soja. Tal manejo agronómico es uno de los más habituales en el $\mathrm{S}$ de la Provincia de Córdoba por lo que podría considerarse el sitio más comparable con los resultados obtenidos en esta tesis. Por otra parte, Colombo et al. (2014) identificaron 29 especies en tres sitios de la Pampa Ondulada pero como este resultado incluye suelos prístinos, la riqueza de especies podría estar sobreestimada para comparaciones con sitios de uso agrícola. Otros autores de nuestro país abordaron el estudio de la diversidad de Glomeromycota a partir de diseños experimentales, por ejemplo: Schalamuk y Cabello (2009) y Schalamuk et al. (2006) hallaron un total de 24 y 21 especies, respectivamente, bajo cultivo de trigo. Menéndez et al. (2001) estudió diferentes rotaciones de gramíneas y leguminosas identificando 17 especies de HFMA. En un relevamiento de ambientes naturales, Lugo y Cabello (2002) identificaron las especies de Glomeromycota asociadas a diferentes gramíneas en zonas de montaña y también observaron 17 especies. A pesar que la riqueza observada en esta investigación fue una de las más altas citadas en nuestro país, aún quedan más especies por identificar en los sitios Agrícolas y de Sierras por lo que la riqueza sería aún mayor si se intensificaran los muestreos (Figura 3.1). Sobre la base de los antecedentes mencionados, podría deducirse que dentro de la problemática asociada al avance de la frontera agrícola por el cultivo de soja, el mantenimiento de niveles elevados de especies de HFMA sería un aspecto favorable desde el punto de vista de la conservación de especies de este representante de la microbiota autóctona del suelo. 
El historial de uso del suelo asociado a las zonas homogéneas definidas en este estudio afectó sensiblemente la riqueza de especies de las muestras (Tabla 3.2). Los lotes muestreados en la zona de Sierras se generaron recientemente luego de la eliminación de la vegetación autóctona. Estas muestras alcanzaron un promedio de 4,5 especies y superaron al promedio de la zona Agrícola y Mixta en un $89 \%$ y $65 \%$, respectivamente. La misma tendencia se observó con los índices de diversidad tanto de especies como de géneros. Las especies de HFMA presentes en un suelo son aquellas que se adaptaron a las condiciones de geografía y uso del suelo (Jansa et al., 2014). Se ha reportado que suelos con vegetación nativa poseen mayor diversidad que cuando son afectados por la mano del hombre (Cofré, 2014; Colombo et al., 2014). Es de esperar, entonces, que un suelo cuya vegetación autóctona ha sido removida recientemente, conserve una microbiota edáfica de mayor riqueza y diversidad que suelos de mayor historial de uso antrópico. De esta manera, los HFMA hallados en los lotes de soja de la zona serrana evidencian un menor historial de uso por el hombre a través de sus parámetros de riqueza y diversidad.

El conjunto de especies halladas en este trabajo y su abundancia constituyen un registro sobre la estructura de la comunidad de Glomeromycota en cultivos de soja para el área de estudio. Para comprender el impacto de estas comunidades en el ecosistema, Peay (2014) propone basarse en la ecología de aquellas especies de HFMA que son importantes tanto por su abundancia como por su presencia en determinadas condiciones. En este sentido, del conjunto de 36 especies halladas en esta tesis, 4 de ellas se destacaron por su abundancia: Acaulospora scrobiculata, Claroideoglomus etunicatum, Funneliformis mosseae y Glomus fuegianum (Figura 3.3, Tabla 3.1). Las tres primeras especies han sido frecuentemente citadas en una amplia gama de ecosistemas terrestres y se caracterizan por su ubicuidad (Oehl et al., 2010; Davison et al., 2015). Glomus fuegianum, en cambio, no constituye una especie tan habitual en los relevamientos publicados por la comunidad científica. Cofré (2014) registró una gran abundancia Acaulosporaceae, Claroideoglomeraceae y Glomeraceae principalmente en los sitios de manejo agrícola no sustentable. Funneliformis mosseae y Claroideoglomus etunicatum han sido frecuentemente citados por su abundancia en sistemas de labranza convencional, lo que demuestra su gran adaptación a la actividad antrópica (Daniell et al., 2001; Helgason et al., 1998; Oehl et al., 2010). Estas 4 especies han logrado sobreponerse exitosamente a las prácticas agronómicas relacionadas con la 
producción de soja, tales como el uso de pesticidas y la fertilización, las cuales afectan negativamente a ciertas especies de Glomeromyota (Druille et al., 2015; Schalamuk et al., 2006). Posiblemente, ante reiterados ciclos de cultivo, la abundancia de estos hongos en el suelo luego de la cosecha sea una ventaja al momento de infectar raíces de la campaña siguiente. Las principales fuentes de propágulos de cualquier HFMA son las esporas, las hifas y las raíces infectadas de las plantas (Smith y Read, 2010). Las especies de Acaulospora, Claroideoglomus y Funneliformis pueden aprovechar las tres fuentes de inóculo: a) su alta tasa de producción de esporas le permite mantener una infectividad elevada para un nuevo ciclo agrícola o bien para reinfecciones en la misma campaña; b) se ha comprobado que las hifas de estas especies son altamente infectivas incluso en situaciones de déficit hídrico (Jasper et al., 1989), y c) las raíces infectadas le permiten iniciar nuevas colonizaciones de un ciclo de cultivo a otro gracias a la presencia de vesículas intraradicales que actúan como estructuras de reserva (Biermann y Linderman, 1983). Cabe agregar que la afinidad de estas especies de HFMA con las plantas de soja constituye un mecanismo necesario para explicar la gran abundancia y frecuencia hallada en este estudio (Bever et al., 1996; Helgason et al., 2002; Vanderkoornhuyse, et al., 2003).

Una especie indicadora es una especie biológica que define un rasgo o característica del ambiente en el que se encuentra. La zona Agrícola fue caracterizada por una única especie indicadora: Glomus fuegianum (Tabla 3.3). Casualmente, dicha especie fue identificada por Spegazzini en 1887 y constituye el primer espécimen de HFMA citado en Argentina. La identificación de esta especie como un miembro representativo de la zona de mayor historial sojero merece su consideración por diversos motivos. Primero, esta zona es una de las más fértiles y productivas de nuestro país y una de las pioneras en la implementación de la siembra directa y del cultivo de soja (Ghida-Daza y Sánchez, 2009). En segundo lugar, Glomus fuegianum es una especie que no ha reportado elevados niveles de abundancia según antecedentes bibliográficos internacionales donde se detectó su presencia (Blaszkowski et al., 1998; Goto y Maia, 2005; McGee y Trappe, 2002), pero es frecuentemente citada en relevamientos taxonómicos nacionales (Becerra et al., 2011; Cofré, 2014; Colombo et al., 2014; Lugo y Cabello, 2002). Las especies indicadoras de la zona de Sierras fueron Ambispora gerdemannii, Diversispora spurca, Racocetra fulgida y Racocetra persicae (Tabla 3.3). La gran diversidad de familias a la que corresponden estas 
especies es un reflejo del reciente pasado de estos suelos cubierto por una comunidad vegetal autóctona y diversa (Torrecillas et al., 2012). La familia Ambisporaceae no es una de las más citadas en los relevamientos taxonómicas de agroecosistemas. No es muy frecuente ni abundante (Cofré, 2014), y se ha hallado asociada preferentemente a arbustos (Sun et al., 2013). En comparación con otras familias de Glomeromycota, se conoce muy poco acerca de su ecología y distribución (Smith y Read, 2010). Por otra parte, Jansa et al. (2014) y Liu et al., (2015) observaron que Diversispora sp predomina en ambientes ricos en humus. Liu et al. (2015) y detectó que su abundancia relativa se incrementó frente a aumentos de la fertilidad, humedad y materia orgánica del suelo siguiendo un patrón opuesto al de Glomus. Esto demuestra que Diversispora es más común de encontrar en suelos de bajo historial de uso antrópico. Por ejemplo, Camenzind et al. (2014) y Saks et al. (2013) hallaron una gran abundancia de Diversisporales (i.e. Gigasporaceae y Diversisporaceae, entre otros) en suelos de una reserva natural tropical y templada, respectivamente; lo contrario a ambientes agrícolas donde predomina casi exclusivamente Glomeraceae (Alguacil et al., 2008; Bainard et a., 2014; Daniell et al., 2001; Helgason et al., 1998). Finalmente, las especies de la familia Gigasporaceae (i.e. Racocetra), se caracterizan por habitar suelos ricos en nutrientes y buena provisión hídrica (Anderson et al., 1984). Son especies que colonizan las raíces a través de la germinación de sus esporas puesto que el micelio no es infectivo (Biermann y Linderman, 1983). Además, poseen una gran importancia desde el punto de vista funcional puesto que la producción de hifas extraradicales es usualmente más alta que la producida por otras familias como Glomeraceae (Hart y Reader, 2002) y en consecuencia es mayor su contribución a la adquisición de nutrientes (Maherali y Klironomos, 2007). La diversidad de especies indicadoras de lotes de soja en la zona de Sierras es una evidencia de la resiliencia de comunidad de Glomeromycota ante el avance de la frontera agrícola que puede ser favorable para el cultivo de soja.

La oferta de $\mathrm{P}$ del suelo afectó negativamente la riqueza, diversidad y densidad de esporas de Glomeromycota (Tabla 3.4). La relación entre estos hongos y el P ha sido extensamente documentada a lo largo de los años (e.g. Smith y Read, 2010; van der Heijden et al., 2006). El impacto negativo del $\mathrm{P}$ sobre los parámetros biológicos de HFMA coincide con lo observado por otros autores (Cofré, 2014; Landis et al., 2004; Oehl et al., 2004; Tchabi et al., 2008). En los agroecosistemas, la disponibilidad de nutrientes de un suelo está determinada en su 
mayor parte por la fertilización mineral y esta práctica no impacta de igual manera sobre todas las especies de HFMA (Verbruggen y Kiers, 2010). Sylvia y Schenk (1983) observaron que altas dosis de fertilizante fosfatado inhiben completamente la colonización de ciertas especies mientras que a otras no las afectaba e incluso estimuló su esporulación. Además, al aportar artificialmente nutrientes, hay una gran competencia entre los microorganismos que colonizan la raíz y son favorecidos aquellos individuos más agresivos en detrimento de otros (Kiers et al., 2002). Aunque en este estudio no se observaron mermas en los niveles de micorrización, es posible que los espacios intra-radicales hayan sido ocupados por aquellas especies más tolerantes a mayores niveles de $\mathrm{P}$ en detrimento de las especies más sensibles y que esto haya incidido en la producción de esporas, y por ende, en la riqueza, diversidad y densidad de esporas.

Por otra parte, la correlación negativa entre la concentración de P de la planta y la riqueza y diversidad de esporas de HFMA podrían ser en realidad consecuencia de la oferta de $\mathrm{P}$ del suelo. Como se mencionó en la sección de resultados, se halló una correlación positiva entre el nivel de $\mathrm{P}$ del suelo y la concentración de este nutriente en la planta. Es decir, que aumentos de $\mathrm{P}$ en la planta fueron consecuencia de una mayor disponibilidad del nutriente en el suelo. Smith et al. (2004) y Smith y Smith (2011) sostienen que aunque el suelo cuente con una elevada provisión de $\mathrm{P}$, las micorrizas igualmente transfieren el nutriente a la planta. En contraposición, Johnson et al. (1997) postulan que en ambientes ricos en P, los hongos destinan gran parte de los fotoasimilados a estructuras de reserva y reproducción más que a la producción de hifas extra-radicales $y$, en consecuencia, pueden ser considerados parasíticos ya que consumen fotoasimilados sin conferir un beneficio al huésped (Johnson; 2010; Johnson et al., 2013). En ocasiones se ha reportado merma en el rendimiento de cultivos debido a este mecanismo (Johnson et al., 1992). Siguiendo con este razonamiento, podría deducirse que la planta toma el $\mathrm{P}$ directamente por las raíces sin que intervengan las hifas pero sigue manteniendo a los hongos. El conocimiento de estos mecanismos debería ser tenido en cuenta al momento de diagramar una estrategia de fertilización fosforada con el fin de no impactar negativamente sobre las comunidades de HFMA del suelo ni atentar en contra de uno de los beneficios más importantes que estos hongos confieren a los cultivos.

Un análisis de la composición de una comunidad hace referencia al arreglo que existe entre cada una de las especies que la integran. Según Johnson et al. (1991) es un abordaje 
cualitativo sobre la comunidad de HFMA y para Rosendalh (2008) cobra mayor importancia ante diferencias de abundancia entre las especies presentes. Al momento del muestreo, los lotes de soja de la zona de Sierras presentaron una comunidad de HFMA estadísticamente diferente a la de las zonas Agrícola y Mixta (Tabla 3.5). Al representarlo gráficamente junto con los vectores de las variables ambientales de mayor ajuste, se observa que la comunidad de HFMA de Sierras se ubica hacia la dirección del vector de altitud, riqueza de especies y $P$ de la planta (Figura 3.6). Esta última variable se refiere al $\mathrm{P}$ absorbido por unidad de superficie $\left(\mathrm{mg} \mathrm{m}^{-2}\right)$ al momento del muestreo. El hecho que el contenido de $\mathrm{P}$ del suelo se ubique en la dirección opuesta, nos brinda información sobre el efecto de la comunidad HFMA en la nutrición fosforada del cultivo de soja. Es curioso observar que no se hallaron especies únicas o exclusivas de la zona de Sierras (Tabla 3.1), pero que su comunidad fue diferente a la de las zonas Agrícola y Mixta (Tabla 3.5). Es decir, fueron las mismas especies de HFMA pero ensambladas de un modo tal que se tradujo en una mayor riqueza por muestra. En los sistemas agrícolas, los factores de mayor incidencia sobre la composición de las comunidades de HFMA son las labranzas, la rotación de cultivos y la fertilización (Johnson et al., 1991; Verbruggen y Kiers, 2012). El impacto de las labranzas no lo discutiremos en esta tesis ya que la totalidad de los lotes muestreados eran cultivos de soja en siembra directa. La rotación de cultivos, en cambio, es el cuello de botella para la conservación de la biodiversidad en agroecosistemas sojeros. Las prácticas de monocultivo pueden ejercer una presión de selección muy fuerte hacia unas pocas especies más afines al cultivo. Por ejemplo, An et al. (1993), Johnson et al. (1991) y Hendrix et al. (1995) observaron que el monocultivo de soja afecta significativamente la composición de la comunidad de HFMA. Más aún, Johnson et al. (1992ab) hallaron correlaciones negativas consistentes entre la densidad de esporas de ciertas especies y la performance del cultivo tras varios ciclos de monocultivo. Además de este efecto negativo derivado de una alta densidad de esporas, Kiers et al. (2002) proponen una teoría relacionada a la evolución del simbionte fúngico. Sugieren que durante años consecutivos de un mismo cultivo, el HFMA podría desarrollar medidas que contrarresten las estrategias de la planta para forzar la cooperación. En consecuencia, este hecho se traduciría en una disminución de la eficacia del simbionte a lo largo del tiempo (Kiers y Denison, 2008). Por otra parte, la rotación de cultivos está vinculada a mayores niveles de diversidad (Oehl et al., 2003; Hijri et al., 2006) e incluso puede provocar que las comunidades de HFMA de sistemas agrícolas se parezcan más a la 
comunidad del ambiente natural del cual derivan (Verbruggen et al., 2010). Los lotes de soja de la zona de Sierras, posiblemente mantengan parte de la comunidad autóctona de HFMA heredada de la vegetación nativa de los montes.

El hecho que los vectores de riqueza y $\mathrm{P}$ de la planta se encuentren próximos y en el mismo sentido no es casual. Se ha demostrado la gran relación existente entre la riqueza de especies y la diversidad de funciones de la comunidad de Glomeromycota debido a la estrategia de colonización de cada especie (Fitter, 2005). Es lo denominado complementariedad funcional en la simbiosis de HFMA (Koide, 2000). Por ejemplo, la mayor protección contra patógenos de la raíz que confiere Glomeraceae vs la mejora en la adquisición de nutrientes de poca movilidad atribuida a Gigasporaceae, según si su crecimiento es mayormente intra o extra-radical, respectivamente (Maherali y Krilonomos, 2007; Hart y Reader, 2002). Cabe destacar que diversas especies de Gigasporaceae son frecuentemente halladas en lotes de soja (An et al., 1993; Cofré, 2014; Hendrix et al., 1995; Johnson et al., 1991; Saito y Vargas., 1991) y que ello se ha atribuido a la gran demanda de $P$ de las leguminosas y su limitada producción de raíces con respecto a otras especies vegetales (Smith y Read, 2010). En esta tesis los resultados obtenidos permiten confirmar la relación entre la riqueza de especies que componen una comunidad de HFMA y la nutrición fosforada de la soja.

\subsection{CONCLUSIONES}

El relevamiento taxonómico de esporas de especies de Glomeromycota de lotes de soja complementado con la multiplicación en plantas trampa permitió identificar 36 especies en un trabajo inédito para el área de estudio. Se observó que:

- La riqueza de especies por muestra fue superior en los lotes de soja ubicados en la zona de Sierras. Los demás índices biológicos ubicaron a los lotes de mayor historial agrícola en una condición menos favorable que los de Sierras y Mixtos ya que mostraron una baja diversidad y una elevada dominancia de especies. Se observó que el $\mathrm{P}$ del suelo correlacionó en forma negativa con la riqueza y diversidad y lo opuesto con la dominancia de especies. 
- La composición de las comunidades de HFMA en la zona de las Sierras fue estadísticamente distinta a la de las zonas Agrícola y Mixta, las cuales no difirieron entre sí. Estuvo correlacionada en forma positiva con el $\mathrm{P}$ absorbido por unidad de superficie del cultivo de soja, la riqueza de especies y la altitud; y en forma negativa con la disponibilidad de P del suelo. 
CAPITULO 4

COMUNIDADES DE GLOMEROMYCOTA ASOCIADAS AL SUELO RIZOSFÉRICO Y A LA RAÍZ DE SOJA IDENTIFICADAS MEDIANTE TÉCNICAS MOLECULARES.

Publicación en preparación:

Faggioli VS, MN Cabello, M Vasar, G Grilli, F Covacevich, M Öpik. 2016.Rhizosphere and rootassociated mycorrhizal communities from soybean fields of contrasting historical land use 
Tesis Doctoral - CAPITULO IV Ing. Agr. M.Sc. Valeria S Faggioli 


\subsection{INTRODUCCIÓN}

Comunidades más diversas de HFMA son más resilientes y adaptables a cambios del ambiente (Fitter, 2005). Sin embargo, en agroecosistemas de la Provincia de Córdoba donde las condiciones edáficas y de cultivo se han modificado considerablemente en las últimas décadas, su impacto sobre los HFMA permanece prácticamente desconocido. Las tecnologías de secuenciación de última generación o next-generation sequencing technologies (por ejemplo: pirosecuenciación) permiten caracterizar comunidades simbióticas con una gran resolución y alta repetitividad. Según Hart et al. (2015) constituirán en el corto plazo el mayor set de información sobre las comunidades de HFMA. En la actualidad, existen bancos de taxonomía molecular de Glomeromycota lo cual facilita la comparación de resultados con otros estudios (Kohout et al., 2014). Por ejemplo, la porción $18 \mathrm{~S}$ rRNA se ha secuenciado en numerosas muestras de suelo, raíces y esporas, y se ha almacenado en una base de datos de acceso abierto, mundialmente reconocida por especialistas en el tema: MaarjaAM database (Öpik et al., 2010; 2013). En esta base de datos, las secuencias con más de $97 \%$ de similitud se agrupan para formar "especies moleculares de HFMA" denominadas "taxa" o "taxa virtual" (VT por sus iniciales en inglés), con un número que lo identifica y asocia con una especie o familia de HFMA. Por ejemplo: el VT39 es un taxa que contiene secuencias de la familia Gigasporaceae. En los últimos años se han realizado relevamientos para la identificación de HFMA en diferentes ecosistemas del mundo (ej. Davison et al., 2015). Estos estudios han permitido ampliar exponencialmente el set de taxa identificados. Por ejemplo, en la última actualización de la base de datos MaarjAM, se alcanzaron los 353 taxa con más de 36000 secuencias para comparación (última actualización: 04/02/2015). Estas metodologías posibilitan ampliar el set de 261 especies descriptas en base a caracteres morfológicos de las esporas (http://schuessler.userweb.mwn.de/ consulta 21/04/2016). Dado el avance en estas técnicas y la posibilidad de identificar las especies de HFMA dentro de las raíces, estas metodologías permiten complementar los estudios taxonómicos tradicionales con información sobre la simbiosis activa en la planta.

El objetivo general de este capítulo fue estudiar la estructura de comunidades autóctonas de HFMA asociadas al cultivo de soja, en áreas productivas del Sur de la Provincia de Córdoba a través de la técnica de pirosecuenciación. Para ello se muestrearon lotes de soja de zonas 
homogéneas de historial de uso agrícola, mixto y de reciente deforestación. Los objetivos específicos fueron:

1) Identificar los taxa de Glomeromycota presentes en suelo rizosférico y raíces de soja a través secuenciación y comparación de secuencias con bases de datos internacionales (NCBI y MaarjAM)

2) Comparar comunidades de suelo y raíz, y estimar el efecto de variables de suelo y cultivo sobre la composición de las mismas

3) Identificar taxa abundantes e indicadores de las situaciones en estudio.

Se pusieron a prueba las siguientes hipótesis:

1) La composición de comunidades de HFMA del suelo diferirá entre las zonas en estudio en respuesta a las características edáficas y del cultivo.

2) La composición de comunidades de HFMA de las raíces será diferente entre zonas debido al efecto de la interacción entre ambos simbiontes y las propiedades edáficas.

3) Si las hipótesis anteriores son ciertas, se identificarán taxa abundantes e indicadores de cada zona. 


\subsection{MATERIALES Y MÉTODOS}

\section{Sitios de estudio}

Los sitios de estudio forman parte de las zonas homogéneas Agrícola, Mixta y de Sierras descriptas en el Capítulo 2. Se seleccionaron 10 puntos de cada zona distribuidos aleatoriamente. De la zona Mixta sólo se incluyeron muestras de Villa Huidobro debido a que por sus condiciones edáficas y geográficas era más representativo de las zonas de historial de uso Mixto. El total de muestras analizadas en este Capítulo fueron 30 muestras de suelo y 30 muestras de raíces.

\section{Muestreo de campo}

Las muestras se extrajeron en la recorrida de lotes de producción de soja descripta en el Capítulo 2. Allí se describe la obtención y procesamiento de las mismas previo a las determinaciones.

\section{Determinaciones}

\section{Propiedades del suelo y del cultivo}

En el Capítulo 2 se detallan las determinaciones realizadas para la caracterización de los suelos y mediciones sobre las plantas de soja extraídas en el muestreo.

\section{Análisis moleculares}

\section{- Extracción de ADN de muestras de suelo}

Se pesaron $50 \mathrm{~g} P \mathrm{PF}$, se procedió con el tamizado en húmedo y decantado (Gerdemann \& Nicolson, 1963), seguido de centrifugación en gradiente de $80 \%$ sacarosa (Walker et al., 1982) y se colectó todo el producto retenido en tamiz de malla 74- $\mu \mathrm{m}$. El material estaba compuesto por hifas, esporas, fragmentos de raíces y demás residuos. Mientras estaba en la malla, el exceso de humedad remanente luego de enjuagarlo con agua destilada, se retiró cuidadosamente mediante el uso de papel tissue desde la parte inferior del tamiz. Luego se transfirió a tubos de $1,5 \mathrm{ml}$ y se conservó a -20 ㄷ C hasta continuar con el procedimiento. La extracción se realizó con el kit Power Soil (MO BIO Lab. Inc. USA) sobre $200 \pm 20$ mg del material recolectado previamente homogeneizado en nitrógeno líquido con la ayuda de un 
micropistilo. Luego de este paso, se prosiguió con el protocolo de extracción siguiendo las recomendaciones del fabricante.

\section{- Extracción de ADN de muestras de raíces}

Se pesaron $10 \mathrm{~g}$ PF de raíces en tubos de $1,5 \mathrm{ml}$ y se trituraron con micropistilo y nitrógeno líquido. La extracción de ADN total se realizó con el kit NucleoSpin ${ }^{\circledR}$ Plant II kit (MachereyNagel GmbH \& Co, Düren, Alemania) con algunas modificaciones del protocolo original para optimizar la extracción. Éstas fueron: a) la muestra de tejido radical se duplicó de 100 mg a $200 \mathrm{mg} \pm 10 \mathrm{mg}$; b) de acuerdo al incremento de material radical, también se duplicaron los volúmenes empleados de Buffer PL1 (lisis celular); RNasa A, y PC (buffer de ligamiento); y c) la incubación para la lisis celular a 65 으 se realizó durante 30 minutos en lugar del tiempo recomendado de 10 minutos de duración.

\section{- PCRs y secuenciación}

La amplificación de secuencias del gen SSU rRNA de Glomeromycota se realizó del mismo modo para muestras de suelo y raíces como se describe a continuación. Se hizo una amplificación semi-anidada con el objetivo de incrementar el rendimiento del amplicón deseado. La primera reacción de PCR se realizó con el par de primers específicos de Glomeromycota f-AML1 y AML2-r los cuales generan un producto de aproximadamente 800 pares de bases del fragmento $18 \mathrm{~S}$ rRNA (Lee et al., 2008). Se utilizó como templado una alícuota de $3 \mu \mathrm{l}$ del extracto de ADN extraído. Las reacciones de PCR se condujeron de la siguiente manera: 2,5 unidades de Taq DNA polymerase (Promega cat\# M300B), $200 \mu \mathrm{M}$ de cada primer, $200 \mu \mathrm{M}$ de cada dNPTs, y $1,8 \mathrm{mM} \mathrm{MgCl}_{2}$ Buffer. Además, se agregó $1 \mu \mathrm{l}$ dimetil sulfoxide (DMSO, Roche cat\#04738284001) y la agua bi-destilada hasta completar $25 \mu$ l. Las reacciones se corrieron en un termociclador T9600-G (Applied Biosystems, NY, USA) como se destalla a continuación: 4 min de desnaturalización inicial a 94으, 40 ciclos de 95ํㅜ por 30 seg, $58^{\circ} \mathrm{C}$ por 40 segundos; y $72^{\circ} \mathrm{C}$ por $1 \mathrm{~min}$, seguido de un período de extensión de $72^{\circ} \mathrm{C}$ por $5 \mathrm{~min}$. Los productos de reacción se chequearon en geles 1,5\% agarosa, 0,5 X TBE, y GelRed $^{\mathrm{TM}}$ (Biotium cat\# 41003) para la tinción.

La segunda reacción se realizó con los primers NS31-f (Simon et al., 1992) y AML2-r que producen un amplicón de aproximadamente 560 pares de bases del fragmento 18S rRNA. Este gen es frecuentemente elegido en estudios ambientales y taxonómicos de Glomeromycota, por lo cual el set de información disponible para comparación de resultados 
es más abundante que el de cualquier otra región genómica (Öpik et al., 2014). De acuerdo con las recomendaciones provistas por el fabricante del equipo de secuenciación Roche GSLX 454, los primers de fusión universales $A($ Univ- $A)$ y $B($ Univ- $B)$ se unieron a cada primer de la PCR semi-anidada. Entonces, el primer forward compuesto fue: 5'CACGACGTTGTAAAACGACTTGGAGGGCAAGTCTGGTGCC-3'; y el primer reverse fue: 5'CAGGAAACAGCTATGACCGAACCCAAACACTTTGGTTTCC-3', donde Univ-A y Univ-B se presentan subrayados, y los primers NS31-f y AML2-r se presentan en cursiva. Cada reacción de PCR contenía: $1 \mu \mathrm{l}$ de dilución1:10 del producto de la primera PCR, y los reactivos del kit Roche (Roche cat\#04738284001) de la siguiente manera: 2,5 unidades de Taq DNA polymerase, $200 \mu \mathrm{M}$ de dNTPs, $1,8 \mathrm{mM} \mathrm{MgCl}_{2}$ Buffer, y $1 \mu \mathrm{l}$ DMSO. Por último, se agregaron $200 \mu \mathrm{M}$ de cada primer compuesto y agua bi-destilada hasta volume de $20 \mu$ l. Las reacciones se corrieron en termociclador T9600-G (Applied Biosystems, NY, USA) como se detalla a continuación: $95^{\circ} \mathrm{C}$ por 15 min; 5 ciclos de $42^{\circ} \mathrm{C}$ por $30 \mathrm{seg}, 72^{\circ} \mathrm{C}$ por 90 seg, y $92^{\circ} \mathrm{C}$ por 45 seg; 35 ciclos de $65^{\circ} \mathrm{C}$ por $30 \mathrm{seg}, 72^{\circ} \mathrm{C}$ por $90 \mathrm{seg}$, y $92^{\circ} \mathrm{C}$ por 45 seg; seguido de $65^{\circ} \mathrm{C}$ por 30 seg y extensión adicional a $72^{\circ} \mathrm{C}$ por 10 min (Öpik et al., 2013). Los productos de reacción se chequearon en gel de agarosa como se describió anteriormente y luego se purificaron con el kit Fast Pure PCR Product Purification Kit (Roche). La preparación de la biblioteca y pasos subsiguientes para la secuenciación se llevaron a cabo en INDEAR (Instituto de Agrobiotecnologia de Rosario, Argentina) siguiendo las instrucciones de Roche para Universal Tailed Amplicon Sequencing (Secciones 4 y 8 en Method Manual publicado es: http://454.com/my454/). Durante este procedimiento se añadió un secuencia identificadora (MID: multiplex identifier) al forward primer de cada muestra como una código de barras para su identificación en sucesivos análisis.

\section{- Análisis bioinformático}

Los análisis de las secuencias se realizaron de acuerdo a Davison et al. (2012) y Moora et al. (2014). Brevemente, este proceso consistió en el filtrado y limpieza de las secuencias previo a los análisis posteriores. Primero: se aplicó un filtro de modo tal que sólo las secuencias con el MID correcto fueran retenidas. Luego, los MIDs y primers se cortaron y las lecturas se limpiaron de acuerdo a parámetros predefinidos (grado de calidad media $\geq 25$; longitud mínima $\geq 170$ pares de bases, y longitud máxima de 520 pares de bases). Las potenciales quimeras se detectaron y removieron con (Edgar et al., 2011) en referencia a la base de 
datos MaarjAM (http://www.maarjam.botany.ut.ee/, Öpik et al. 2010). MaarjAM contiene 21486 secuencias (última actualización: 04/02/2015) del amplicon NS31/AML2 tanto de muestras de esporas como ambientales. Estas secuencias se agruparon en base a un umbral de $97 \%$ de similitud filogenética con el objetivo que cada filogrupo se asemeje al nivel taxonómico de especies denominado Virtual Taxa (VT) (Öpik et al., 2010, 2014). Esta base de datos se utilizó para designar taxonómicamente las secuencias obtenidas. Se realizó una búsqueda BLAST con las secuencias de MaarjAM (similitud $\geq 97 \%$ ) de no menos del $10 \%$ de la longitud total alineada. Las secuencias que no coincidieron con las de las base de datos (i.e. no-hits), se sometieron a un nuevo BLAST con la base de dato INSD (similitud $\geq 90 \%$ ). Aquellas secuencias con coincidencias con miembros de Glomeromycota con más de 100 lecturas se alinearon con las secuencias de MaarjAM usando MAFFT, el servicio online de alineamiento múltiple en Jalview v2.8 (Waterhouse et al., 2009) y luego se analizaron mediante neighbor joining analysis en TOPALi v2.5 TOPALi v2.5 (Milne et al., 2009). Los nuevos VT se definieron en base a similitud de secuencias y agrupamiento filogenético (Öpik et al., 2010). Finalmente, una secuencia representativa de cada nuevo VT se incluyó al set de secuencias de referencias de MaarjAM y el set completo de lecturas originales se sometió a un nuevo BLAST. Las secuencias de los nuevos VT se depositaron en la base de datos del NCBI con los números: KU708516-KU708528

\section{Análisis estadístico}

Los análisis estadísticos de los resultados fueron los mismos que se llevaron a cabo con las esporas y se describen en el Capítulo 3. 


\subsection{RESULTADOS}

\section{Características del suelo y del cultivo}

Los sitios de estudio presentaron suelos con propiedades texturales y nutricionales contrastantes. Sin embargo, los cultivos de soja no difirieron en las variables medidas en este estudio (Tabla 4.1).

\section{Secuenciación}

El proceso de pirosecuenciación dio como resultado 225.114 lecturas filtradas de un total de 30 muestras de suelo y 28 muestras de raíces ( 2 muestras de raíz no dieron ninguna lectura). Un total de 204.396 lecturas se pudieron asignar a un VT de Glomeromycota existente en MaarjAM (Öpik et al., 2010), 99.738 lecturas de muestras de suelo y 104.658 de raíces. El número medio de lecturas por muestra fue de 47 a 8108 con una mediana de 3918. En total, se detectaron 93 VTs de 8 familias (Tabla 4.2): Acaulosporaceae (3), Archaeosporaceae (3), Claroideoglomeraceae (5), Diversisporaceae (10), Gigasporaceae (6), Glomeraceae (60), Pacisporaceae (1), y Paraglomeraceae (5). Estos valores incluyen 13 VT nuevos detectados de las secuencias que no coincidieron con los VT existentes en la base de referencia MaarjaAM y con 2 VT identificados por Grilli et al. (2014). Los 13 VT inéditos hallados en este estudio se denominaron INTA (acrónimo de Instituto Nacional de Tecnología Agropecuaria) con un subíndice de 1 a 13. Además, se hallaron 8 VT que como estuvieron representados por una sola secuencia se excluyeron de posteriores análisis. Por último, las secuencias NoGlomeromycota (6937 lecturas) halladas según BLAST en INSD (>90\% similitud) fueron: 72\% Streptophyta (Fabaceae), 1\% Chlorophyta, 23,5 \% to Chytridiomycota, 2\% Ascomycota, y 1,5\% Basidiomycota. 
Tabla 4.1: Características del suelo y del cultivo de las zonas homogéneas ( \pm Desviación estándar)

\begin{tabular}{|c|c|c|c|c|c|c|c|c|c|c|c|c|c|c|c|c|c|c|}
\hline \multirow{4}{*}{$\begin{array}{c}\text { Zona } \\
\text { Ecológica } \\
\text { Homogénea } \\
\text { Agrícola }\end{array}$} & \multicolumn{9}{|c|}{ Suelos } & \multicolumn{7}{|c|}{ Cultivo de soja } & \multirow{3}{*}{$\begin{array}{c}\text { PMA } \\
m m \\
\end{array}$} & \multirow{3}{*}{$\begin{array}{l}\text { Altitud } \\
\text { msnm }\end{array}$} \\
\hline & \multirow{2}{*}{$\begin{array}{c}\text { USDA } \\
\text { Clasific. }\end{array}$} & $\mathbf{P}$ & $\mathbf{N}$ & \multirow{2}{*}{$\begin{array}{l}\mathrm{C} \\
\% \\
\end{array}$} & \multirow[t]{2}{*}{$\mathrm{pH}$} & \multirow{2}{*}{$\begin{array}{c}\text { EC } \\
\mu S \mathrm{~cm}^{-1}\end{array}$} & \multirow[t]{2}{*}{ Agua } & \multirow{2}{*}{$\begin{array}{c}\text { Arena } \\
\% \\
\end{array}$} & \multirow[t]{2}{*}{ Arcilla } & \multicolumn{2}{|c|}{ MS } & \multicolumn{3}{|c|}{$\mathbf{P}$} & \multirow{2}{*}{$\begin{array}{c}\text { Densidad } \\
p / m^{2}\end{array}$} & \multirow{2}{*}{$\begin{array}{c}\text { Mico } \\
\%\end{array}$} & & \\
\hline & & \multicolumn{2}{|c|}{$m g k g^{-1}$} & & & & & & & $g p I^{-1}$ & $g m^{-2}$ & $m g g^{-1}$ & $m g p I^{-1}$ & $m g m^{-2}$ & & & & \\
\hline & Argiudol & $14,6 \mathbf{b}$ & 44,6 & $3,1 \mathbf{a}$ & $6,0 \mathbf{b}$ & 186,5 & $6,9 a$ & $24,0 \mathrm{a}$ & $76,0 \mathrm{a}$ & 11,2 & 316,3 & 1,2 & 13,7 & 396,7 & 29,3 & $67 a$ & 900 & $119,8 \quad$ b \\
\hline & & $( \pm 6,0)$ & $( \pm 22,8)$ & $( \pm 0,4)$ & $( \pm 0,2)$ & $( \pm 265,5)$ & $( \pm 0,77)$ & $( \pm 8,2)$ & $( \pm 8,2)$ & $( \pm 4,2)$ & $( \pm 105,9)$ & $( \pm 0,4)$ & $( \pm 6,3)$ & $( \pm 218,2)$ & $( \pm 6,4)$ & $( \pm 16)$ & & $( \pm 14,9)$ \\
\hline \multirow[t]{2}{*}{ Mixta } & Haplustol & $37,9 a$ & 29,7 & $1,6 \mathbf{b}$ & $6,5 \mathrm{a}$ & 80,0 & 1,5 b & $66,0 \mathrm{c}$ & $34,0 \mathrm{c}$ & 9,2 & 240,5 & 1,5 & 13,9 & 351,2 & 27,7 & $57 a b$ & 800 & 203,3 b \\
\hline & & $( \pm 23,4)$ & $( \pm 23,0)$ & $( \pm 0,6)$ & $( \pm 0,2)$ & $( \pm 20,5)$ & $( \pm 0,34)$ & $( \pm 12,4)$ & $( \pm 12,4)$ & $( \pm 3,3)$ & $( \pm 61,4)$ & $( \pm 0,3)$ & $( \pm 6,9)$ & $( \pm 96,3)$ & $( \pm 7,9)$ & $( \pm 15)$ & & $( \pm 53,4)$ \\
\hline \multirow[t]{2}{*}{ Sierras } & Haplustol & $22,0 \mathrm{ab}$ & 55,6 & $3,2 \mathrm{a}$ & $6,4 a b$ & 155,0 & $6,5 \mathrm{a}$ & 41,2 b & 58,8 b & 9,7 & 428,9 & 1,4 & 14,5 & 506,9 & 37,9 & 48 b & 700 & 638,6 a \\
\hline & & $( \pm 19,7)$ & $( \pm 47,1)$ & $( \pm 1,0)$ & $( \pm 0,6)$ & $( \pm 164,8)$ & $( \pm 0,84)$ & $( \pm 14,2)$ & $( \pm 14,2)$ & $( \pm 3,1)$ & $( \pm 219,2)$ & $( \pm 0,3)$ & $( \pm 7,5)$ & $( \pm 217,1)$ & $( \pm 14,4)$ & $( \pm 18)$ & & $( \pm 135,8)$ \\
\hline \multicolumn{19}{|c|}{ 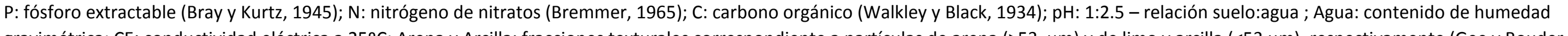 } \\
\hline \multirow{2}{*}{\multicolumn{19}{|c|}{ 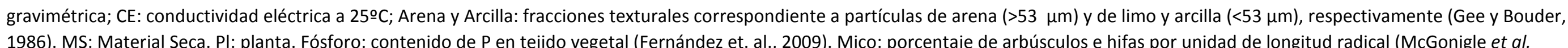 }} \\
\hline & & & & & & & & & & & & & & & & & & \\
\hline \multicolumn{19}{|c|}{ 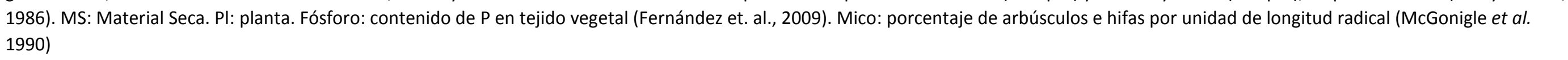 } \\
\hline \multicolumn{19}{|c|}{ PMA: Precipitación media anual } \\
\hline \multicolumn{19}{|c|}{ Las medias con letras diferentes difieren significativamente según test de Tukey $(p<0,05)$. } \\
\hline
\end{tabular}


Tabla 4.2: Abundancia relativa (\%) de VT en muestras de raíces y suelo asociados a plantas de soja de diferentes zonas homogéneas.

\begin{tabular}{|c|c|c|c|c|c|c|c|}
\hline \multicolumn{2}{|c|}{ Taxonomía de MaarjAM } & \multicolumn{2}{|c|}{ Agrícola } & \multicolumn{2}{|c|}{ Mixta } & \multicolumn{2}{|c|}{ Sierras } \\
\hline Grupo & VT & Raíz & Suelo & Raíz & Suelo & Raíz & Suelo \\
\hline \multirow[t]{3}{*}{ Acaulosporaceae } & INTA_12 & -- & 0,01 & -- & -- & -- & -- \\
\hline & VT026 & 0,01 & 1,19 & 3,51 & 0,60 & 1,78 & 0,95 \\
\hline & VT028 & -- & -- & -- & 0,07 & -- & 1,32 \\
\hline \multirow[t]{3}{*}{ Archaeosporaceae } & INTA_7 & 0,05 & 0,59 & -- & -- & -- & -- \\
\hline & VT005 & 0,38 & 2,34 & -- & -- & -- & 0,31 \\
\hline & VT338 & -- & -- & -- & -- & -- & 0,18 \\
\hline \multirow[t]{5}{*}{ Claroideoglomeraceae } & INTA_8 & 0,06 & 0,06 & -- & 0,01 & -- & 0,21 \\
\hline & VT055 & 0,18 & -- & -- & -- & 0,16 & -- \\
\hline & VT056 & -- & -- & -- & 0,05 & -- & 0,13 \\
\hline & VT193 & 0,76 & 7,60 & -- & 0,97 & 0,98 & 6,82 \\
\hline & VT278 & 0,93 & 1,16 & 2,93 & 1,48 & -- & -- \\
\hline \multirow[t]{10}{*}{ Diversisporaceae } & INTA_10 & -- & -- & -- & -- & -- & 0,07 \\
\hline & INTA_11 & -- & -- & -- & -- & -- & 0,30 \\
\hline & INTA_3 & -- & -- & 0,01 & -- & -- & 0,08 \\
\hline & VT054 & -- & -- & -- & -- & 0,21 & 2,87 \\
\hline & VT060 & -- & -- & -- & -- & 0,63 & 1,84 \\
\hline & VT061 & -- & -- & -- & -- & 0,28 & 1,80 \\
\hline & VT062 & -- & -- & -- & 0,08 & 1,34 & 2,14 \\
\hline & VT263 & -- & -- & -- & -- & -- & 0,01 \\
\hline & VT353 & 0,07 & -- & 1,65 & 0,28 & 0,01 & 0,55 \\
\hline & VT380 & -- & -- & -- & 0,01 & 0,27 & 0,25 \\
\hline \multirow[t]{6}{*}{ Gigasporaceae } & INTA_1 & -- & -- & -- & -- & 0,10 & 0,27 \\
\hline & INTA_2 & -- & 0,83 & -- & -- & -- & -- \\
\hline & VT039 & 0,41 & 27,13 & 5,57 & 8,43 & 15,59 & 22,29 \\
\hline & VT041 & 0,01 & -- & 3,50 & 0,37 & 3,14 & 9,93 \\
\hline & VT255 & 0,01 & 0,02 & -- & 0,40 & 0,19 & 1,86 \\
\hline & VT318 & 0,15 & 0,02 & 0,04 & 0,12 & 0,38 & 0,10 \\
\hline \multirow[t]{19}{*}{ Glomeraceae } & $\mathrm{GCL}_{4} 4$ & 0,42 & 0,87 & 0,01 & 0,01 & 0,28 & 0,30 \\
\hline & INTA_4 & 0,34 & 1,34 & -- & -- & 0,07 & -- \\
\hline & INTA_5 & -- & 0,03 & -- & 0,36 & -- & 0,07 \\
\hline & INTA_6 & -- & -- & -- & 0,03 & -- & 0,02 \\
\hline & INTA_9 & -- & -- & -- & 0,26 & -- & -- \\
\hline & t_GCL_3 & -- & -- & 0,04 & 0,01 & 0,01 & -- \\
\hline & VT063 & 22,58 & 14,13 & 6,61 & 3,04 & 2,34 & 2,88 \\
\hline & VT064 & 0,07 & 0,01 & -- & -- & 2,44 & 1,31 \\
\hline & VT067 & 0,01 & 8,74 & -- & 9,87 & -- & 16,16 \\
\hline & VT069 & 3,32 & 0,63 & 4,90 & 2,13 & 21,99 & 0,35 \\
\hline & VT075 & -- & -- & 1,28 & 1,54 & -- & 0,01 \\
\hline & VT077 & -- & -- & 0,06 & 0,02 & -- & -- \\
\hline & VT087 & -- & -- & 0,01 & 0,10 & -- & -- \\
\hline & VT092 & 0,01 & -- & 0,13 & 0,11 & 0,04 & 0,05 \\
\hline & VT093 & 0,01 & 0,21 & 0,06 & 0,22 & 0,78 & 0,02 \\
\hline & VT096 & 3,20 & 1,58 & 5,27 & 1,83 & 0,32 & 0,05 \\
\hline & VT099 & -- & -- & -- & 0,36 & -- & 0,02 \\
\hline & VT100 & -- & -- & -- & -- & 0,57 & 0,06 \\
\hline & & & & & & & Cont. \\
\hline
\end{tabular}


Tabla 4.2 (Cont.): Abundancia relativa (\%) de VT

\begin{tabular}{|c|c|c|c|c|c|c|c|}
\hline \multicolumn{2}{|c|}{ Taxonomía de MaarjAM } & \multicolumn{2}{|c|}{ Agrícola } & \multicolumn{2}{|c|}{ Mixta } & \multicolumn{2}{|c|}{ Sierras } \\
\hline Grupo & VT & Raíz & Suelo & Raíz & Suelo & Raíz & Suelo \\
\hline \multirow[t]{42}{*}{ Glomeraceae } & VT105 & -- & -- & 0,01 & 0,01 & 0,01 & 0,11 \\
\hline & VT108 & -- & -- & -- & -- & -- & 0,01 \\
\hline & VT111 & -- & -- & -- & -- & -- & 0,01 \\
\hline & VT113 & 16,78 & 9,94 & 15,35 & 10,71 & 7,97 & 20,69 \\
\hline & VT114 & 3,92 & 0,56 & 1,18 & 1,68 & 7,47 & 12,89 \\
\hline & VT115 & 0,14 & 0,14 & 0,21 & 0,14 & 0,21 & 0,16 \\
\hline & VT120 & -- & -- & -- & -- & -- & 0,01 \\
\hline & VT125 & 0,02 & 1,87 & 0,98 & -- & -- & -- \\
\hline & VT130 & 0,17 & 0,35 & 3,80 & 0,24 & -- & 0,09 \\
\hline & VT132 & 0,04 & -- & -- & -- & 11,61 & 5,71 \\
\hline & VT140 & 0,04 & -- & 0,01 & -- & -- & -- \\
\hline & VT143 & 0,18 & 1,85 & 0,24 & -- & -- & 2,86 \\
\hline & VT146 & 0,02 & -- & -- & -- & 2,75 & 0,66 \\
\hline & VT155 & -- & 0,26 & 1,51 & 0,39 & 0,01 & 0,32 \\
\hline & VT172 & 19,84 & 1,62 & 2,37 & -- & -- & -- \\
\hline & VT185 & -- & -- & 0,01 & -- & -- & -- \\
\hline & VT195 & -- & 0,03 & -- & 0,02 & -- & 0,06 \\
\hline & VT197 & 0,47 & 0,25 & 0,66 & -- & -- & -- \\
\hline & VT199 & 0,07 & -- & -- & -- & -- & -- \\
\hline & VT209 & -- & -- & -- & -- & -- & 0,01 \\
\hline & VT212 & 5,34 & 0,17 & 0,27 & 0,10 & -- & -- \\
\hline & VT214 & -- & -- & 0,66 & -- & -- & -- \\
\hline & VT222 & 0,63 & 5,72 & 8,66 & 1,42 & 0,65 & 0,92 \\
\hline & VT247 & 0,28 & 0,05 & 0,03 & 0,07 & 0,02 & 0,07 \\
\hline & VT248 & 0,03 & -- & -- & -- & 9,43 & 2,27 \\
\hline & VT270 & -- & -- & -- & -- & 0,01 & 0,02 \\
\hline & VT280 & 0,10 & -- & 6,17 & 1,03 & 20,28 & 13,30 \\
\hline & VT293 & -- & 0,01 & 0,01 & 0,01 & -- & -- \\
\hline & VT295 & -- & -- & 0,01 & -- & -- & 0,01 \\
\hline & VT296 & -- & -- & -- & 0,01 & -- & -- \\
\hline & VT304 & -- & -- & 0,02 & -- & -- & -- \\
\hline & VT306 & -- & -- & -- & 0,01 & -- & -- \\
\hline & VT310 & 11,19 & 0,08 & 0,09 & -- & 0,28 & 0,88 \\
\hline & VT312 & 0,01 & -- & 0,01 & -- & 0,06 & 0,14 \\
\hline & VT326 & -- & -- & 0,02 & -- & -- & -- \\
\hline & VT331 & 0,01 & -- & -- & -- & -- & -- \\
\hline & VT359 & -- & 0,01 & 0,01 & 0,01 & -- & 0,02 \\
\hline & VT364 & -- & -- & -- & 0,02 & 3,66 & 2,05 \\
\hline & VT385 & -- & -- & -- & 0,01 & 0,03 & 0,25 \\
\hline & VT387 & 0,01 & -- & -- & -- & -- & -- \\
\hline & VT409 & 6,40 & 4,01 & 0,01 & 0,31 & 0,01 & -- \\
\hline & VT418 & -- & -- & -- & -- & -- & 0,01 \\
\hline Pacisporaceae & VT284 & -- & -- & -- & -- & -- & 1,32 \\
\hline \multirow[t]{5}{*}{ Paraglomeraceae } & INTA_13 & -- & -- & -- & 0,02 & -- & -- \\
\hline & VT001 & 0,53 & 2,39 & 2,84 & 3,23 & -- & 0,46 \\
\hline & VT238 & -- & -- & -- & 0,01 & -- & 0,19 \\
\hline & VT239 & -- & -- & -- & 0,18 & -- & 0,03 \\
\hline & VT281 & 0,72 & 2,19 & 0,96 & 4,78 & -- & 1,67 \\
\hline Total de VTs & & 45 & 39 & 34 & 59 & 50 & 58 \\
\hline
\end{tabular}




\section{Riqueza de HFMA}

En las muestras de suelo, los análisis de rarefacción y curvas de acumulación de especies muestran que la profundidad de secuenciación y que la intensidad de muestreo, respectivamente, fueron suficientes como para detectar todos los taxa existentes (Figuras 4.1a, 4.2a). En las muestras de raíces, estos análisis sugieren que algún taxa permanece no detectado en las zonas Agrícola y de Sierras debido a que las curvas no llegaron a ser asintóticas (Figura 1b, 2b).

a)

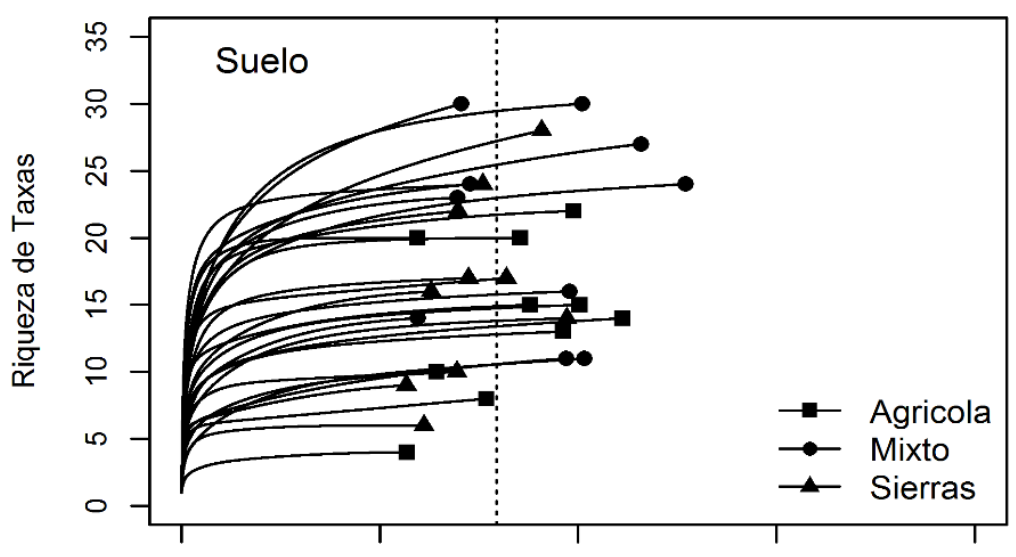

b)

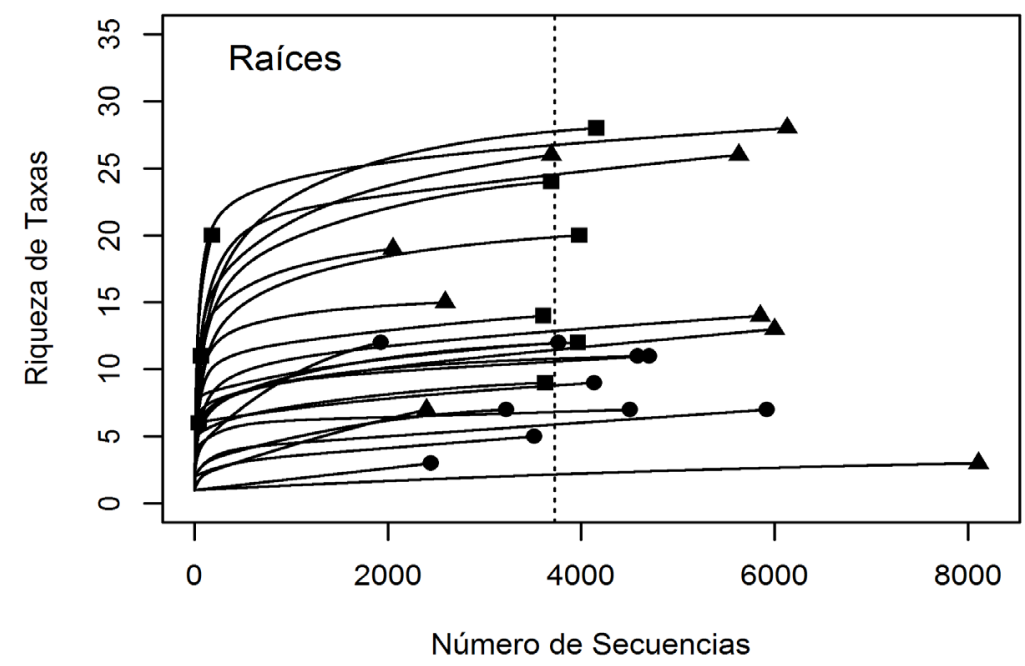

Figura 4.1: Análisis de rarefacción de secuencias obtenidas de muestras de suelo (a) y raíces (b) de soja de diferentes zonas homogéneas. Las líneas de puntos perpendiculares al eje " $x$ " (Número de secuencias) corresponden a la mediana. 


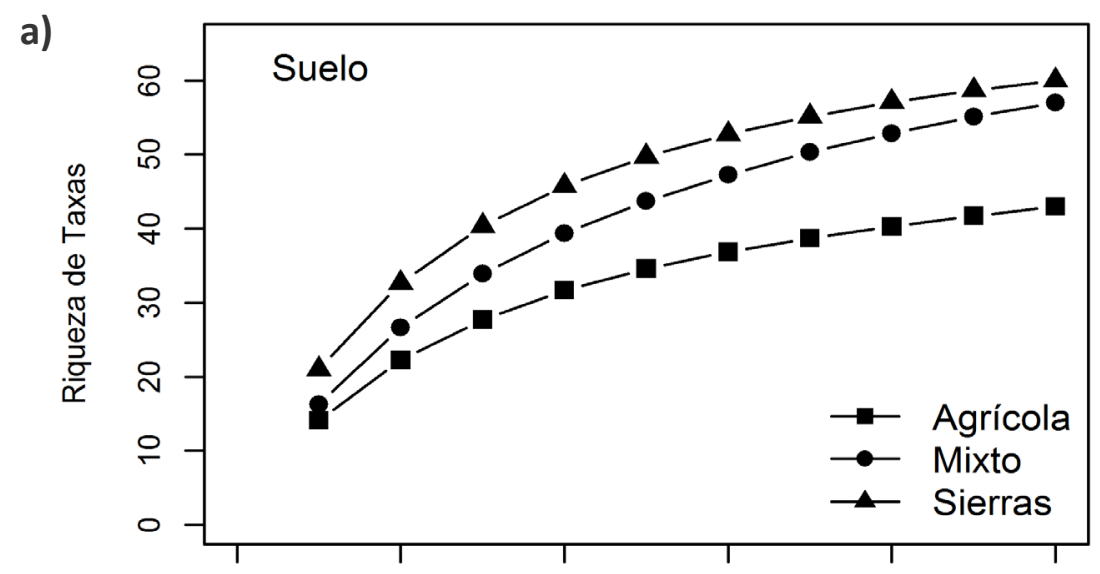

b)

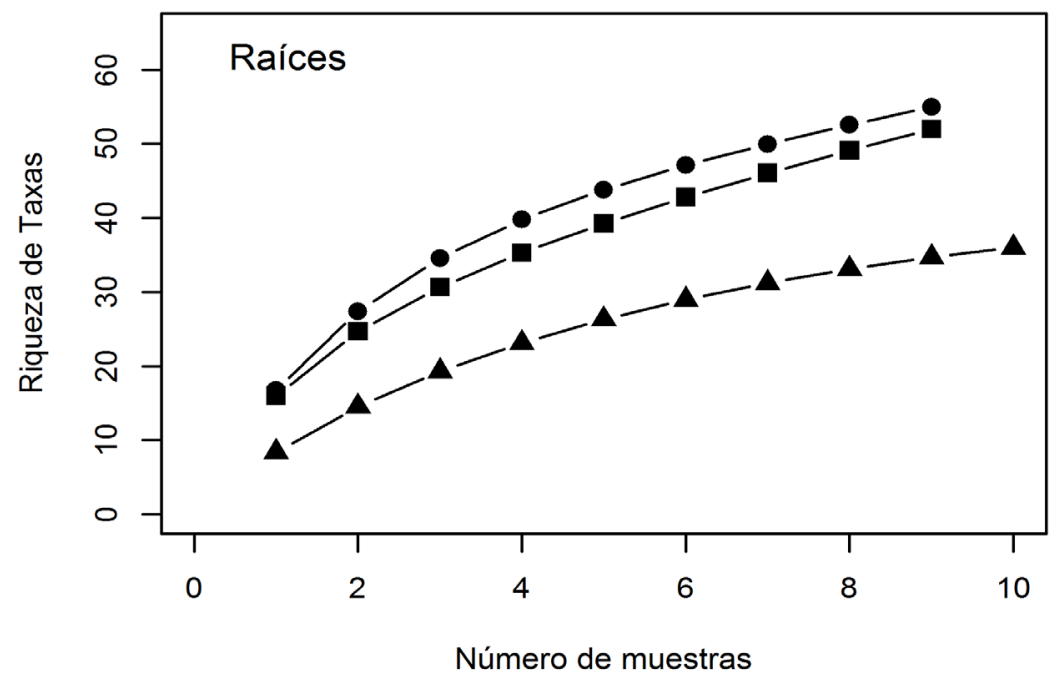

Figura 4.2: Curvas de acumulación de especies con los taxa obtenidos por secuenciación de muestras de suelo (a) y raíces (b) de soja de diferentes zonas homogéneas.

La riqueza de HFMA media por muestra fue de 15,6 VT y no difirió entre zonas homogéneas. Se encontró una interacción significativa entre el tipo de muestra (i.e. suelo o raíz) y la zona (Figura 4.3). En particular, en la zona Mixta el promedio de VT en raíces (8,6 VT) fue significativamente inferior al observado en el suelo (21,6 VT).

La riqueza de VT de HFMA estuvo correlacionada significativamente con variables del suelo y del cultivo (Tabla 4.3). Se encontró que la textura se correlacionó fuertemente con la riqueza de ambos tipos de muestras pero de manera inversa (Figura 4.4). 


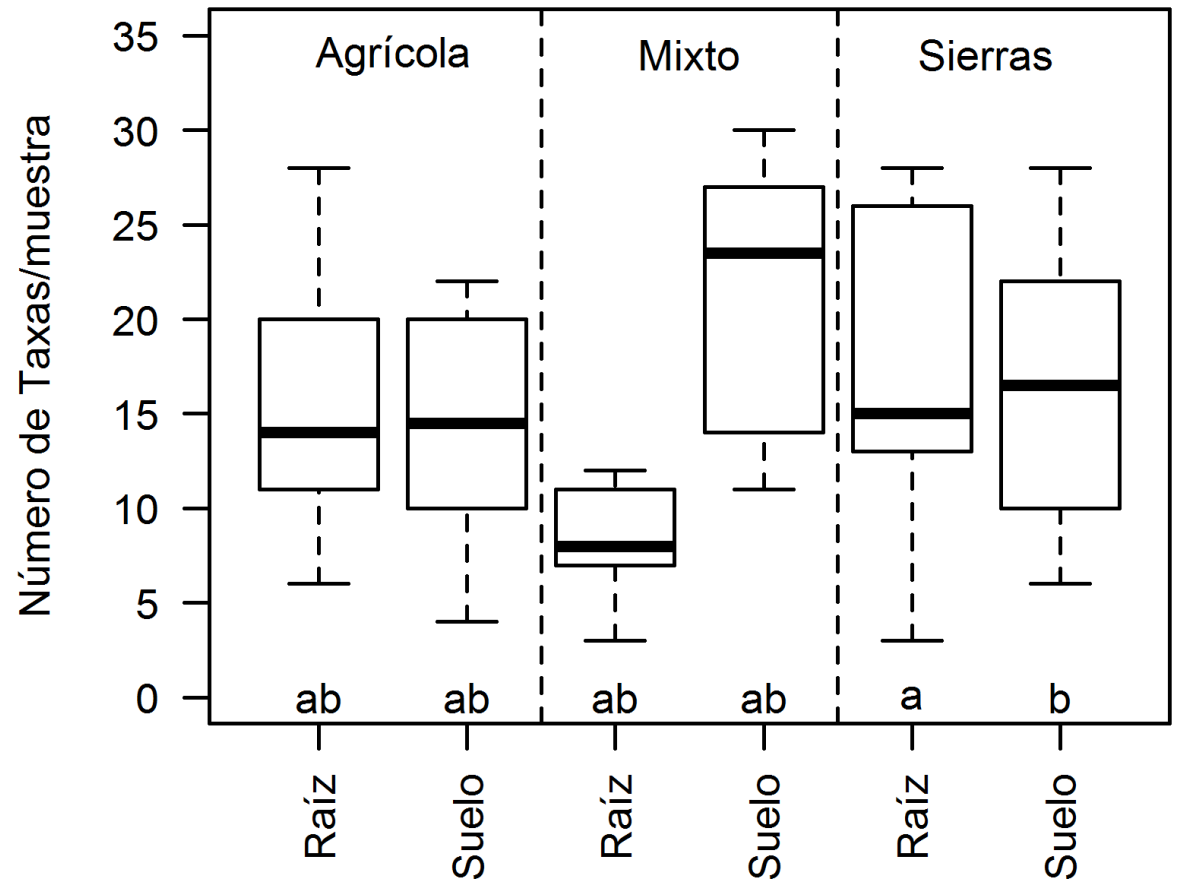

Figura 4.3: Riqueza de taxa de HFMA en muestras de suelo y raíz de soja de diferentes zonas homogéneas. Las líneas sólidas indican la mediana, las cajas y barras indican los cuartiles y rangos, respectivamente. La riqueza difiere significativamente (ANOVA, Zona*Tipo de muestra, $p<0,002$ ). Letras diferentes debajo de los boxplots indican diferencias significativas entre todas las muestras (Tukey, $p<0,05$ )

Tabla 4.3: Coeficientes y $p$-valor de correlaciones significativas (Spearman, $p<0,05$ ) entre riqueza de taxa y variables de suelo y del cultivo en muestras de raíz y suelo rizosférico de soja de diferentes áreas homogéneas.

\begin{tabular}{|c|c|c|c|c|}
\hline Zona & Tipo de muestra (n) & Variable & Coeficiente & $p$-valor \\
\hline \multirow[t]{2}{*}{ Agrícola (A) } & Raíz (9) & $P$ aéreo $\left(\mathrm{mg} \mathrm{pl}^{-1}\right)$ & 0,68 & $<0,04$ \\
\hline & Suelo (10) & $\mathrm{N}-\mathrm{NO}_{3}\left(\mathrm{mg} \mathrm{kg}^{-1}\right)$ & $-0,84$ & $<0,001$ \\
\hline Mixta (M) & Raíz (10) & $\mathrm{pH}$ & 0,75 & $<0,01$ \\
\hline Sierras (S) & Suelo (10) & Densidad $\left(\mathrm{pl} \mathrm{m} \mathrm{m}^{-2}\right)$ & 0,86 & $<0,001$ \\
\hline \multirow[t]{6}{*}{$A+M+S$} & Raíz (28) & Arena (\%) & $-0,48$ & $<0,01$ \\
\hline & & Arcilla (\%) & 0,48 & $<0,01$ \\
\hline & & Agua (\%) & 0,58 & $<0,001$ \\
\hline & Suelo (30) & Arena (\%) & 0,39 & $<0,01$ \\
\hline & & Arcilla (\%) & $-0,39$ & $<0,01$ \\
\hline & & $\mathrm{N}-\mathrm{NO}_{3}\left(\mathrm{mg} \mathrm{kg}^{-1}\right)$ & $-0,37$ & $<0,04$ \\
\hline
\end{tabular}




$\begin{array}{lll}\mathrm{pH} & 0,43 & <0,01 \\ \text { Densidad }\left(\mathrm{pl} \mathrm{m}^{-2}\right) & 0,47 & <0,01\end{array}$

a)

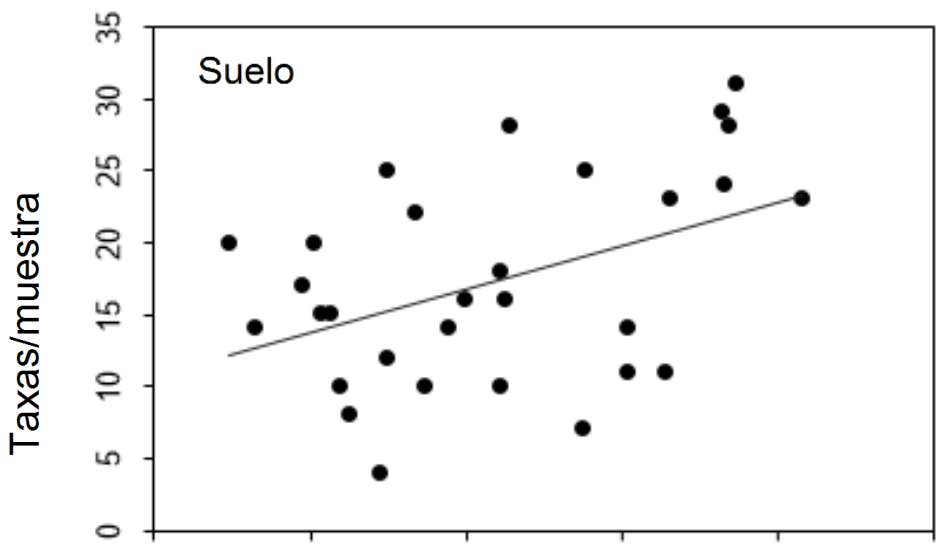

b)

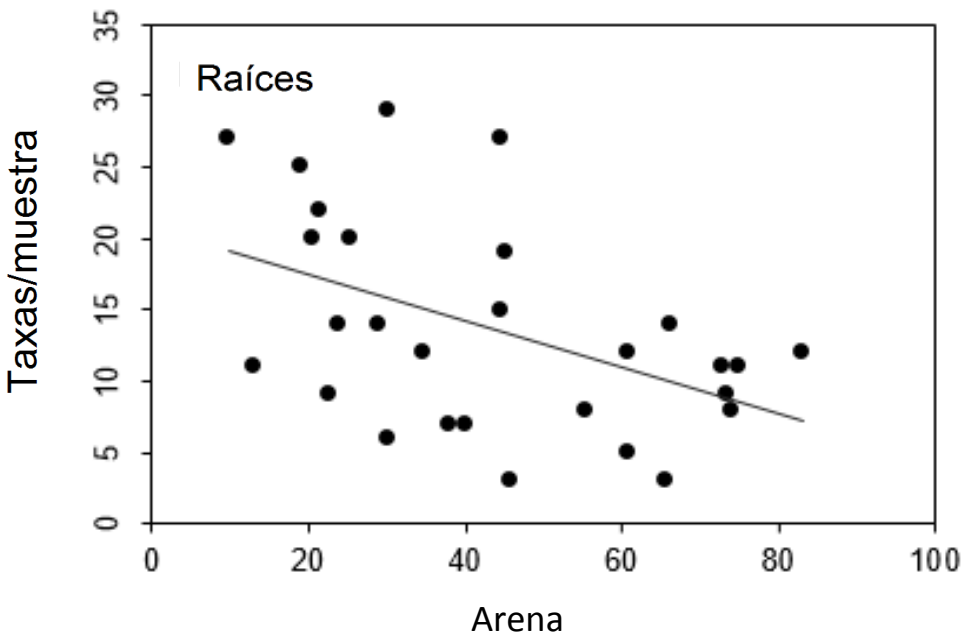

Figura 4.4: Correlaciones entre el contenido de arena del suelo (\%) y el número de taxa por muestra (riqueza) de muestras de suelo (a) y raíces (b). Las líneas representan correlaciones lineales significativas (Spearman, Suelo: $r=0,39, p<0,03$; Raíces: $r=-0,48, p<0,01$ ). Obsérvese en Tabla 4.3 que las correlaciones halladas entre riqueza y contenido de arcilla fueron opuestas pero de igual magnitud a las representadas en esta figura (i.e. Spearman, Suelo: $r=-0,39, p<0,03$; Raíces: $r=0,48, p<0,01)$. 


\section{Composición de la comunidad}

Los análisis de Permanova y NMSD revelaron diferencias marginalmente significativas entre la composición de comunidades de las zonas en estudio (Permanova, pseudo-F=3.31, $\mathrm{P} \leq$ $0.001, R^{2}=0.10$ ) y entre los 2 tipos de muestras (Permanova, pseudo-F=2.14, $P \leq 0.014$, $\mathrm{R}^{2}=0.03$ ). El gráfico NMSD mostró que las comunidades de suelo de la zona Agrícola se ubicaron junto con las de Sierras, mientras que la zona Mixta formó un grupo separado (Figura 4.5a). La composición de la comunidad de HFMA de suelo se correlacionó con la humedad del suelo (Mantel, $R=0,16 ; P<0,008$ ), arena (Mantel, $R=0,11 ; P<0,02$ ), arcilla y limo (Mantel, $R=0,11 ; P<0,03$ ) y peso seco de la planta (Mantel, $R=0,14 ; P<0,01$ ).

Finalmente, se estudió la composición de las comunidades de HFMA de las raíces (Tabla 4.4, Figura 4.6). Se observó que sólo en los sitios Agrícolas, las comunidades de la raíz presentaron una composición estadísticamente diferente a la observada en las muestras de suelo (Tabla 4.4), lo cual se visualiza en la Figura 4.6.

Tabla 4.4: Análisis de comparación de composición de comunidades (PERMANOVA) entre las muestras de suelo y raíces de las diferentes áreas homogéneas. Análisis basado en la matriz de abundancia relativa.

\begin{tabular}{|c|c|c|c|c|c|c|c|}
\hline \multirow{2}{*}{\multicolumn{2}{|c|}{$\begin{array}{c}\text { Resultados PERMANOVA } \\
R^{2} \mid p \text {-valor (adj.) }\end{array}$}} & \multicolumn{2}{|c|}{ Agrícola } & \multicolumn{2}{|c|}{ Mixta } & \multicolumn{2}{|c|}{ Sierras } \\
\hline & & \multirow{2}{*}{$\begin{array}{c}\text { Raíz } \\
-\end{array}$} & \multirow[t]{2}{*}{ Suelo } & \multirow[t]{2}{*}{ Raíz } & \multirow[t]{3}{*}{ Suelo } & \multirow[t]{2}{*}{ Raíz } & \multirow[t]{2}{*}{ Suelo } \\
\hline Agrícola & Raíz & & & & & & \\
\hline & Suelo & $0,13 * *$ & - & & & & \\
\hline \multirow[t]{2}{*}{ Mixta } & Raíz & $0,15 * *$ & $0,12 * *$ & - & & & \\
\hline & Suelo & $0,14 * * *$ & $0,12^{*}$ & 0,06 & - & & \\
\hline \multirow[t]{2}{*}{ Sierras } & Raíz & $0,16 * * *$ & 0,11 & 0,09 & $0,14^{* *}$ & - & \\
\hline & Suelo & $0,21 * * *$ & 0,07 & $0,10^{*}$ & $0,11 *$ & 0,07 & - \\
\hline
\end{tabular}


Los $p$-values se indican: ${ }^{* * *} .<0,01 * * .<0,01 ;{ }^{*},<0,05$ y se resaltaron en negrita.

Tesis Doctoral - CAPITULO IV Ing. Agr. M.Sc. Valeria S Faggioli 
a)

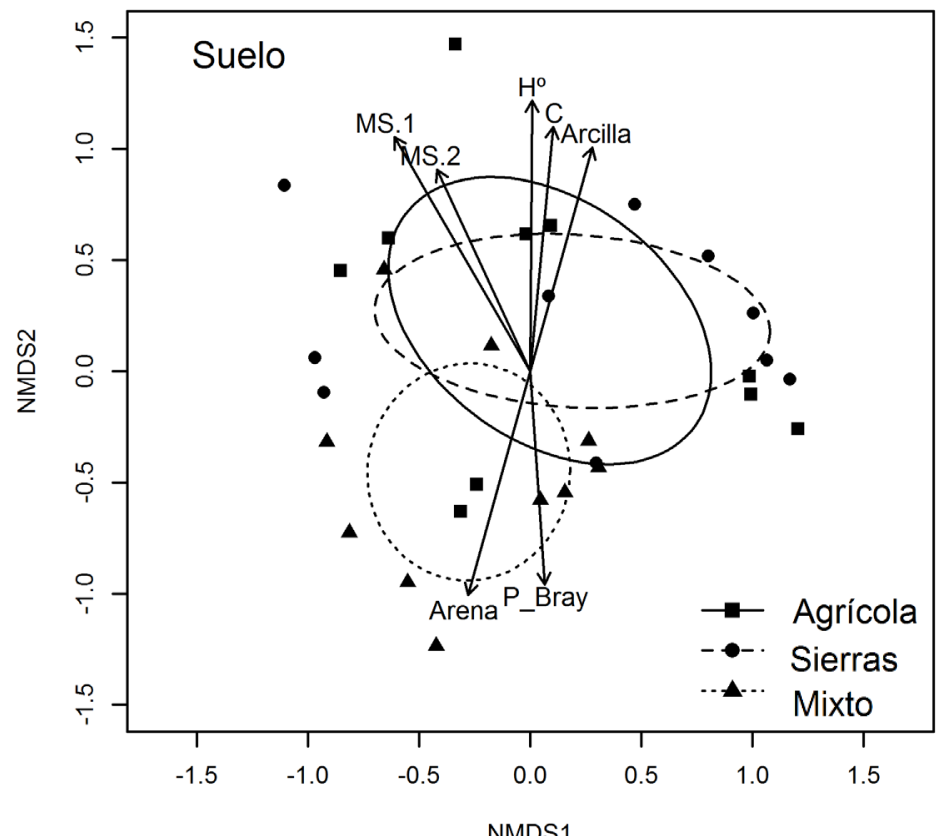

b)

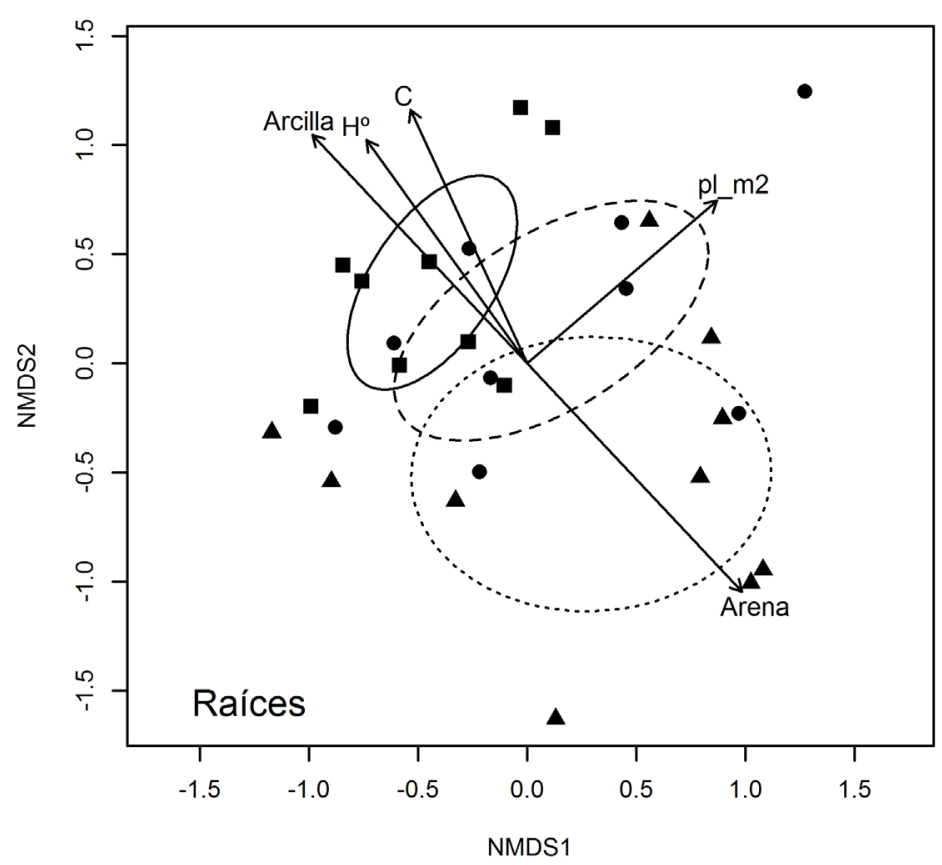

Figura 4.5: Composición de la comunidad de HFMA (NMDS) de lotes de producción de soja de diferentes áreas homogéneas del $S$ de la Pcia de Cba. (a) muestras de suelo (stress=0,14), y (b) muestras de raíces (stress=0,13). Los análisis están basados en disimilitud de Bray-Curtis. Las elipses indican 1 desvío estándar del centroide del grupo. Las flechas representan los vectores estadísticamente significativos $(p<0,05)$ de variables de suelo y del cultivo, donde la dirección de la flecha indica la dirección del gradiente y la longitud representa la correlación entre los datos del NMDS y la variable. Los vectores significativos fueron: MS.1: materia seca de la planta de soja (g $\mathrm{pl}^{-}$ $\left.{ }^{1}\right)$, MS.2: materia seca por unidad de área $\left(\mathrm{g} \mathrm{m}^{-2}\right)$; $\mathrm{pl} \_\mathrm{m2}$ : densidad de plantas ( $\left.\mathrm{pl} \mathrm{m}^{-2}\right)$; $\mathrm{C}$ \%C suelo; Arcilla: \% de arcilla y limo; Arena: \% de arena; Ho: \% agua del suelo; y P_Bray: contenido de P del suelo ( $\left.\mathrm{mg} \mathrm{kg}^{-1}\right)$. 
a)

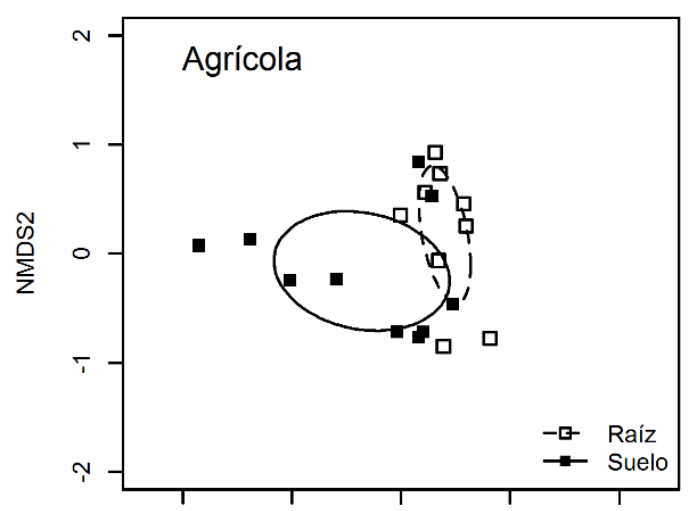

b)

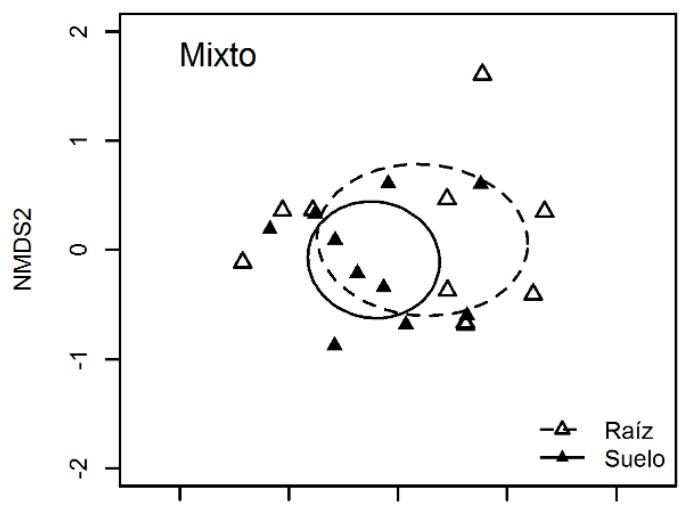

c)

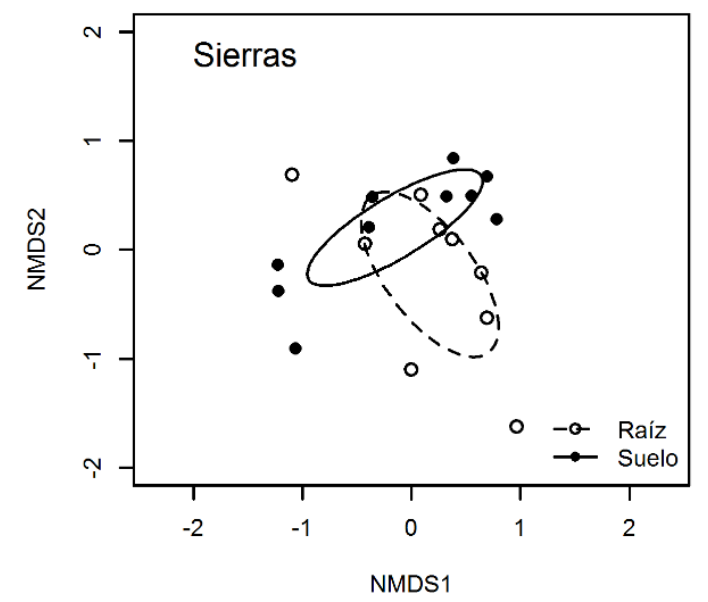

Figura 4.6: Composición de comunidades de HFMA de diferentes zonas homogéneas del $\mathrm{S}$ de la Pcia de Córdoba: (a) Agrícola (stress=0,09); (b) Mixta (stress=0,10), y (c) Sierras (stress=0,10). Comparación entre muestras de raíces (línea de rayas) y suelo (línea sólida). Análisis basado en matriz de disimilitud de Bray Curtis. Las elipses indican un desvío estándar alrededor del centroide de cada grupo. 


\section{VT indicadores y VT dominantes}

El análisis de especies indicadoras detectó varios VT representativos de cada zona tanto en muestras de suelo como de raíces (Tabla 4.5). En total, se identificaron 25 taxa con valor indicador significativo $(>0,25)$, los cuales correspondieron al $25,8 \%$ de los VT hallados.

Tabla 4.5: Taxa indicadores de cada zona homogénea (valor indicador $>0,25$ ) de muestras de suelo y raíz.

\begin{tabular}{|c|c|c|c|c|c|c|}
\hline Zona & Muestra & Taxa & $\begin{array}{c}\text { Accession } \\
\text { number }\end{array}$ & Grupo & $\begin{array}{c}\text { Valor } \\
\text { indicador }\end{array}$ & Probabilidad \\
\hline \multirow[t]{7}{*}{ Agrícola } & Suelo & INTA_4 & KU708519 & Glomeraceae & 0,5049 & 0,002 \\
\hline & & INTA_2 & KU708517 & Gigasporaceae & 0,4000 & 0,008 \\
\hline & & INTA_7 & KU708522 & Archaeosporaceae & 0,2834 & 0,027 \\
\hline & Raíz & VT172 & EF109857 & Glomeraceae & 0,6357 & 0,001 \\
\hline & & VT310 & FJ194510 & Glomeraceae & 0,5687 & 0,003 \\
\hline & & VT063 & AJ505812 & Glomeraceae & 0,3878 & 0,014 \\
\hline & & VT140 & AJ563896 & Glomeraceae & 0,2746 & 0,017 \\
\hline \multirow[t]{8}{*}{ Mixta } & Suelo & VT105 & AJ505617 & Glomeraceae & 0,5732 & 0,001 \\
\hline & & INTA_5 & KU708520 & Glomeraceae & 0,5365 & 0,001 \\
\hline & & VT08̄ & AY129635 & Glomeraceae & 0,4613 & 0,003 \\
\hline & & VT114 & AM849267 & Glomeraceae & 0,4156 & 0,032 \\
\hline & & VT363 & FR821540 & Glomeraceae & 0,4000 & 0,003 \\
\hline & & VT385 & FR821554 & Glomeraceae & 0,3519 & 0,008 \\
\hline & & VT312 & FN263137 & Glomeraceae & 0,2788 & 0,041 \\
\hline & Raíz & VT132 & AY129605 & Glomeraceae & 0,3035 & 0,041 \\
\hline \multirow[t]{11}{*}{ Sierras } & Suelo & VT054 & AJ315524 & Diversisporaceae & 0,4719 & 0,001 \\
\hline & & VT041 & AJ418851 & Gigasporaceae & 0,4365 & 0,008 \\
\hline & & VT060 & AM849296 & Diversisporaceae & 0,3916 & 0,001 \\
\hline & & VT061 & X86687 & Diversisporaceae & 0,3559 & 0,007 \\
\hline & & VT067 & AJ306438 & Glomeraceae & 0,3403 & 0,013 \\
\hline & & INTA_11 & KU708526 & Diversisporaceae & 0,3000 & 0,021 \\
\hline & & VT028 & AY129590 & Acaulosporaceae & 0,2854 & 0,050 \\
\hline & & VT380 & FN869704 & Diversisporaceae & 0,2521 & 0,048 \\
\hline & Raíz & VT064 & AM849308 & Glomeraceae & 0,3632 & 0,007 \\
\hline & & VT318 & GU353455 & Gigasporaceae & 0,3626 & 0,008 \\
\hline & & VT222 & AM849264 & Glomeraceae & 0,3305 & 0,025 \\
\hline
\end{tabular}


Del conjunto de VT identificados, sólo 2 de ellos fueron hallados dominantes, es decir, $>0,20$ abundancia relativa por muestra en al menos 10 muestras (Figura 4.7): Glomus VT 113 (13,5\% de las lecturas), y Gigaspora VT 39 (13,5\%). Ambos VT, sólo representan el $2 \%$ del total de VT de este estudio, pero juntos alcanzan el $27 \%$ del total de lecturas. Entre las 58 muestras totales, Gigaspora VT39 (relacionada a G. albida, G. decipiens, G. gigantea, G. margarita, G. rosea) se detectó en 43 muestras y con alta abundancia en 11; mientras que Glomus VT 113 (Glomus fasciculatum) se detectó en 49 muestras y fue abundante en 14.
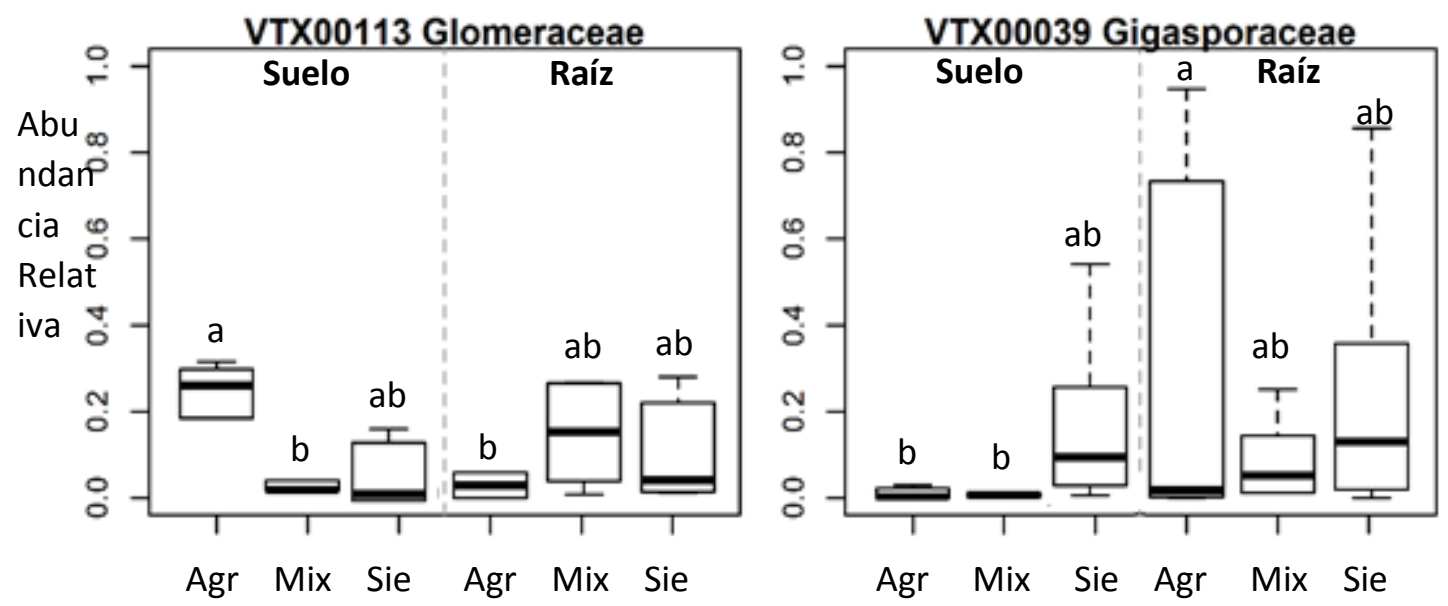

Figura 4.7: Abundancia relativa por muestra de taxa abundantes $(>0,20$ abundancia relativa en al menos 10 muestras) de muestras de suelo y raíz de soja de diferentes áreas homogéneas del Sur de la Provincia de Córdoba: Agrícola (Agr); Mixta (Mix) y de Sierras (Sie). Las líneas sólidas indican la mediana, las cajas y barras indican los cuartiles y rangos, respectivamente. Letras diferentes indican diferencias significativas entre las muestras de cada VT (Test de comparación de rangos Kruskal-Wallis, $p<0,05$ ) 


\subsection{DISCUSION}

En total, se detectaron 94 VT lo cual constituye uno de los valores de riqueza de HFMA más altos registrados en sistemas agrícolas, con un esfuerzo de muestreo comparable. Las raíces de soja presentaron 73 VT, y el suelo 84 VT. Hiiesalu, et al. (2014) muestrearon 100 puntos en una pastura nativa de aproximadamente 75 especies vegetales y detectaron un total de 63 VT. Vályi et al. (2014), en un estudio basado en 250 muestras de raíces detectaron 74 VT. Considerando que solo se analizaron 28 muestras de raíces de una sola especie vegetal, estos resultados demuestran que la soja puede alojar un gran número de HFMA. Por otro lado, los resultados hallados en cuanto al número de VT en el suelo es coincidente con otros estudios (Lumini et al., 2010; Klabi et al., 2015), lo cual sugiere que el suelo mantiene un número similar de VT en sistemas antropogénicos.

La riqueza de HFMA hallada en las muestras no difirió entre zonas (Figura 4.3). Considerando las diferencias en cuanto al historial de uso de las mismas, una posible explicación para la ausencia de efecto sobre los HFMA es el uso masivo de la siembra directa. Este sistema de manejo del suelo ha sido documentado como muy positivo en el mantenimiento de la riqueza de Glomeromycota (Alguacil et al., 2008; Brito et al., 2012; Zhang et al., 2015). Sin embargo, hay que considerar que las condiciones del suelo y geográficas también determinan el número de especies de HFMA (Jansa et al., 2014). Desafortunadamente, las comunidades de suelos prístinos en el área de estudio permanecen desconocidas y por lo tanto no es posible obtener una visión genuina del efecto del uso antrópico que ha ocurrido en las zonas evaluadas. No obstante, puesto que la riqueza hallada de VT se ubicó entre las más altas publicadas en agroecosistemas (ej. Lumini et al., 2010; Bainard, et al., 2014), podría deducirse que las prácticas agronómicas actuales relacionadas al cultivo de soja permiten el mantenimiento de niveles considerables de taxa de HFMA. Este es un resultado muy promisorio considerando la gran extensión de superficie ocupada por este cultivo en nuestro país.

Entre las propiedades del suelo, la riqueza de HFMA por muestra estuvo correlacionada significativamente con el nitrógeno $(\mathrm{N}), \mathrm{pH}$ y textura; pero no se correlacionó con el fósforo (P), carbono (C), ni conductividad eléctrica (Tabla 4.3). El efecto negativo del $\mathrm{N}$ sobre la riqueza de HFMA se ha reportado anteriormente (Egerton-Walburton et al., 2007; Tian et al., 
2013). Esta reducción en número de especies ocurre porque algunas son más afectadas que otras por el incremento de $\mathrm{N}$ del suelo (Liu et al., 2015; Camenzind et al., 2014). Por otro lado, se hallaron correlaciones positivas entre el $\mathrm{pH}$ del suelo y la riqueza de VT en raíces (Tabla 4.3). El efecto del pH sobre las especies de Glomeromycota es impredecible. Mientras que Verbruggen et al. (2012) detectaron efectos positivos en la riqueza de raíces pero no en la de suelo, Moora et al. (2014) encontraron una fuerte correlación en muestras de suelo, y Bainard et al. (2014) observó que el pH no se correlacionó con la riqueza de especies pero sí tuvo una gran incidencia sobre la estructura de las comunidades. Además, también se ha reportado que el efecto del pH del suelo varía según a especie fúngica (Jansa et al., 2014; Veresoglou et al., 2013). En este Capítulo, el efecto del pH sólo fue hallado en la zona Mixta la cual estuvo más caracterizada por su alto contenido de arena que por valores inusuales de pH (Tabla 4.1). En este sentido, ya que el efecto del pH sólo halló en estas muestras de raíces, puede asumirse que el pH desempeñó un rol crítico en la simbiosis micorrícica de este tipo de suelos.

La textura del suelo apareció como un fuerte determinante de la riqueza de HFMA (Figura 4.4). Posiblemente, esto ocurrió debido a la relación entre la textura y la disponibilidad de agua del suelo (Moebius-Clune et al., 2013). La combinación de ambos parámetros afectó de manera opuesta a los HFMA del suelo y de la raíz. En primer lugar, la riqueza de VT del suelo se correlacionó positivamente con el contenido de arena (Tabla 4.3). En este estudio los suelos arenosos correspondieron a la región semiárida de la zona Mixta. Entonces, es posible que ante la ausencia de remoción del suelo por el uso de la siembra directa y la condición de semi-aridez hayan conformado una situación muy favorable para la conservación de propágulos del suelo (Jasper et al., 1989). Contrariamente, un escenario arenoso y seco no sería el ideal para el establecimiento de la simbiosis micorrícica, en especial para algunas especies. En efecto, la riqueza de HFMA de raíces hallada en la zona Mixta fue la más baja de todo este estudio (Figura 4.3). La humedad del suelo y el contenido de arcilla, en cambio, fueron las propiedades del suelo correlacionadas positivamente con la riqueza de Glomeromycota en raíces (Tabla 4.3). Es posible suponer, entonces, que aunque algunas especies de HFMA son capaces de sobrevivir en ambientes áridos, no pueden colonizar las raíces ante bajos contenidos hídricos. Jasper et al. (1989) demostraron que las hifas y raíces infectadas pueden permanecer infectivas por varias semanas en un suelo seco, y Tommerup 
y Abbot (1981) encontraron que las hifas de ciertas especies pueden renovar su crecimiento luego de almacenamientos a -50 MPa durante 5 meses o más. Sin embargo, la escasez de agua afecta negativamente el proceso de germinación de esporas y la infección radical (Tommerup, 1984). Puesto que las raíces de soja de la zona Mixta presentaban un nivel de micorrización considerable (Tabla 4.1), es posible que la infección haya sido llevada a cabo por especies capaces de colonizar a partir de hifas y raíces infectadas. Aquellas especies que colonizan preferentemente desde esporas, seguramente estuvieron en desventaja. Estas condiciones explicarían por qué se hallaron valores tan bajos de riqueza en raíces a pesar de la gran riqueza de HFMA en el suelo circundante.

Finalmente, entre las variables edáficas que no afectaron la riqueza, la ausencia de correlación con el $\mathrm{P}$ del suelo no era esperada pero sí ha sido reportada anteriormente. Algunos autores han arribado a la misma conclusión (Beauregard et al. 2013; Moora et al., 2014), mientras que otros encontraron reducciones de la riqueza luego del agregado de $P$ (Verbruggen et al. 2012; Gosling et al., 2013; Camenzind et al., 2014; Klabi et al., 2015), e incluso un sorpresivo aumento en el número de VT (Liu et al., 2015). Esta respuesta errática entre estudios también ocurre en la abundancia de especies, por ejemplo, en un metaanálisis, Treseder (2004) encontró un impacto negativo de niveles crecientes de $\mathrm{P}$, pero Jansa et al. (2014) no observó ningún efecto significativo del P. En esta investigación, la falta de efecto del $\mathrm{P}$ podría deberse a que los sitios que integraban las zonas homogéneas estaban bien provistos de $\mathrm{P}$, es decir, tenían más de $10 \mathrm{ppm} \mathrm{P}$ Bray al momento del muestreo (Gutierrez-Boem y Salvagiotti, 2015)

Las plantas de soja exhibieron valores extremadamente uniformes de acumulación de materia seca y $\mathrm{P}$ (Tabla 4.1) y ello puede ser considerado como una evidencia de la gran adaptación del cultivo a ambientes contrastantes. De acuerdo con Klironomos et al. (2000), las micorrizas extienden el nicho de las plantas. En este estudio, los niveles de micorrización estuvieron entre los más altos citados en la literatura científica internacional (Tabla 4.1) (An et al., 1993; Zhang et al., 1995; Beauregard et al., 2013; Gosling et al., 2013; Higo et al., 2014). Entonces, coincidiendo con Maherali y Klironomos (2007), podría inferirse que la simbiosis micorrícica podría estar cumpliendo un rol clave en la exitosa performance de la soja en los agroecosistemas. 
El mantenimiento de especies nativas de HFMA tiene consecuencias favorables en el ecosistema debido a que la diversidad estructural está relacionada con la diversidad funcional (Hart y Reader, 2002). Además, se ha demostrado que comunidades de HFMA con mayor riqueza estimularon más la productividad de la planta que una comunidad pobre en especies (Maherali y Klironomos, 2007). Esto fue particularmente evidente en los sitios Agrícolas donde el contenido de $\mathrm{P}$ de la planta estuvo correlacionado positivamente con la riqueza de HFMA (Tabla 4.3). Considerando que las leguminosas en simbiosis con bacterias fijadoras de $\mathrm{N}$ se asocian preferentemente con especies de HFMA eficaces en adquirir P del suelo (Scheublin y van der Heijden, 2006) y la evidencia de la selectividad física y funcional ejercida por las plantas (Helgason et al. 2002), se podría inferir que en los sitios Agrícolas (de mayor historial sojero que Mixtos y de Sierras) predominan ciertas especies de HFMA que no sólo son infectivos sino que también son eficaces en la adquisición de $P$ del suelo. Finalmente, es interesante considerar la estequiometria del N y P (Johnson, et al., 2010). Se ha reportado que el agregado de $\mathrm{N}$ en suelos ricos en $\mathrm{P}$ puede reducir tanto la riqueza de HFMA (Egerton-Walburton et al. 2007) como la colonización micorrícica (Mendoza et al., 2016), pero que ello no ocurre en suelos deficientes de P. Paradójicamente, aunque la riqueza fue afectada negativamente por el $\mathrm{N}$ del suelo, se requirieron más especies de HFMA para mejorar la nutrición P (Tabla 4.3). La identificación de prácticas de manejo y de recursos que afectan la simbiosis micorrícica y en consecuencia los beneficios en la adquisición de nutrientes, es un desafío para incrementar las funciones de las micorrizas en los agroecosistemas.

Entender cómo se ensamblan las especies para formar una comunidad de Glomeromycota puede ayudar a identificar qué factores naturales y antrópicos gobiernan la ocurrencia de especies en agroecosistemas. En este estudio se halló que las zonas ejercieron un efecto significativo sobre la composición de las comunidades, con respuestas particulares en las muestras de suelo y raíces (Tabla 4.4, Figura 4.5). En las muestras de suelo, la zona Mixta reveló una composición diferente en comparación con la Agrícola y la de Sierras, mientras que éstas últimas no difirieron entre sí (Tabla 4.4). Esto fue sorpresivo ya que uno esperaría que la comunidad de HFMA de una zona recientemente deforestada fuera distinta a aquellas de suelos históricamente dedicados a la producción agrícola. Sin embargo, los vectores representados sobre la Figura de composición de comunidad mostraron que el gradiente 
textural habría sido la característica de las zonas que definió la composición de las comunidades de HFMA (Figura 4.5a). Kivlin et al. (2014) encontraron que las especies de HFMA del suelo se ensamblan principalmente debido al "filtro" impuesto por el ambiente. Del mismo modo, Moebius-Clune et al. (2013) reportaron que el gradiente textural estuvo fuertemente relacionado con la composición de la comunidad debido a su relación con la disponibilidad de agua del suelo. Los suelos arenosos (ej. Zona Mixta), tienden a tener más fluctuaciones en el contenido de agua y una baja retención hídrica, lo cual es exacerbado durante períodos de sequía. En contraste, los suelos arcillosos poseen mayores contenidos de humedad y C (ej. Zonas Agrícolas y de Sierras) con condiciones más estables para la producción de cultivos, lo cual se ve reflejado en su mayor producción de materia seca, como se observa en los vectores de la Figura 4.5a. Las diferencias observadas en la composición de las comunidades de HFMA podrían ser consecuencia de la performance preferencial de ciertas especies de hongos en cada situación textural (Lekberg et al., 2007; Jansa et al., 2014; Veresoglou et al., 2013). Finalmente, en la Figura 4.5 se observa que los suelos con más P correspondieron a los de mayor contenido de arena (zona Mixta). Esto podría ser consecuencia de su historial ganadero y las reposiciones de nutrientes por heces y orina. Aunque el efecto negativo de la disponibilidad de $\mathrm{P}$ del suelo sobre la composición de las comunidades de HFMA fue reportado anteriormente (Bainard et al., 2014; Camenzind et al., 2014), en este estudio no se halló un efecto significativo mediante test de Mantel. Es posible inferir, entonces, que el efecto del $\mathrm{P}$ del suelo estuvo subordinado a otras condiciones restrictivas inherentes a los suelos arenosos. Es decir, según los resultados obtenidos, el gradiente textural observado sería el factor más importante en el ensamblaje de las comunidades de Glomeromycota del suelo.

El modo en que las especies de HFMA forman comunidades dentro de las raíces depende de la interacción entre las condiciones del ambiente circundante y de los simbiontes. La composición de las comunidades revelaron un efecto significativo de la zona (Tabla 4.4) y una fuerte influencia de la textura del suelo (Figura 4.5b). En efecto, las comunidades de raíces de la zona Agrícola estuvieron asociadas a suelos arcillosos, ricos en $\mathrm{C}$ y agua; lo que les permitió contar con una comunidad que difirió de cualquier otra de este estudio (Figura 4.5b, Tabla 4.4). Por otro lado, las comunidades de la zona de Sierras estuvieron asociadas a la densidad de plantas y no difirieron de las halladas en la zona Mixta (Figura 4.5b, Tabla 
4.4). Entre los potenciales causantes del ensamblaje de las comunidades, la intensidad del manejo agrícola se ha citado como generador de anidamiento de las comunidades (Verbruggen et al., 2012). Este concepto es muy utilizado para describir un patrón de ensamblaje no aleatorio de las especies. Aunque Verbruggen et al. (2012) y Vályi et al. (2014) encontraron que la causa del anidamiento era la pérdida de especies debido a las prácticas de manejo y la intensidad de manejo del suelo, respectivamente; en este estudio la riqueza se mantuvo estable entre las zonas (Figura 4.3). Entonces, las diferencias en abundancia de los taxa sería la causa del ensamblaje diferencial de las comunidades de HFMA dentro de las raíces. Chappin et al., (2000) enfatiza la importancia del estudio de la abundancia de las especies debido a que responde más rápidamente a las actividades del hombre que los cambios en la riqueza de especies, y porque tiene importantes consecuencias en el ecosistema mucho antes que una especie desaparezca. En este estudio, los sitios Agrícolas fueron los de mayor historial bajo prácticas antropogénicas, las cuales en los últimos años se focalizaron en priorizar el rendimiento de la soja mediante el uso de pesticidas y fertilizantes. Druille et al. (2013ab; 2015) demostraron que el glifosato afecta la viabilidad de las esporas y la colonización micorrícica, y hay cuantiosa información sobre el efecto de la fertilización sobre la composición de las comunidades dentro de las raíces y la abundancia de especies (Camenzind et al., 2014, Beauregard et al., 2013; Liu et al., 2015). En consecuencia, ante un mayor historial sojero sería esperable que ciertos taxa desarrollen habilidades competitivas para colonizar las raíces dando como resultado una comunidad que no sólo fue diferente a cualquier otra en este estudio (Figura 4.5b), sino que también difirió a la hallada en el suelo Agrícola (Figura 4.6a, Tabla 4.4).

Finalmente, como en las comunidades del suelo, la relación entre la textura y la humedad también podría ser el factor estructurante de la comunidad micorrícica de las raíces (Figura 4.5b). En este estudio, los suelos mostraron un generalizado bajo contenido de humedad, y es sabido que el agua del suelo tiene consecuencias sobre ambos simbiontes. En primer lugar, la sequía genera respuestas fisiológicas en la planta que pueden afectar la simbiosis micorrícica (Augé, 2001). Además, el proceso de germinación de las esporas y la infección de raíces es altamente afectado por el agua del suelo (Tommerup, 1984). Entonces, de acuerdo a la estrategia de colonización que posean, algunas especies pueden ser más afectadas que otras (Hart y Reader, 2002). Por ejemplo, Glomeraceae coloniza intensamente las raíces a 
partir de las hifas, mientras que la colonización de Gigasporaceae recae sobre la germinación de las esporas ya que sus hifas no son infectivas (Biermann y Linderman, 1983). Más aún, la variación en el contenido de agua del suelo afecta fuertemente tanto la duración como el éxito de la germinación de esporas en suelos arenosos (Tommerup, 1984), especialmente en Gigasporaceae (Koske, 1981). En consecuencia, la interacción entre dichos factores podría explicar las diferencias en la composición de las comunidades de Glomeromycota dentro de las raíces de soja en respuesta a la textura del suelo.

El uso de técnicas de secuenciación de última generación es una herramienta poderosa para la identificación de hongos a partir de muestras ambientales con una alta resolución. Sin embargo, Peay (2014) propone encarar un enfoque intensivo de la ecología fúngica y no solo estudios basados en su composición taxonómica molecular. Esto significa entender más detalladamente la biología de algunas especies consideradas importantes. Aunque el término "importante" puede ser subjetivo, en este estudio, la elevada abundancia relativa de los taxa VT113 y VT39 se empleó como criterio para considerarlos taxa importantes y discutir su relevancia en el agroecosistema sobre la base de su ecología. Glomus VT113 incluye Glomus fasciculatum y taxa relacionados, y es uno de los taxa más ubicuos de planeta (Öpik, et al., 2006, 2010; Moora et al., 2011). Gigaspora VT39 también está muy distribuido geográficamente e incluye G. albida, G. decipiens, G. gigantea, G. margarita (Öpik et al., 2010). En contraste con Glomus VT113 el cual es reportado comúnmente en suelos antropogénicos, Gigaspora VT39 usualmente es relacionado con ambientes sin disturbar y es prácticamente no detectado en suelos bajo el uso del hombre (ej. Brito et al., 2012; Hiiesalu et al., 2014; Vályi et al., 2014). Interesantemente, en este estudio ambos taxa se hallaron con la misma abundancia. Esto revela que las prácticas agronómicas asociadas con el cultivo de soja generaron un hábitat favorable para Gigasporaceae. Posiblemente, los siguientes factores serían los mayores causantes de este hecho: a) el uso generalizado de la siembra directa, y b) la selección de la soja por miembros de Gigasporaceae. Como se mencionó anteriormente, las esporas representan un propágulo clave para Gigasporaceae ya que las hifas no son infectivas (Biermann y Linderman, 1983). En ausencia de disrupción del suelo por las prácticas de siembra directa, las esporas formadas durante un ciclo de cultivo permanecen en la misma zona donde fueron formadas, protegidas de la exposición ambiental. De este modo, están ubicadas estratégicamente para el contacto con las nuevas 
raíces del cultivo del año siguiente. Más aún, las prácticas asociadas a la siembra directa promueven una mejor conservación del agua del suelo lo cual también es favorable para la germinación de esporas (Koske, 1981; Tommerup, 1984).

Por otro lado, la selección preferencial por Gigasporaceae ejercida por las plantas de soja ha sido propuesta anteriormente por Higo et al. (2013), y los resultados de este capítulo lo corroboraron. Schenck y Kinloch (1980) compararon diferentes monocultivos y hallaron que las esporas de G. margarita, G. gregaria y G. gigantea fueron las más abundantes bajo monocultivo de soja. Años después, en los 90's, varios estudios reportaron la presencia de Gigaspora spp. en campos de soja (An et al., 1993; Hendrix et al., 1995; Saito y Vargas, 1991; Johnson et al., 1991). Más recientemente, con el avance las técnicas de secuenciación de última generación, se confirmaron los patrones mencionados tanto en muestras de suelo como de raíces de soja (Beauregard et al., 2013; Cheng et al., 2013; Higo et al., 2013, 2014, 2015). Entonces, aunque la presencia de VT39 debería haber sido prevista en nuestras muestras, queda por dilucidar las causas y posibles consecuencias de su elevada abundancia en los lotes de soja del área en estudio.

La simultanea gran abundancia de VT113 y VT39 implica ventajas ecológicas para las plantas de soja. Las especies de HFMA relacionadas a ambos taxa difieren fuertemente en sus atributos funcionales. Glomeraceae coloniza más intensamente las raíces que el suelo, mientras que Gigasporaceae coloniza más intensamente el suelo que la raíz (Hart y Reader, 2002). Estos patrones de crecimiento implican beneficios para las plantas. La extensiva colonización extra-radical del micelio avanzando más allá de la zona de agotamiento de la raíz contribuye a la nutrición fosforada, mientras que el micelio interno brinda protección contra patógenos (Maherali y Klironomos, 2007). En este estudio, la elevada abundancia relativa de VT39 en el suelo comparada con la hallada dentro de la raíz es coincidente con el patrón de crecimiento previsto para Gigasporaceae, especialmente en suelos de la zona Agrícola donde se encontraron los menores niveles de P del suelo (Figura 4.7, Tabla 4.1). Tal como postula Rosendahl (2008): "el ser raro o común depende del hábitat...", aquí se puede deducir que mientras que Glomus VT113 es definitivamente muy común en suelos agrícolas, Gigaspora VT39 no parece ser una especie rara en suelos bajo cultivo de soja.

Se identificaron un total de 25 taxa indicadores en este estudio. Se encontró que 3 de los nuevos VT fueron indicadores de los suelos de la zona Agrícola: Glomeraceae INTA_4; 
Gigasporaceae INTA_2 y Archaeosporaceae INTA_7 (Tabla 4.5). La distribución de estos taxa entre 3 familias distintas de Glomeromycota revela un aspecto positivo para el mantenimiento de la diversidad. Los taxa indicadores de las raíces de la zona Agrícola correspondieron exclusivamente a Glomeraceae y fueron especies ampliamente distribuidas de HFMA. Se halló en la base de datos MaarjAM que el taxa VT63 es más frecuente en suelos antropogénicos que los VT172 y VT140, los cuales son reportados principalmente en pastizales y bosques. El VT310 no había sido citado aún en Argentina, Alguacil et al. (2014) lo reportó en huertos de Venezuela y ese fue el único antecedente en Sudamérica. La zona de Sierras estuvo caracterizada por un gran número de especies indicadoras, las cuales pertenecieron a 4 familias de HFMA: Acaulosporaceae, Diversisporaceae, Gigasporaceae y Glomeraceae. De acuerdo a la base de datos MaarjAM, este es el primer reporte en Sudamérica de los taxa de Diversisporaceae VT 54, 60, 61, 380, y Gigasporaceae VT318. Por otro lado, encontrar el taxa Glomeraceae VT67 dentro de los indicadores de la zona de Sierras fue inesperado. De acuerdo a MaarjAM, VT67 está relacionado con Funneliformis mosseae, una especie hallada comúnmente en suelo arados (Helgason et al., 1998). Es posible que la disrupción del suelo producto de la reciente deforestación haya generado un ambiente más propicio para esta especie. En oposición, la historia en siembra directa de las zonas Agrícolas y Mixta aparenta ser menos favorables para VT67. Por último, los taxa indicadores de la zona Mixta pertenecieron en su totalidad a Glomeraceae y todos ellos ya habían sido citados en Argentina en pastizales y bosques (Davison et al., 2015).

\subsection{CONCLUSIONES}

En este capítulo se identificaron un total de 94 taxa de Glomeromycota en muestras de suelo rizosférico y raíces de soja, de los cuales 13 taxa eran inéditos. De acuerdo a las hipótesis planteadas al inicio del capítulo se concluye que:

H1- No se rechaza la primera hipótesis. La composición de las comunidades de HFMA del suelo difirió entre las zonas en estudio y tuvo una gran correlación con las variables de 
edáficas, en especial la textura. La zona Mixta mostró una composición estadísticamente diferente a la observada en las zonas Agrícola y de Sierras, las cuales no difirieron entre sí. H2- No se rechaza la segunda hipótesis. La comunidad de HFMA hallada en la zona Agrícola, la de mayor historial de cultivo de soja, fue diferente a las del resto de las zonas en estudio. Posiblemente esto se deba a cierta adaptación del hongo a las prácticas agronómicas inherentes a la producción de la leguminosa.

H3- No se rechaza la tercera hipótesis. Se identificó gran abundancia de los taxa Glomus VT113 y Gigaspora VT39 los cuales están ligados a atributos funcionales complementarios. Las 3 zonas estudiadas pudieron ser definidas a través de un total de 25 taxa indicadores. Cabe destacar que los suelos de la zona Agrícola se caracterizaron por 3 de los nuevos taxa hallados en esta tesis. 
CAPITULO 5

EFECTO DE MICORRIZAS NATIVAS SOBRE LA NUTRICIÓN FOSFORADA Y PARTICION DE FOTOASIMILADOS DE SOJA 


\subsection{INTRODUCCIÓN}

El fósforo $(P)$ es un macronutriente esencial que constituye el $0,2 \%$ del peso seco de una planta (Schachtman et al., 1998). Aunque es abundante en los suelos, su fuerte carga iónica negativa hace que sea fácilmente retenido por cationes tales como el hierro (Fe), aluminio (Al) y calcio (Ca) o complejos orgánicos (Marschner, 1994). Sin embargo, la única forma en que puede ser absorbido por las raíces es como ion ortofosfato $\left(\mathrm{H}_{2} \mathrm{PO}_{4}{ }^{-}\right)$. Es por esto que a pesar que la planta lo requiere en grandes cantidades su concentración en la solución de suelo es ínfima y varía en un rango de 1-10 $\mu \mathrm{M}$ (Marschner, 1994). La baja disponibilidad de este nutriente en el suelo ha llevado a que las plantas desarrollen diversas estrategias para sortear su escasez. Una de las más importantes y distribuidas en los ecosistemas es la formación de simbiosis con hongos formadores de micorrizas arbusculares (HFMA).

Se ha demostrado que el influjo de $\mathrm{P}$ en raíces con micorrizas puede ser 3 a 5 veces mayor que en plantas no micorrizadas (Smith y Read, 2010). Las hifas extra radicales, al crecer más allá del suelo no colonizado por raíces, pueden acceder a $\mathrm{P}$ de la solución de suelo fuera de la zona de agotamiento de la rizósfera y transferirlo a la raíz (Munkvold, et al., 2004). Este proceso permite una difusión más rápida del $\mathrm{P}$ a través de la matriz edáfica. Según Tinker (1975), por unidad de longitud, la producción de hifas demanda menos carbono (C) para la planta que producir raíces y, además, su reducido diámetro les permite acceder a poros de menor tamaño que los pelos radicales, aumentando efectivamente el volumen de suelo explorado por la planta. Además, la rápida proliferación de hifas le permite acceder a nuevos parches ricos en $\mathrm{P}$ en un tiempo menor que el que necesitaría una planta para generar raíces en esa zona. Un segundo mecanismo de importancia en la nutrición fosforada mediada por los HFMA, es que las hifas tienen un menor $\mathrm{K}_{\mathrm{m}}$ que las raíces, por lo que pueden tomar $\mathrm{Pa}$ menores concentraciones en la solución de suelo (Schachtman et al., 1998). Por último, el tercer mecanismo consiste en la habilidad del hongo en aprovechar formas de P del suelo que no son accesibles para la raíz. Esto puede implicar la solubilización de $\mathrm{P}$ inorgánico o la hidrólisis de $\mathrm{P}$ orgánico a través de modificaciones localizadas de $\mathrm{pH}$, producción de aniones orgánicos y fosfatasas (Smith y Read, 2010). Gracias al conjunto de estos mecanismos, las hifas transfieren $\mathrm{P}$ a las células radicales en forma de polifosfatos que luego son depolimerizados en la raíz y distribuidos a toda la planta (Ezawa et al., 2002; Smith et al., 2003). 
Los HFMA son completamente dependientes de su huésped para cubrir los requerimientos de $\mathrm{C}$ y no pueden completar su ciclo vital sin una planta (Smith y Read, 2010). Las células corticales de la raíz liberan azúcares al apoplasto, los cuales son hidrolizados y tomados por el hongo (Schüßler et al., 2006). Una vez en la estructura fúngica, el C es incorporado en lípidos y transportado a través del micelio (Pfeffer et al., 1999; Bago et al., 2002). Los lípidos son metabolizados y representan la principal fuente de C para el mantenimiento y extensión de micelio extraradical en el suelo (Bago et al., 2000; Douds et al., 2000). La demanda de C del hongo constituye un gran destino de fotoasimilados. La relación entre el costo de la simbiosis micorrícica y su beneficio determinará respuestas positivas o negativas en la planta.

En sistemas antrópicos, se ha observado que en ciertas condiciones los HFMA pueden promover mermas en el crecimiento y rendimiento de cultivos (Bever et. al. 2002, Johnson et al., 1992a; Johnson, 2009). Bethlenfalvay et al., (1983) demostraron que la respuesta de la planta depende de la composición de la comunidad de HFMA del suelo y su interacción con el huésped. Ciertas prácticas agrícolas pueden favorecer el predominio de hongos menos mutualistas que priorizan la producción de estructuras de reserva, tales como vesículas, en lugar de la generación de hifas absorbentes (Powell et al., 2009). Además, los sitios de colonización radical pueden alojar HFMA que no son metabólicamente activos desde el punto de vista nutricional (Abdel-Fatah, 2001; Smith y Read, 2010). En los sistemas agrícolas actuales, los beneficios atribuidos a los HFMA son puestos a prueba por diversos factores. Por ejemplo, la existencia de cultivares seleccionados en ambientes de alta productividad (Verbruggen y Kiers, 2010), y prácticas poco sustentables, como el monocultivo, que pueden favorecer a especies de HFMA más infectivas en detrimento de otras más mutualistas (Fester y Sawers, 2011). En consecuencia, los agroecosistemas podrían estar desaprovechando los beneficios de la simbiosis micorrícica (Kiers y Denison, 2014).

El objetivo general de este capítulo fue estudiar el efecto de HFMA autóctonos y la oferta de P sobre el crecimiento y partición de fotoasimilados de plantas de soja. Para ello se realizó un experimento en macetas con suelo de 40 años de historial de monocultivo de soja sin fertilización y se compararon dos niveles de oferta de $\mathrm{P}$ en presencia o ausencia de HFMA. Los objetivos específicos fueron: 
1) Medir niveles de colonización intra-radical (porcentaje y viabilidad de estructuras micorrícias) y extra-radical (longitud de hifas en el suelo).

2) Cuantificar variables de respuesta de la planta de soja relacionadas a la acumulación de biomasa y nutrición fosforada.

3) Cuantificar variables relacionadas a la partición de azúcares en tejidos foliares y radicales de la planta de soja.

Se pusieron a prueba las siguientes hipótesis:

1) Los mayores niveles de colonización micorrícica intra y extra-radical se hallarán en la situación de baja oferta fosforada del sustrato.

2) La simbiosis micorrícica mejorará las variables de respuesta evaluadas en comparación con las plantas sin micorrizas, especialmente en la situación de baja oferta fosforada del sustrato.

3) La partición de azúcares en tejidos foliares y radicales de las plantas de soja será afectada tanto por la oferta fosforada del sustrato como por la presencia de micorrizas. 


\subsection{MATERIALES Y METODOS}

\section{Descripción del suelo}

El experimento en macetas se llevó a cabo con suelo de un ensayo a campo iniciado en 1975 en la Estación Experimental Agropecuaria del Instituto Nacional de Tecnología Agropecuaria (INTA) de Marcos Juárez, Provincia de Córdoba (Argentina, $32^{\circ} 43^{\prime} \mathrm{S} .62^{\circ} 06^{\prime} \mathrm{O}$ ). El suelo es un Argiudol típico, profundo, franco arcillo limoso de capacidad de uso I (INTA, 1978). El experimento posee un diseño en bloques completamente aleatorizado con 4 repeticiones. Para este estudio se escogieron las parcelas mantenidas bajo monocultivo de soja en siembra directa, sin fertilización desde el inicio del experimento, para que constituyeran la fuente de inóculo micorrícico en las macetas. Se seleccionó este suelo ya que la comunidad nativa de HFMA es resultado de 40 años de experimentación y constituye un inóculo de historial conocido, adaptado a las condiciones de baja oferta nutricional y a la posible selección impuesta por el hospedante. Al momento del muestreo se identificaron las esporas siguiendo la metodología descripta en el Capítulo 2 y se hallaron las siguientes especies: Acaulospora mellea (Schenk); Acaulospora scrobiculata (Trappe); Claroideoglomus etunicatum (Becker y Gerdemann) Schußler y Walker, 2010) y Rhizophagus intraradices (Schenk y Smith) Schußler y Walker).

\section{Diseño del experimento}

Para estudiar el efecto de la simbiosis micorrícica y $\mathrm{P}$ disponible sobre el crecimiento y partición de fotoasimilados de plantas de soja se evaluaron 2 tratamientos, con 2 niveles cada uno: HFMA (+HFMA y -HFMA) y fertilización fosforada (+P y -P). La fuente de inóculo de HFMA fue el suelo extraído del experimento de campo descripto anteriormente. La recolección se realizó a fines de septiembre de 2015, previo a la siembra del cultivo de soja. Se muestrearon $0-10 \mathrm{~cm}$ superficiales con barreno de $7,5 \mathrm{~cm}$ de diámetro, un total de 20 puntos por parcela, distribuidos al azar y luego se unificaron. El suelo se tamizó por $5 \mathrm{~mm}$ de malla y se conservó a -5ํㅡ hasta la realización del experimento.

La preparación del tratamiento -HFMA demanda metodologías que no afecten las propiedades del suelo, en especial la movilización de nutrientes (Endlweber y Scheu, 2006). 
En este sentido, la erradicación de propágulos micorrícicos autóctonos se realizó mediante la incubación del suelo fresco con una dosis de $10 \mu \mathrm{g} \mathrm{g}^{-1}$ de formaldehido (CAS 50-00-0) de acuerdo a lo propuesto por Covacevich y Echeverría (2003). El procedimiento se llevó a cabo en bolsas de polietileno con $200 \mathrm{~g}$ de suelo fresco, suministrando de manera uniforme una solución $5 \%(\mathrm{v} / \mathrm{v})$ de formaldehido y agua destilada hasta alcanzar la dosis requerida. Se mezcló la solución con el suelo, luego las bolsas se cerraron herméticamente y se mantuvieron en oscuridad a $25^{\circ} \mathrm{C}$ durante $48 \mathrm{hs}$. Finalizado ese lapso de tiempo, se airearon a temperatura ambiente durante 48 hs en capas de suelo no mayores a $1 \mathrm{~cm}$ de espesor sobre bandejas plásticas. Para lograr una eliminación completa de los gases de formaldehido luego del aireado, las muestras se distribuyeron en volúmenes de $50 \mathrm{~g}$ en frascos de vidrio de 500 cc y se sometieron a 5 ciclos de vacío y recirculación de aire (Jenkinson y Powlson, 1976). Un experimento preliminar demostró que esta técnica permite utilizar el suelo inmediatamente sin afectar el crecimiento de las plantas de soja ni la formación de nódulos de Bradyrhizobium japonicum. Por último, se separaron 4 sub-muestras de suelo con y sin tratamiento de eliminación de HFMA para realizar análisis químicos (Tabla 5.1)

Tabla 5.1: Propiedades químicas del suelo antes (+HFMA) y después (-HFMA) del tratamiento con formaldehido ( \pm Error Estándar)

\begin{tabular}{llrr}
\hline Propiedad & \multicolumn{2}{c}{ + HFMA } & \multicolumn{1}{c}{ - HFMA } \\
\hline P & $m g k g^{-1}$ & $23,8( \pm 0,26)$ & $23,3( \pm 0,64)$ \\
C & $\%$ & $3,3( \pm 0,16)$ & $3,8( \pm 0,36)$ \\
$\mathrm{pH}$ & & $6,1( \pm 0,06)$ & $6,6( \pm 0,10)$ \\
\hline
\end{tabular}

Los resultados corresponden a una profundidad de muestreo 0-10 cm. Se identificaron como +HFMA y -HFMA a las muestras de suelo sin y con tratamiento de formaldehído, respectivamente.

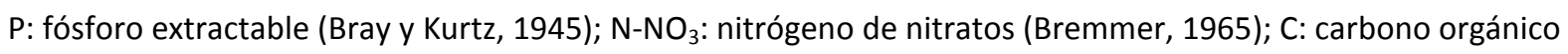
(Walkley y Black, 1934); $\mathrm{pH}$ : relación suelo:agua 1:2,5

Ensayos preliminares demostraron que la naturaleza arcillo-limosa de este tipo de suelo (80\% arcilla y limo, INTA 1978), al ser tamizado impide una adecuada circulación del agua y del aire, dificultando el normal crecimiento de la planta. Es por esto que debió recurrirse a la dilución del suelo con otro material que favorezca dichos procesos. Se utilizó arena fina de río previamente enjuagada con agua destilada y tamizada en húmedo por malla de $250 \mu \mathrm{m}$. 
Debido a la importancia de la oferta de P y reacción del sustrato para el objetivo en estudio, se midió el P extractable (Bray y Kurtz, 1945) y pH de la arena $(1: 2,5$ p/v) luego del lavado. Se detectó un nivel de P igual a $2( \pm 0,5) \mathrm{mgP} \mathrm{kg}^{-1}$ y $\mathrm{pH} 8( \pm 0,01)$. En base a estos resultados se decidió lavar la arena con una solución $0,5 \mathrm{M} \mathrm{Cl}_{2} \mathrm{Ca}$ para extraer el $\mathrm{P}$ y disminuir el pH, luego se enjuagó con agua destilada hasta obtener un líquido de percolación transparente y pH 6,5 constante. Para este proceso la arena se colocó en recipientes de 1000 cc, con perforaciones en la base a través de las cuales se recolectó el fluido de percolación. Finalizado el lavado, la arena se secó en estufa de ventilación forzada a 65 으 y se repitieron los análisis, no detectándose trazas de $\mathrm{P}$ (Bray y Kurtz, 1945) ni cambios en el pH. La perlita se enjuagó con agua destilada, no se halló $\mathrm{P}$ ni reacción iónica para la determinación de pH (el pH medido era igual al del agua destilada de la relación 1:2,5). Por último, la arena y perlita secas se tindalizaron en autoclave a $121^{\circ} \mathrm{C}$ durante 1 h, 2 ciclos cada 48 hs. Previo a su uso se verificó si mantenían el $\mathrm{P}$ y $\mathrm{pH}$ medidos antes del tratamiento de calor. Al confirmarlo, se utilizaron inmediatamente para la preparación del ensayo. El experimento se realizó en macetas de 1000 cc siguiendo un diseño completamente aleatorizado con 8 repeticiones. Cada recipiente se rellenó de la siguiente manera:

- Superficie: $100 \mathrm{~g}$ de arena

- Medio: $555 \mathrm{~g}$ de una mezcla homogénea de $500 \mathrm{~g}$ arena, 50 g suelo, 5 g perlita

- Fondo: $100 \mathrm{~g}$ de una mezcla homogénea de $90 \mathrm{~g}$ arena y $10 \mathrm{~g}$ perlita

La mezcla de la porción corresponde el sustrato que definió los tratamientos +HFMA y HFMA según si correspondía al suelo fresco sin o con eliminación de propágulos micorrícicos, respectivamente. La dilución con arena permitió exacerbar la deficiencia fosforada de los tratamientos $-\mathrm{P}$, una medición realizada arrojó resultados de 8,7 a 10,2 $\mathrm{mgP} \mathrm{kg}^{-1}$. Finalizada la preparación, las macetas se regaron con 150 cc de agua destilada, ya que era el volumen necesario para llegar a la máxima capacidad de retención de agua de la maceta según estudios preliminares.

Para el tratamiento de fertilización fosforada (+P) se aplicaron 15,5 $\mathrm{mgP}_{\text {maceta }}{ }^{-1}$ con una solución $10 \mathrm{mM}$ de $\mathrm{K}_{2} \mathrm{PO}_{4}$ (Cassman, 1980). Las macetas $+\mathrm{P}$ recibieron un riego inicial con 50 cc de dicha solución, mientras que las de -P se regaron con 50 cc de agua destilada. 
Las semillas de soja (Glycine max (L) Merr. cv NS-4611) previamente desinfectadas con una solución $10 \%$ de $\mathrm{H}_{2} \mathrm{O}_{2}$ y enjuagadas con agua destilada, se pre-germinaron en arena estéril a 25C C durante 10 días. Se seleccionaron plántulas de tamaño uniforme y se colocó una por maceta. En ese momento, se extrajeron los cotiledones para promover la actividad de absorción de la raíz, según las recomendaciones de investigadores del Instituto de Fisiología y Recursos Genéticos Vegetales de INTA (Dr. Ramiro Lascano 2015, comunicación personal).

Con la finalidad de aportar componentes de la microbiota nativa del suelo en el tratamiento -HFMA, se preparó un extracto $75 \%(p / v)$ de suelo fresco con agua destilada que fue filtrado a través de poros de $2,5 \mu \mathrm{m}$ de diámetro (Whatman 589/3) con ayuda de una bomba de vacío. Dicha apertura de malla no permite el pasaje de estructuras de HFMA pero sí de bacterias fijadoras de $\mathrm{N}$ y otros microorganismos (Coyne, 1999). Al momento del trasplante, se aplicaron $2 \mathrm{ml}$ del extracto sobre las radículas de soja.

Los riegos se realizaron periódicamente con agua destilada según la pérdida de peso de las macetas. El contenido hídrico de mantuvo constante, igual al peso registrado al inicio del experimento. Semanalmente se repitió la fertilización con $\mathrm{P}$ en el tratamiento $+\mathrm{P}$. El $\mathrm{N}$ se suministró semanalmente con $50 \mathrm{ml}$ de $15 \mathrm{mM} \mathrm{ClNH}_{4}$ ya que se decidió no realizar inoculación con bacterias fijadoras de N (Cassman, 1980). Se ha reportado que la ausencia de micorrizas se correlaciona fuertemente con la nodulación de soja y se podría haber interferido indirectamente en la nutrición nitrogenada (Ossler et al., 2015). Debido a la escasa cantidad de suelo y para evitar posibles deficiencias nutricionales, todas las macetas se fertilizaron cada 10 días con $50 \mathrm{ml}$ de solución de macronutrientes: $1 \mathrm{mM} \mathrm{CaCl} 2.2 \mathrm{H}_{2} \mathrm{O}$; 0,75 mM MgSO $\mathrm{mM}_{4} \mathrm{H} \mathrm{H}_{2}$ 0,5 $\mathrm{mM} \mathrm{K}_{2} \mathrm{SO}_{4}$; y $50 \mathrm{ml}$ de solución de micronutrientes $10 \mu \mathrm{M} \mathrm{H}_{3} \mathrm{BO}_{3}$; $4 \mu \mathrm{M} \mathrm{FeSO}$. $7 \mathrm{H}_{2} \mathrm{O} ; 2 \mu \mathrm{M} \mathrm{MnSO}{ }_{4} \cdot \mathrm{H}_{2} \mathrm{O} ; 1 \mu \mathrm{M} \mathrm{KI} ; 0,5 \mu \mathrm{M} \mathrm{CuSO}_{4} .5 \mathrm{H} 2 \mathrm{O} ; 0,1 \mu \mathrm{M} \mathrm{NaMoO} \cdot 2 \mathrm{H}_{2} \mathrm{O}$; $0,2 \mu \mathrm{M} \mathrm{CoCl}_{2} \cdot 6 \mathrm{H}_{2} \mathrm{O}$ (Cassman, 1980).

El experimento se mantuvo por 60 días en invernáculo, bajo luz natural durante los meses de octubre y noviembre 2015 , a 25 으 $( \pm 5$ 으), a humedad relativa ambiente. 


\section{Determinaciones}

La totalidad de las mediciones se realizaron a la finalización del experimento. Para llevarlas a cabo, 4 de las repeticiones se destinaron únicamente a la cuantificación de biomasa vegetal y concentración de $P$, mientras que las restantes se emplearon para las mediciones en raíces y tejidos foliares que implicaban la destrucción de las muestras.

\section{- Porcentaje de micorrización}

El porcentaje de hifas, vesículas y arbúsculos se midió de acuerdo a lo descripto en el Capítulo 2. No se hallaron estructuras micorrícicas en el tratamiento-HFMA.

\section{- Viabilidad de estructuras micorrícicas radicales}

El test de viabilidad se basa en la actividad de la enzima succinato deshidrogenasa por deposición de púrpura de formazán luego de la reducción del azul de tetrazolio en presencia de succinato (Kough et al., 1987). La solución de incubación se preparó como se detalla a continuación: $1 \mathrm{ml}$ de 2,5 M succinato disódico (CAS 6106-21-4); 2,5 ml de solución (4 $\mathrm{mg} \mathrm{ml}^{-}$

${ }^{1}$ ) de azul-nitro-tetrazolio cloruro (CAS 298-83-9); 2,5 ml Tris- $\mathrm{HCl}(0,2 \mathrm{M}, \mathrm{pH}$ ); $1 \mathrm{ml}$ de $5 \mathrm{mM}$ $\mathrm{Cl}_{2} \mathrm{Mg}$ y $3 \mathrm{ml}$ de agua destilada. Las raíces de soja al momento de la finalización del experimento, se lavaron y cortaron en fragmentos de $0,5 \mathrm{~cm}$ de largo. Un total de $0,5 \mathrm{~g}$ se incubó en $2 \mathrm{ml}$ de la solución anterior durante 16 hs. Luego se eliminó la solución incubadora, se añadió 75\% (p/v) hidrato de cloral (CAS 302-17-0) y se llevó a ebullición en baño termostático durante 15 minutos. Por último, se descartó dicha solución y las raíces se cubrieron con 0,01\% (p/v) fucsina ácida (CAS 3244-88-0) diluida en ácido láctico (598-82-3) y se incubaron a $90 \circ \mathrm{C}$ durante 10 minutos. Finalizada la tinción, las muestras se enjuagaron en agua destilada y se conservaron en ácido láctico hasta la cuantificación. Las raíces se montaron en portaobjeto y se realizó el recuento en microscopio óptico con aumento 50X en 90 intercepciones por muestra. Para referirse a esta variable, a lo largo de esta tesis se mencionará viabilidad y actividad como sinónimos.

\section{- Longitud de hifas extra radicales}

El nivel de colonización del sustrato por HFMA se determinó midiendo la longitud de las hifas extra radicales extraídas de la porción media de la maceta. La metodología descripta a continuación se adaptó de Hart y Reader (2002). Se pesaron 10 g de sustrato y se 
suspendieron en $250 \mathrm{ml}$ de 3,6\% (p/v) hexametafosfato de sodio (CAS 68915-31-1) durante 16 h para la dispersión del sustrato. Posteriormente, la suspensión se homogeneizó en agitador magnético durante 2 minutos y se extrajeron alícuotas de $10 \mathrm{ml}$ de cada muestra. Luego se diluyeron en $250 \mathrm{ml}$ de agua, se mezclaron en agitador magnético, se tomaron alícuotas de $10 \mathrm{ml}$ y se centrifugaron durante 5 minutos a $1000 \mathrm{xg}$. Se descartó el sobrenadante, se suspendió el pellet en $5 \mathrm{ml}$ glicerol (CAS 56-81-5) y se centrifugó nuevamente a 75 xg durante 30 segundos. El sobrenadante se tiñó siguiendo la metodología descripta para las raíces en el Capítulo 2. Por último, cada muestra se decantó en filtros de jeringas de $13 \mathrm{~mm}$ de diámetro y 0,45 mm de malla (AC Whatman GD/X) los cuales se enjuagaron con agua destilada, se montaron en portaobjetos y se dejaron secar a temperatura ambiente. Previo a la cuantificación se les aplicó aceite de inmersión para que las estructuras se pudieran visualizar claramente. La presencia o ausencia de hifas se midió en 100 intercepciones en microscopio óptico a 50X. La longitud de hifas por gramo de sustrato se calculó según la Ecuación 1 (Newman, 1966).

$$
H=\frac{\pi * N * A}{2 * L}
$$

Ecuación 1

Dónde: $\mathrm{H}$ es la longitud de hifas $(\mathrm{mm}), \mathrm{N}$ es el número de intercepciones, $\mathrm{A}$ es el área del filtro, L es la longitud de la línea de intercepto del objetivo del microscopio. Luego H se dividió por la cantidad de sustrato empleado, se le descontó la humedad de la muestra y se multiplicó por los factores de dilución empleados para llegar al resultado final expresado en $\mathrm{mm} \mathrm{g}^{-1}$.

\section{- Crecimiento vegetal y concentración de P}

Al finalizar el experimento, se registró la altura de las plantas (órganos aéreos) y el peso fresco. Posteriormente, las plantas se secaron en estufa para cuantificar su peso seco y concentración de $\mathrm{P}$ siguiendo la metodología descripta en el Capítulo 2. Estas determinaciones se realizaron en órganos aéreos y radicales separadamente.

Adicionalmente, también se realizó el recuento y peso de nódulos de la raíz principal con la finalidad de corroborar la existencia de componentes de la biota del suelo en interacción con 
la planta de soja. La presencia de estos microorganismos, permitió evaluar la efectividad del extracto de suelo aplicado sobre las radículas en el tratamiento de suelo con erradicación de propágulos.

\section{- Concentración de azúcares solubles y almidón}

El contenido de azúcares solubles e insolubles (i.e. almidón) se determinó a partir de tejido vegetal fresco extraído de la planta al momento de finalizar el experimento. En tubos de 1,5 $\mathrm{ml}$ se pesaron por un lado $100 \mathrm{mg}$ de la primera hoja trifoliada completamente expandida, $\mathrm{y}$ $100 \mathrm{mg}$ de raíces en otro set de tubos. Las muestras se homogeneizaron en nitrógeno líquido con la ayuda de micro-pistilos y se conservaron a $-20^{\circ} \mathrm{C}$ hasta su posterior análisis. La metodología que se describe a continuación está basada en Leyva et al. (2008)

- Extracción de azúcares solubles: se realizó mediante el agregado de $1 \mathrm{ml}$ de $80 \%(\mathrm{v} / \mathrm{v})$ etanol 96 e e incubación durante 30 minutos a $80^{\circ} \mathrm{C}$. Luego, las muestras se dejaron enfriar a temperatura ambiente y se centrifugaron durante $10 \mathrm{~min}$ a una velocidad de $12000 \mathrm{xg}$ a 5으. El sobrenadante se transfirió a un tubo limpio y se prosiguió con la extracción de los azúcares insolubles del pellet.

- Extracción de azúcares insolubles: al pellet remanente del paso anterior se le agregó $1 \mathrm{ml}$ de 0,2 $\mathrm{N} \mathrm{H}_{2} \mathrm{SO}_{4}$, se homogeneizó con agitador vortex durante 30 segundos, y se incubó a 100 ㄷ C durante 30 minutos.

El proceso de análisis para la cuantificación de azúcares solubles e insolubles se realizó con diluciones de 1:100 de los extractos obtenidos. El reactivo empleado para este análisis fue 0,1\% antrona (CAS 90-44-8) diluido en $98 \% \mathrm{H}_{2} \mathrm{SO}_{4}$ (7664-93-9). Se agregaron $250 \mu \mathrm{l}$ de 0,1\% antrona a $750 \mu \mathrm{l}$ de las diluciones de cada muestra. Se refrigeraron 10 minutos a 4 으, y se llevaron a incubación durante 30 minutos a $80^{\circ} \mathrm{C}$. Para finalizar, se llevaron a temperatura ambiente durante 20 minutos y se midió la absorbancia a $620 \mathrm{~nm}$. Estos procedimientos se realizaron paralelamente sobre diluciones seriadas de glucosa para la confección de la curva de calibración.

\section{- Estimación de la dependencia micorrícica}

Con la finalidad de estimar el efecto de las micorrizas en ambas condiciones de nutrición fosforada, se estimó la dependencia micorrícica de la plantas de soja según la Ecuación 2 
(Plenchette et al., 1983). Las variables analizadas fueron la altura de plantas, biomasa y concentración de $\mathrm{P}$, y azúcares.

$$
\text { Dependencia micorrícica }(\%)=\frac{M-N M}{M} * 100
$$

Ecuación 2

Dónde: $M$ y NM se refiere a la variable vegetal medida con y sin micorrizas, respectivamente.

\section{Análisis estadísticos}

Se verificó previamente los supuestos de normalidad y homogeneidad de varianzas del set de datos mediante test de Shapiro-Wilks y gráfico de dispersión de residuales vs predichos; respectivamente. Los datos de porcentaje de micorrización, viabilidad de estructuras micorrícicas y dependencia micorrícica no cumplieron el supuesto de normalidad y por ello se transformaron mediante el cálculo del arcoseno de la raíz cuadrada de la variable expresada como proporción (Newsham, et al., 1995). En los gráficos se presentan las medias porcentuales para una mejor visualización. Una vez verificados los supuestos, los datos se analizaron estadísticamente mediante ANOVA con el fin de determinar los efectos de HFMA, P y la interacción HFMA*P. Cuando la interacción o alguno de los efectos individuales resultaron significativos $(p<0,05)$, las medias se compararon mediante test Tukey. Las mediciones relacionadas con la concentración y acumulación de P se compararon mediante contrastes ortogonales entre las medias de +HFMA y -HFMA dentro de cada situación de nutrición fosforada. Se recurrió a dicho análisis debido a la magnitud de las diferencias entre ambos niveles de P. Previamente se evaluaron posibles transformaciones de los datos pero no resultaron adecuadas para incluir todo el set de datos en un único test de comparación. Todos los análisis se realizaron con el software Infostat (Di Rienzo et al., 2014). 


\subsection{RESULTADOS}

\section{Micorrizas en soja}

\section{- Presencia y viabilidad}

La presencia de micorrizas en soja sólo se registró en +HFMA, mientras que el tratamiento de erradicación de propágulos con formaldehído eliminó completamente las estructuras propagativas de estos hongos. En la Figura 5.1a se presentan los porcentajes de micorrización de +HFMA en ambas situaciones de nutrición fosforada. Se registraron valores de hifas y arbúsculos en $-P$ que superaron significativamente a los hallados en $+P$. Los valores medios de hifas y arbúsculos fueron: $58,8 \%( \pm 4,8)$ y $57,2 \%( \pm 5,8)$ en $-P$, y $37,9 \%( \pm$ $2,4)$ y $36,2 \%( \pm 2,3)$ en $+P$, respectivamente. La presencia de vesículas, en cambio, fue similar en ambos tratamientos alcanzando un promedio de $18 \%( \pm 3,8)$ en $-P$ y $15,3 \%( \pm 2,9)$ en $+P$. La viabilidad de las estructuras micorrícicas mostró diferencias según la nutrición fosforada (Figura $5.1 \mathrm{~b})$. El $78 \%( \pm 4,2)$ de hifas y el $93 \%( \pm 6,3)$ de arbúsculos observados en $-\mathrm{P}$ presentaban actividad, mientras que en $+P$ los valores alcanzaron $32 \%( \pm 7,4)$ y $20 \%( \pm 7,1)$, respectivamente. También hubo diferencias en la actividad de las vesículas, con un $68 \%$ $( \pm 7,3)$ en $+P$ y $35 \%(6,5 \%)$ en $-P$. 

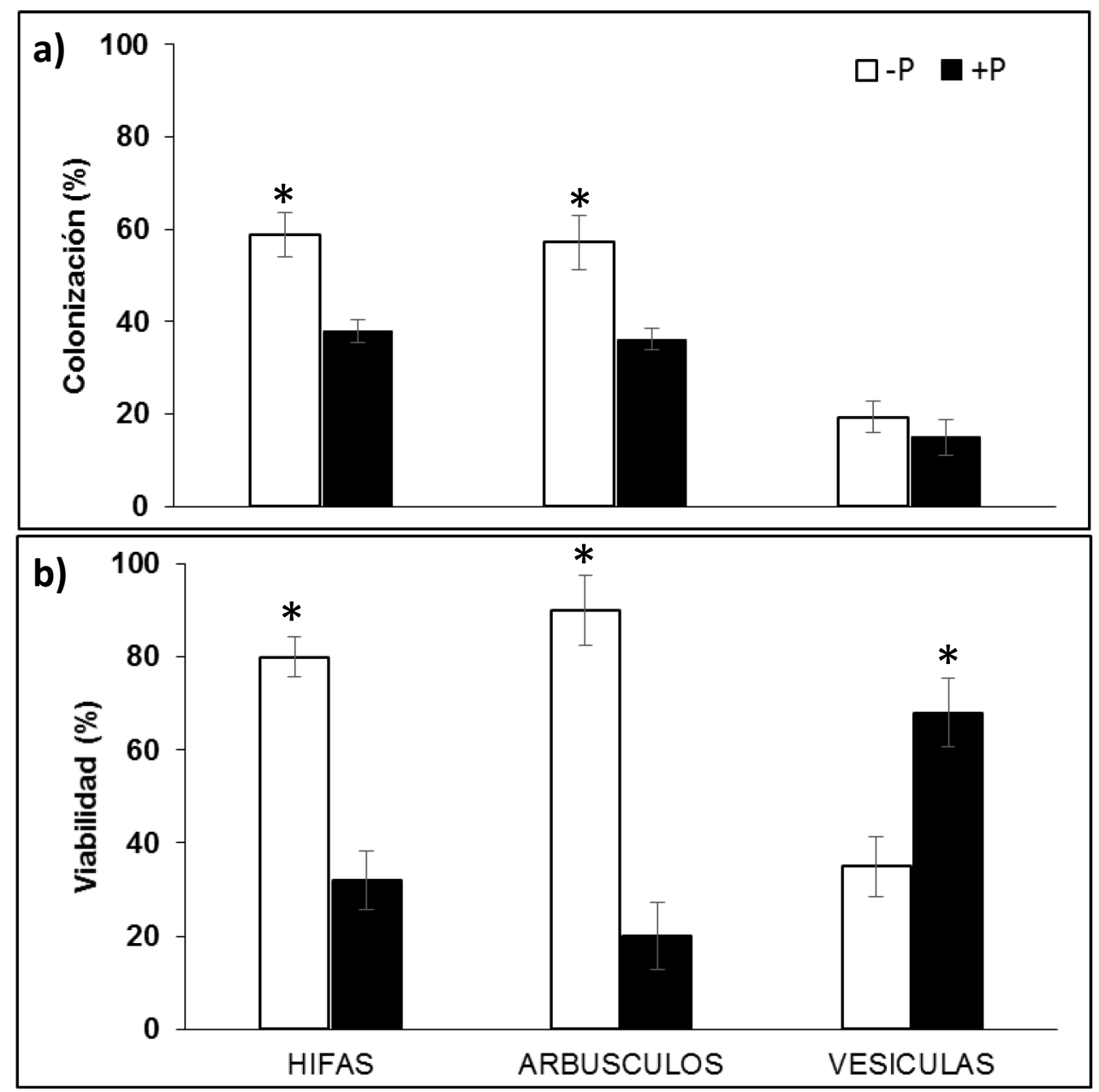

Figura 5.1: Porcentaje de colonización (a) y viabilidad (b) de hifas, arbúsculos y vesículas en raíces de soja a los 60 días de recibir dos niveles de oferta fosforada (-P y +P). Los resultados pertenecen al tratamiento +HFMA ya que no se hallaron estructuras micorrícicas en -HFMA. Las barras corresponden al error estándar $(n=4)$. El asterisco (*) representa diferencias estadísticamente significativas entre niveles de $P$ en cada estructura fúngica (Tukey $p<0,05$ ) 
- Longitud de hifas micorrícicas extra-radicales

La oferta de P afectó la colonización micorrícica del sustrato medida a través de la longitud de las hifas extra-radicales (Figura 5.2). La longitud en $-\mathrm{P}$ fue en promedio de $8,3 \mathrm{~mm} \mathrm{^{-1 }}$ $( \pm 1,25)$ y en $+P 3,2 \mathrm{~mm} \mathrm{~g}^{-1}( \pm 1,01)$. En comparación, esto representa un $60 \%$ más de exploración por unidad de masa de sustrato en $-P$ que en $+P$, para las condiciones en las que se llevó a cabo el experimento.

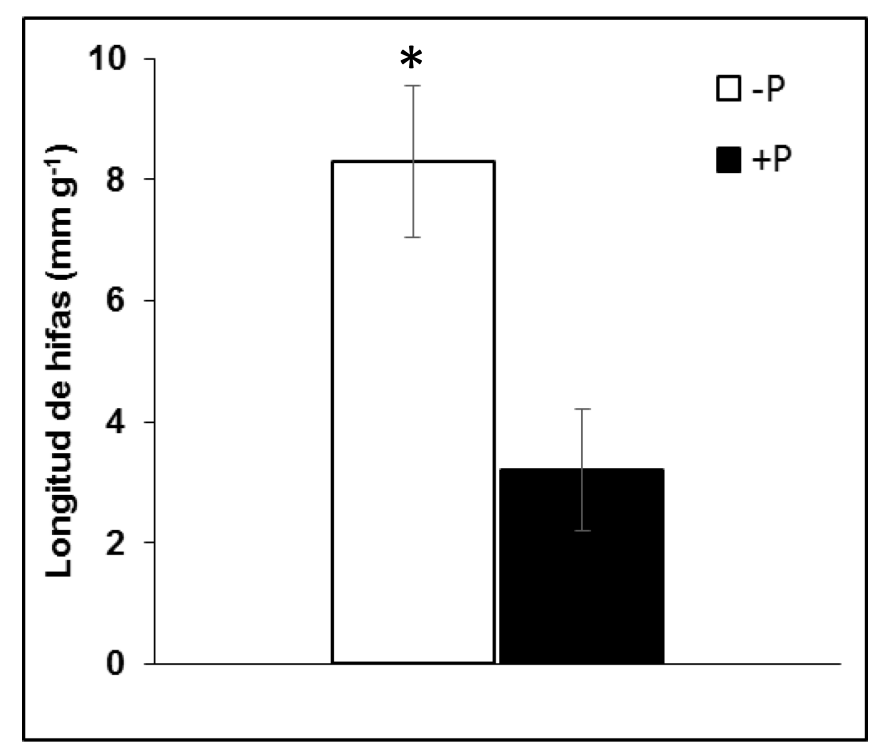

Figura 5.2: Longitud de hifas de Glomeromycota $\left(\mathrm{mm} \mathrm{g}^{-1}\right)$ en sustrato con plantas de soja a los 60 días de crecimiento bajo dos niveles de oferta fosforada (-P y +P). Los resultados pertenecen al tratamiento +HFMA ya que no se hallaron estructuras micorrícicas en HFMA. Las barras corresponden al error estándar $(n=4)$. El asterisco $(*)$ representa diferencias estadísticamente significativas entre niveles de $P$ (Tukey $p<0,05)$

\section{Parámetros de crecimiento de plantas de soja}

\section{- Altura, biomasa vegetal y nodulación}

Se observaron respuestas a los tratamientos de HFMA y P (Tabla 5.2). Se destacó que el peso de las raíces, tanto fresco como seco, no fue afectado significativamente por los tratamientos. Sin embargo, la variable R:A fue altamente sensible, lo cual evidencia el impacto de los efectos estudiados sobre la biomasa aérea de la planta. 
Tabla 5.2: Altura, peso y nodulación de plantas de soja luego de 60 días de crecimiento en presencia (+HFMA) o ausencia (-HFMA) de propágulos micorrícicos autóctonos y condiciones de nutrición fosforada contrastantes $(+P$ y $-P)$. Valores medios ( $n=4)$ y resultados de

\begin{tabular}{|c|c|c|c|c|c|c|c|c|c|c|c|}
\hline \multicolumn{2}{|c|}{ Tratamientos } & \multirow[t]{2}{*}{ Altura $(\mathrm{cm})$} & \multicolumn{3}{|c|}{ Peso Fresco $(g)$} & \multicolumn{3}{|c|}{ Peso Seco $(g)$} & \multicolumn{3}{|c|}{ Nódulos ${ }^{\S}$} \\
\hline & & & Aéreo & Raíz & $\mathbf{R}: \mathbf{A}^{\mp}$ & Aéreo & Raíz & $\mathbf{R}: \mathbf{A}^{\mp}$ & Número & PF & PS \\
\hline \multirow{3}{*}{ + HFMA } & $+P$ & $26,0 a$ & $7,9 a$ & 4,0 & $0,5 \quad b$ & $1,6 \mathrm{a}$ & 0,5 & $0,3 \mathrm{c}$ & $32,5 a$ & $25,3 a$ & $3,8 \mathrm{a}$ \\
\hline & $-P$ & $21,5 a b$ & $5,0 \quad$ b & 4,9 & $1,0 \mathrm{a}$ & $1,1 \quad b$ & 0,6 & $0,5 \mathbf{a}$ & 19,0 bc & 15,0 b & $2,3 \mathrm{ab}$ \\
\hline & $+P$ & $18,8 \quad b$ & $6,7 \mathrm{ab}$ & 5,6 & 0,9 a & $1,2 \quad b$ & 0,6 & $0,4 \quad b$ & 23,3 b & 16,4 b & $2,9 a b$ \\
\hline - HFMA & $-P$ & 18,3 b & $3,7 \quad \mathrm{c}$ & 4,2 & $1,1 \mathrm{a}$ & $0,8 \quad \mathrm{c}$ & 0,4 & $0,5 \mathrm{a}$ & $15,7 \mathrm{c}$ & $7,2 \mathrm{c}$ & $1,3 \mathrm{~b}$ \\
\hline
\end{tabular}

\begin{tabular}{llllllllllll}
\multicolumn{2}{l}{ Resultados de ANOVA } \\
\hline HFMA & $* * *$ & $n s$ & $n s$ & $*$ & $*$ & $n s$ & $* *$ & $*$ & $*$ & $*$ \\
P & $n s$ & $* * *$ & $n s$ & $n s$ & $* * *$ & $n s$ & $* * *$ & $* *$ & $*$ & $n s$ & \\
HFMA & $n s$ & $n s$ & $n s$ & $* *$ & $n s$ & $n s$ & $* *$ & $n s$ & $n s$ & $n s$ & \\
\hline
\end{tabular}

${ }^{\mp} R$ :A es la relación entre la biomasa acumulada por tejidos radicales (R) y aéreos (A) con los datos de peso fresco o seco, según corresponda.

${ }^{\S}$ Nódulos: Número (nódulos planta ${ }^{-1}$ ); PF: Peso fresco $\left(\mathrm{mg}\right.$ nódulo $\left.^{-1}\right)$; PS: Peso seco (mg nódulo ${ }^{-1}$ )

Resultados de ANOVA: *. $p<0,05 ;{ }^{* *}$. P $<0,01{ }^{* * *}$. P $<0,001$

Letras distintas indican diferencias significativas según test Tukey $(p<0,05)$

ANOVA. 


\section{Concentración y absorción de P}

La concentración de $\mathrm{P}$ fue drásticamente afectada por la oferta del nutriente. En la situación $+P$ (Figura 5.3a y 5.3c) fue en promedio 10 veces superior a la hallada en $-P$ (Figura 5.3b y 5.3d). Ante la deficiencia de $P$ impuesta en el experimento, las raíces que crecieron en +HFMA (Figura 5.3d) tuvieron 3 veces más $P$ que aquellas que no contaron con simbiosis micorrícica, aunque los valores se mantuvieron muy por debajo de lo observado en $+P$ (Figura 5.3c)
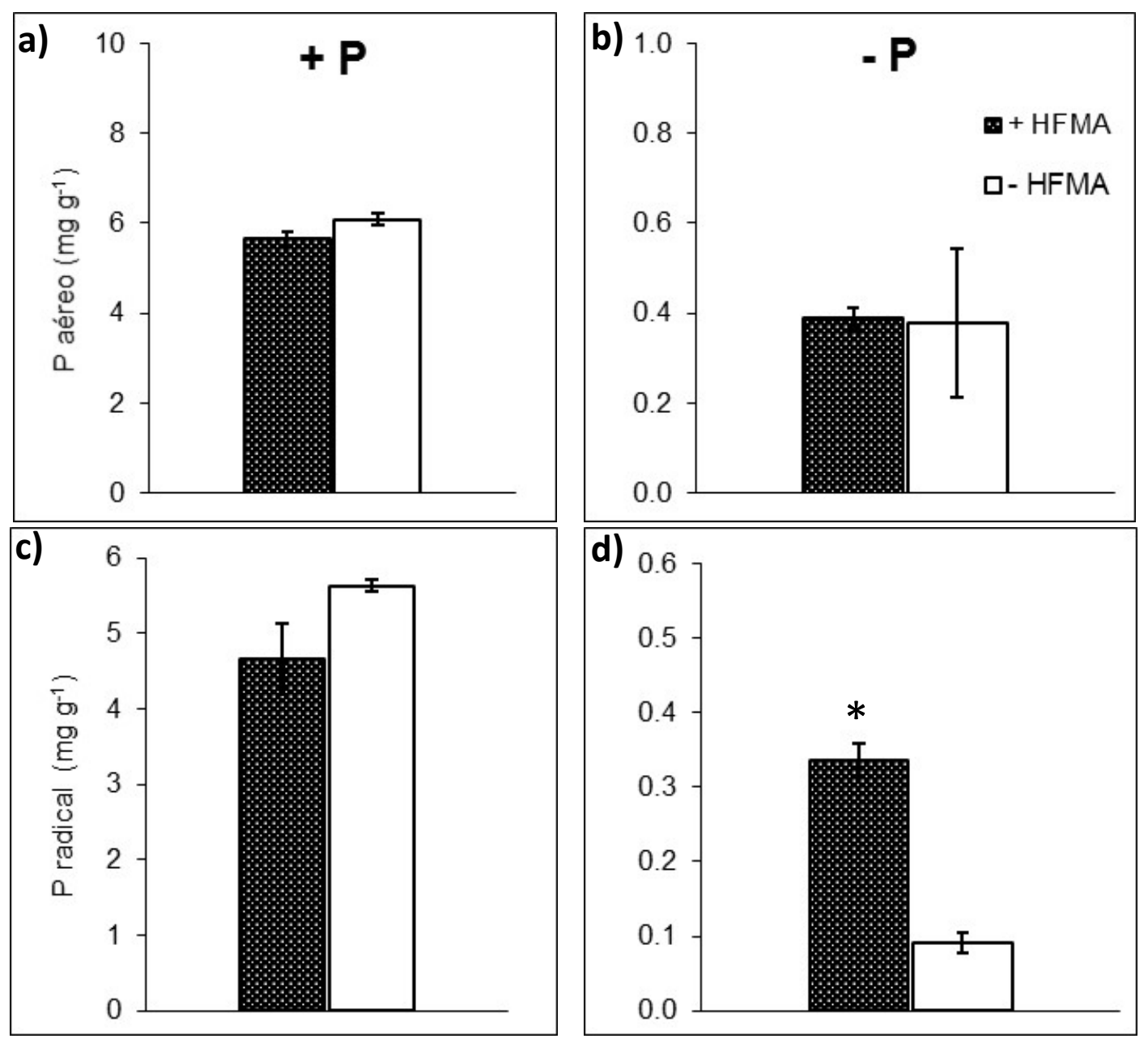

Figura 5.3: Concentración de $P$ de tejidos aéreos ( $a$ y $b$ ) y radicales (c y d) de plantas de soja a los 60 días de crecimiento bajo dos niveles de oferta fosforada: +P (izq.) y -P (der.); en presencia (+HFMA) o en ausencia (-HFMA) de inóculo micorrícico autóctono. Las barras corresponden al error estándar $(n=4)$. El asterisco $(*)$ indica diferencias estadísticamente significativas entre +HFMA y -HFMA para cada nivel de $\mathbf{P}$ individualmente, por contrastes ortogonales $(p<0,001)$. Nótese las diferencias de orden de magnitud del eje de ordenadas (y) entre las Figuras de la izq. (+P) y der. (-P) 
La acumulación de este nutriente en los tejidos vegetales de la planta de soja fue altamente afectada por la disponibilidad de P (Figura 5.4). Se observó que el contenido de P acumulado en las raíces difirió significativamente entre +HFMA y -HFMA, de manera opuesta según el tratamiento $\mathrm{P}$ (Figura 5.4c y 5.4d). El P acumulado en órganos aéreos mostró resultados marginalmente significativos $(p<0,08)$ en la situación $+P$ (Figura 5.4a)
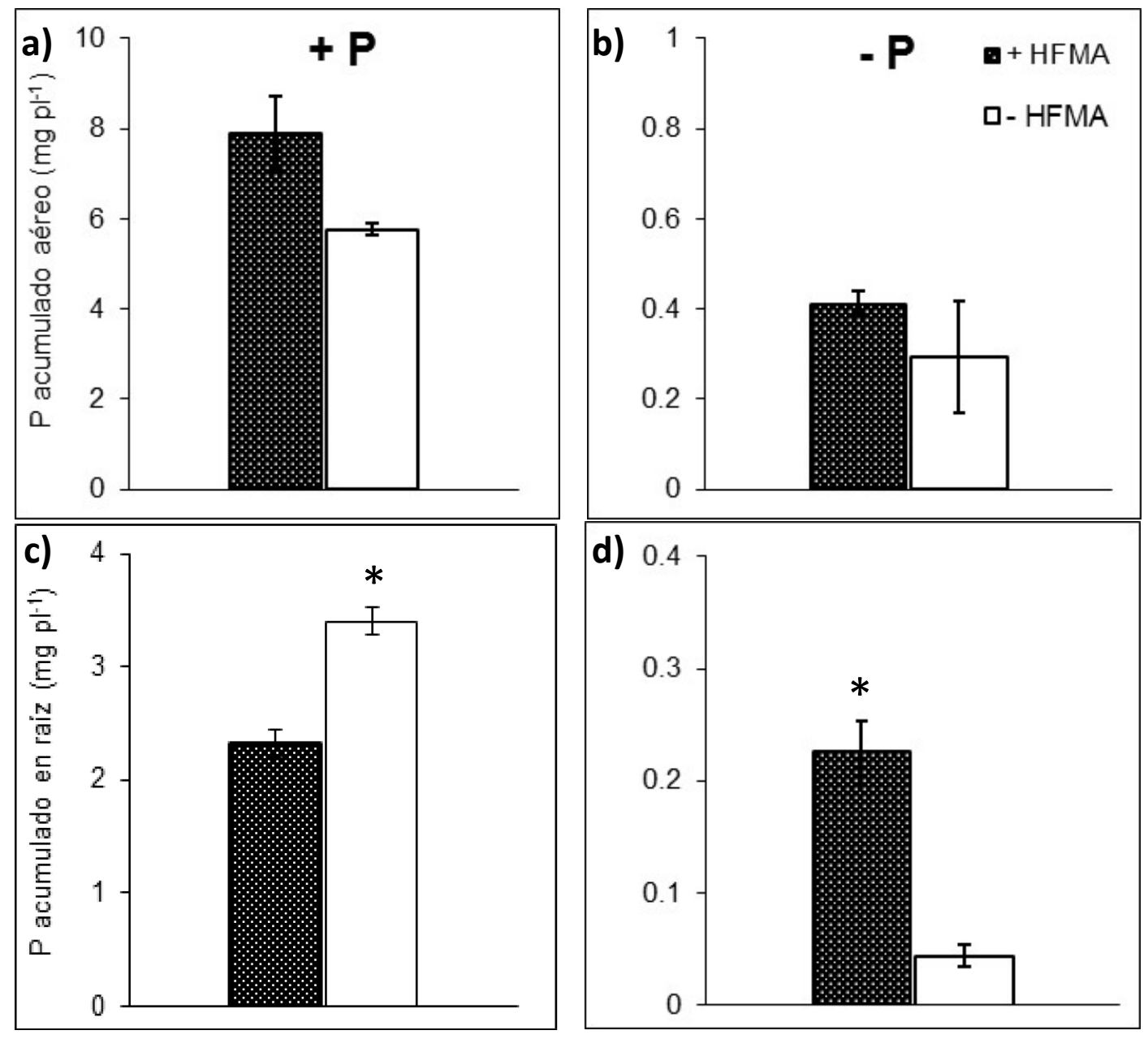

Figura 5.4: Acumulación de $P$ de tejidos aéreos (a y b) y radicales ( $\mathrm{c}$ y $\mathrm{d}$ ) de plantas de soja a los 60 días de crecimiento bajo dos niveles de oferta fosforada: +P (izq.) y -P (der.); en presencia (+HFMA) o en ausencia (-HFMA) de inóculo micorrícico autóctono. Las barras corresponden al error estándar $(n=4)$. El asterisco $(*)$ representa diferencias estadísticamente significativas entre +HFMA y -HFMA para cada nivel de $\mathbf{P}$ 
individualmente, por contrastes ortogonales $(p<0,001)$. Nótese las diferencias de orden de magnitud del eje de ordenadas ( $y$ ) entre las Figuras de la izq. (+P) y der. (-P) 


\section{- Concentración de azúcares solubles y almidón}

La distribución de fotoasimilados de la planta de soja fue afectada por los tratamientos evaluados en este experimento (Tabla 5.3). Se observó una interacción significativa HFMA*P en la concentración de azúcares solubles del tejido foliar vegetal (ANOVA, $p<0,05$ ). En los tejidos radicales, en cambio, se hallaron diferencias altamente significativas en respuesta al P (ANOVA, $p<0,001)$. La menor concentración de azúcares solubles se registró en +HFMA y +P (4,2 $\left.\mu \mathrm{g} \mathrm{mg}^{-1} \mathrm{PF}\right)$. La relación entre la concentración de azúcares solubles y almidón ( $\left.\mathrm{S}: \mathrm{A}\right)$ fue afectada significativamente tanto por la oferta de P como por la presencia de micorrizas. En promedio, los tratamientos +HFMA tuvieron una menor relación S:A que -HFMA para cada nivel de P. En la raíz, en cambio, S:A se mantuvo constante para todos los tratamientos.

Tabla 5.3: Concentración de azúcares solubles y almidón ( $\mu \mathrm{g} \mathrm{mg}^{-1} \mathrm{PF}$ ) de plantas de soja luego de 60 días de crecimiento en presencia (+HFMA) o ausencia (-HFMA) de propágulos micorrícicos autóctonos y condiciones de nutrición fosforada contrastantes (+P y -P). Valores medios $(n=4)$ y resultados de ANOVA.

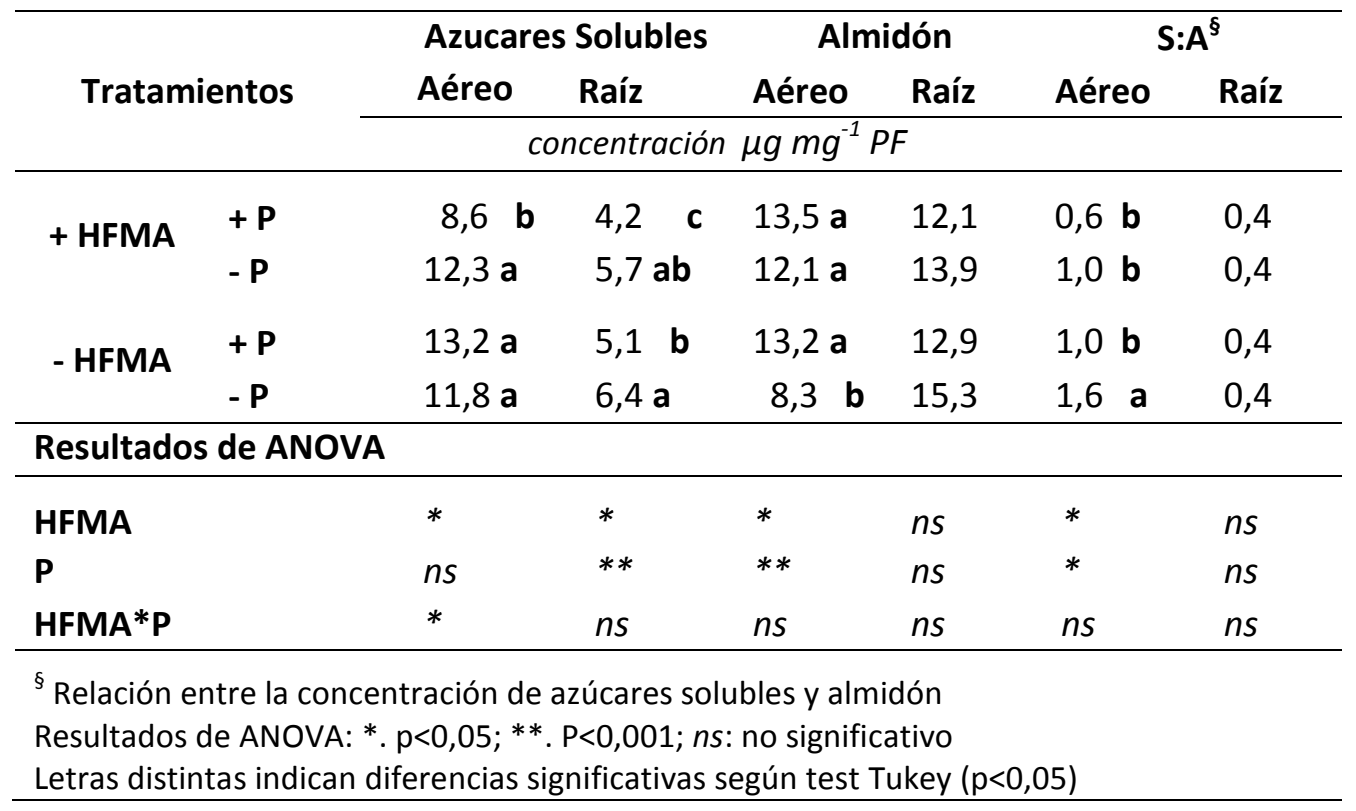




\section{Dependencia micorrícica}

\section{- Biomasa y contenido de P}

En la Figura 5.5 se presentan los resultados de la dependencia micorrícica (DM) para las variables de respuesta evaluadas sobre plantas de soja en dos condiciones de nutrición fosforada. Los valores de DM mayores que cero indican una mejor performance de la planta en +HFMA que en -HFMA, mientras que una DM menor que cero indica lo opuesto. En el set de datos analizados, se observó que los tejidos radicales tuvieron una mayor respuesta a la micorrización y que la misma fue afectada significativamente por la oferta de P. En este sentido, tanto el peso, como la concentración y acumulación de $\mathrm{P}$ de raíces tuvieron DM positiva en $-P$, y viceversa en $+P$. Los mayores valores de $D M$ se observaron en la concentración y acumulación de $P$ en la raíz, los cuales alcanzaron un $81 \%( \pm 3)$ y $73 \%( \pm 2)$, respectivamente, en el tratamiento $-\mathrm{P}$ (Figura 5.5). El resto de las variables medidas no tuvieron respuesta estadísticamente significativa aunque se observaron tendencias según el tratamiento de $\mathrm{P}$.

\section{- Azúcares solubles y almidón}

Se observaron diferencias significativas en DM en la concentración de azúcares solubles y almidón del tejido foliar en respuesta a la fertilización fosforada (Figura 5.6). Para ambos parámetros, se hallaron valores fuertemente negativos en $+P$, lo cual significa que en dicho tratamiento de nutrición $\mathrm{P}$, la presencia de micorrizas generó disminución de la proporción de azucares solubles con respecto a la de almidón. 


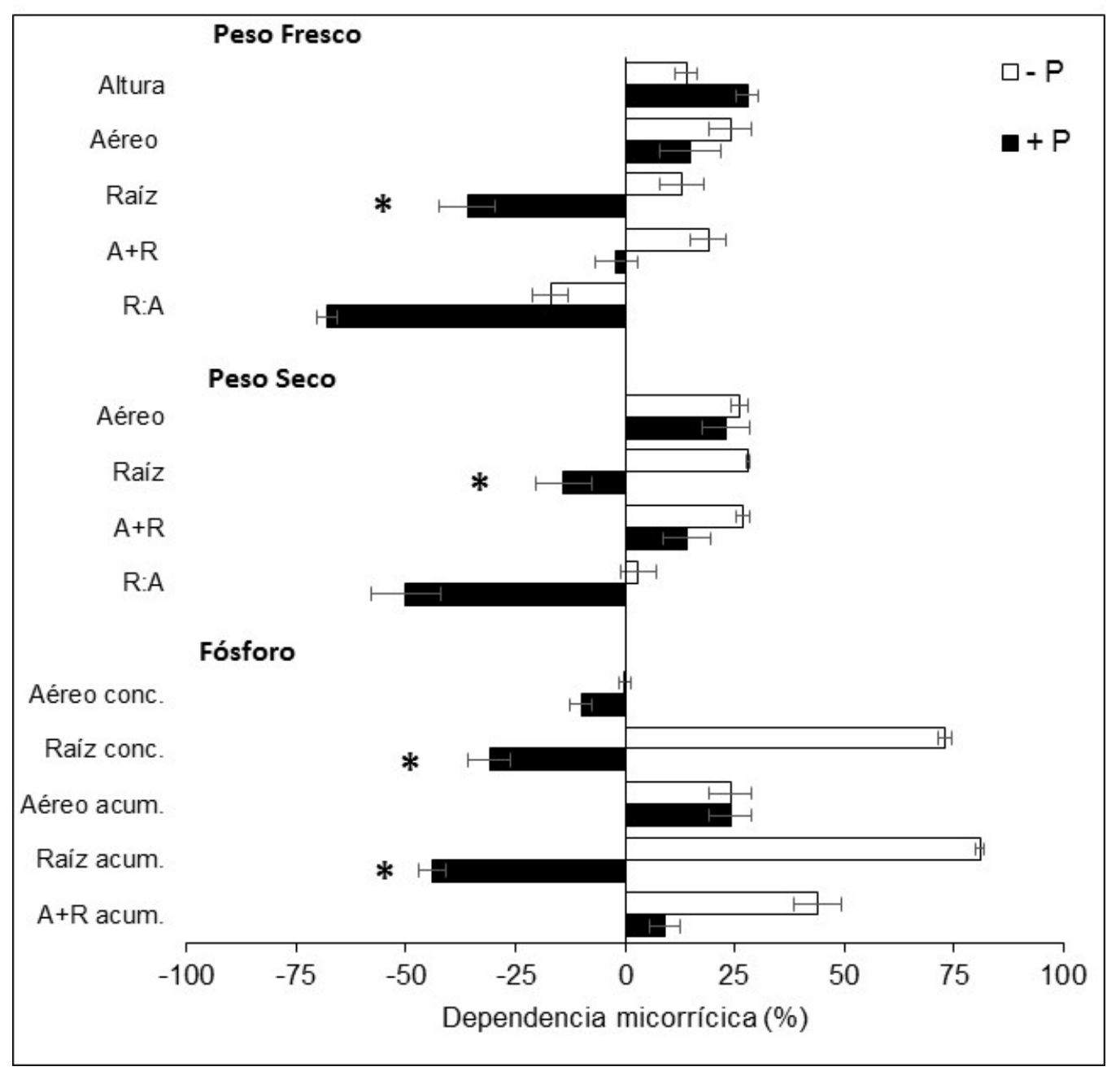

Figura 5.5: Dependencia micorrícica (\%) de plantas de soja a los 60 días de crecimiento bajo dos niveles de oferta fosforada: +P y -P; para las siguientes variables: Altura $(\mathrm{cm})$; Aéreo $\left(\mathrm{g} \mathrm{pl}^{-1}\right)$, Raíz $\left(\mathrm{g} \mathrm{pl}^{-1}\right), A+\mathrm{R}$ : peso de la planta entera $\left(\mathrm{g} \mathrm{pl}^{-1}\right), \mathrm{R}$ :A: relación entre peso de raíces y órganos aéreos; basado en peso fresco o seco, según corresponda. Fósforo: Aéreo conc. y Raíz conc.: concentración de $\mathrm{P}$ en órganos aéreos y radicales $\left(\mathrm{mgP} \mathrm{g}^{-1}\right)$, respectivamente. Aéreo acum. y Raíz acum.: acumulación de $P$ en órganos aéreos $y$ radicales $\left(\mathrm{mg} \mathrm{pl}^{-1}\right)$, respectivamente. A+R: es la suma de las fracciones anteriores (mgP $\mathrm{pl}^{-}$ $\left.{ }^{1}\right)$. Las barras corresponden al error estándar $(n=4)$. El asterisco $\left({ }^{*}\right)$ representa diferencias estadísticamente significativas entre $+P$ y $-P(A N O V A, p<0,05)$. 


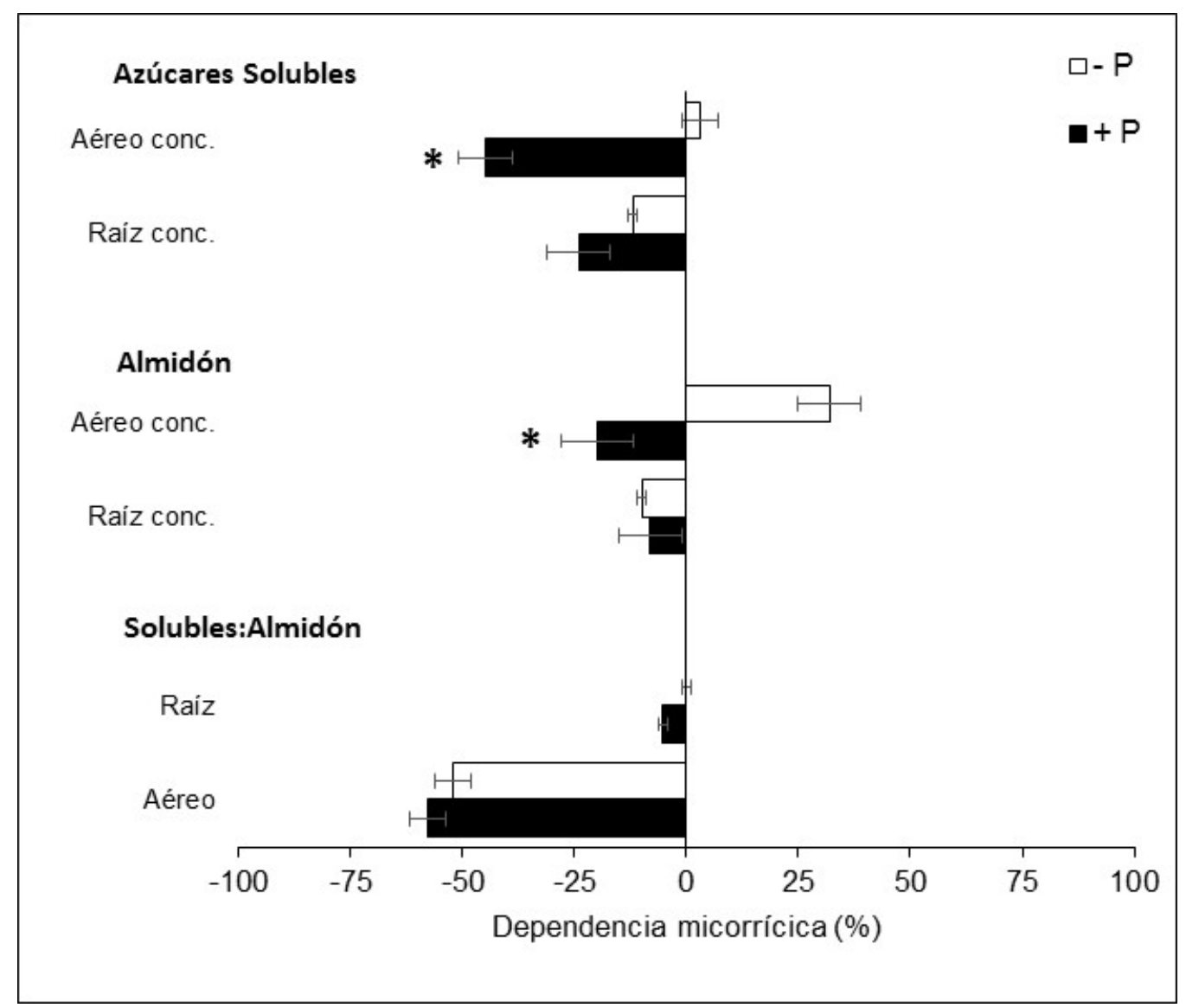

Figura 5.6: Dependencia micorrícica (\%) de plantas de soja a los 60 días de crecimiento bajo dos niveles de oferta fosforada: +P y -P; de azúcares solubles e insolubles en hojas y raíces de soja ( $\mu \mathrm{g} \mathrm{mg}^{-1} \mathrm{PF}$ ). Las barras corresponden al error estándar $(n=4)$. Los asteriscos $(*)$ indican diferencias estadísticamente significativas entre $+P$ y $-P(A N O V A, p<0,05)$.

\subsection{DISCUSION}

La oferta de $\mathrm{P}$ del sustrato inhibió parcialmente el establecimiento de la simbiosis micorrícica. Se observaron reducciones de la colonización intra-radical de 33\% de hifas y un $40 \%$ de arbúsculos (Figura 5.1a). Aunque estos resultados indican una disminución, también demuestran que la alta concentración de $\mathrm{P}$ no impidió completamente el inicio de la micorrización. Sin embargo, los resultados más contrastantes entre ambos niveles de $P$ se observaron en la actividad de las estructuras fúngicas intracelulares y en la densidad de hifas extra-radicales (Figura 5.1b, 5.2). Las hifas y arbúsculos viables en -P superaron 2 y 5 veces lo observado en $+\mathrm{P}$, respectivamente. Sumado a ello, la longitud de hifas extra-radicales en - 
P superaron en un $60 \%$ la hallada en $+P$. Uno de los mecanismos más citados sobre la regulación de la micorrización de las plantas en condiciones de alta disponibilidad de $\mathrm{P}$ es la supresión de la asignación de C al hongo (Javot et al., 2007). Este proceso explicaría la pérdida de viabilidad de las estructuras fúngicas presentes en las raíces. Es posible que ante niveles altos de $\mathrm{P}$ la planta afecte la vida útil de arbúsculos e hifas acortando su período activo y promoviendo su disrupción (Gutjahr y Parniske, 2013). De este modo la planta ejerce un doble control sobre los HFMA, el primero es inhibiendo parcialmente los niveles de micorrización y el segundo disminuyendo el período de vida de las estructuras intraradicales. En situaciones de deficiencia de $\mathrm{P}$, sucedió todo lo contrario. Los HFMA, además de contar con estructuras micorrícicas más activas dentro de las raíces, destinaron más fotoasimilados para la extensión del micelio extra-radical. Las hifas que colonizan el suelo poseen eficientes mecanismos para la adquisición de $P$, tales como la secreción de enzimas para hidrolizar compuestos orgánicos, y la exudación de aniones que modifican el pH favoreciendo la solubilización de P precipitado o fuertemente adsorbido a coloides del suelo (Jakobsen, 1995). Su reducido diámetro le confiere una mayor superficie específica, en comparación con los tejidos radicales, haciendo más eficiente su poder de absorción de $\mathrm{P}$ por unidad de C (Smith y Read 2010). Jansa et al. (2005) observaron que la densidad de hifas se correlacionó fuertemente con la transferencia de ${ }^{33} \mathrm{P}$ a la planta. Observaron que la capacidad de extensión hifal puede alcanzar los $10 \mathrm{~cm}$ desde la raíz. Lo cual confirma la habilidad de estas estructuras de ir mucho más allá de las zonas de agotamiento rizosférico. Similares relaciones entre la densidad del micelio y la cantidad de $\mathrm{P}$ en la planta fueron citadas por Jakobsen et al. (2001) y Schweiger et al. (1999). En un estudio comparando diferentes especies, Munkvold et al. (2004) hallaron que la capacidad de absorción de las hifas es muy variable y que la densidad total es la que determina el beneficio neto en la adquisición de P. Finalmente, el hecho que la actividad de vesículas haya sido mayor en los tratamientos $+P$, también demuestra la capacidad del hongo de priorizar el destino de los fotoasimilados hacia estructuras poco benéficas para la planta (Verbruggen y Kiers, 2010). Nijjer et al. (2010) observaron que los HFMA destinaron 4 veces más recursos a las vesículas en tratamientos con fertilización que en el tratamiento control. Los resultados hallados en este capítulo corroboran la importancia de la regulación de la planta sobre la simbiosis micorrícica de acuerdo a la oferta de P del medio. 
Los parámetros de crecimiento relacionados a la acumulación y partición de biomasa respondieron significativamente a los tratamientos de HFMA y P (Tabla 5.2). Particularmente en $+P$, se observó que la presencia de micorrizas (+HFMA) promovió incrementos en la altura, mejoras en la acumulación de materia seca aérea y reducción en R:A (Tabla 5.2). Plenchette et al. (1983) demostraron que al hacer crecer distintos cultivos bajo una adecuada provisión de $\mathrm{P}$ y otros nutrientes, algunos manifestaron mejoras en el crecimiento en presencia de micorrizas, especialmente las leguminosas. Safir et al. (1972) observaron que la simbiosis micorrícica incrementó el crecimiento de soja tanto en situaciones de baja como de alta oferta de nutrientes. El efecto benéfico de las micorrizas aún en ambientes sin limitaciones nutricionales puede ser atribuido a las interacciones sinérgicas entre los HFMA y las bacterias del suelo (Artursson et al., 2006). Cuando se establece la simbiosis micorrícica se conforma una región en la proximidad de las hifas denominada micorrizosfera, la cual tiene propiedades muy diferentes a las del suelo circundante (Rambelli, 1973). El efecto de la micorrizosfera se debe a que el micelio libera compuestos orgánicos ricos en energía que incrementan la actividad y la proliferación de microorganismos micorrizosféricos (Barea et al., 2002). Entre ellos se encuentran bacterias reconocidas por su capacidad de promover el crecimiento de las plantas (PGPR). Estas bacterias usualmente se ubican en contacto con las raíces y pueden incrementar el crecimiento de la planta a través de mecanismos tales como mejoras en la nutrición mineral, supresión de enfermedades y la producción de fitohormonas (Zablotowicz et al., 1991). Algunas de ellas, por ejemplo, Pseudomonas y Rhizobium crecen fuertemente adheridas al micelio y a través de éste pueden ingresar a espacios de la raíz (Bianciotto et al., 1996a). Además, también se ha reportado que estas bacterias tienen un gran poder estimulatorio sobre el crecimiento de los HFMA (Linderman, 1997). La fuerte relación existente entre los HFMA y bacterias queda de manifiesto al demostrarse la presencia de células bacterianas como endosimbiontes micorrícicos en varias especies de Glomeromycota (Bianciotto et al., 1996b). El vínculo sinérgico entre los HFMA con otros integrantes de la microbiota del suelo podría ser una de las principales causas de las mejoras en los parámetros de crecimiento hallados en plantas micorrizadas en ausencia de limitaciones nutricionales (Artursson et al., 2006). Finalmente, además de la mayor producción de biomasa de +HFMA en $+P$, también se observó una reducción en $\mathrm{R}: \mathrm{A}$, es decir, se halló una menor proporción de biomasa asignada a la raíz en presencia de HFMA $(0,31$ vs 0,47). Menores valores de R:A son frecuentemente asociados a mejoras nutricionales y 
algunos estudios también lo han asociado a las simbiosis micorrícicas (Asimi et al., 1980; Piccini et al., 1988). La competencia entre el hongo y la raíz por los fotoasimilados es el principal factor responsable de la típica menor proporción de peso de raíces que de órganos aéreos en plantas micorrizadas (Berta et al., 1990). Estos resultados confirman una vez más, el efecto significativo de los HFMA aún en condiciones no limitantes de nutrientes.

La deficiencia de $\mathrm{P}$ provocó drásticas disminuciones en el crecimiento aéreo de la planta, tanto en + HFMA como en - HFMA, sin afectar el crecimiento de la raíz (Tabla 5.2). Uno de los mecanismos mediante los cuales las plantas ajustan el desbalance de recursos exógenos es asignando más biomasa a los órganos involucrados en la adquisición de los recursos escasos (Marschner, 1995). En consecuencia, ante una baja oferta de P del suelo, las plantas tienden a asignar una mayor proporción de la biomasa a los órganos radicales, lo cual se traduce en una mayor relación R:A (Ciereszko et al., 1996). Fredeen et al. (1989) estudiaron la influencia de la nutrición fosforada sobre el crecimiento de soja. Observaron reducciones significativas del crecimiento aéreo en el tratamiento de bajo $P$ y un efecto no detectable sobre la biomasa acumulada en órganos radicales (menor R:A). En su trabajo hallaron que ante deficiencia de P, la soja disminuyó un $85 \%$ la expansión foliar y que ésta fue la causa primaria de reducción del crecimiento. Nuestros resultados sugieren que ante la deficiencia de $\mathrm{P}$ impuesta en el experimento, la planta respondió primeramente a la escasez de $\mathrm{P}$, mientras que las micorrización no influyó en la respuesta de la planta en términos de asignación proporcional de biomasa a los órganos aéreos y radicales (Tabla 5.2).

La oferta de $\mathrm{P}$ determinó grandes diferencias en la concentración y acumulación del nutriente en las plantas de soja (Figuras 5.3 y 5.4). En promedio, las concentraciones halladas en $+P$ fueron un orden de magnitud superior al promedio de $-P$. Estos resultados coinciden con los hallados por Lendenmann et al. (2011) quienes registraron un aumento en la concentración de $\mathrm{P}$ en plantas micorrizadas con deficiencia del nutriente, pero aun así los niveles de $\mathrm{P}$ permanecieron muy por debajo de los detectados en condiciones de alta oferta del nutriente. Por tal motivo, en la discusión de estos resultados, el efecto de las micorrizas se abordará para $+\mathrm{P}$ y $-\mathrm{P}$ por separado. Así, por ejemplo, en $+\mathrm{P}$ la concentración del nutriente no mostró diferencias significativas debido a la presencia de micorrizas, ni en órganos aéreos ni radicales (Figura 5.3a y 5.3c). Este resultado era esperable, puesto que al crecer sin escases de $\mathrm{P}$, la planta cuenta con mecanismos para regular su concentración sin 
que llegue a valores tóxicos (Marschner, 1995). Los valores hallados coinciden con los registrados por otros autores en cultivo de soja (Fernández, et al., 2011; Fredeen et al., 1989). En cuanto a la acumulación total del nutriente en $+P$, se observaron incrementos en las raíces del tratamiento -HFMA (Figura 5.4c). Este resultado es muy particular porque pone de manifiesto una mayor eficiencia en el uso de $\mathrm{P}$ en las plantas micorrizadas. Según Marschner (1995), en ausencia de limitaciones, las plantas más eficientes son aquellas que destinan más recursos a la producción de tejido foliar para aumentar la fijación de $C$ vía fotosíntesis. Sin embargo, como se observa en la Figura 5.4c, por algún motivo que se desconoce, las plantas en -HFMA priorizaron la producción de raíces y se tornaron menos eficientes. Esto podría suceder si algún otro recurso fuera limitante, como el agua o $\mathrm{N}$ (Hermans et al., 2006), pero no sería lo que sucedió en este experimento ya que se fertilizó con $\mathrm{N}$ para evitar prescindir de la fijación simbiótica y se mantuvieron constantes los niveles de agua del suelo. En términos de asignación de biomasa, tal vez ésta sea una característica propia del cultivar en ambientes ricos en $\mathrm{P}$ que, en este caso, presentó un gran potencial de mejora gracias a la simbiosis micorrícica (Verbruggen y Kiers, 2010).

El efecto de las micorrizas en -P se manifestó con aumentos significativos de la concentración y acumulación de $P$ en las raíces (Figuras $5.3 \mathrm{~d}$ y 5.4d). Los órganos aéreos no presentaron diferencias entre sí para dichos parámetros. En ambientes pobres en $\mathrm{P}$ el efecto inmediato de las micorrizas es una mejora en la nutrición de la planta (Smith y Read, 2010). Los resultados confirmaron parcialmente esta afirmación. Es decir, sí se registró una mejora en las variables relacionadas al P en las plantas de +HFMA; pero en lugar de observarse en tallos y hojas se observó en la raíz (Figuras $5.3 \mathrm{bd}$ y $5.4 \mathrm{bd}$ ). Definitivamente, este hecho no coincide con lo esperado según los antecedentes consultados. Por lo general, en plantas micorrícicas, la concentración de $\mathrm{P}$ por unidad de peso seco es mayor, pero no tan exacerbada por unidad de peso seco de la raíz (Koide, 1991). La mayor concentración y acumulación de P en +HFMA en comparación con -HFMA, especialmente en la raíz, podría indicar que otro factor de crecimiento (carbohidratos, otros nutrientes) comenzó a ser limitante (Marschner y Dell, 1994). Las plantas adaptadas a ambientes extremadamente deficitarios de $\mathrm{P}$ se caracterizan por tener bajas tasas de crecimiento $\mathrm{y}$ de este modo mantienen estable la concentración del nutriente (Chapin, 1980). Las variedades comerciales, en cambio, tienen ciclos muy cortos, con altas tasa de crecimiento y demanda 
inmediata de recursos (Marschner, 1995). Lo que habría ocurrido en este experimento es que las plántulas de soja crecieron rápidamente en los primeros días después del trasplante, al ser pequeñas, la disponibilidad de $\mathrm{P}$ del sustrato sumado al beneficio de las micorrizas les permitió mantener una alta tasa de crecimiento. Es decir, el P del medio y el tomado por las micorrizas les alcanzaba. Sin embargo, en un momento dado el P comenzó a ser fuertemente limitante y los hongos micorrícicos ya no pudieron abastecer la demanda de la planta. En soja, la deficiencia de $\mathrm{P}$ disminuye la asimilación fotosintética de dióxido de $\mathrm{C}$ debido a la disminución en el pool de RuBP lo cual se visualiza como una reducción en la tasa de expansión de hojas (Fredeen et al., 1989). Entonces, en este experimento, los tejidos foliares habrían dejado de crecer y en consecuencia se redujo la demanda aérea de nutrientes tomados por la raíz, los cuales comenzaron a acumularse. Es interesante comparar lo que ocurrió en $-P$ entre ambos tratamiento de HFMA. En -HFMA, la tasa de crecimiento foliar parece haberse detenido antes puesto que la biomasa aérea fue de $0,88 \mathrm{~g} \mathrm{pl}^{-1} \mathrm{y}$ en $+\mathrm{HFMA}$ alcanzó $1,18 \mathrm{~g} \mathrm{pl}^{-1}$ (Tabla 5.2). Esta diferencia de crecimiento (+25\%) sería gracias al plus de $\mathrm{P}$ conferido por las micorrizas. Sin embargo, ante tan extrema deficiencia fosforada, la simbiosis no pudo abastecer la demanda de la planta y comenzaron a manifestarse las consecuencias de la deficiencia de $P$.

La partición de fotoasimilados es una de las propiedades más afectadas por la deficiencia de P. Cantidades sub-óptimas del nutriente disminuyen la tasa de fijación de dióxido de carbono y la expansión de superficie fotosintética foliar (Brooks, 1986). En soja esto se produce por una reducción de la actividad de la enzima RuBP (Freeden et al., 1989). La baja concentración de $\mathrm{P}$ en el citoplasma de dichas células tiene consecuencias sobre el metabolismo de los azúcares, particularmente en la fotosíntesis, glicólisis y respiración (Plaxton y Carswell, 1999). El almidón comienza a acumularse como consecuencia de la disminución de la demanda para crecimiento y respiración (Pieters et al., 2001). En plantas de soja, se ha observado un incremento en la concentración de almidón en hojas y raíces, mientras que los azúcares solubles tienden a alojarse principalmente en la raíz (Fredeen et al., 1989). En plantas micorrizadas estos patrones de asignación de carbohidratos se ven modificados por la demanda de C del hongo (Graham et al., 1997). Por lo general, la presencia de micorrizas está correlacionada con una reducción en concentración de hidratos de $\mathrm{C}$ solubles, mientras que el efecto sobre el almidón puede o no ser detectado (Douds, 
2000). Los resultados obtenidos en este capítulo, en general corroboran lo esperado en cuanto a la partición de hidratos de $C$ en respuesta a la oferta de $\mathrm{P}$ y HFMA.

En las plantas micorrizadas que crecieron en $+P$ se observó una reducción en la concentración de azúcares solubles tanto en hojas como en raíz (Tabla 5.3). La relación entre la concentración de ambos tipos de hidratos de $C$ en hojas fue la más baja de todo el experimento (Tabla 5.3). Estos resultados coinciden con lo hallado por otros autores (ej. Douds, 2000; Graham et al., 1997). Cuando el metabolismo del C no se ve afectado por la deficiencia de $P$, la raíz demanda más $C$ rápidamente asimilable para el mantenimiento de la simbiosis micorrícica y esto se manifiesta en una menor concentración de azúcares solubles en la planta. En este sentido, en ausencia de limitantes, la simbiosis estimula la fotosíntesis debido a la mayor demanda de fotoasimilados (Jakobsen, 1995). El comportamiento de la planta de soja ante deficiencia de P y -HFMA fue completamente opuesto al descripto anteriormente. Las plantas tuvieron una gran concentración de azúcares solubles en la raíz y muy bajo nivel de almidón en hojas (Tabla 5.3). El aumento de la concentración responde a la detención del crecimiento de la planta y a que movilizaron los azúcares hacia la raíz para favorecer su desarrollo y exploración del sustrato en búsqueda de P (Douds, 2000). Finalmente, los tratamientos $-P$ de plantas micorrizadas $y+P$ de plantas sin micorrizas tuvieron una distribución de hidratos de C no diferente estadísticamente entre sí (Tabla 5.3). Esto permite inferir que la presencia de micorrizas en -P promovió una asignación de fotoasimilados similar al de una planta que creció sin deficiencias del nutriente. En general, los resultados obtenidos en este capítulo corroboran la importancia del P en el metabolismo de los azúcares y el efecto de las micorrizas en cuanto a su demanda desde la raíz.

La dependencia micorrícica (DM) fue un índice propuesto por Plenchette et al. (1983) para estimar el grado de respuesta de una planta a la presencia de micorrizas. En este capítulo, la estimación de la DM permitió resaltar las diferencias, mencionadas anteriormente, en el crecimiento, nutrición fosforada y asignación de hidratos de C de la planta de soja (Figuras 5.5 y 5.6). Se observó que todas las variables medidas en la raíz (i.e biomasa, concentración y acumulación de P) fueron afectadas negativamente por la fertilización P (Figura 5.5). Estos resultados eran predecibles debido al efecto antagónico de la fertilización y las micorrizas en cuanto a la asignación de recursos a la raíz (Jakobsen, 1995). Sin embargo, algunas de las DM halladas merecen especial atención, por ejemplo, la DM positiva en el peso seco (+25\%) y 
acumulación de P aéreo (+25\%) de las plantas en ambos tratamientos de P. Esto corrobora la importancia de los hongos micorrícicos para la leguminosa en términos de la partición de biomasa y nutrientes, independientemente del nivel de P del medio (Fredeen y Terry, 1988; Safir et al., 1972; Verbruggen y Kiers, 2010). En cuanto a la concentración de azucares, la DM también resalta los aspectos mencionados anteriormente. Los valores negativos de la DM en la concentración de azúcares solubles (en $+P$ ) y en la relación $S: A$ en hojas (en $+P$ y $-P$ ) puede atribuirse directamente a la demanda de C por parte del hongo (Tinker et al., 1994). Es decir, vuelve a confirmarse el efecto de la simbiosis incluso en la situación +P.

\subsection{CONCLUSIONES}

Los resultados obtenidos en este capítulo permitieron detectar diferencias en los niveles de colonización micorrícica intra y extra-radical, en el crecimiento y acumulación de P y en la partición de azúcares de las plantas de soja en respuesta a los tratamientos de fertilización fosforada y micorrización.

Con respecto a las hipótesis planteadas al inicio del capítulo, se concluye que:

H1- No se rechaza la primera hipótesis. La severa restricción de $\mathrm{P}$ impuesta en el experimento elevó significativamente los valores hallados de estructuras micorrícicas (hifas y arbúsculos) dentro de las raíces y la formación de micelio extra-radical en comparación con la situación de alto $\mathrm{P}$ del sustrato. Las estructuras fúngicas de reserva (vesículas) mantuvieron su valor en ambos escenarios de nutrición $\mathrm{P}$ pero incrementaron significativamente su viabilidad en ante elevado nivel de $P$ del sustrato.

H2- No se rechaza la segunda hipótesis. La simbiosis micorrícica generó aumentos en la producción de biomasa aérea en ambos tratamientos de nutrición $\mathrm{P}$ y en la acumulación de este nutriente en plantas con severa deficiencia fosforada.

H3- No se rechaza la tercera hipótesis. Ante elevada oferta de P hubo menor concentración de azúcares solubles de la planta y estos valores se redujeron aún más en presencia de micorrizas. El almidón, en cambio, fue más estable y respondió en tejido aéreo a la deficiencia de $\mathrm{P}$ en ausencia de micorrizas. 
CAPÍTULO 6

DISCUSION GENERAL 
Los agroecosistemas son ecosistemas artificiales simplificados en biodiversidad, que se han vuelto muy productivos gracias a los aportes externos. La producción de soja en Argentina ha generado la simplificación de la estructura del ambiente en grandes extensiones, afectando fuertemente la diversidad natural. La dominancia de una especie a escala geográfica determina la exclusión de otras, y en consecuencia la riqueza específica (número de especies) y el equilibrio en la abundancia (importancia relativa de las distintas especies) decrecen tanto a nivel local como regional (Chapin et al., 2000). Una menor diversidad agrícola también es indicadora de deterioro ambiental, donde tanto la diversidad de cultivos como la diversidad de especies y procesos ecológicos asociados a paisajes heterogéneos se ven afectados negativamente (Altieri, 1999).

El conocimiento de un agroecosistema no sólo incluye a los cultivos sino también a las comunidades de la microbiota autóctona sobre las cuales se incide directamente (Kiers y Denison, 2014). Al ser simbiontes obligados, los hongos formadores de micorrizas arbusculares (HFMA) son organismos altamente sensibles a las prácticas agrícolas y muy relacionados a las leguminosas (Smith y Read, 2010). Se han reportado innumerables beneficios sobre los cultivos no sólo relacionados a la nutrición sino también a la contribución de servicios ecosistémicos tales como la conservación del carbono del suelo, reducción de emisión de gases de efecto invernadero y disminución de la contaminación por lixiviación y escurrimiento (Verbruggen y Kiers, 2014). Fester y Sawers (2011) proponen que uno de los desafíos más grandes de la agricultura moderna es adaptar los agroecosistemas a las necesidades de las comunidades de la microbiota benéfica para optimizar las funciones en las que intervienen. Para ello debe contarse una visión holística que contemple la adopción de prácticas sustentables para mantener la diversidad de los HFMA autóctonos y, en consecuencia, la provisión de los servicios ecosistémicos que éstos confieren.

A pesar de la importancia de la simbiosis micorrícica en los agroecosistemas y de la gran expansión del cultivo de soja, la información local disponible sigue siendo escasa. El objetivo general de esta tesis fue estudiar variables de estructura y función de comunidades nativas de HFMA en soja con énfasis en la nutrición fosforada del cultivo en agroecosistemas de la provincia de Córdoba. Para ello, se delimitaron áreas homogéneas de historial de uso Agrícola, Mixto y de reciente desforestación de la serranía cordobesa. Se generó conocimiento acerca de la capacidad infectiva de los suelos (Capítulo 2), la composición de las comunidades autóctonas basada en la morfología de las esporas (Capítulo 3) y en 
técnicas de secuenciación de última generación tanto en muestras de suelo como de raíces de soja (Capítulo 4), y la contribución de las micorrizas a la nutrición fosforada de soja (Capítulo 5).

La infectividad micorrícica se ha definido como la habilidad natural de un suelo que contiene HFMA de inducir la formación de micorrizas en las plantas (Plenchette et al., 1989). Dada su relevancia, Jansa et al. (2009) proponen que sea considerada como un indicador de la calidad del suelo y sugieren establecer umbrales de infectividad considerados "normales" para ciertos manejos de suelo y condiciones ambientales. En esta tesis se identificaron dos escenarios para las micorrizas en cuanto a la infectividad, por un lado, los suelos de la zona Agrícola y de Sierras y por el otro, los suelos de la zona Mixta. Se observó que en promedio la infectividad del primero fue un $46 \%$ superior a la del segundo (Tabla 2.2). Esta diferencia estuvo basada en características intrínsecas de cada ambiente, en especial, debido al suelo y al clima. La infectividad se correlacionó en forma positiva con variables del suelo (C, agua y arcilla); de la planta (biomasa y $\mathrm{P}$ absorbido); y con la presencia de estructuras fúngicas en las raíces de soja (hifas, arbúsculos). En cambio, el contenido de $\mathrm{P}$ del suelo y la arena se correlacionaron de manera negativa con la infectividad (Tabla 2.4). La correlación hallada con el $\mathrm{C}$ del suelo es una evidencia del rol de estos organismos en la dinámica del $\mathrm{C}$ edáfico. Clemmensen et al. (2013) observaron que los HFMA son reguladores importantes de la dinámica de $\mathrm{C}$ en el suelo debido a la degradación gradual de las estructuras fúngicas residuales. Sumado a ello, otra porción de la reserva de C de origen micorrícico es la conformada por los exudados de estos hongos los cuales contribuyen a la agregación y a la acumulación de materia orgánica del suelo (Wilson et al., 2009). Por otra parte, la particularidad de la zona Mixta es que correspondió no sólo a los suelos de texturas más gruesas sino que también fueron los de mayor contenido de P. Ambos factores, fueron relacionados negativamente con la infectividad. El efecto de la arena se atribuyó a las variaciones en el contenido hídrico del suelo que podría dificultar el establecimiento de la simbiosis. Mientras que el impacto del $\mathrm{P}$ sobre las micorrizas, deriva de respuestas fisiológicas de las plantas que atentan contra los mecanismos de formación y mantenimiento de las micorrizas. La importancia de la infectividad como parámetro de calidad del suelo se manifestó a través de su relación con la producción de biomasa vegetal y acumulación de $P$ del cultivo. Al observarse que estos resultados correspondieron a valores basados en la comunidad (i.e. variables por unidad de superficie) y no en plantas individuales, es posible 
que las redes de micelio micorrícico que conectan a las plantas del cultivo estén permitiendo una mejor distribución de los recursos entre plantas conectadas. Estos resultados permitieron dilucidar las implicancias del mantenimiento de los HFMA del suelo ya que una producción sustentable es aquella que considera tanto la performance de los cultivos como de las comunidades de microorganismos simbióticos del suelo (Kiers y Denison, 2014).

El estudio de la estructura de las comunidades autóctonas de Glomeromycota basado en la morfología de esporas y en técnicas moleculares sobre muestras de suelo, generó valiosa información que servirá de antecedente para futuras investigaciones. Ambas técnicas fueron complementarias desde el punto de vista de la información que proporcionaron. Basados en la morfología de esporas, en este trabajo se identificaron 36 especies de HFMA, 7 de las cuales se hallaron luego de multiplicación en plantas trampa. Este resultado representa uno de los relevamientos de mayor riqueza de especies hallada en un agroecosistema (Cofré, 2014; Schalamuk y Cabello, 2009; Schalamuk et al., 2006). Adicionalmente, la secuenciación a partir de muestras de ADN de suelo detectó 84 VT (taxa virtual o filogrupo), uno de los valores más altos registrados en sistemas agrícolas (Lumini et al., 2010; Helgason et al., 1998). Ambas metodologías brindaron información complementaria y en cierto punto contradictoria. Por un lado, las esporas reflejaron que la zona de Sierras poseía una comunidad más rica, diversa y equilibrada. Se ha reportado que suelos con vegetación nativa poseen mayor diversidad que cuando son afectados por la mano del hombre (Cofré, 2014; Colombo et al., 2014) y que la fertilización y el uso de pesticidas pueden alterar el equilibrio de las comunidades nativas de HFMA afectando la diversidad (Bainard et al., 2014; Beauregard et al., 2013; Druille et al., 2013ab). Por otro lado, el ADN demostró que los suelos de las zonas Agrícola y de Sierras no diferían entre sí en la riqueza de HFMA y que la zona Mixta alojaba una comunidad diferente (Tabla 4.4). Los análisis de correlación (vectorial y test de Mantel) mostraron que el gradiente textural habría sido la característica definitoria de las comunidades de HFMA identificadas a partir de muestras de ADN (Figura 4.5a). Es decir, según esta metodología, el predominio de arena (i.e. zona Mixta) o arcilla (i.e. zonas Agrícola y de Sierras) fue el factor que determinó la estructura de la comunidad de HFMA del suelo. Al interpretar esta información puede deducirse que ambos análisis (taxonómico y molecular) fueron necesarios para comprender el verdadero impacto del cultivo de soja y del ambiente edáfico sobre este componente de la biota del suelo. La gran diferencia entre ambas aproximaciones metodológicas (i.e. morfología de esporas vs 
técnicas moleculares) radica en que mientras las esporas reflejan componentes activos y viables de HFMA; la técnica molecular basada en ADN genómico del suelo puede contener moléculas de ADN o células de especies que no necesariamente podrán establecer simbiosis por no ser metabólicamente activas (Baldrian et al., 2012). La siembra directa, al prescindir de la remoción del suelo, podría ser propicia para la preservación de dicha información genética (Zhang et al., 2015). En términos generales, el hecho de que a través de las esporas se haya detectado un efecto deletéreo del historial de uso del suelo, que trascendió la característica textural, es un alerta sobre la pérdida de diversidad de Glomeromycota como consecuencia de la agriculturización a largo plazo.

Sin lugar a dudas, una de las ventajas más notables de las técnicas moleculares es la identificación de especies o taxa de HFMA dentro de las raíces de la planta huésped. En esta tesis, se observó que las raíces de la zona de mayor historial de uso antrópico (zona Agrícola) presentaron una comunidad micorrícica distinta a la de cualquier otra comunidad hallada en este estudio (Tabla 4.4). Entre los potenciales causantes del ensamblaje intra-radical de las comunidades, la intensidad del manejo agrícola se ha citado como generador de anidamiento de las comunidades (Verbruggen et al., 2012). Este concepto es muy utilizado para describir un patrón de ensamblaje no aleatorio de las especies. Aunque Verbruggen et al. (2012) y Vályi et al. (2014) encontraron que la causa del anidamiento era la pérdida de especies debido a las prácticas de manejo y la intensidad de uso del suelo, respectivamente; en este estudio la riqueza se mantuvo estable entre las zonas (Figura 4.3). Entonces, la variación en abundancia de los taxa sería la causa del ensamblaje diferencial de las comunidades de HFMA dentro de las raíces. En este estudio, los sitios Agrícolas fueron los de mayor historial bajo prácticas antropogénicas, las cuales en los últimos años se focalizaron en priorizar el rendimiento de la soja mediante el uso de pesticidas y fertilizantes. Druille et al. (2013ab; 2015) demostraron que el glifosato afecta la viabilidad de las esporas y la colonización micorrícica, y hay cuantiosa información sobre el efecto de la fertilización sobre la composición de las comunidades dentro de las raíces y la abundancia de especies (Camenzind et al., 2014, Beauregard et al., 2010; Liu et al., 2015). En consecuencia, ante un mayor historial sojero es posible que ciertos taxa hayan desarrollado habilidades competitivas para colonizar las raíces dando como resultado una comunidad que no sólo fue diferente a cualquier otra en este estudio (Figura 4.5b), sino que también difirió a la hallada 
en el suelo circundante (Figura 4.6a, Tabla 4.4). Mediante la secuenciación de la porción del gen 18S rRNA amplificado a partir de las muestras de ADN de raíces, también se pudo corroborar los resultados inferidos del bioensayo de infectividad micorrícica. En este sentido, se observó que los suelos de menor infectividad (zona Mixta) fueron los de menor riqueza de taxa dentro de las raíces de soja (Figura 4.3). Es decir, que se confirmaron los efectos negativos del alto $\mathrm{P}$ y arena del suelo, tanto en el inicio como en el mantenimiento de la simbiosis. En el Capítulo 2 se había planteado que en condiciones semiáridas, de suelos arenosos, la simbiosis posiblemente era llevada a cabo por un reducido número de especies de acuerdo a su estrategia de colonización (Hart y Reader, 2005). Los resultados obtenidos sugieren que fueron las condiciones edáficas las que no favorecieron el inicio de la simbiosis. Podría especularse, entonces, que la macroporosidad de los suelos arenosos habría dificultado el contacto entre el inóculo y las raíces de soja, lo cual es un requisito indispensable para el inicio de la infección (Wilson y Trinick, 1983); además, la escasez de agua y las altas temperaturas propias de un clima semiárido interfieren en las etapas de germinación de esporas (Tommerup, 1983) y el desarrollo de microorganismos intervinientes en dicho proceso (Tommerup, 1985). El establecimiento de la simbiosis en plantas de soja aún bajo condiciones tan desfavorables plantea el interrogante acerca de los mecanismos que les permite llevarlo a cabo.

Otro aspecto a destacar de este estudio son las especies indicadoras y abundantes halladas a través del método tradicional de identificación de esporas y la secuenciación. Una especie indicadora es un organismo que define un rasgo o característica del ambiente en el que se encuentra, pueden ser especies raras o dominantes ante un ambiente o condición (Dufrene y Legendre, 1997). Las especies o taxa abundantes, en cambio, son generalmente ubicuas y altamente frecuentes y abundantes en gran variedad de ecosistemas (Vályi et al., 2014). Según Peay (2014), con el advenimiento de las técnicas de secuenciación de última generación, la información disponible sobre la composición de las comunidades fúngicas es cada día más abundante. El autor propone que los estudios no se limiten solamente a generar un listado de los taxa sino que se aborden con más detalle especies individuales, al menos, aquellas predominantes. Entonces, en los Capítulos 3 y 4 se identificaron las especies más abundantes; y su presencia e implicancias en el agroecosistema se discutieron detalladamente. En este sentido, una de las especies halladas merece especial atención: 
Glomus fuegianum. A través de la morfología de esporas, se pudo identificar como una especie de gran abundancia en el área de estudio e indicadora de la zona Agrícola (Tablas 3.1 y 3.3; Figura 3.3). Se mencionó además, que es un caso especial ya que es escasamente citada en la literatura internacional (Blaszkowski et al., 1998; Goto y Maia, 2005; McGee y Trappe, 2002), y aunque es más frecuente en estudios locales, no ha sido reportada como una especie abundante (Becerra et al., 2011; Cofré, 2014; Colombo et al., 2014; Lugo y Cabello, 2002). Sin embargo, la abundancia de esta especie no apareció reflejada en los resultados obtenidos a partir de técnicas moleculares. Varios motivos podrían ser los causantes de la diferencia entre la información generada a partir de ambas metodologías. En primer lugar, la asignación taxonómica de las secuencias de este estudio se realizó mediante la comparación con una base de datos de secuencias pre-existentes (MaarjAM), en la cual no hay registros de Glomus fuegianum. Este hecho no es anómalo ya que de las 261 especies identificadas por caracteres de esporas, (http://schuessler.userweb.mwn.de/ consulta 21/04/2016) sólo c. 30\% ha sido secuenciada a partir de cultivos puros (Hart et al. 2015). En la base de datos de MaarjAM, los filogrupos compuestos por secuencias con $\geq 97 \%$ de similitud fueron identificados como "taxa virtual" (Öpik et al., 2010). Esto correspondería a "especies moleculares" o "especies ambientales" ya que muchas de ellas no poseen dentro de su filogrupo ninguna secuencia de HFMA obtenida a partir de cultivos puros de esporas (Hibbett y Taylor, 2013). En MaarjAM, se alcanzaron los 353 taxa (última actualización: 04/02/2015), y este número sigue creciendo, lo que podría indicar que la riqueza de Glomeromycota aún está siendo subestimada (Öpik et al., 2014). Por otra parte, Öpik et al. (2010) observaron que el criterio de asignación de taxa basado en la similitud de una porción del gen $18 \mathrm{~S}$ rRNA no posee el mismo poder resolutivo en la diferenciación de especies para todos los géneros de HFMA, principalmente Ambispora, Diversispora y Scutellospora (de Souza et al., 2005; Walker et al., 2007; Gamper et al., 2009). Es decir, para estos géneros, la base de datos MaarjAM clasifica en un rango taxonómico más alto que el de especie (Gamper et al., 2009). Lo que podría haber sucedido con las secuencias de Glomus fuegianum es que quedaron agrupadas junto con las de Glomus fasciculatum en el filogrupo denominado VT113. Esto se fundamenta en que, mientras que Glomus fuegianum fue muy frecuente y abundante, no se identificaron esporas de Glomus fasciculatum ni en las muestras de campo ni a partir de plantas trampa (Tabla 3.1). Tal como menciona Peay (2014), incluso cuando los algoritmos y las bases de datos se perfeccionen, los estudios no 
pueden prescindir del conocimiento sobre la ecología y la biología de las especies. Los resultados de este estudio demuestran la importancia de la generación de información basada en la taxonomía de esporas como complemento de la información generada a partir de técnicas de secuenciación de última generación, y viceversa.

El rol del P en la simbiosis entre HFMA autóctonos y el cultivo de soja se pudo ir visualizando a lo largo de los Capítulos de esta tesis. En el Capítulo 2, se demostró su rol en la regulación y desarrollo de la infección micorrícica, y mantuvo siempre correlaciones negativas tanto con la infectividad como con los porcentajes de estructuras fúngicas cuantificadas en la raíz. En el Capítulo 3, este nutriente demostró afectar negativamente a las comunidades nativas de HFMA, principalmente la riqueza, diversidad y densidad de esporas. Además, en la Figura 3.6, se observa cómo las comunidades de mayor riqueza de especies se correlacionaron fuertemente con el contenido de P de la planta y, de modo opuesto, con la oferta de P del suelo. Este resultado posee una connotación sobresaliente acerca de la importancia del mantenimiento de las especies autóctonas de Glomeromycota para garantizar el aprovechamiento de $\mathrm{P}$ del suelo, especialmente en suelos de baja disponibilidad del nutriente. En el Capítulo 4, se infirió que el efecto del P del suelo estuvo parcialmente subordinado por otras condiciones restrictivas inherentes a las propiedades texturales. Finalmente, en el Capítulo 5, en un experimento ad hoc con una comunidad de HFMA nativa adaptada a 40 años de monocultivo de soja sin fertilización, los resultados demostraron el rol benéfico de estos organismos. Por un lado, el monocultivo podría haber favorecido a especies de HFMA más infectivas en detrimento de otras más mutualistas, sin embargo, la ausencia de fertilización podría haber generado lo opuesto (Fester y Sawers, 2010; Johnson, 2009). Los resultados demostraron el efecto benéfico en términos de adquisición de $P$ y acumulación de biomasa de las plantas de soja incluso en niveles altos de P (Figura 5.4, Tabla 5.2). El vínculo sinérgico entre los HFMA con otros integrantes de la microbiota del suelo podría ser una de las principales causas de las mejoras en los parámetros de crecimiento hallados en plantas micorrizadas en ausencia de limitaciones nutricionales (Artursson et al., 2006). Es posible concluir entonces, que a pesar del efecto del P sobre la composición de las comunidades nativas de Glomeromycota y el impacto negativo que presentó sobre índices biológicos e infectividad; en esta tesis se detectaron evidencias de respuesta positiva de la soja a la formación de la simbiosis micorrícica, aún en condiciones de elevada oferta del nutriente. 


\section{Futuras líneas de investigación que surgen de la tesis}

Los resultados obtenidos han permitido dilucidar gran parte de los interrogantes planteados. Sin embargo, surgieron nuevas inquietudes y una de las más destacadas es la necesidad de generar cultivos puros de esporas de Glomus fuegianum y su posterior secuenciación para incorporarlo a bases de datos internacionales pertinentes. Para tener en cuenta la variabilidad de secuencias dentro de la misma especie habría que secuenciar esporas generadas a partir de diferentes cultivos de Glomus fuegianum, varias esporas de cada uno (Selosse et al., 2016), e ingresar a las bases de datos la totalidad de las secuencias generadas para obtener información de la variabilidad de las mismas (Hart et al., 2015). De esta manera se podrá conocer la prevalencia de esta especie a nivel internacional, sin embargo, debido a su frecuencia en estudios locales, permitirá enriquecer los estudios nacionales basados en estas nuevas tecnologías. Esto mismo debería realizarse para diferentes especies halladas en los suelos en estudio y contemplando diferentes regiones del ribosoma para la asignación taxonómica en estudios ambientales (Lindahl, et al., 2013). 


\section{BIBLIOGRAFIA}

Abdel-Fattah GM. 2001. Measurement of the viability of arbuscular-mycorrhizal fungi using three different stains; relation to growth and metabolic activities of soybean plants. Microbiological Research 156(4): 359-367.

Alguacil Mdel M, Lumini E, Roldan A, Salinas-García JR, Bonfante P, Bianciotto V. 2008. The impact of tillage practices on arbuscular mycorrhizal fungal diversity in subtropical crops. Ecological Applications 18(2): 527-536.

Alguacil Mdel M, Torrecillas E, Lozano Z, Torres MP, Roldan A. 2014. Prunus persica crop management differentially promotes arbuscular mycorrhizal fungi diversity in a tropical agro-ecosystem. PLoS One 9(2): e88454.

Altieri MA. 1999. The ecological role of biodiversity in agroecosystems. Agriculture, Ecosystems \& Environment 74(1): 19-31.

An Z-Q, Hendrix J, Hershman D, Ferriss R, Henson G. 1993. The influence of crop rotation and soil fumigation on a mycorrhizal fungal community associated with soybean. Mycorrhiza 3(4): 171-182.

Anderson MJ. 2001. A new method for non-parametric multivariate analysis of variance. Austral Ecology 26: 32-46.

Anderson R, Liberta A, Dickman L. 1984. Interaction of vascular plants and vesiculararbuscular mycorrhizal fungi across a soil moisture-nutrient gradient. Oecologia 64(1): 111-117.

Artursson V, Finlay RD, Jansson JK. 2006. Interactions between arbuscular mycorrhizal fungi and bacteria and their potential for stimulating plant growth. Environmental Microbiology 8(1): 1-10.

Asghari HR, Cavagnaro TR. 2012. Arbuscular mycorrhizas reduce nitrogen loss via leaching. PLoS One 7(1): e29825.

Asimi S, Gianinazzi-Pearson V, Gianinazzi S. 1980. Influence of increasing soil phosphorus levels on interactions between vesicular-arbuscular mmycorrhizae and Rhizobiu, in soybeans. Canadian Journal of Botany 58: 2200-2205. 
Augé RM. 2001. Water relations, drought and vesicular-arbuscular mycorrhizal symbiosis. Mycorrhiza 11(1): 3-42.

Bago B, Pfeffer PE, Schachar-Hill Y. 2000. Carbon metabolism and transport in arbuscular mycorrhizas. Plant Physiology 124: 949-957.

Bago B, Zipfel W, Williams RM, Jun J, Arreola R, Lammers PJ, Pfeffer PE, Shachar-Hill Y. 2002. Translocation and utilization of fungal storage lipid in the arbuscular mycorrhizal symbiosis. Plant Physiology 128(1): 108-124.

Bainard LD, Bainard JD, Hamel C, Gan Y. 2014. Spatial and temporal structuring of arbuscular mycorrhizal communities is differentially influenced by abiotic factors and host crop in a semi-arid prairie agroecosystem. FEMS Microbiology Ecology 88(2): 333-344.

Baldrian P, Kolařík M, Štursová M, Kopecký J, Valášková V, Větrovský T, Žifčáková L, Šnajdr J, Rídl J, Vlček Č. 2012. Active and total microbial communities in forest soil are largely different and highly stratified during decomposition. ISME Journal 6(2): 248-258.

Balzergue C, Puech-Pagès V, Bécard G, Rochange SF. 2010. The regulation of arbuscular mycorrhizal symbiosis by phosphate in pea involves early and systemic signalling events. Journal of Experimental Botany: erq335.

Barea J-M, Azcón R, Azcón-Aguilar C. 2002. Mycorrhizosphere interactions to improve plant fitness and soil quality. Antonie van Leeuwenhoek 81(1-4): 343-351.

Beauregard MS, Gauthier MP, Hamel C, Zhang T, Welacky T, Tan CS, St-Arnaud M. 2013. Various forms of organic and inorganic $P$ fertilizers did not negatively affect soil- and root-inhabiting AM fungi in a maize-soybean rotation system. Mycorrhiza 23(2): 143154.

Becerra AG, Cabello MN, Bartoloni NJ. 2011. Native arbuscular mycorrhizal fungi in the Yungas forests, Argentina. Mycologia 103(2): 273-279.

Bender SF, Conen F, Van der Heijden MG. 2015. Mycorrhizal effects on nutrient cycling, nutrient leaching and N 20 production in experimental grassland. Soil Biology and Biochemistry 80: 283-292. 
Berbery E, Doyle M, Barros V, Barros V, Clarke R, Silva Dias P. 2006. Tendencias regionales en la precipitación. El cambio climático en la Cuenca del Plata. CONICET, Buenos Aires: 67-92.

Bert FE, Podestá GP, Rovere SL, Menéndez ÁN, North M, Tatara E, Laciana CE, Weber E, Toranzo FR. 2011. An agent based model to simulate structural and land use changes in agricultural systems of the argentine pampas. Ecological Modelling 222(19): 34863499.

Berta G, Fusconi A, Trotta A, Scannerini S. 1990. Morphogenetic modifications induced by the mycorrhizal fungus Glomus strain E3 in the root system of Allium porrum L. New Phytologist 114(2): 207-215.

Bethlenfalvay GJ, Bayne HG, Pacovsky RS. 1983. Parasitic and mutualistic associations between a mycorrhizal fungus and soybean: The effect of phosphorus on host plant-endophyte interactions. Physiologia Plantarum 57(4): 543-548.

Bever JD, Morton JB, Antonovics J, Schultz PA. 1996. Host-dependent sporulation and species diversity of arbuscular mycorrhizal fungi in a mown grassland. Journal of Ecology: 71-82.

Bever JD. 2002. Negative feedback within a mutualism: host-specific growth of mycorrhizal fungi reduces plant benefit. Proceedings of the Royal Society of London B: Biological Sciences 269(1509): 2595-2601.

Bianciotto V, Bandi C, Minerdi D, Sironi M, Tichy HV, Bonfante P. 1996a. An obligately endosymbiotic mycorrhizal fungus itself harbors obligately intracellular bacteria. Applied Environmental Microbiology 62(8): 3005-3010.

Bianciotto V, Minerdi D, Perotto S, Bonfante P. 1996b. Cellular interactions between arbuscular mycorrhizal fungi and rhizosphere bacteria. Protoplasma 193(1-4): 123131.

Biermann B, Linderman RG. 1983. Use of vesicular -arbuscular mycorrhizal roots, intraradical vesicles and extraradical vesicles as inoculum. New Phytologist 95: 97-105.

Biermann B, Linderman RG. 1983. Use of vesicular -arbuscular mycorrhizal roots, intraradical vesicles and extraradical vesicles as inoculum. New Phytologist 95: 97-105. 
Błaszkowski J. 2012. Glomeromycota: W. Szafer Institute of Botany, Polish Academy of Sciences. ISBN 8389648822

Blazskowski, J; T. Madej, M. Tadych. 1998. Entrophospora baltica sp nov and Glomus fuegianum, two species in the Glomales from Poland. Mycotaxon 68:165-184

Bonfante-Fasolo P 1988. The role of the cell wall as a signal in mycorrhizal associations. Cell to cell signals in plant, animal and microbial symbiosis: Springer, 219-235.

Bray RH, Kurtz L. 1945. Determination of total, organic, and available forms of phosphorus in soils. Soil Science 59(1): 39-46.

Bremmer J. 1965. Nitrogen availability indexes. Methods of soil analysis, part 2: 1324-1345.

Breuillin F, Schramm J, Hajirezaei M, Ahkami A, Favre P, Druege U, Hause B, Bucher M, Kretzschmar T, Bossolini E. 2010. Phosphate systemically inhibits development of arbuscular mycorrhiza in Petunia hybrida and represses genes involved in mycorrhizal functioning. The Plant Journal 64(6): 1002-1017.

Brito I, Goss MJ, de Carvalho M, Chatagnier O, van Tuinen D. 2012. Impact of tillage system on arbuscular mycorrhiza fungal communities in the soil under Mediterranean conditions. Soil and Tillage Research 121: 63-67.

Brooks A. 1986. Effects of phosphorus nutrition on ribulose-1, 5-bisphosphate carboxylase activation, photosynthetic quantum yield and amounts of some Calvin-cycle metabolites in spinach leaves. Functional Plant Biology 13(2): 221-237.

Brown AD, Pacheco S, Brown A, Martínez Ortiz U, Acerbi M, Corcuera J. 2005. Propuesta de actualización del mapa ecorregional de la Argentina. La situación ambiental Argentina: 28-31.

Brundrett MC. 1999. Coevolution of roots and mycorrhizas of land plants. New Phytologist 154: $275-304$.

Brundrett MC. 2009. Mycorrhizal associations and other means of nutrition of vascular plants: understanding the global diversity of host plants by resolving conflicting information and developing reliable means of diagnosis. Plant and Soil 320(1-2): 3777. 
Bucher M. 2007. Functional biology of plant phosphate uptake at root and mycorrhiza interfaces. New Phytologist 173(1): 11-26.

Bundrett M, Ashwath N, Jasper D. 1996. Mycorrhizas in the Kakadu region of tropical Australia. Plant and Soil 184(1): 173-184.

Bunn R, Lekberg Y, Zabinski C. 2009. Arbuscular mycorrhizal fungi ameliorate temperature stress in thermophilic plants. Ecology 90(5): 1378-1388.

Cabello M, Gaspar L, Pollero R. 1994. Glomus antarcticum sp. nov., a vesicular-arbuscular mycorrhizal fungus from Antarctica. Mycotaxon (USA).

Cabido M, Zak M. 2010. Deforestación, agricultura y biodiversidad: apuntes sobre el panorama global y la realidad de Córdoba. Revista HOY la Universidad-UNCiencia. Universidad Nacional de Córdoba. Córdoba.

Camenzind T, Hempel S, Homeier J, Horn S, Velescu A, Wilcke W, Rillig MC. 2014. Nitrogen and phosphorus additions impact arbuscular mycorrhizal abundance and molecular diversity in a tropical montane forest. Global Change Biology 20(12): 3646-3659.

Canosa, FR. 2009. La producción de carne bovina. Un buen negocio para todos. En: El futuro dela ganadería. Boletín de la Asociación Argentina de Angus. Buenos Aires. Sitio: www.produccion-animal.com.ar. Consulta: 8 de febrero 2016

Cassman KG, Whitney AS, Stockinger K. 1980. Root growth and dry matter distribution of soybean as affected by phosphorus stress, nodulation, and nitrogen source. Crop Science 20(2): 239-244.

Chapin FS. 1980. The mineral nutrition of wild plants. Annual review of ecology and systematics $11: 233-260$.

Chapin III FS, Zavaleta ES, Eviner VT, Naylor RL, Vitousek PM, Reynolds HL, Hooper DU, Lavorel S, Sala OE, Hobbie SE. 2000. Consequences of changing biodiversity. Nature 405(6783): 234-242.

Cheng Y, Ishimoto K, Kuriyama Y, Osaki M, Ezawa T. 2013. Ninety-year-, but not single, application of phosphorus fertilizer has a major impact on arbuscular mycorrhizal fungal communities. Plant and Soil 365(1-2): 397-407. 
Ciereszko I, Gniazdowska A, Mikulska M, Rychter AM. 1996. Assimilate translocation in bean plants (Phaseolus vulgaris L.) during phosphate deficiency. Journal of Plant Physiology 149(3-4): 343-348.

Clemmensen K, Bahr A, Ovaskainen O, Dahlberg A, Ekblad A, Wallander H, Stenlid J, Finlay R, Wardle D, Lindahl B. 2013. Roots and associated fungi drive long-term carbon sequestration in boreal forest. Science 339(6127): 1615-1618.

Cofre MN 2014. Comunidades nativas de hongos micorrícicos arbusculares: respuesta frente a distintas prácticas agrícolas y efectos sobre el crecimiento de Glycine max (L.) Merril. In (IMBIV-CONICET) IMdBV, Facultad de Ciencias Exactas FyN, Córdoba UNd. 123.

Colombo RP, Fernández Bidondo L, Silvani V, Carbonetto M, Rascovan N, Bompadre M, Pérgola M, Cuenca G, Godeas A. 2014. Diversity of arbuscular mycorrhizal fungi in soil from the Pampa Ondulada, Argentina, assessed by pyrosequencing and morphological techniques. Canadian Journal of Microbiology 60(12): 819-827.

Covacevich F, Echeverría HE, Aguirrezabal LA. 2007. Soil available phosphorus status determines indigenous mycorrhizal colonization of field and glasshouse-grown spring wheat from Argentina. Applied Soil Ecology 35(1): 1-9.

Covacevich F, Echeverría HE. 2003. Utilización de formaldehído para la erradicación de hongos micorriticos arbusculares de muestras de suelo. Ciencia del Suelo 21: 9-17.

Coyne MS. 1999. Soil Microbiology - An Exploratory Approach: Delmar Cengage Learning. ISBN 9780827384354

DACYT 2003. Regiones naturales de la provincia de Córdoba: DIreccion de Ambiente. Web site: http://www.efn.unc.edu.ar/otros/bibliocentro/index archivos/37-Regiones.pdf

Daniell TJ, Husband R, Fitter AH, Young JP. 2001. Molecular diversity of arbuscular mycorrhizal fungi colonising arable crops. FEMS Microbiology Ecology 36: 203-209.

Davison J, Moora M, Öpik M, Adholeya A, Ainsaar L, Ba A, Burla S, Diedhiou A, Hiiesalu I, Jairus T. 2015. Global assessment of arbuscular mycorrhizal fungus diversity reveals very low endemism. Science 349(6251): 970-973. 
Davison J, Öpik M, Zobel M, Vasar M, Metsis M, Moora M. 2012. Communities of arbuscular mycorrhizal fungi detected in forest are spatially heterogeneous but do not vary throughout the growing season. PLoS One 7(8): e41938.

de Souza FA, Kowalchuk GA, Leeflang P, van Veen JA, Smith E. 2005. PCR-denaturing gradient gel electrophoresis profiling of inter- and intraspecies 18S rRNA gene sequence heterogeneity is an accurate and sensitive method to assess species diversity of arbuscular mycorrhizal fungi of the genus Gigaspora. Applied Environmental Microbiology 70: 1413-1424.

Di Rienzo JA, Casanoves F, Balzarini MG, Gonzalez L, Tablada M, Robledo CW 2014. InfoStat versión 2014. Grupo InfoStat.In Agrarias FdC, Córdoba UNd, Argentina.

Douds Jr DD, Pfeffer PE, Shachar-Hill Y 2000. Carbon partitioning, cost, and metabolism of arbuscular mycorrhizas. Arbuscular mycorrhizas: physiology and function: Springer, 107-129.

Driver, J.D., W.E. Holben, and M.C. Rillig. 2005. Characterization of glomalin as a hyphal wall Component of arbuscular mycorrhizal fungi. Soil Biology and Biochemistry 37:101106.

Druille M, Cabello M, Parisi PG, Golluscio R, Omacini M. 2015. Glyphosate vulnerability explains changes in root-symbionts propagules viability in pampean grasslands. Agriculture, Ecosystems \& Environment 202: 48-55.

Druille M, Cabello MN, Omacini M, Golluscio RA. 2013a. Glyphosate reduces spore viability and root colonization of arbuscular mycorrhizal fungi. Applied Soil Ecology 64: 99103.

Druille M, Omacini M, Golluscio RA, Cabello MN. 2013b. Arbuscular mycorrhizal fungi are directly and indirectly affected by glyphosate application. Applied Soil Ecology 72: 143-149.

Dufrêne M, Legendre P. 1997. Species assemblages and indicator species: the need for a flexible asymmetrical approach. Ecological monographs 67(3): 345-366.

Duvert P, Perrin R, Plenchette C. 1990. Soil receptiveness to VA mycorrhizal association: concept and method. Plant and Soil 124(1): 1-6. 
Edgar RC, Haas BJ, Clemente JC, Quince C, Knight R. 2011. UCHIME improves sensitivity and speed of chimera detection. Bioinformatics 27(16): 2194-2200.

Egerton-Warburton LM, Johnson NC, Allen EB. 2007. Mycorrhizal community dynamics following nitrogen fertilization: a cross-site test in five grasslands. Ecological monographs 77(4): 527-544.

Endlweber K, Scheu S. 2006. Establishing arbuscular mycorrhiza-free soil: a comparison of six methods and their effects on nutrient mobilization. Applied Soil Ecology 34(2): 276279.

Ezawa T, Smith SE, Smith FA. 2002. P metabolism and transport in AM fungi. Plant and Soil 244(1-2): 221-230.

Fabrizzi K, Garcia F, Costa J, Picone L. 2005. Soil water dynamics, physical properties and corn and wheat responses to minimum and no-tillage systems in the southern Pampas of Argentina. Soil and Tillage Research 81(1): 57-69.

FAO 2002. Agricultura mundial: hacia los años 2015/2030: informe resumido. World agriculture: towards 2015/2030: summary report. Agriculture mondiale: horizon 2015/2030: rapport abrégé.

FAO 2015. FAOSTAT: Food and Agriculture Organization of the United Nations. - Statistics Division.

Fehr W, Caviness C, Burmood D, Pennington J. 1971. Stage of development descriptions for soybeans, Glycine max (L.) Merrill. Crop Science 11(6): 929-931.

Fernandez M, Belinque H, Boem FG, Rubio G. 2009. Compared phosphorus efficiency in soybean, sunflower and maize. Journal of plant nutrition 32(12): 2027-2043.

Fernández M, Gutiérrez Boem F, Rubio G. 2011. Effect of indigenous mycorrhizal colonization on phosphorus-acquisition efficiency in soybean and sunflower. Journal of Plant Nutrition and Soil Science 174(4): 673-677.

Fester T, Sawers R. 2011. Progress and challenges in agricultural applications of arbuscular mycorrhizal fungi. Critical Reviews in Plant Sciences 30(5): 459-470.

Fitter AH. 2005. Darkness visible: reflections on underground ecology. Journal of Ecology 93(2): 231-243. 
Fougnies L, Renciot S, Muller F, Plenchette C, Prin Y, de Faria S, Bouvet J, Sylla SN, Dreyfus B, Bâ A. 2007. Arbuscular mycorrhizal colonization and nodulation improve flooding tolerance in Pterocarpus officinalis Jacq. seedlings. Mycorrhiza 17(3): 159-166.

Fredeen AL, Rao IM, Terry N. 1989. Influence of phosphorus nutrition on growth and carbon partitioning in Glycine max. Plant Physiology 89(1): 225-230.

Fredeen AL, Terry N. 1988. Influence of vesicular-arbuscular mycorrhizal infection and soil phosphorus level on growth and carbon metabolism of soybean. Canadian Journal of Botany 66(11): 2311-2316.

Gamper HA, Walker C, Schußler A. 2009. Diversispora celata sp. nov:molecular ecology and phylotaxonomy of an inconspicuous arbuscular mycorrhizal fungus. New Phytologist 182: 495-506.

Gee G, Bauder J. 1986. 15-Particle size analyses. Madison: ASA and SSSA.

Gerdemann JW, Nicolson TH. 1963. Spores of mycorrhizal Endogone species extracted from soil by wet sieving and decanting. Transactions of the British Mycological Society 46(2): 235-244.

Ghida-Daza C, Sanchez C. 2009. Zonas agroeconómicas homogeneas de Córdoba. Buenos Aires, Argentina: INTA.

Giovannetti M, Sbrana C, Avio L, Strani P. 2004. Patterns of below-ground plant interconnections established by means of arbuscular mycorrhizal networks. New Phytologist 164(1): 175-181.

Gosling P, Mead A, Proctor M, Hammond JP, Bending GD. 2013. Contrasting arbuscular mycorrhizal communities colonizing different host plants show a similar response to a soil phosphorus concentration gradient. New Phytologist 198(2): 546-556.

Goto BT, Maia LC. 2005. Sporocarpic species of arbuscular mycorrhizal fungi (Glomeromycota), with a new report from Brazil. Acta Botanica Brasilica 19(3): 633637.

Graham J, Duncan L, Eissenstat D. 1997. Carbohydrate allocation patterns in citrus genotypes as affected by phosphorus nutrition, mycorrhizal colonization and mycorrhizal dependency. New Phytologist 135(2): 335-343. 
Graham JH, Leonard RT, Menge JA. 1981. Membrane-mediated decrease in root exudation responsible for phorphorus inhibition of vesicular-arbuscular mycorrhiza formation. Plant Physiology 68(3): 548-552.

Grilli G, Urcelay C, Galetto L, Davison J, Vasar M, Saks U, Jairus T, Opik M. 2014. The composition of arbuscular mycorrhizal fungal communities in the roots of a ruderal forb is not related to the forest fragmentation process. Environmental Microbiology. DOI 10.1111/1462-2920.12623

Grümberg BC, Urcelay C, Shroeder MA, Vargas-Gil S, Luna CM. 2015. The role of inoculum identity in drought stress mitigation by arbuscular mycorrhizal fungi in soybean. Biology and Fertility of Soils 51(1): 1-10.

Gutierrez Boem F, Salvagiotti F. 2015. Soja. En: Fertilidad de Suelos y Fertilización de Cultivos. Editores: Echeverria HE, García FO. Buenos Aires Agentina. INTA. Páginas: 479-508

Gutjahr C, Parniske M. 2013. Cell and developmental biology of arbuscular mycorrhiza symbiosis. Annual Review of Cell Develpment Biology 29: 593-617.

Harrison MJ. 2005. Signaling in the arbuscular mycorrhizal symbiosis. Annual Review of Microbiology 59: 19-42.

Hart MM, Aleklett K, Chagnon PL, Egan C, Ghignone S, Helgason T, Lekberg Y, Opik M, Pickles BJ, Waller L. 2015. Navigating the labyrinth: a guide to sequence-based, community ecology of arbuscular mycorrhizal fungi. New Phytologist 207(1): 235-247

Hart MM, Reader RJ. 2002. Taxonomic basis for variation in the colonization strategy of arbuscular mycorrhizal fungi. New Phytologist 153(2): 335-344.

Hart MM, Reader RJ. 2002. Taxonomic basis for variation in the colonization strategy of arbuscular mycorrhizal fungi. New Phytologist 153(2): 335-344.

Hart MM, Reader RJ. 2005. The role of the external mycelium in early colonization for three arbuscular mycorrhizal fungal species with different colonization strategies. Pedobiologia 49(3): 269-279.

Helgason T, Daniell TJ, Husband R, Fitter AH, Young JP. 1998. Ploughing up the wood-wide web? Nature 394: 431. 
Helgason T, Merryweather W, Denison J, Wilson P, Young JP, Fitter AH. 2002. Selectivity and functional diversity in arbuscular mycorrhizas of co-occuring fungi and plants from a temperate deciduos woodland. Journal of Ecology 90: 371-384.

Hendrix JW, Guo B, An Z-Q. 1995. Divergence of mycorrhizal fungal communities in crop production systems. Plant and Soil 170(1): 131-140.

Hermans C, Hammond JP, White PJ, Verbruggen N. 2006. How do plants respond to nutrient shortage by biomass allocation? Trends in Plant Science 11(12): 610-617.

Hibbett DS, Taylor JW. 2013. Fungal systematics: is a new age of enlightenment at hand? Nature Review Microbiology 11(2): 129-133.

Higo M, Isobe K, Drijber RA, Kondo T, Yamaguchi M, Takeyama S, Suzuki Y, Niijima D, Matsuda Y, Ishii R, et al. 2014. Impact of a 5-year winter cover crop rotational system on the molecular diversity of arbuscular mycorrhizal fungi colonizing roots of subsequent soybean. Biology and Fertility of Soils 50(6): 913-926.

Higo M, Isobe K, Kondo T, Yamaguchi M, Takeyama S, Drijber RA, Torigoe Y. 2015. Temporal variation of the molecular diversity of arbuscular mycorrhizal communities in three different winter cover crop rotational systems. Biology and Fertility of Soils 51(1): 2132.

Higo M, Isobe K, Yamaguchi M, Drijber RA, Jeske ES, Ishii R. 2013. Diversity and vertical distribution of indigenous arbuscular mycorrhizal fungi under two soybean rotational systems. Biology and Fertility of Soils 49(8): 1085-1096.

Hiiesalu I, Partel M, Davison J, Gerhold P, Metsis M, Moora M, Opik M, Vasar M, Zobel M, Wilson SD. 2014. Species richness of arbuscular mycorrhizal fungi: associations with grassland plant richness and biomass. New Phytologist 203(1): 233-244.

Hijri I, Sykorova Z, Oehl F, Ineichen K, Mader P, Wiemken A, Redecker D. 2006. Communities of arbuscular mycorrhizal fungi in arable soils are not necessarily low in diversity. Molecular Ecology 15(8): 2277-2289.

INTA. 1978. Carta de Suelos de la Republica Argentina. Instituto Nacional de Tecnologia Agropecuaria - Argentina Hoja 3363-17 
INTA. 1985. Carta de Suelos de la Republica Argentina. Instituto Nacional de Tecnologia Agropecuaria - Argentina Hoja 3363 - 23.

INTA. 1996. Carta de Suelos de la Republica Argentina. Instituto Nacional de Tecnologia Agropecuaria - Argentina Hojas 3366 - 12; 3366 - 18.

INTA. 2004. Carta de Suelos de la Republica Argentina. Instituto Nacional de Tecnologia Agropecuaria - Argentina Hojas 3563 - 7; 3566 - 12; 3566 - 18.

Jakobsen I 1995. Transport of phosphorus and carbon in VA mycorrhizas. Mycorrhiza: Springer, 297-324.

Jakobsen I, Abbott L, Robson A. 1992. External hyphae of vesicular-arbuscular mycorrhizal fungi associated with Trifolium subterraneum L. New Phytologist 120(3): 371-380.

Jakobsen I, Gazey C, Abbott L. 2001. Phosphate transport by communities of arbuscular mycorrhizal fungi in intact soil cores. New Phytologist 149(1): 95-103.

Jakobsen I, Rosendahl L. 1990. Carbon flow into soil and external hyphae from roots of mycorrhizal cucumber plants. New Phytologist 115(1): 77-83.

Jansa J, Erb A, Oberholzer HR, Šmilauer P, Egli S. 2014. Soil and geography are more important determinants of indigenous arbuscular mycorrhizal communities than management practices in Swiss agricultural soils. Molecular Ecology 23(8): 21182135.

Jansa J, Mozafar A, Frossard E. 2005. Phosphorus Acquisition Strategies within Arbuscular Mycorrhizal Fungal Community of a Single Field Site. Plant and Soil 276(1-2): 163-176.

Jansa J, Oberholzer H-R, Egli S. 2009. Environmental determinants of the arbuscular mycorrhizal fungal infectivity of Swiss agricultural soils. European Journal of Soil Biology 45(5): 400-408.

Jasper D, Abbott L, Robson A. 1989. Hyphae of a vesicular-arbuscular mycorrhizal fungus maintain infectivity in dry soil, except when the soil is disturbed. New Phytologist 112(1): 101-107.

Javot H, Pumplin N, Harrison MJ. 2007. Phosphate in the arbuscular mycorrhizal symbiosis: transport properties and regulatory roles. Plant, Cell and Environment 30(3): 310322. 
Jenkinson D, Powlson D. 1976. The effects of biocidal treatments on metabolism in soil-I. Fumigation with chloroform. Soil Biology and Biochemistry 8(3): 167-177.

Johansson JF, Paul LR, Finlay RD. 2004. Microbial interactions in the mycorrhizosphere and their significance for sustainable agriculture. FEMS Microbiology Ecology 48(1): 1-13.

Johnson D, Leake J, Ostle N, Ineson P, Read D. 2002. In situ ${ }^{13} \mathrm{CO}_{2}$ pulse-labelling of upland grassland demonstrates a rapid pathway of carbon flux from arbuscular mycorrhizal mycelia to the soil. New Phytologist 153(2): 327-334.

Johnson N, Graham JH, Smith F. 1997. Functioning of mycorrhizal associations along the mutualism-parasitism continuum. New Phytologist 135(4): 575-585.

Johnson NC, Angelard C, Sanders IR, Kiers ET. 2013. Predicting community and ecosystem outcomes of mycorrhizal responses to global change. Ecology letters 16(s1): 140-153.

Johnson NC, Chaudhary VB, Hoeksema JD, Moore JC, Pringle A. 2009. Mysterious Mycorrhizae? A Field Trip and Classroom Experiment to Demystify the Symbioses Formed Between Plants and Fungi. The American Biology Teacher, 71(7).

Johnson NC, Copeland PJ, Crookston RK, Pfleger F. 1992a. Mycorrhizae: possible explanation for yield decline with continuous corn and soybean. Agronomy Journal 84(3): 387390.

Johnson NC, Tilman D, Wedin D. 1992b. Plant and soil controls on mycorrhizal fungal communities. Ecology 73(6): 2034-2042.

Johnson NC, Pfleger F, Crookston R, Simmons SR, Copeland PJ. 1991. Vesicular-arbuscular mycorrhizas respond to corn and soybean cropping history. New Phytologist 117(4): 657-663.

Johnson NC. 1993. Can fertilization of soil select less mutualistic mycorrhizae? Bulletin of the Ecological Society of America 3(4): 749-757.

Johnson NC. 2010. Resource stoichiometry elucidates the structure and function of arbuscular mycorrhizas across scales. New Phytologist 185(3): 631-647.

Kabir, Z., 2005. Tillage or no-tillage: impact on mycorrhizae. Canadian Journal of Plant Science 85, 23-29. 
Kahiluoto, H., E. Ketoja, and M. Vestberg. 2009. Contribution of arbuscular mycorrhiza to soil quality in contrasting cropping systems. Agriculture, Ecosystems \& Environment 134:36-45.

Kelly R, Edwards D, Thompson J, Magarey R. 2001. Responses of sugarcane, maize, and soybean to phosphorus and vesicular-arbuscular mycorrhizal fungi. Crop and Pasture Science 52(7): 731-743.

Kiers E, West S, Denison R 2008. Maintaining cooperation in the legume-rhizobia symbiosis: identifying selection pressures and mechanisms. Nitrogen-fixing Leguminous Symbioses: Springer, 59-76.

Kiers ET, Denison RF. 2014. Inclusive fitness in agriculture. Philosophical Transaction of the Royal Society - Biological Sciences 369(1642): 20130367.

Kiers ET, Duhamel M, Beesetty $Y$, Mensah JA, Franken O, Verbruggen E, Fellbaum CR, Kowalchuk GA, Hart MM, Bago A. 2011. Reciprocal rewards stabilize cooperation in the mycorrhizal symbiosis. Science 333(6044): 880-882.

Kiers ET, West SA, Denison RF. 2002. Mediating mutualisms: Farm management practices and evolutionary changes in symbiont co-operation. Journal of applied Ecology 39(5): 745-754.

Kiriachek SG, Azevedo Ld, Peres LEP, Lambais MR. 2009. Regulação do desenvolvimento de micorrizas arbusculares. Revista Brasileira de Ciencia do Solo 33(1): 1-16.

Kivlin SN, Winston GC, Goulden ML, Treseder KK. 2014. Environmental filtering affects soil fungal community composition more than dispersal limitation at regional scales. Fungal Ecology 12: 14-25.

Klabi R, Bell TH, Hamel C, Iwaasa A, Schellenberg M, Raies A, St-Arnaud M. 2015. Plant assemblage composition and soil $\mathrm{P}$ concentration differentially affect communities of AM and total fungi in a semi-arid grassland. FEMS Microbiology Ecology 91(1): 1-13.

Klironomos JN, Hart MM. 2002. Colonization of roots by arbuscular mycorrhizal fungi using different sources of inoculum. Mycorrhiza 12(4): 181-184. 
Klironomos JN, McCune J, Hart M, Neville J. 2000. The influence of arbuscular mycorrhizae on the relationship between plant diversity and productivity. Ecology letters 3(2): 137-141.

Kohout $P$, Sudová $R$, Janoušková $M$, Čtvrtlíková $M$, Hejda $M$, Pánková $H$, Slavíková $R$, Štajerová K, Vosátka M, Sýkorová Z. 2014. Comparison of commonly used primer sets for evaluating arbuscular mycorrhizal fungal communities: Is there a universal solution? Soil Biology and Biochemistry 68: 482-493.

Koide RT. 1991. Nutrient supply, nutrient demand and plant response to mycorrhizal infection. New Phytologist 117(3): 365-386.

Koide RT. 2000. Functional complementarity in the arbuscular mycorrhizal symbiosis. New Phytologist 147(2): 233-235.

Koske R. 1981. Gigaspora gigantea: observations on spore germination of a VA-mycorrhizal fungus. Mycologia: 288-300.

Kough J, Gianinazzi-Pearson V, Gianinazzi S. 1987. Depressed metabolic activity of vesiculararbuscular mycorrhizal fungi after fungicide applications. New Phytologist 106(4): 707-715.

Lal R, Shukla MK. 2004. Principles of soil physics: CRC Press.

Lambais M. 2000. Regulation of plant defense-related genes in arbuscular mycorrhizae. Current Advances in Mycorrhizae Research. Section II: Mycorrhizal fungi and plant defense.(GK Podilla \& DD Douds Jr. eds.). APS Press USA: 45-60.

Landis FC, Gargas A, Givnish TJ. 2004. Relationships among arbuscular mycorrhizal fungi, vascular plants and environmental conditions in oak savannas. New Phytologist 164(3): 493-504.

Leake J, Johnson D, Donnelly D, Muckle G, Boddy L, Read D. 2004. Networks of power and influence: the role of mycorrhizal mycelium in controlling plant communities and agroecosystem functioning. Canadian Journal of Botany 82(8): 1016-1045.

Leake JR. 1994. The biology of myco-heterotrophic ('saprophytic') plants. New Phytologist 127(2): 171-216. 
Lee J, Lee S, Young JP. 2008. Improved PCR primers for the detection and identification of arbuscular mycorrhizal fungi. FEMS Microbiology Ecology 65(2): 339-349.

Lekberg Y, Koide R. 2006. Is plant performance limited by abundance of arbuscular mycorrhizal fungi? A meta-analysis of studies published between 1988 and 2003. New Phytologist 168(1): 189-204.

Lekberg Y, Koide RT, Rohr JR, Aldrich-Wolfe L, Morton JB. 2007. Role of niche restrictions and dispersal in the composition of arbuscular mycorrhizal fungal communities. Journal of Ecology 95(1): 95-105.

Lendenmann M, Thonar C, Barnard RL, Salmon Y, Werner RA, Frossard E, Jansa J. 2011. Symbiont identity matters: carbon and phosphorus fluxes between Medicago truncatula and different arbuscular mycorrhizal fungi. Mycorrhiza 21(8): 689-702.

Lendzemo V, Kuyper TW, Kropff M, van Ast Av. 2005. Field inoculation with arbuscular mycorrhizal fungi reduces Striga hermonthica performance on cereal crops and has the potential to contribute to integrated Striga management. Field Crops Research 91(1): 51-61.

Leyva A, Quintana A, Sánchez M, Rodríguez EN, Cremata J, Sánchez JC. 2008. Rapid and sensitive anthrone-sulfuric acid assay in microplate format to quantify carbohydrate in biopharmaceutical products: Method development and validation. Biologicals 36(2): 134-141.

Lindahl BD, Nilsson RH, Tedersoo L, Abarenkov K, Carlsen T, Kjoller R, Koljalg U, Pennanen T, Rosendahl S, Stenlid J, et al. 2013. Fungal community analysis by high-throughput sequencing of amplified markers--a user's guide. New Phytologist 199(1): 288-299.

Linderman R 1997. Vesicular-arbuscular mycorrhizal (VAM) fungi. Plant Relationships Part B: Springer, 117-128.

Liu W. 2010. Do genetically modified plants impact arbuscular mycorrhizal fungi? Ecotoxicology 19(2): 229-238.

Liu Y, Mao L, Li J, Shi G, Jiang S, Ma X, An L, Du G, Feng H. 2015. Resource availability differentially drives community assemblages of plants and their root-associated arbuscular mycorrhizal fungi. Plant and Soil 386(1-2): 341-355. 
Lovelock, C.E., S.F. Wright, D.A. Clark, and R.W. Ruess. 2004. Soil stocks of glomalin produced by arbuscular mycorrhizal fungi across a tropical rain forest landscape. Journal of Ecology 92:278-287.

Lugo MA, Cabello MN. 2002. Native arbuscular mycorrhizal fungi (AMF) from mountain grassland (Córdoba, Argentina) I. Seasonal variation of fungal spore diversity. Mycologia 94(4): 579-586.

Lumini E, Orgiazzi A, Borriello R, Bonfante P, Bianciotto V. 2010. Disclosing arbuscular mycorrhizal fungal biodiversity in soil through a land-use gradient using a pyrosequencing approach. Environmental Microbiology 12(8): 2165-2179.

Mäder P, Edenhofer S, Boller T, Wiemken A, Niggli U. 2000. Arbuscular mycorrhizae in a longterm field trial comparing low-input (organic, biological) and high-input (conventional) farming systems in a crop rotation. Biology and Fertility of Soils 31(2): 150-156.

Magrin GO, Travasso MI, Rodríguez GR. 2005. Changes in climate and crop production during the 20th century in Argentina. Climatic change 72(1-2): 229-249.

Magurran AE, McGill BJ. 2011. Biological diversity. Frontiers in Measurement and Assessment, Oxford University Press.

Maherali H, Klironomos JN. 2007. Influence of phylogeny on fungal community assembly and ecosystem functioning. Science 316(5832): 1746-1748.

Marschner H, Dell B. 1994. Nutrient uptake in mycorrhizal symbiosis. Plant and Soil 159(1): 89-102.

Marschner H. 1995. Functions of mineral nutrients: macronutrients. Mineral nutrition of higher plants 2nd Edition. Academic Press, NY: 299-312.

Martins, M., Read, D.J., 1997. Efeitos da distribuição do micélio externo de fungos micorrízicos arbusculares sobre o crescimento vegetal. Pesquisa Agropecuaria Brasileira 32, 1183-1189.

McGee P. 1989. Variation in propagule numbers of vesicular-arbuscular mycorrhizal fungi in a semi-arid soil. Mycological Research 92(1): 28-33. 
McGee PA, Trappe JM. 2002. The Australian zygomycetous mycorrhizal fungi. II. Further Australian sporocarpic Glomaceae. Australian Systematic Botany 15(1): 115-124.

McGonigle T, Miller M, Evans D, Fairchild G, Swan J. 1990. A new method which gives an objective measure of colonization of roots by vesicular-arbuscular mycorrhizal fungi. New Phytologist 115(3): 495-501.

Mendoza R, García I, Depalma D, López CF. 2016. Competition and growth of a grass-legume mixture fertilized with nitrogen and phosphorus: effect on nutrient acquisition, root morphology and symbiosis with soil microorganisms. Crop and Pasture Science 67: $629-640$

Menéndez AB, Scervino JM, Godeas AM. 2001. Arbuscular mycorrhizal populations associated with natural and cultivated vegetation on a site of Buenos Aires province, Argentina. Biology and Fertility of Soils 33(5): 373-381.

Mikkelsen BL, Rosendahl S, Jakobsen I. 2008. Underground resource allocation between individual networks of mycorrhizal fungi. New Phytologist 180(4): 890-898.

Milne I, Lindner D, Bayer M, Husmeier D, McGuire G, Marshall DF, Wright F. 2009. TOPALi v2: a rich graphical interface for evolutionary analyses of multiple alignments on HPC clusters and multi-core desktops. Bioinformatics 25(1): 126-127.

Moebius-Clune DJ, Anderson ZU, Pawlowska TE. 2013. Arbuscular mycorrhizal fungi associated with a single agronomic plant host across the landscape: the structure of an assemblage. Soil Biology and Biochemistry 64: 181-190.

Moora M, Davison J, Opik M, Metsis M, Saks U, Jairus T, Vasar M, Zobel M. 2014. Anthropogenic land use shapes the composition and phylogenetic structure of soil arbuscular mycorrhizal fungal communities. FEMS Microbiology Ecology 90(3): 609621.

Morton J. 1988. Taxonomy of VA mycorrhizal fungi: classification, nomenclature, and identification. Mycotaxon 32: 267-324.

Morton JB, Bever JD, Pfleger FL. 1997. Taxonomy of Acaulospora gerdemannii and Glomus leptotichum, synanamorphs of an arbuscular mycorrhizal fungus in Glomales. Mycological Research 101(05): 625-631. 
Munkvold L, Kjøller R, Vestberg M, Rosendahl S, Jakobsen I. 2004. High functional diversity within species of arbuscular mycorrhizal fungi. New Phytologist 164(2): 357-364.

Murphy J, Riley JP. 1962. A modified single solution method for the determination of phosphate in natural waters. Analytica chimica acta 27: 31-36.

Newman E. 1966. A method of estimating the total length of root in a sample. Journal of applied Ecology: 139-145.

Newsham KK, Fitter AH, Watkinson AR. 1995. Arbuscular Mycorrhiza Protect an Annual Grass from Root Pathogenic Fungi in the Field. Journal of Ecology 83(6): 991-1000.

Nijjer S, Rogers WE, Siemann E. 2010. The impacts of fertilization on mycorrhizal production and investment in Western Gulf Coast Grasslands. The American Midland Naturalist 163(1): 124-133.

Nottingham AT, Turner BL, Winter K, van der Heijden MG, Tanner EV. 2010. Arbuscular mycorrhizal mycelial respiration in a moist tropical forest. New Phytologist 186(4): 957-967.

Oehl F, Laczko E, Bogenrieder A, Stahr K, Bösch R, van der Heijden M, Sieverding E. 2010. Soil type and land use intensity determine the composition of arbuscular mycorrhizal fungal communities. Soil Biology and Biochemistry 42(5): 724-738.

Oehl F, Laczko E, Bogenrieder A, Stahr K, Bösch R, van der Heijden M, Sieverding E. 2010. Soil type and land use intensity determine the composition of arbuscular mycorrhizal fungal communities. Soil Biology and Biochemistry 42(5): 724-738.

OehI F, Sieverding E, Ineichen K, Mader P, Boller T, Wiemken A. 2003. Impact of Land Use Intensity on the Species Diversity of Arbuscular Mycorrhizal Fungi in Agroecosystems of Central Europe. Applied Environmental Microbiology 69(5): 2816-2824.

Oehl F, Sieverding E, Ineichen K, Mäder P, Wiemken A, Boller T. 2009. Distinct sporulation dynamics of arbuscular mycorrhizal fungal communities from different agroecosystems in long-term microcosms. Agriculture, Ecosystems \& Environment 134(3): 257-268. 
Oehl F, Sieverding E, Mäder P, Dubois D, Ineichen K, Boller T, Wiemken A. 2004. Impact of long-term conventional and organic farming on the diversity of arbuscular mycorrhizal fungi. Oecologia 138(4): 574-583.

Oka N, Karasawa T, Okazaki K, Takebe M. 2010. Maintenance of soybean yield with reduced phosphorus application by previous cropping with mycorrhizal plants. Soil Science and Plant Nutrition 56(6): 824-830.

Oksanen J 2013. Multivariate Analysis of ecological communities in R: vegan tutorial. http://cc.oulu.fi/ jarioksa/opetus/metodi/vegantutor.pdf.

Olsson PA, van Aarle IM, Allaway WG, Ashford AE, Rouhier H. 2002. Phosphorus effects on metabolic processes in monoxenic arbuscular mycorrhiza cultures. Plant Physiology 130(3): 1162-1171.

Omar M, Bolland L, Heather W. 1979. A permanent mounting medium for fungi. Bulletin of the British Mycological Society 13(1): 31-32.

Öpik M, Davison J, Moora M, Zobel M. 2014. DNA-based detection and identification of Glomeromycota: the virtual taxonomy of environmental sequences1. Botany 92(2): 135-147.

Öpik M, Moora M, Liira J, Zobel M. 2006. Composition of root-colonizing arbuscular mycorrhizal fungal communities in different ecosystems around the globe. Journal of Ecology 94(4): 778-790.

Öpik M, Vanatoa A, Vanatoa E, Moora M, Davison J, Kalwij JM, Reier U, Zobel M. 2010. The online database MaarjAM reveals global and ecosystemic distribution patterns in arbuscular mycorrhizal fungi (Glomeromycota). New Phytologist 188(1): 223-241.

Öpik M, Zobel M, Cantero JJ, Davison J, Facelli JM, Hiiesalu I, Jairus T, Kalwij JM, Koorem K, Leal ME, et al. 2013. Global sampling of plant roots expands the described molecular diversity of arbuscular mycorrhizal fungi. Mycorrhiza 23(5): 411-430.

Ossler JN, Zielinski CA, Heath KD. 2015. Tripartite mutualism: Facilitation or trade-offs between rhizobial and mycorrhizal symbionts of legume hosts. American journal of botany 102(8): 1332-1341. 
Peay KG. 2014. Back to the future: natural history and the way forward in modern fungal ecology. Fungal Ecology 12: 4-9.

Pfeffer PE, Douds DD, Bécard G, Shachar-Hill Y. 1999. Carbon uptake and the metabolism and transport of lipids in an arbuscular mycorrhiza. Plant Physiology 120(2): 587-598.

Phillips JM, Hayman DS. 1970. Improved procedures for clearing roots and staining parasitic and vesicular-arbuscular mycorrhizal fungi for rapid assessment of infection. Transactions British Mycological Society 55(1): 158-161.

Piccini D, Ocampo J, Bedmar E. 1988. Possible influence of Rhizobium on VA mycorrhiza metabolic activity in double symbiosis of alfalfa plants (Medicago sativa L.) grown in a pot experiment. Biology and Fertility of Soils 6(1): 65-67.

Pieters AJ, Paul MJ, Lawlor DW. 2001. Low sink demand limits photosynthesis under Pi deficiency. Journal of Experimental Botany 52(358): 1083-1091.

Plaxton WC, Carswell MC. 1999. Metabolic aspects of the phosphate starvation response in plants. Plant responses to environmental stresses: from phytohormones to genome reorganization. Marcel Dekker, New York: 349-372.

Plenchette C, Fortin J, Furlan V. 1983. Growth responses of several plant species to mycorrhizae in a soil of moderate P-fertility. Plant and Soil 70(2): 199-209.

Plenchette C, Perrin R, Duvert P. 1989. The concept of soil infectivity and a method for its determination as applied to endomycorrhizas. Canadian Journal of Botany 67(1): 112115.

Qaim M, Traxler G. 2005. Roundup Ready soybeans in Argentina: farm level and aggregate welfare effects. Agricultural economics 32(1): 73-86.

Qian L, Yu WJ, Cui JQ, Jie WG, Cai BY. 2015. Funneliformis mosseae affects the root rot pathogen Fusarium oxysporum in soybeans. Acta Agriculturae Scandinavica, Section B-Soil \& Plant Science 65(4): 321-328.

Rambelli A. 1973. The rhizosphere of mycorrhizae. Ectomycorrhizae: Their ecology and physiology: 229-343.

Read DJ. 1991. Mycorrhizas in ecosystems. Experientia 47(4): 376-391. 
RIAN. 2016. Red de Información Agropecuaria Nacional - Argentina. http://rian.inta.gov.ar/. Fecha de consulta: febrero 2016

Rillig, M.C., P.W. Ramsey, S. Morris, and E.A. Paul. 2003. Glomalin, an arbuscular-mycorrhizal fungal soil protein, responds to land-use change. Plant and Soil 253:293-299

Rillig, M.C., S.F. Wright, K.A. Nichols, W.F. Schmidt, and M.S. Torn. 2001. Large contribution of arbuscular mycorrhizal fungi to soil carbon pools in tropical forest soils. Plant and Soil 233:167- 177 .

Rinaudo V, Bàrberi P, Giovannetti M, van der Heijden MG. 2010. Mycorrhizal fungi suppress aggressive agricultural weeds. Plant and Soil 333(1-2): 7-20.

Robert D 2012. Labdsv: Ordination and Multivariate Analysis for Ecology. R package version 1.5-0.

Roger A, Colard A, Angelard C, Sanders IR. 2013. Relatedness among arbuscular mycorrhizal fungi drives plant growth and intraspecific fungal coexistence. ISME Journal 7(11): 2137-2146.

Rosendahl S, Stukenbrock EH. 2004. Community structure of arbuscular mycorrhizal fungi in undisturbed vegetation revealed by analyses of LSU rDNA sequences. Molecular Ecology 13(10): 3179-3186.

Rosendahl S. 2008. Communities, populations and individuals of arbuscular mycorrhizal fungi. New Phytologist 178(2): 253-266.

Rubio G, Faggioli V, Scheiner JD, Gutiérrez-Boem FH. 2011. Rhizosphere phosphorus depletion by three crops differing in their phosphorus critical levels. Journal of Plant Nutrition and Soil Science 175(6): 810-871.

Safir GR, Boyer JS, Gerdemann JW. 1972. Nutrient Status and Mycorrhizal Enhancement of Water Transport in Soybean. Plant Physiology 49(5): 700-703.

SAGPyA 2016. Secretaria de Agricultura Ganaderia, Pesca y Alimentación. http://www.agroindustria.gob.ar/sitio/ Fecha de consulta: febrero 2016

Saito M, Vargas R. 1991. Vesicular-arbuscular mycorrhizal fungi in some humus-rich Ando soils of Japan. 土と微生物(38): 3-15. 
Saks Ü, Davison J, Öpik M, Vasar M, Moora M, Zobel M. 2013. Root-colonizing and soil-borne communities of arbuscular mycorrhizal fungi in a temperate forest understorey 1. Botany 92(4): 277-285.

Schachtman DP, Reid RJ, Ayling SM. 1998. Phosphorus uptake by plants: from soil to cell. Plant Physiology 116(2): 447-453.

Schalamuk SV, H. Chidichimo, and M. Cabello. 2006. Fungal spore diversity of arbuscular mycorrhizal fungi associated with spring wheat: effects of tillage. Mycologia 98(1): $22-28$.

Schalamuk S, Cabello M. 2009. Arbuscular mycorrhizal fungal propagules from tillage and notillage systems: possible effects on Glomeromycota diversity. Mycologia 102(2): 261268.

Schalamuk S, Velázquez S, Cabello M. 2013. Dynamics of arbuscular mycorrhizal fungi spore populations and their viability under contrasting tillage systems in wheat at different phenological stages. Biological Agriculture \& Horticulture 29(1): 38-45.

Schenck N, Kinloch R. 1980. Incidence of mycorrhizal fungi on six field crops in monoculture on a newly cleared woodland site. Mycologia: 445-456.

Scheublin TR, Sanders IR, Keel C, van der Meer JR. 2010. Characterisation of microbial communities colonising the hyphal surfaces of arbuscular mycorrhizal fungi. ISME Journal 4(6): 752-763.

Scheublin TR, van der Heijden MG. 2006. Arbuscular mycorrhizal fungi colonize nonfixing root nodules of several legume species. New Phytologist 172(4): 732-738.

Schnepf RD, Dohlman EN, Bolling HC. 2001. Agriculture in Brazil and Argentina: Developments and prospects for major field crops: US Department of Agriculture Washington, DC.

SchüBler A, Walker C. 2010. The Glomeromycota. A species list with new families and new genera. The Royal Botanic Garden Edinburgh, The Royal Botanic Garden Kew, Botanische Staatssammlung Munich and Oregon State University. 
SchüBler A, Walker C. 2010. The Glomeromycota. A species list with new families and new genera. The Royal Botanic Garden Kew, Botanische Staatssammlung Munich, and Oregon State University.

Schüßler A, Martin H, Cohen D, Fitz M, Wipf D. 2006. Characterization of a carbohydrate transporter from symbiotic Glomeromycotan fungi. Nature 444(7121): 933-936.

Schweiger P, Thingstrup I, Jakobsen I. 1999. Comparison of two test systems for measuring plant phosphorus uptake via arbuscular mycorrhizal fungi. Mycorrhiza 8(4): 207-213.

Selosse MA, Vincenot L, Öpik M. 2016. Data processing can mask biology: towards better reporting of fungal barcoding data? New Phytologist. 210: 1159-1164

SENASA 2016. Servicio Nacional de Sanidad Animal. http//www.senasa.gov.ar/ Fecha de consulta: febrero 2016

Shennan C. 2008. Biotic interactions, ecological knowledge and agriculture. Philosophical Transactions of the Royal Society of London B: Biological Sciences 363(1492): 717739.

Sieverding E, Friedrichsen J, Suden W. 1991. Vesicular-arbuscular mycorrhiza management in tropical agrosystems. Sonderpublikation der GTZ (Germany).

Simon L, Lalonde M, Bruns T. 1992. Specific amplification of $18 \mathrm{~S}$ fungal ribosomal genes from VA endomycorrhizal fungi colonizing roots. Applied Environmental Microbiology 58: 291-295.

Smith FW, Mudge SR, Rae AL, Glassop D. 2003. Phosphate transport in plants. Plant and Soil 248(1-2): 71-83.

Smith SE, Read DJ. 2010. Mycorrhizal symbiosis: Academic press. Third Edition. 787 páginas

Smith SE, Smith FA, Jakobsen I. 2004. Functional diversity in arbuscular mycorrhizal (AM) symbioses: the contribution of the mycorrhizal $\mathrm{P}$ uptake pathway is not correlated with mycorrhizal responses in growth or total P uptake. New Phytologist 162(2): 511524.

Smith SE, Smith FA. 2011. Roles of arbuscular mycorrhizas in plant nutrition and growth: new paradigms from cellular to ecosystem scales. Annual Review of Plant Biology 62: 227250. 
Song YY, Zeng RS, Xu JF, Li J, Shen X, Yihdego WG. 2010. Interplant communication of tomato plants through underground common mycorrhizal networks. PLoS One 5(10): e13324.

Sun X, Su Y, Zhang Y, Wu M, Zhang Z, Pei K, Sun L, Wan S, Liang Y. 2013. Diversity of arbuscular mycorrhizal fungal spore communities and its relations to plants under increased temperature and precipitation in a natural grassland. Chinese Science Bulletin 58(33): 4109-4119.

Sýkorová Z, Ineichen K, Wiemken A, Redecker D. 2007. The cultivation bias: different communities of arbuscular mycorrhizal fungi detected in roots from the field, from bait plants transplanted to the field, and from a greenhouse trap experiment. Mycorrhiza 18(1): 1-14.

Sylvia D, Schenck N. 1983. Application of superphosphate to mycorrizal plants stimulates sporulation of phosphorus-tolerant vesicular-arbuscular mycorrhizal fungi. New Phytologist 95(4): 655-661.

Tadano T, Ozawa K, Sakai H, Osaki M, Matsui H. 1993. Secretion of acid phosphatase by the roots of crop plants under phosphorus-deficient conditions and some properties of the enzyme secreted by lupin roots. Plant and Soil 155(1): 95-98.

Tadano T, Sakai H. 1991. Secretion of acid phosphatase by the roots of several crop species under phosphorus-deficient conditions. Soil Science and Plant Nutrition 37(1): 129140.

Taverna N. 2013. Anuario 2013. Fundación para la promoción y el desarrollo de la cadena láctea argentina. En: http://www.lacteos2020.org.ar/Anuario.pdf

Tchabi A, Coyne D, Hountondji F, Lawouin L, Wiemken A, Oehl F. 2008. Arbuscular mycorrhizal fungal communities in sub-Saharan Savannas of Benin, West Africa, as affected by agricultural land use intensity and ecological zone. Mycorrhiza 18(4): 181195.

Tian H, Drijber RA, Zhang JL, Li XL. 2013. Impact of long-term nitrogen fertilization and rotation with soybean on the diversity and phosphorus metabolism of indigenous arbuscular mycorrhizal fungi within the roots of maize (Zea mays L.). Agriculture, Ecosystems \& Environment 164: 53-61. 
Tinker P 1975. Effects of vesicular-arbuscular mycorrhizas on higher plants. Symposia of the Society for Experimental Biology. 325.

Tinker P, Durall D, Jones M. 1994. Carbon use efficiency in mycorrhizas theory and sample calculations. New Phytologist 128(1): 115-122.

Toljander JF, Santos-González JC, Tehler A, Finlay RD. 2008. Community analysis of arbuscular mycorrhizal fungi and bacteria in the maize mycorrhizosphere in a longterm fertilization trial. FEMS Microbiology Ecology 65(2): 323-338.

Tommerup I, Abbott L. 1981. Prolonged survival and viability of VA mycorrhizal hyphae after root death. Soil Biology and Biochemistry 13(5): 431-433.

Tommerup I. 1983. Spore dormancy in vesicular-arbuscular mycorrhizal fungi. Transactions of the British Mycological Society 81(1): 37-45.

Tommerup I. 1984. Effect of soil water potential on spore germination by vesiculararbuscular mycorrhizal fungi. Transactions of the British Mycological Society 83(2): 193-202.

Tommerup I. 1985. Inhibition of spore germination of vesicular-arbuscular mycorrhizal fungi in soil. Transactions of the British Mycological Society 85(2): 267-278.

Torrecillas E, Alguacil MM, Roldan A. 2012. Host preferences of arbuscular mycorrhizal fungi colonizing annual herbaceous plant species in semiarid Mediterranean prairies. Applied Environmental Microbiology 78(17): 6180-6186.

Trappe JM. 1987. Phylogenetic and ecologic aspects of mycotrophy in the angiosperms from an evolutionary standpoint. ISBN 0849364922

Treseder KK, Turner KM. 2007. Glomalin in Ecosystems. Soil Science Society of America Journal 71(4): 1257.

Treseder KK. 2004. A meta-analysis of mycorrhizal responses to nitrogen, phosphorus, and atmospheric $\mathrm{CO}_{2}$ in field studies. New Phytologist 164(2): 347-355.

Trigo E, Cap E, Malach V, Villarreal F. 2009. The case of zero-tillage technology in Argentina: Intl Food Policy Res Inst. 
Turrini A, Sbrana C, Nuti MP (2004) Development of a model system to assess the impact of genetically modified corn and aubergine plants on arbuscular mycorrhizal fungi. Plant and Soil 266:69-75

Unger PW, Vigil MF. 1998. Cover crop effects on soil water relationships. Journal of Soil and Water Conservation 53(3): 200-207.

USDA. 2014. USDA Soil Classification. Soil Survey Staff. Keys to Soil Taxonomy, 12th ed. USDA-Natural Resources Conservation Service, Washington, DC.

Vályi K, Rillig MC, Hempel S. 2014. Land-use intensity and host plant identity interactively shape communities of arbuscular mycorrhizal fungi in roots of grassland plants. New Phytologist 205(4), 1577-1586.

van der Heijden MG, Martin FM, Selosse MA, Sanders IR. 2015. Mycorrhizal ecology and evolution: the past, the present, and the future. New Phytologist 205(4): 1406-1423.

Van Der Heijden MG, Streitwolf-Engel R, Riedl R, Siegrist S, Neudecker A, Ineichen K, Boller T, Wiemken A, Sanders IR. 2006. The mycorrhizal contribution to plant productivity, plant nutrition and soil structure in experimental grassland. New Phytologist 172(4): 739-752.

van der Heijden MG. 2010. Mycorrhizal fungi reduce nutrient loss from model grassland ecosystems. Ecology 91(4): 1163-1171.

Vandenkoornhuyse P, Ridgway K, Watson I, Fitter A, Young J. 2003. Co-existing grass species have distinctive arbuscular mycorrhizal communities. Molecular Ecology 12(11): 3085-3095.

Velázquez MS, Cabello MN, Barrera M. 2013. Composition and structure of arbuscularmycorrhizal communities in El Palmar National Park, Argentina. Mycologia 105(3): 509-520.

Verbruggen E, Kiers ET, Bakelaar PNC, Röling WFM, van der Heijden MG. 2011. Provision of contrasting ecosystem services by soil communities from different agricultural fields. Plant and Soil 350(1): 43-55.

Verbruggen E, Toby Kiers E. 2010. Evolutionary ecology of mycorrhizal functional diversity in agricultural systems. Evolutionary Applications 3(5-6): 547-560. 
Verbruggen E, van der Heijden MG, Weedon JT, Kowalchuk GA, Roeling WF. 2012. Community assembly, species richness and nestedness of arbuscular mycorrhizal fungi in agricultural soils. Molecular Ecology 21(10): 2341-2353.

Veresoglou SD, Caruso T, Rillig MC. 2013. Modelling the environmental and soil factors that shape the niches of two common arbuscular mycorrhizal fungal families. Plant and Soil 368(1-2): 507-518.

Veresoglou, SD, Shaw L, Hooker JE, Sen R. 2012. Arbuscular mycorrhizal modulation of diazotrophic and denitrifying microbial communities in the (mycor)rhizosphere of Plantago lanceolate. Soil Biology and Biochemistry 53:78-81

Walker C, Mize C, McNabb Jr H. 1982. Populations of endogonaceous fungi at two locations in central lowa. Canadian Journal of Botany 60(12): 2518-2529.

Walker C, Vestberg M, Demircik F, Stockinger H, Saito M, Sawaki H, Nishmura I, Schußler A. 2007. Molecular phylogeny and new taxa in the Archaeosporales (Glomeromycota): Ambispora fennica gen. sp. nov., Ambisporaceae fam. nov., and emendation of Archaeospora and Archaeosporaceae. Mycological Research 111: 137-153.

Walkley A, Black IA. 1934. An examination of the Degtjareff method for determining soil organic matter, and a proposed modification of the chromic acid titration method. Soil Science 37(1): 29-38.

Wang YY, Vestberg M, Walker C, Hurme T, Zhang X, Lindström K. 2008. Diversity and infectivity of arbuscular mycorrhizal fungi in agricultural soils of the Sichuan Province of mainland China. Mycorrhiza 18(2): 59-68.

Wang YY, Vestberg M, Walker C, Hurme T, Zhang X, Lindström K. 2008. Diversity and infectivity of arbuscular mycorrhizal fungi in agricultural soils of the Sichuan Province of mainland China. Mycorrhiza 18(2): 59-68.

Waterhouse AM, Procter JB, Martin DMA, Clamp M, Barton GJ. 2009. Jalview Version 2-a multiple sequence alignment editor and analysis workbench. Bioinformatics 25(9): 1189-1191.

Wilson GW, Rice CW, Rillig MC, Springer A, Hartnett DC. 2009. Soil aggregation and carbon sequestration are tightly correlated with the abundance of arbuscular mycorrhizal fungi: results from long-term field experiments. Ecology letters 12(5): 452-461. 
Wilson J, Trinick M. 1983. Infection development and interactions between vesiculararbuscular mycorrhizal fungi. New Phytologist 93(4): 543-553.

Wright S, Upadhyaya A. 1999. Quantification of arbuscular mycorrhizal fungi activity by the glomalin concentration on hyphal traps. Mycorrhiza 8(5): 283-285.

Zablotowicz RM, Tipping EM, Lifshitz R, Kloepper JW 1991. Plant growth promotion mediated by bacterial rhizosphere colonizers. The rhizosphere and plant growth: Springer, 315-326.

Zhang F, Hamel C, Kianmehr H, Smith DL. 1995. Root-zone temperature and soybean [Glycine max.(L.) Merr.] vesicular-arbuscular mycorrhizae: development and interactions with the nitrogen fixing symbiosis. Environmental and Experimental Botany 35(3): 287-298.

Zhang S, Li Q, Lü Y, Sun X, Jia S, Zhang X, Liang W. 2015. Conservation tillage positively influences the microflora and microfauna in the black soil of Northeast China. Soil and Tillage Research 149(0): 46-52. 